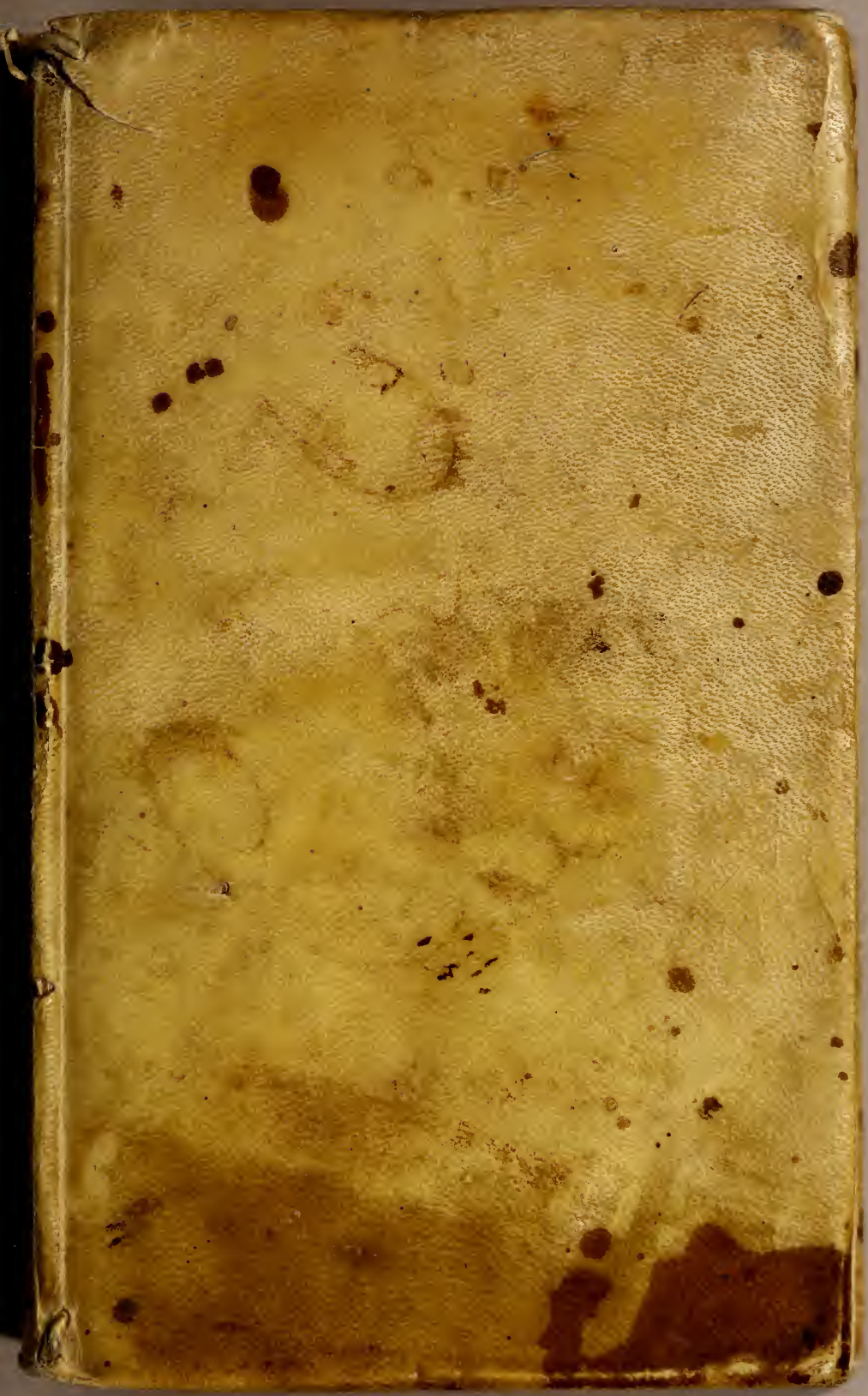


Vire, 92-93

The John Carter Brown Library กากาก

Acquired with the assistance of the

LYMAN G. BLOOMINGDALE BOOK FUND 


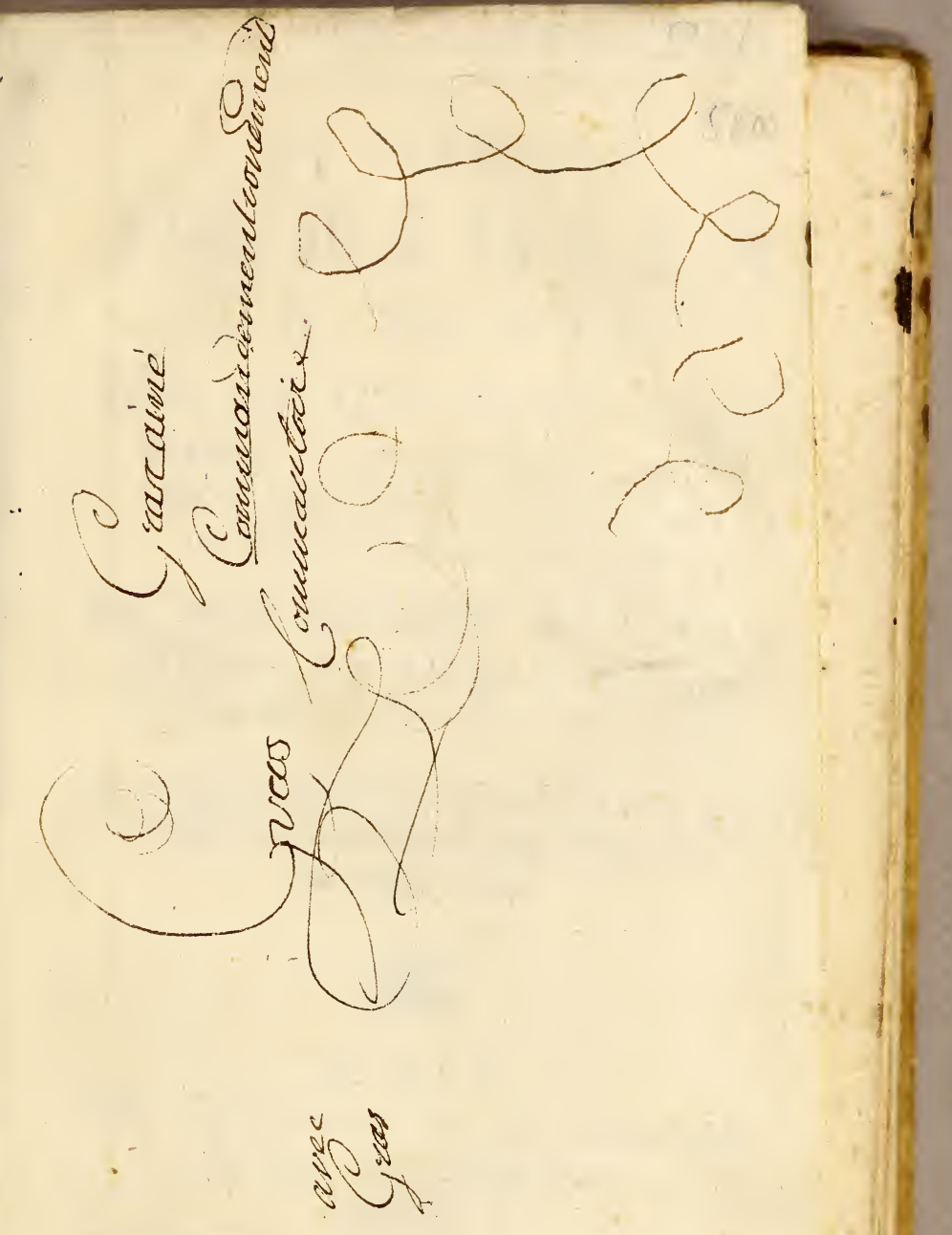




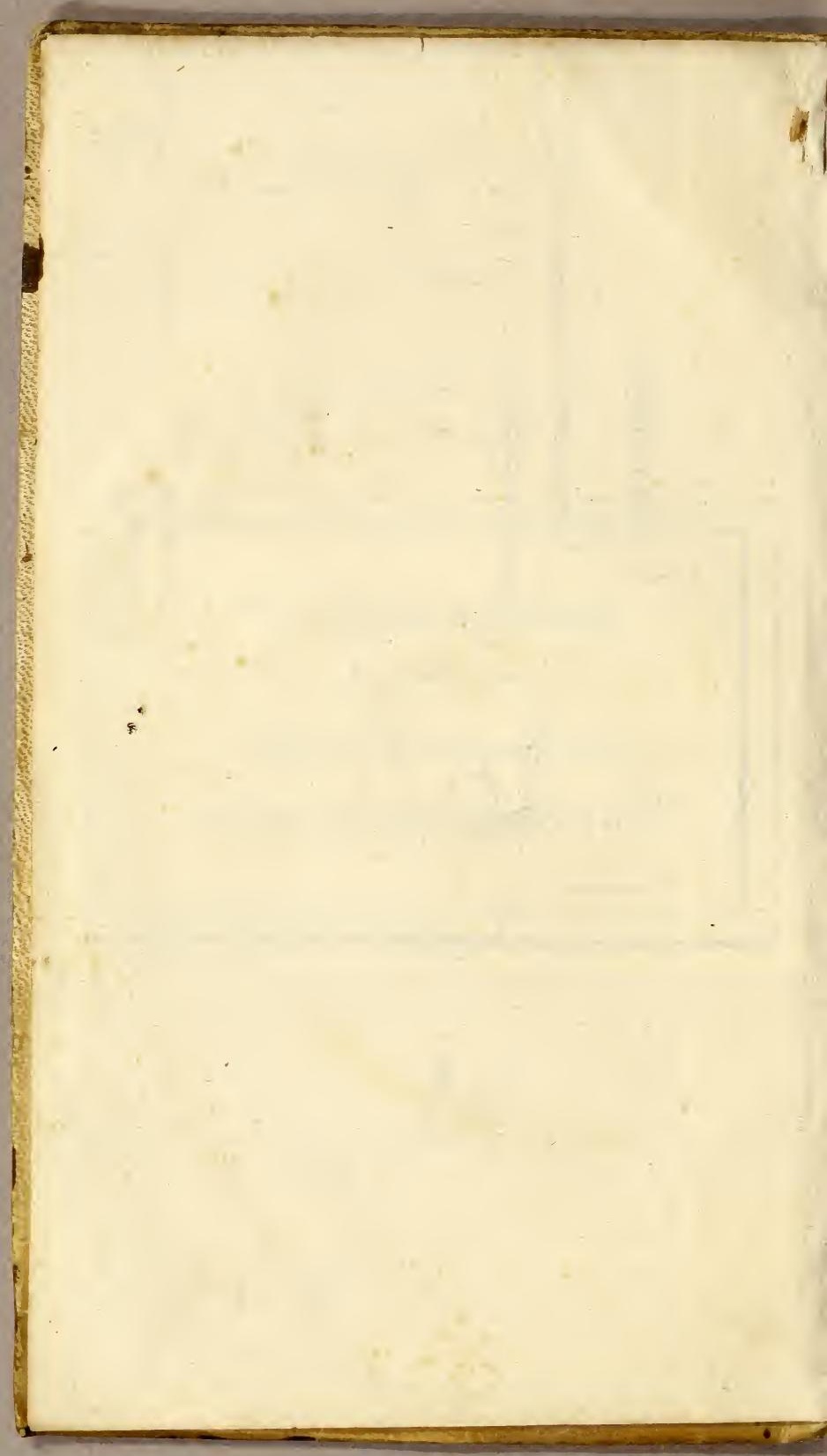




\section{LA MANIERE}

DE R E G L R LA SANTE'

PAR CE QVI NOVS ENVIRONNE, PAR CE QVE NOVS RECEVONS, ET PAR LES EXERCICES, ou par la Gymnaftique moderne.

LE TOVT APPLIQVE' AV PEVPLE de France, '\& pour feruir d'exemple quelquefois aux Habitans de la Ville d'Aix.

Par Maiftre MICHEL BICAIS Docteur, of Profeffeur en Medecine dans I'Vniuerfité de ladite ville.

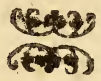

A A I X,

Chez Charles David Imprimeus du Roy, du Clergé \& de la Ville.

$$
\begin{aligned}
& \text { M. D C. LXIX. } \\
& \text { AVEC PRIVILEGE. }
\end{aligned}
$$




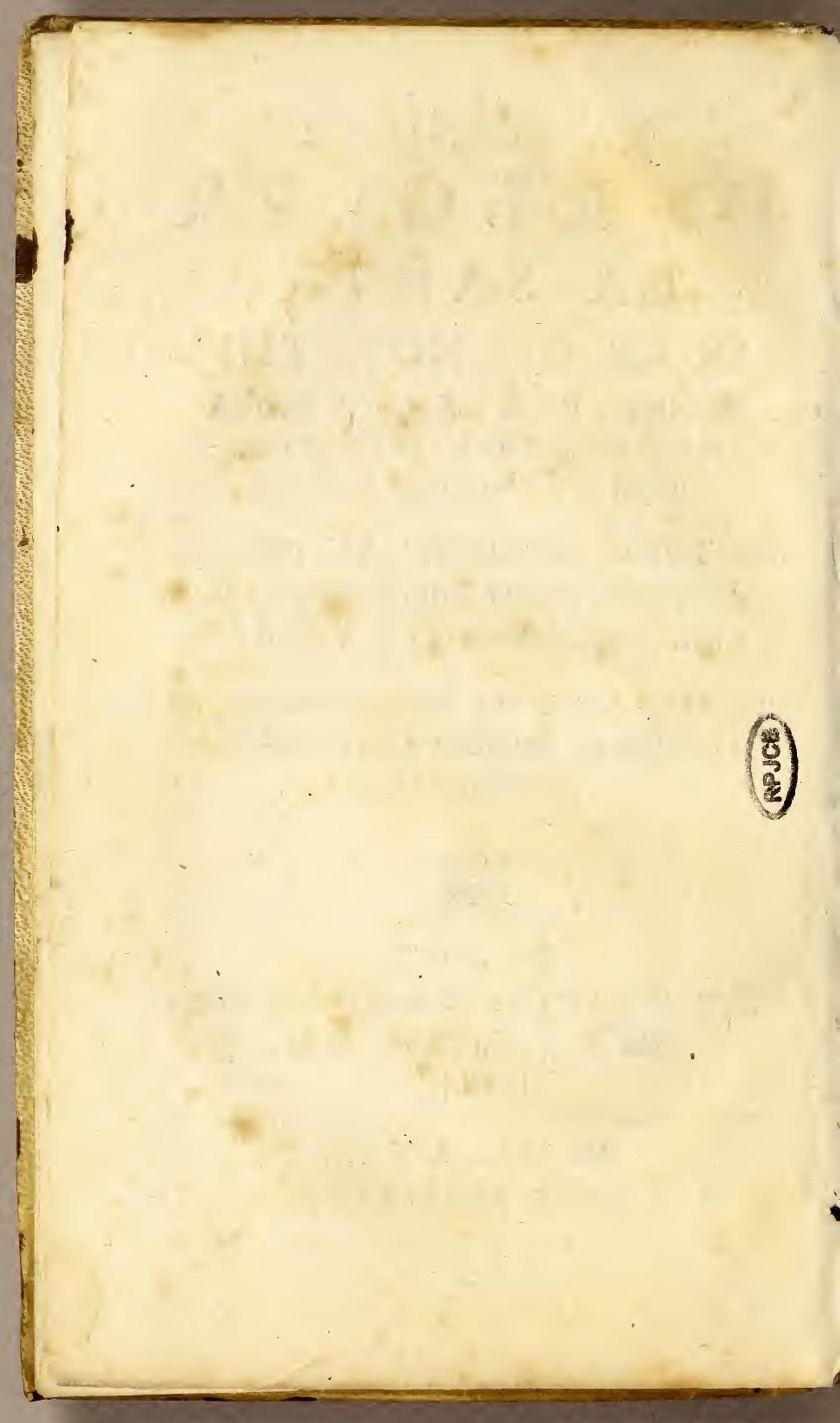



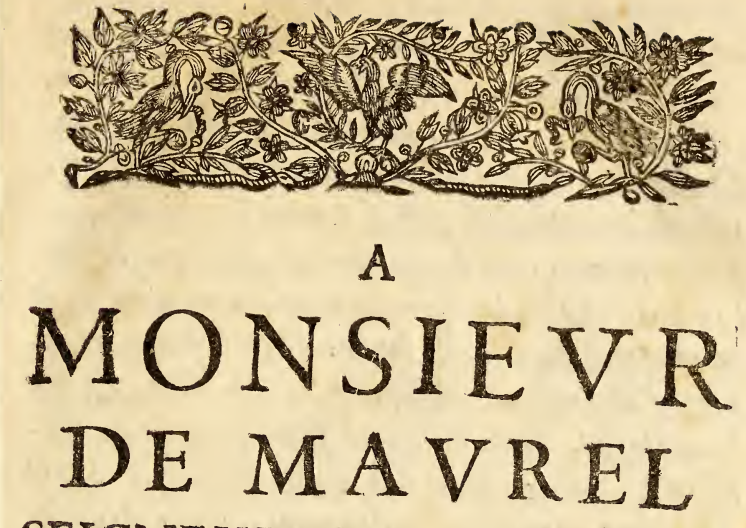
SEIGNEVR DV CHAFFAVT, DE VALBONNETTE, \&c。 CONSEILIER DV ROY EN SES CONSEILS, $\&$ en fon Parlement de Prouence.

NOOOONSIEVR:

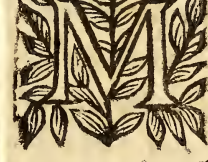

woux, ito offrir wos refpects ane fo confacrer des à ceux-là fans doute quects aux hommes, c'efe lifie des Dieux que que la Ste. Efcriture quaifie des Dieux, que le Dieu viuant, comrse elle parle, conftitué fur les peuples, qui leur infpirent la vertu, o qui partagent leur fortune. 


\section{EPISTRE!}

en rendant juffice à chacun. Maris ce qui nous oblige encore i leur addreffer vn culte tout pur, $c^{\prime}$ eft sils confolent les afflige's dans la bauteur, \& l'independence oì ils $\int_{c}$ treunent, s'ils protegent les orphelins, of fiparmy les feintes, les defguifemens, er les calomnines, ils font briller la verité, of ils la de fueloppent du menfonge, 离 la maniere dus Soleil, lors qui il fait paroifire las pompe des rofes en diffepont les tenebres, do les broiilllards. Des reflexions femblables, CMONSIEFR, w'ont obligé à vous dreffer l'Autel que vous voyés fous vofire nom, à m'y dewouër comme vne victime, à y faire wies prieres, os as y concenoir mes denotions, non feulement parce que fuiuant l'E fcriture vous eftes an nombre des Dieux, quion vous a reueftu de pourpre, pour vous confitituer fur les peuples, que vos exemples corrigent leur defreglemsent, \& que vous balancés leur fortune; mais d'ailleurs parce que vofire probité, \&o vos lumieres ont Secouru les orphelives, que la force de voftre jugement a énentél las calomnie, que vous aués demélé les intrigues concertées fans, fondement : Enfin que vous en ausés tiré la verité Sans intereft. \& Sans attache. De lì vient auffz, MONSIEVR, qu'ayant recomnu vne vertu fi rare, j'ay du déplaifir maintenant que l' Aut el que je vous confacre, foit tout defpourue d'ornemens, que ce ne foit point 


\section{EPISTRE.}

on monument propre à montrer à la pofterité vos merites, of mon eftime; \& quion niy voye point reluire l'efclat de l'or, ny la fplendeur des diamans. Vous vous founiendrés neantmoins, sil vous plait, que les Dieux, dit vn Ancien, Sont fat isfaits de nos parfuns, (ans rechercher les richeffes du monde; que les fruits, ó les fleurs ont appaifé la colere du ciel, que vous ea treuuerés en quelque endroit de ce volume, or que vous verrés, puis que ce que je vous offre maintenant enfeigne à conferuer la fanté de nos corps, qu'on le doit definer par confequent à celuy qui entretient par fon integrité l'barmonie, ơ la fanté du corps politique. C'eft

GONSIEVR,

Voftre tres-humbie \& tresobeiffant feruiteur

M. BICAIS。 


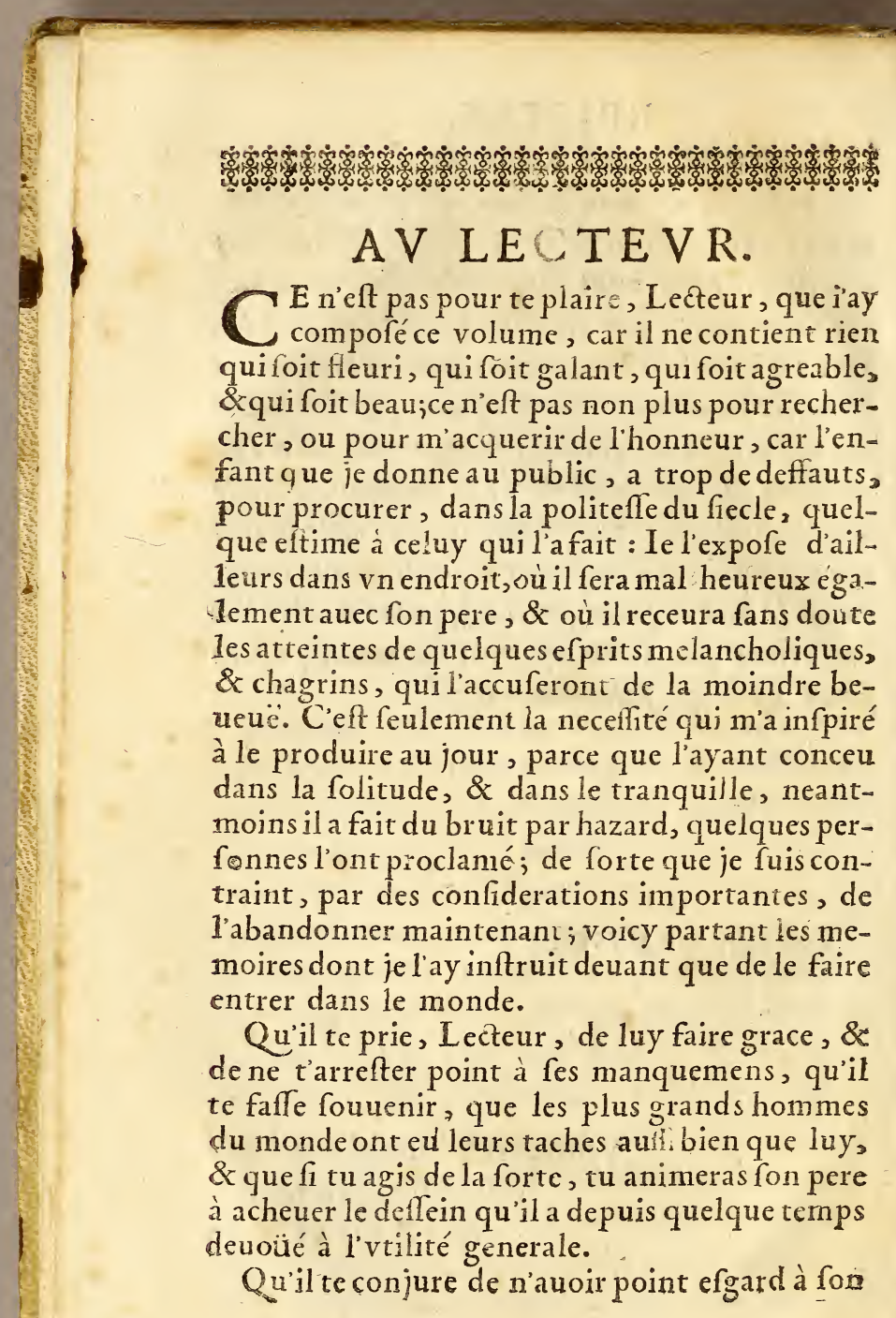




\section{A V LECTEVR?}

langage, car en cela, on t’a plus confideré que luy mefme, on l'a deftiné à entretenir ainfi quantité de perfonnes qui fe feroient rebutées de la langue latine; \& on a creu qu'elles feront affés charitables pour excufer le lieu où nous fommes, \& le peché originel que nous y prenons.

Qu'il t'aduertiffe que les diuerfes chofes, dont il eft reueftu, ont vn enchainement entre elles, qu'il eft neceffaire de retenir; qu'elles d'ailleurs font plus profitables en queiques lieux, qu elles ne paroiffent, fi tu veux prendre la peine de les lire fans preuention; qu'elles font mefme allés fteriles, \& qu'on n'a pas eu tout le moyen, ny, tout le fecours pour les embellir.

Enfin qu'il te fafre remarquer quau chapitre des Poiflons, je me fuis arrelté au Poiffon qui embellit la gorge, parce que cela regarde en quelque maniere l'hiftoire naturelle de la Prouince, \& que jay jugé que je pounois efcrire fur cette matiere apres Pline, Rondelet, \& Monfieur Merindol, nonobftant que ces f̧̧auans hommes ne foient pas d'accord entre eux. En effet Rondélet \& Pline veulent que ce Poiffon agifle par 1a feule application, \&qu'il endurciffe codiminuë la gorge; \& Monfieur Merindol pretend auec plus de raifon, qu'il éleue, arondit, \& affermit cette partie, apres qu'on s'en eft nourry quelque temps. 


\section{A. D \\ D OCTISS I MVM CLARISSIMVMQVE DOMINVM MICHAELEM BICHAIS REGIVM MEDICIN乎 PROEESSOREM. $A N A G R A M M A$. MICHAEL BICHAIS CHELIS BIS AMICA.}

\section{AKPO $T$ TXI}

Sercarius citharam qui jam noue Phobe Sanoram andidit, of merito famam decorauit Oaftalides pronas fecit, Phabiqueper Mxta armoniam traxit: nobis $v t$ dulce reuanes

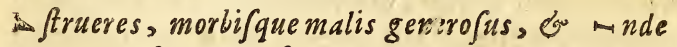
tritium ferres, noftram reparando is alutem Hanguen eris, validi medicaminis arte onigne. landilocas firmare locos tibi prebuit $\rightarrow l l e$, - llaftres fpargendo fonos, vt cuncta is udore Dorriperes ingrata viris, cum Epidaurius lter, is ermes of bic pariter, mox primusin arte achaon $\therefore$ rippi firmans titulos, $v t$ dulcis tmago nngenii Muse; aglaiis, tandemque Oamonis to is Bis AMICA CHELIS, noftrïq; folamen s mice.

Clavdivs Berard Iocenfis V.I. D. amico chariflíno. 


\section{ULIVD AD EVNDEM. MICHAEL BICAISSIVS.}

A MICE HIC' TIBISALVS.

I quondă veteres decorarunt nomen Hygeix $S$ Lauris, \& Medico templa dedêre Deo. Nunc liceat nobis eadem fic inunera ferre,

Cum liber, \& nomen dona falutis habent. Nomen Hygeia dedit, nomen Bicailfus offert; Vt fit $A$ M ICE malis mic ti 1 y vera $S_{A L V s}$.

\section{TDEM。}

\section{AV MESME. \\ SONNET:}

$F$ Sprit prodigieux, flambeau de la nature, E Qui faites voir au jource que le jour n'a veu, Quimontrés aux f̧̧auãsce qu'ililsn'ont jamaisfçeu Et reglés tout par poids, par nöbre \&par mefure. Voftre Liure parfait dans la viue peinture Defcouurant les fecrets rares, \& curieux, Cachés par la nature, \& referués aux Dieux, Doit eftre comme vous exempt de pourriture: Car en vous preparant vn Glorieux Autel Dãs le tếple d' hōneur, pourvous faìre inmortel, Fait voir que vos vertus fe font entrelaffes Auec le Mittatron qui vous rēed plusqu'humain, Et que cebon Demon vous a guidé la main, Pendãt que fonMoteur vous dictoit les penfées.

LE MESME. 


\section{ERVDITISSIMYO DOMINO MICHAELI BICAISIO DOCTORI MEDICO CLARISSIMI HONORATI FILIO \\ E T \\ IN AQVENSI VNIVERSITATE PRIMARIO CIVITATIS PROFESSORI.}

\section{feres}

Anguebant Mure, genitoris funera Hebant, 1 Iam plaudũt Choreas, jam fibi fefta canunt, Filius, extinctum, retulit cum foenore patrem, Euafit genitor, qui modò partus erat; Hujus virtuti, geminant proeconia Muræ, Qni fimul efficitur, Filius, atque parens.

STEPHANVS IOSEPHVS

DE Castillon Doctor Medicus \& Scutifer Aquifextienfis. 


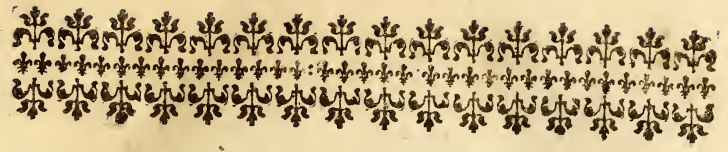

\section{EXTRAIT DES REGISTRES}

\section{DE PARLEMENT.}

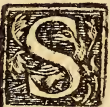

VRla Requefte prefentée à la Cour par Charles Dauid Imprimeur du Roy, \& de la Cour, tendente à fin pour les caufes y contenuës; quayant imprimé vn Liure intitulé, La Maniere de Regler la Santé, compofé par Maiftre M. Bicais Doteur en Medecine, \& Profeffeur er I'Vniuerfité de cette Ville d'Aix: Pour l'impreffion duquel ledis Dauid a fait des grands frais, \& dépenfes confiderables: Et parce qu'il apprehende que les autres Imprimeurs de cette Prouince, ou Marchands Libraires, impriment, ou faffent imprimer ledic Liure : requiert qu'il plaife à la Cour; Ordonner qu'inhibitions, $\&$ deffenfes foient faites à tous Imprimeurs, Marchands Libraires \& autres, d'imprimer, vendre, ny debiter ledit Liure, fans l'ordre, ou confentement dudit Dauid, durant le temps de dix ans, à peine de trois cens liures, \& confifeation des
exemplaires.

Veu la Requefte auec le Decret de foit montré au Procureur general du Roy \& fes conclufions du douziéme Octobre 1669.'

DIT A ESTE'

DIT A ESTE' que la Cour a fait, \& fait inhibitions \& deffenfes à tous Imprimeurs, Marchands Libraires, \& autres, d'imprimer, vendre, ny débiter ledit Liure, fans l'ordre, ou confentement dudit Dauid, durant le temps de dix ans, à peine de trois cens liu res d'amende \& confifcation des exemplaires. Fait Aix en Parlement, \& publié à la Barre le douziéme Octo-
bre mil fix cens foldante-neuf.

$$
\text { Signé ESTIENNE: Collationné: }
$$




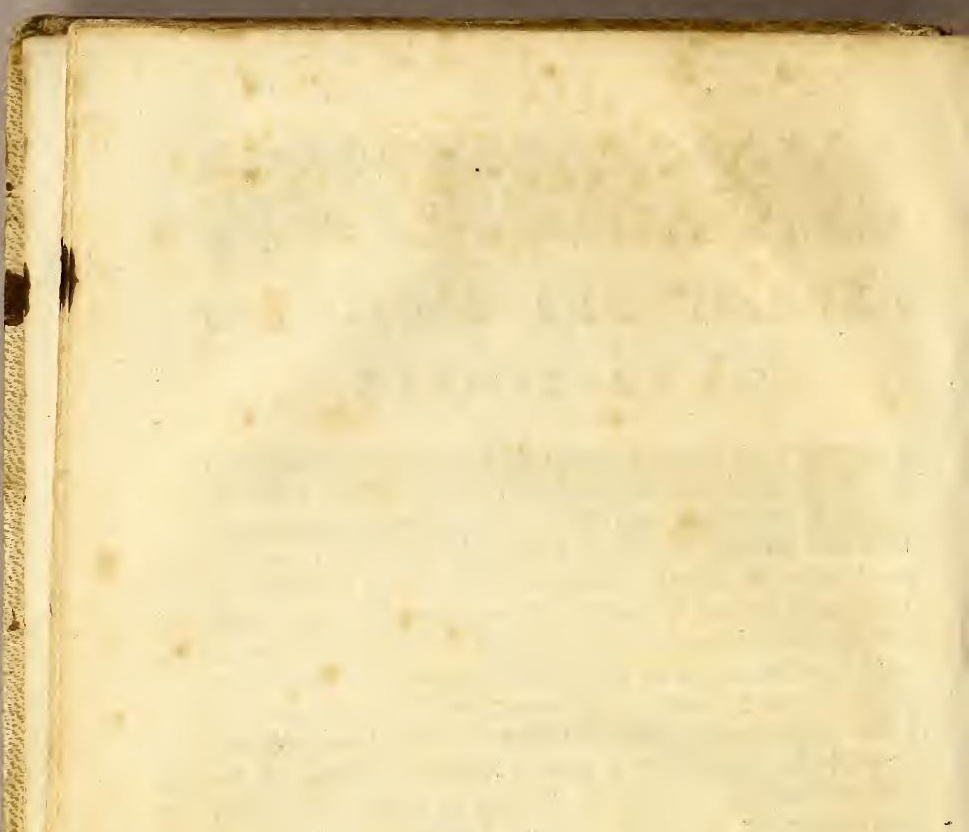




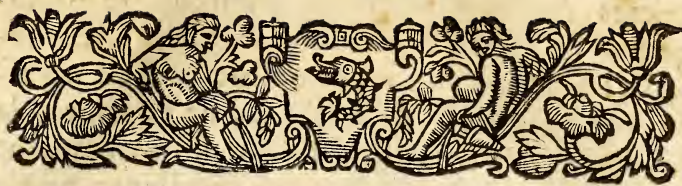

LA MANIERE DE REGLER LA SANTE',

\section{I V R E I.}

Des chofes qui nous enwironnent, ou qui fons au debors de nous.

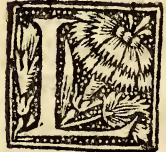

ES chofes qui nous enuironnent, qui font eftrangeres, \& hors de nous, font en fi grand nombre; \& la Medecine d'ailleurs les a fi bien examinées, que nous ne toucherons qu'à quelquesvines en particulier, \& nous ferons feulement choix de celles qu'on a ou negligées ou omifes, \& दui ne laiffent pas pourtant de nous emouuoir, \& de nous alterer fort founent.

\section{H A I T RE I.}

- Des Aftres qui nous inflment.

DVifque nous allons tracer vn chemin, \& 1 pourfuiure vne route aflez difficile; on ne trouuera pas eftrange que nous cherchions du fecours dans le Ciel, que nous obferuions fes $L u$. 
2. Des Aftres qui nous influent.

mieres, \& que nous commancions noltre ouurage par ce quifert à produire les plus belles chofésdel Vniuers; on verra mefme qu'il eft neceffaired orner ainfi le frontifpice de ce Liure, la Medecine, quien eft le fondement; ne pouuant agir fans les Aftres : \& cette excellente magie eltant inutile, fi elle n'eft efclairée de leurs afpects. Examinons donc quelles font les Planettes qui nous communiquent leur influence, \& quel auantage la fanté en peut receuoir: Et tirons de tous ces principes le temperament, que nous jugerons conuenable pour la conferuer.

Il y a de l'apparence que Mars nous domine auec tout le peuple de France, \& que Saturne nous fait reffentir quelquefois fes qualités \& fes vertus. Pour faire voir l'Empirede Mars, it n'y a quà confiderer que l'Aries elt fa maifon. que ce Signe fuiuant les Afrologues augmente: fon pouvoir \& fa force, \& qu'il influe fur Marfeille, \& fur le refte du Pays.

D'ailleurs, d'ou deriuent ces chaleurs vio. lentes, qui nous importunent durant l'Efté, fi ce n'eft de Mars, c'eft luy fans doute qui brûle nos humcurs, \& nos corps, quiles rend fecs \& tranfpirables, qui nous donne la franchife \&e ouure nos cœurs, qui nous difpofeà la bilè, \& aux fimptomesqui en prouiennent, enfin qui anime les enfans à fe battre à coups decailloux dans les plus grands jours de l'année, prefque à la maniere des Egyptiens, dont le Poëte-a exageré le tumulte.

Pauca fine vulnere male.

Vix cuiquam, aut nullizozo certamine najus 


\section{Des Aftres qui nous infixent:

En troifiéme lieu, nos femmes ne font matgres qu'à caufe de l'arpect de Mars, elles en deuiennent hardies, \& fieres : c'eft luy qui faic orner leurs juppes de quelque chofe de brillant \& qui les infpire à choifir des diamans, pluftoft que des autres bijoux, fur lefquels Mifaldus graue vne Image, qui attire les vertus de cette Planette, parce qu'elle regit tout ce qui jette du feu, de l'éclat, \& de la lueur.

Le pouuoir de Saturne n'eft pas moins affuré que celuy de Mars. Pour le bien faire voir,

Il faut remarquer ce que Campanella obferue dans fon Aftrologie; que l'Empire que les $\mathrm{Pla}$ nettes ont fur les peuples, paroift par les jours de leur negoce, \& de leur trafic. Ainfi on connoiftra les influences de Mars \& de Saturne. puis que c'eft le Mardy \& le Samedy, que nos Politiques ont eftabli pour le commerce, \& qu'ils ont choifi pour eflire les Magiftrats deuss jours qui font à ces Eftoiles, \& auquels elles ont impofé leurs noms.

Outre cette obferuation les effets de Saturne paroiffent encore par les maladies, par la conftitution de nos corps, \& par les inclinations de nos ames.

On les découure par les maladies, puifque les maux de ratte nous afligent fouuent, que la plufpart ont leurs dents cariées, \& que la melan. cholie eft prefque la feule qui abbat \& altere noftrefanté.

La conftitution de nos corps les fait voir par 
4 Des Aftres qui nous influent.

les lignes qui marquent nos fionts, comme elle monftre l'influence de Mars parcelles qui font dans fa pleine.

Et les inclinations de nos ames fortifient toutes ces preuues; non feulement parce que nos femmus dans vnâge vn peu auancé prennent fubitement le tané, ou le noir, deux couleurs qui ont du rapport au ton graue, qui eftentierement fous Saturne; mais d'ailleurs, parce qu'elles deuiennent ennemies de Venus, qu'elles s'oppofent à leur fexe, \& qu'elles renferment les femmes Veneriennes däs des lieux tenebreux, pour leur infpirer vne vie fainte \& reglée.

Il eft donc certain que Mars \& Saturne nous font fentir leurs influences, il faut maintenant chercher les moyens qui peuuent adoucir les imprefficns trop fortes qu'elles font fur nos corps \& fur nos humeurs; mais pour bien faire cecy, nous deuons encore implorer le fecours du Ciel, \& trouuer parmy les Planettes celles qui font ennemies des noftres, qui s'oppofent à leurs ấpects, \& quimoderent leurs vertus.

A ce deffein on doit confiderer que Mars ne peut rien fouffrir pres de foy, que Iupiter luy eft contraire, \& qu'il ny aque Venus, qui le fuiue, quil'aime, \& qui puiffe appaifer fes fureurs. C'eft pourquoy Claudien donnevn merme temple à tous deux.

Mauors fanguinea qui cufpide verberat vrbes,

Et Venus humanas qua laxat in otia curas,

Aurati delubratenent communia templi.

On remarque mefme que des filles riches \& belles preferent la brauoure des pauures $\mathrm{C}$. ualiers inconnus, à la modeftie $\&$ auxbiens de 
Des Aftres qui nous influent.

quantité de jeunes gens de leur Prouince : par la raifon que nous venons d'auancer que Mars \& Venus s'accordent enfemble.

Puis donc que Venus adoucit Mars, \& que Iupiter luy eft ennemy, alterons par ces belles eftoiles les qualités qui decoulent de celle-cy, \& joignons-y les influences de la Lune, qui emourfe la chaleur de Mars par fa froideur, \& dont l'humidité modere la feichereffe de Saturne.

C'eft pourquny il faut prendre garde à ce que Trifmegifte, Procle, \& Iamblicque ont montré fi diftinctement, \& à ce que les Caldeens ont practiqué auec tant de ceremonie : f̧̧auoir, que pour s'oppofer aux Aftres qui font malfaifans, on doit attirer les qualités des eftoiles quiles temperent. Ce font ces attrations que Sinefius ap pelle Magiques, que les Barbares recherchoient pour fabriquer leurs Talifmans, \& qu'Orphée recómande dans fes hymnes, en compofant des parfuns pour I u piter, pour Venus\&c.

11 faut donc choifir \& mettre en vage les chofes quifont fous Iupiter, fous Venus, \& fous la Lune, contre Mars \& contre Saturne, \& nous feruir de tout ce qui nous peut difpofer à receuoir leurs facultés. Or il n'y a rien qui foit plus propreà ce deffein, que les ruiffeaux, les fleurs, les prés, les vallons, les cafcades \&. fontaines, les jardins, \& les belles campagnes quifont fous Iupiter, fous Venus, \& fous la domination de la Lune, \& que les Druides cherchoiēt pour vaincre la malignité deSaturne.

Saturnumque grauem noftro Ioue frang amus vna. A quoy on peut adjoufter les alimens qui ra: A iij 
6

\section{Des Aftres qui nous influent.}

fraichiffent, \& quihumeitent ies couleurs mo: derées, comme les vertes \& les blues, la mufique, les airs agreables, \& la tranquillité de l'efprit, les mariages à des femmes douces, \& fans chagrin, la mediocrité aux habits, parce que leur grande fimplicité eft de Saturne, comme leur efclat eft de Mars, la conuerfation auec les perfonnes agreables \& enjoüées : enfin tout ce que nous deduirons au long dans la fuite de cét ouurage, qui a ce Chapitre praliminaire pour fondement.

Il ne refte maintenant à examiner que les $\mathrm{Si}_{\text {- }}$ gnes qui nous influent; mais il eft facile à voir que c'eft l'A ries \& le Sagitaire : non feulement parce que le premier eft la maifon de Mars; mais encore par les vifagesboutonnés, par les maux de tefte, la cheutte des cheueux, le dégaft des berbes, \& par les maladies des jambes fort dangereufes, qui nous font caufées du Sagitaire, ainf que les Aftrologues ont remarqué.

\section{CHAPITRE II.}

\section{Du soieil.}

A Presanoir examiné quelles font les eftoiles A qui font couler leurs influences fur nous, il efta propos d'obferuer la Planete, dont elles tirent leur lumiere, \& d'efcrire du Soleil, que les anciens on erigé en Dieu des Medecins, \& qu'ils ont honore comme le diftributeur de la fanté \& le foultien de noftre vje. 
Du soleil.

Inuentum medicina meum eft, opifexque per orbem

Dicor, do berbarum Jubiecta potentia nobis.

Il faut fuppofer à cet effet que l'homme, fuiuant les Aftrologues, eft foumis à Mercure, a Iupiter, \& au Soleil : de Mercure, il a le negoce \& les fciences, 1 induftrie, l'eloquence \& les Arts : de I upiter, la politique, le temperament \& la douceur, la juftice \& vn Empire Souueran dans le monde; mais il retient du Soleil vne taille auantageufe \& éleuée, les cheueux blonds \& la beauté, les chairs fucculentes, \& vne inclination fi grande à la lumiere, que c'eft de là qu'il a rendu du culte aux Afres, \& que le Soleil a efté la fource de l'Idolatrie des fiecles paffés. Et certesc'eft luy quiobligeoit les Bragmanes à s'expofer tous les iours a fes rayons, \& à confiderer fa route, quelques peuples à prefenter leurs corps parfumez de liqueurs precieufes à fa chaleur, jufques à vne entiere feichereffe.

Noftrabibat vernum contract a cuticula Solem.

Et quifaifoit dire à A naxagore que nous deuions agir ainfi par la raifon, commele tourne-fol par fa proprénature.

Neantmoins parce que nous fommes dans la mediocrité, \& que le foleil poffede plainement les qualitez actiues, nous ne pouuons foument qu'eftreefmeus par fa force \& par fon efclat, \& il n'y a que l'éloignement \& les ombres qui nous en puiffent garentir. Pour montrer cecy auec ordre, faifons vn examen de la nature de cet Aftre, \&ainfi chacun verra clairement, c'eft à dire auec le Soleil, les effets extraordinaires qui procedent de fon ardeur.

A iiij 
Et certainement comme le Soleil eft la fource de la lumiere, il eft par confe quent le centred'vne infinité de rayons qui en fortent, commeautiant de lignes brillantes. Or le mouuement de tous ces rayons eft fi prompt, qu'à ce fujet on les peut comparer à des fleches lancées d'vne actiuité merueilleufe, qui penetrent les corps folides, \& quiles ouurent jufqu'au fond : c'eft rans doute ce qui a infpire aux Poëres de donner des armes à A pollon, de le peindre auec vn Carquois, \& de publier les traits de ce Dieu comme les plus perçans \& les plus aigus. De là vient que puifque les fleches font repouffes par les fujects plus efpais \& plus durs, \& arreftées par les mols, les corps opaques reflechiflent ainfi les rayons, \& ils font repouflez fortement par leur confiftence folide; mais ils s'embarraffent au cotton, à la laine, aux efponges, \& leur molefle abbat \& alentit leur mounement. On peut expliquer ce difcours par vne bafle relancée du lieu qu'elle frappe, d'ou elle s'efcarte plus ou moins, par la petite ou par la grande refiftance qui s'oppofe à l'impulfion que le bras luy donne. Ce fondement fert maintenant à tirer des confequences importantes.

La premiere, qu'il nefaut pas trouuer efrange $\mathbb{f}_{1}$ lescouleurs terniffent \& perdent leur efclat au Soleil, \& fi les vifages s'y halent, fi les corps y amaigriffent, \& s'ils y deuiennent fecs: Enfin fi tout y diminue \& y fleftrit, \& fi ce Mailtre du temps, qui roule continuellement fur la terre, deuore ce qu'il touche \& ce qu'il produit, puifque fesrayons font autant de fle- 


\section{Du soleil.}

ches, qui penetrent \& fout des bleffures, qui deftachent inceffamment, \& qui enleuent de toutes chofes des atomes \& des portions.

La 2. confequence eft, que ceux qui ont la tefte dure, rolide, \& femblable à ces voutes qui reflechiffent les rayons, ne fouffrent point de la chaleur du Soleil, dont les pointes font émouffées par la refiftence du crane, \& comme il n'y a que l'vnion (ainfi qu'on void aux miroirs concaues) qui fortifie la lumiere, il fe troure là vne confiftance quila fepare, \& qui luy fait faire des angles fort grands, ainfi que nous auons expliqué par le relancement de la bâle : c'eft par cette raifon que le Soleil fait peu d'impreftion aux Payfans \& aux perfonnes populaires, dont les teftes font fort dures \& fort inegales; qu'il $y$ a des vieillards qui s'y expofent fans danger, parce que le temps a rendu leur crane comme petrifié, \& qu'il en eft pourtant bien au contraire des femmes, des enfans $\&$ des delicats, lefquels à caufe de la molleffe de leur peau, de leur chair, \& de la fubftance quieft fous le crane, font fortement alterez du Soleil \& de fa chaleur par les raifons que nous auons defcrites.

Mais fur tout les enfans en font fi mal traittez qu'on peut dire que le Soleil n'a dés rayons que pour les perdre, \& que c'eft en cette qualité qu'on les doit appeller des dards, \& des traits bien aigus. En effet, puifque leurs os font encore tendres \& cartilagin eux, \& que leur cerueau eft femblable à la crefme, fuiuant Hippocrate, [Lil.defept.part.] il arriue que les rayons font autant de pointes fubtiles qui murtrifent 
10 Du soleil.

cette fubftance mo fe repoufler; qu'ils en euaporent l'humidité ; en vn mot, qu'ils la percent \& la diffoluent, à la façon des efprits corrofifs, \& la changent en des cerofitez verdaftres, que la diflection nous decouure fouvent. Ce ront ces accidens fans doute qui obligeoient les fuperfitieux dans Hippocrate, [Lib.de Fpilept.] d'abjurer le Soleil aux inaladies du cerueau, qui faifoit chanter aux Poites que Saturne deuoroit fes enfans, luy qui n'eft autre chore que le Soleil, fuiuant Porphyre, [2. de abft. Carnis.] à qui les Phœniciens facrifioient les leurs, en les pafians au fuquien cft la Figure \& l'lmage, [Voffius.] Enfin c'eft de Jà que les Medecins ont tiré le nom de Syriatis, \& qu'ils l'ont imporé à la maladie qui vient aux cnfans du Soleil, non pas feulement de oelpráuás c'eft à dre enflamer; mais principalemēt du mot Eeipíos, qui fe prend pour le Soleil, mefme dans Hefrode \& dans Suidas, quiluy attribuë le nō de Esıp, qu'Homere a donné à la Canicule à caufe de fon efclat, de fonfeu, \& de fa qualité brûlante.

Le 2. fondement s'eftablit par des obferuations modernes, quiaffeurent que le Soleil eft vn corps caue, fpongieux \& tout percé, du centre duquel on ne voit pas feulement fortir des eitincelles \& desflammes, mais encores des fumées groffieres, dont l'opacité fait ces tafches qui difparoiffent fi fouuent: de là vient que quelques-vns [Auerr.] fe font imaginez que le Soled n'auoit plus fa grandeur premiere, pas 
Dx Soleil.

yne continuelle confommation de fon corps, \& qu'il eftoit ce feu quifaifoit les digeftions, \& les cuites dans la nxture; comme par fon excez il caufoit les fecherefles \& les plus ardentes chaleurs. De toutcela il faut maintenant tirer des confequences qui ne font pas moins fortes que les premieres.

En premier lieu, que ce feu fait quelquefois perdre au cerueau fa qualité \& fa nature. Pour bien entendre cecyil faut remarquer qu' Hippocrate a diuifé le corps humain fuiuant la doetrine des Egyptiens, il a donné le cour au Soleil, l'habitude du corps aux Aftres, \& il a foûmis le cerueau à la Lune, auec toutes fes cauités. Cet Efprit excellent a voulu que ce que la $L$ une fait au monde, le cerueau le fift en nous-mefmes, \& qu'il temperât par fa froideur le fang \& les efprits qui fortent allumés du cœur, a peu prés comme la Lune modifie les rayons du Soleil par vne qualité femblable. C'eft ainfi qu'il faut enrendre A riftote, qui en feigne que le cerueau n'eft que pour rafraîchir le coeur, c'elt à dire, pour reduire dans la mediocrité ies humeurs qui deriuent de cette fource allumée, de peur que roulans à grands flots dans la tefte, elles ne caufent \$l'amedu trouble \& de la confufion. Ce qui arriue infailliblement lors que le Soleila trop fortement échaufé le cerueau; car rendant alors commevn feu, par vne qualité turbulente, lé fang, les efprits, les cerofités, \& la bile decette façon fait perdre à cette partie le titrequ'Hippocrate luy a donné, d'eftre vne autre Lunedans pos parties, \& le fiege du glutineux \& du froid; 
\& authorifece que les Anciens ont auancé, que les peuples ont des inclinations eftranges fuiuant fesafpects differents. Et certainement c'eft icy la raifon pourquoy la jeuneffe $\&$ nos payfans foument font fi fougueux à la campagne; d'où viennent les inquietudes des voyageurs, \& les douleurs de tefte de ceux qui font furpris du hale : enfin pourquoy les Abdereites deuinrent fols, eftant fpectateurs d'vne Comedie d'Ar: ftophane qu'on reprefentoit au Soleil.

La 2. confequence eft que ce feu, outre fa chaleur imprime encore la fechereffe au cerueau, en abforbant ou euaporant ce qu'il a de fucculent \& d'humide, de maniere que dans cet eftat il fouffre bien des maladies. Le fondement de cela eft tiré de Platon, quiappelle vn homme vn arbre, dont les racines font renuerfées : Ces racines au refte confiftent au cerveau $\&$ aux nerfs, qui compófent comme vn gros Bulbe, \& il faut qu'elles foient humectées pour empefcher la fechereffe de leurs rameaux \& de leur tronc. Il eft partant veritable que le Soleil, en rendant les humeurs volatiles, introduit cette fechereffe dont nous parlons, \& éboit l'humidité qui fert à la conferuation du tout: \& c'eft scy peut-eftre la raifon pourquoy les cheueux tombent à ceux qui demeurent trop long-temps au Soleil, foit parce qu'ils font priuez de leur nourriture, ou que la chaleur rarefie les pores auec excez, ou bien fuiuant Hippocrate au 6 . des Epidemies, parce que lecerueaufleftrit, \& fe retire loin du crane.

$\mathrm{La}_{3}$. confequencefe prend de ce que ce feu 
ศúoy qu'il foit tout épuré \& tout celefte, altere pourtant quelquefois les efprits par fa force, il efface leur clarté, \& diminué leur tranfparance ; il les rend tous fuligineux, \& en bruflant le fang, les proportionne tous à la fuye; on voit vne apparence de cela aux vifages qui font halez, dont la noirceur ne procede pas feulement de la peau roltie \& ridée; mais auffi de ce que le fpiritueux s'eft reduit en charbon, qui s'y eft attaché auec vne humeur que la chaleur a efpaifie, comme on void tous les joursdans les fucs \& dans les fyrops. Or les efprits fuligineux infpirent à l'ame des facheufes inclinations, ils l'embarraffent dans des nuages, ainfi que lors que la lumiere eft obfcurcie des broüillards, ils la rendent melancholique, \& font conceuoir aux peuples, qui fouffrent de cette maniere, des foupçons, desdefiances, des deffeins à empoiConner \& à trahir, ils les pouffent à aymer la noirceur, \& toutes les chofes oblcures; mais fur tout ils les inclinent à n'auoir qu'vne Religion materielle, groffiere \& brutale, \& quelquefois à l'abandonner tout à fait. On voit ainfi les Mores \& les Barbares du midy, qui haiffent le Chriftianifme, parce que la hauteur de cette Religion demande des efprits efpurez, \& femblables à l'Element des Aftres, au dela defquels l'ame doit porter fes penfées. Il eft certain neantmoins que fi le Soleil efclaire auec moderation, qu'il fait les efprits plus brillans, au lieu de les rendre fuligineux ; qu'il les clarifie, au lieu de les épaiflir, qu'il reftablit leur tranfparence, \& qu'il fait gliffer ainfi la joye, \& 
74 Dusoleil.

chaffe la melancolie du cour : c'eft de cette fa çon que l'aurore nous réjoüit, que les Medecins ordonnent la Campagne, pour eua porer la trifteffe, \& qu'Hippocrate voulut monter vn nauire qui eftoit confacré au Soleil, pour guesir l'atra-bile du Philofophe qui rioit.

Le troifiéme fondement ne deriue que de la reflexion qu'il faut faire fur l'origine \& le commencement du monde; car il eft certain que l'Efprit ne fe promenoit autrefois fur les abyfmes que pour feparer les Elemenis de leur confufion; Il rouloit à cet effet inceffamment, \& donnoit la figure ronde à tout: $1: V$ niuers par fon mouuement circulaire; \& apres auoir fublimé les matieres les plus fubtiles, il les difporoit pour les Cieux, ayant depofé en bas les plus épaiffes pour.la Terre. Orcet Efprit fut apparemment vny au Sole1l, puifque cet Aftre roule toûjours comme luy fur le globe, qui l'imite par fa vertu, qui fait v n cercle pour communiquer fes lumieres, \& que les nuits, l'hyuer, \& le temps de la pluye font comme diuers cahos, qui ne f̧̧aroient eftre éclaircis que par fon éclat.

De tout cela il faut donc conclurre quón ne doit pas s'eftonner fi ceux quifont trop échaufés du Soleil font émeus, \& reffentent vin fouleuement dans leurs membres, s'ils font malades des fluxions, \& s'il fe fait, vn remuëment dans leurs humeurs $\&$ dans leurs entrailles; puifque cet Aftre ćleue en haut \& repouffe en bas, quil fait vne difgregation dans le petit, auffi bien que dans le grand monde; qu'il détache tout cequi eltoit ramaflé, \& qu'sl ouure ce qui ne deuoit 
Du soleil.

point d'iffue : C'eft pourquoy au Printemps lors que cette Planete entre dans l'Aries, \& que fes rayons feparent ce $q u i$ eftoit refferré pendant le. froid, on eft faifi de l'A poplexie, des Rheumatifmes, on reflent des Vertiges opiniaftres \& dangereux, \& les efprits qui font Solaires fuiuans le mouuement de leur principe, entrainent \& font bouillonner lescerofités \& le fang.

Le dernier fondement auec lequel nous allons finir ce Chapitre, depend de ce que le Soleil fait la fonction du coeur dans le rronde, ainfi que les autres Planettes font à proportion celle du foy, \& des principales parties, qui compofent les animaux. En effet comme le cour en souurant \& fe fermant, retient ou pouffe les efprits, \& comme ceux-cy fortans par la diaftole, font autant de petites lumieres qui viuifient tout le corps, qui luy impriment la chaleur Be le mouuement, \& qui pouffent le fang dans les veines; le Soleil garde le mefme ordre, \& ce qu'on void de l'afpect \& du cours de cet Aftre, eft femblable aux fonctions du cour. Pour preuue decela, il ne faut que confiderer fes rayons; car apres qu'ils fe font ouuerts, \& fe font dilatés dans I'Orient, a pres qu'on les a veu comme. fouffrir vne tumefaction, \& reprefenter les. corps qui fe gonflent dans cet eftat, ils rarefient tout l'Vniuers, ils r'animent ce qui languiffoit dansles tenebres, ils pouffent l'air comme l'efprit vniuerfel, d'où vient qu'on reffent toûjours vn vent agreable à l'aurore, l'air poufle les eaux, les caux font mounoir tout ce qui les approche, toutes chofes s'entrechoquent par vn enchainement mutuel ; jufqu'à ce qu'il fe falfe 
vne contraction, \& vn retour dans le couchane; \& dans les Eclipfes, fuiuant l'enigme d'Hippocrate au liure de l'aliment, que le grand principe influë jufqu'à la derniere partie qui s'en retourne au grand principe, \& que fa nature eft d'eftre, \& de n'eftre point. Voyons maintenant ce qu'on doit inferer de ces veritables principes.

Premierement on peut conclurre que le Soleil rarefiant l'air, il fait fans doute le mefme aux efprits, ceux-cy font ainf des humeurs, \& les humeurs emeuës \& coulantes, ouurent \& s'infinuent dans les parties; de façon qualors les animaux, qui font autant de petites machines, reflentent vn changement bien grand, à caufe des differens détours de leurs membres, les coqs par exemple ont vn preffentiment du Soleil, parce que leurs efprits fe dilatent à l'approche dela lumiere, ceux-cy remuent les parties, qui fedechargent le matin, par le battement des ailes, de ce qui les embarrafloit, à peu pres commelors qu'on eftend les membres pour les degourdir du fommeil; le chant mefme des oifeaux eft ainfi que le baaillement, enfin ce font leurs particules fubtiles, \& leurs humeurs qui re remuent par leur grande tenuité, qui comme autant de petits reflorts, font des coqs, des horloges animées, qui marquent bien mieux que celles qu'on ajufteauec tant de foin, les diuers changemens du temps.

Il en eft des plantes folaires ainfi que de ces animaux, elles s'ouurent par la rarefaction de leur fuc, \& par les efprits nitreux qui les gonflent, ce font cux qui pouffent les fleurs iे fui- 


\section{Du Soleil.}

ure le Soleil, ce cour du monde en le ouurane les épanouit \& les dilate, il fait ainfi de leurs fibres \& de leurs tuyaux, elles cherchent tô̂jours cette chaleur viuifiante, jufqu'à ce que fa fource fe foit retirée, \& qu'elle aye ramaffé fes rayons, comme par vne contraction.

Faifons les mefmes confiderations fur les hommes, qui ne font pas moins folaires que ces plantes \& ces animaux : le Soleil fat de pareilles impreffions fur leurs corps, par les raifons que nous auons déja déduites : c'eft ainfi que les melancoliques, \& les chagrins diminuent les jours de leur trifteffe par la dilatation des efo prits; que les fçauants conçoiuent mieux le matin, que lors que le Soleil fe couche; que nous dormons dans les tenebres, \& que nous veillonsà la clarté ; que les voyageurs font plus de chemin au Soleíl, que durant la nuit , fur tout s'ils fuituent fa carriere; enfin que leurs mouuemens font plus grands par les rarefactions fufdites, \& par le détachement \& la tenuité des efprits.

De là vient que fi le Soleil eft trop ardent; toutes ces rarefactions fe changent en boüillons, $\&$ rendent les humeurs \& les efprits tumultuaires; ces atomes fe choquent, \& pouffent iो grands flots le fang, elles détachent les efpeces, les roulent par le cerueau, les agitent \& les balottent, vous diriez que c'elt vn peuple mutiné, qui veut depofer fon Souuerain; \& comme la lumiere moderée les remuë doucement dans l'auro re, elle les arrache au contraire $\&$ les confond par la force de fa chaleur. C'eft ainfi qu'on 
I

Da soleil.

devient fol, quand la difpofition spy troutue, on s'expofe long-temps au Solcil; quion a du moins la nuict des inquietudes par des cont:nuelles images, en forte que c'eft peut-eftre à caufe de cecy, [Lib. de Som.] qu'H'H ippocrate a voulu quon fift des pricres au Soleil apres les fonges; que les anciens luy venoient raconter les leurs apres s'eftre laués de leau, \& qu'ils difoient qu'A pollon in piroit dans le fommeil les Prophetes, \& leur decouuroit le futur.

Au refte fi cette rarefaction n'eft pas fi violen. te, elle prouoque à la volupté les homines \& le refte des animaux; la raifon en eft tirée du bouil. lonnement que le Soleil caufe aux humeurs, \& del'emotion de l'efprit qui luy eft proportionné, fuiuant Ariftote; cal eftant le principe de la generation, \& ayant du rapport à cet Aftre, il a fait dire à cét effet, que l'homme eft engendré de l'homme \& de la lumiere, que le Soleil eftoit la fource de la fecondité, \& qu'il ne faut pas s'eftonner fi lOrient eft fi peuplé, \& sil a fournides habitans à toute la terre, puis qu'il eft fous fes influences. Les Grecs \& les Egyptiens ont fort bien reconnu cecy, les premiers luy ont facrifié vn coq \& vn afne, pour marquer par ces animaux voluptueux que le Soleil donnoit l'amour; \& les feconds pour tefmoigner v mefme fentiment, luy ont offertila partie qui mous fait hommes: en forte que c'eft de leurs ces remonies qu'Orphée a compofé cet Hymne.

\section{Pep munduta}

Etricantem ducens lusen, \& qua te Phamera vacs Atguse Sriapum' Regem. 
Et veritablement quand on confidere que le Soleil anime \& donne la vigueur à tout $1 \mathrm{~V}$ Vniuers, il faut que ce foit en efueillant cette eftuncelle qui rend les plantes fertiles, \& qui donne la fecondité aux femences des animaux; de for te qu'on ne peut nier que les canaux qui la contiennent, riayent vi fentiment tout particulier, par la caufe qui fert de leuain general, \&s qui fouleue la nature. Les Aftrologues niont point douté de cette verité, lors qu'ils ont foûtenu que la grande chaleur du Soleil produifoit des puftules à la matrice, \& que fes rayons agifo foient fur la terre du petit monde, comme ils font par des fouleuemens ordinaires dans celle du grand. Il y a partant à s'eftonner pourquoy eft-ce qu'ils afleurent que les femmes enceintes conçoiutent de leurs influences, ce defir prodio gieux de vouloir manger de la chair d'vn homme fucculent \& gras: nous pouuons neantmoins croire qu'ils ont efté perfuadés à cela, parce que le Soleil produit ie ne fçay quoy d'oleagineux, lors qu'il domine à la generation, qui donnel l'embon-point à l'enfant, ainfi qu'on lit dans Hippocrate, Alijs excellers fatus fols maxime consusrisos, de forte quili peut prouoquer de ia cét appetit eftrange, que quantité de grands perfonnages ont obferué. Mais c'eft trop nous arrefter au Soleil, il eft temps que nous imitions les voyageurs, \& que comme euz nous pres saions du repos à l'ombre. 


\section{CHA PITRE III. \\ Des Ombres \& des Parajols.}

T T pleût à Dieu que cette ombre fûtà mon oulEurage, de la nature de celle dont les Peintres releuent les leurs, \& en font paroiltre la beauté auec plus d'éclat \& de luftre, ou du moins qu'elle en peût cacher les défauts, \& couurir les futes que nous y auons refpanduës : Mais efperant cette grace de la bonte du Lecteur, difons cependant que la confideration des ombres neft pas moins importante que celle du Soleil, \& qu'on doit s'eltonner que les Medecins ayent oublié d'en traitter au long dans cette partie qui prefcrit les regles de la fanté. Pour authorifer cecy auec ordre, il faut diuifer les ombres en artificielles \& naturelles, \& examiner lẹs vertus de chacune en particulier.

Ies ombres artificielles n'agiffent feulement que parce qu'elles repouffent les rayons du Soleil, qu'elles les.rompent \& les affoibliffent, \& en diminuent la chaleur; auffi ou elles font faites des tentes, que les Romains appelloient vmbras dans les Foires [Cafaub. in Theoph.] ou bien elles deriuent des parefols, dont les anciens eftimoient fi fort l'ombre, qu'Ouide en remarque le luxe.

Aurea pellebant repidos vmbracula Soles.

Sur quoy il faut prendre garde qu'ils auoient encores cette couftume d'en faire, dont le berd 
Des ombres \& des parafols.

eftoit flottant à la moindre ficourte, de peur te ne ramaffer les rayons, \& afin que l'air battu parvne agitation moderée, fift comme vnagreable zephire. Ce font les parafols de cette façon, qui eftoient firemarquables chez les Atheniens, qu'il n'y auoit parmy eux que la plus ancienne famille qui s'en peuft feruir ; c'eftoit d'eux que leur grand Preftre alloit couuert, lois qu'il deuoit facrifier au Soleil, \& on connoiffoit par leur vfage la faifon propre pour baftir. Nos parafols ne font pas tout a fair femblables à ceux-là, ils nelaiffent pas neantmoins d'eftre fort commodes aux femmes \& aux delicats, quiprennentfeu à la moindre chaleur : les Portuguais mourroient dans l'Ifle de Iaua fans leur fecours, \&les Moluques n'oferoient laiffer fortir leur Roy, \& leurs Epoufées fans eftre fous yn parafolde plumes colorées diuerfement. Il feroit pourtant neceffaire de ne porter point au Soleil ceux qui éclattent d'vne couleur viue, parce que la lumiere s'vniffant auec elle, la porre jufques dans les yeux, de maniere que la veuë en eft alterée, que le fang mefine en elt émeu par l'agitation des efprits : de forte que c'eft ainfi que les taureaux deuiennent furieux, voyant du rougeà la campagne; qu'on tache par cette couleur de faire fortir la picote, \& que beaucoup portant des fleurs, \& quelques fruits vermeils à la main, fe trouuent fai s d'vne hæmorragie, fans qu'ils en fachent la raifon.

L'ombre naturelle procede des arbres \& des autres corps opaques, de laquelle Pline a dit, nom faftidienda hac quoque fcientia, neque in vltimispes B iij 
cende, guerdo quebufue folis vmbra, aut nustix, aut wowersa fir, appellant lombre nourrice, ou maraftre parce qu'elle fait du bien ou du mal. Ap. puyonsces fentimens par les confiderations fuivantes, quine rouleront que fur les ombres en general, fur leurs differences, \& rur leurs effets.

La ¿. eft quion void les objets plus gros, \& que la veue fe conferue mieux fous les ombres, parceque la prunele fe refferre au grand iour \& a lumiere, \& elle fe dilate à l'oblcurité; $C$ 'eft posrquoy la nature a ombragé les yeux, nous y portons la main, \& nous nous feruons de fon ombre quand leur force eft diminuée, \& nous difcernons mieux les objets le matin \& lefoir; qu'à midy.

La 2. que l'ombre tempere la chaleur du Soleil, en modifiant fa lumiere, qu'elle emperche d'ailleurs la féchereffe, \& l'exolution que les gayons font reflentir à nos parties : delà vient que les electriques qui perdent leur attraction au So. 1eil, par la difipation de leurs particules fubtiles, la reprennent de nouueau fous les ombres auec viguaur.

La 3. quion fent fous lombre le plus foument, vn petit zephire, qui flatte par fon haleine, \& par fa fraicheur ceux qui s'y arrefent quelque temps: or cevent ne prouient que del'air rareGé par la chaleur, quis'emeût pour chercher vne plus grande place, \&qui fe refferre enfin en trouuant vn lieu temperé, \& donne à vn nouueau le moyen de fe ioindre à luy. Et pource qui eft de la fraicheur, elle ne procede que des exhalaifons humides, \& nitreufes que la terre \& les ar: 


\section{Desombres \& desparafols.}

bres répandent urdinairement au dehors. Auff les voyageurs efchaufez, qui repofent fouvent fous l'ombre, foufrent quelquefois vne condenfation des efprits \& du fang, à la façon de celle de l'air, quiles rend enfin pleureciques, \& qui à fait croireà quelques-vns que Damon n'auoit chaud à l'ombre \& froid au Soleil, qu'à caufe de l'vnion \& du retour de ces tranfpiracions ardentes qui fortent toûjours hors des pores, \& fe dif fipent au Soleil.

La 4. que l'ombre eft aux corps opaques, ce que l'echo eft au fon, \& la fplendeur a la lumiere; de maniere que comme la fplendeur ne reprefente pas feulement les corps lumineux, mais elle en communique encore la chaleur \&e les influences; ainfi l'ombre ne porte pas feulement la figure des corps opaques, mais en: core leurs qualitez \& leurs vertus.

La g. que ces vertus fe conferuent à lombre? ainfi que nous auons dit des Electriques, \& euaporent au Soleil ; qu'elles procedent des feparations, des bouillonnements, \& des cuites qui fe font dans les arbres, \& dans la terre; qu'elles font de differente nature, furuant la diuerfité de fujets; qu'elles fe communiquent à l'air \& à tout ce quiluy eft voifin; qu'elles font ordinairement humides \& froides, \& verifient le paffage d'Hippocrate au 2. de la diete, vmbra ó frigus moderate bumectant, plus enim dant qud̀m accipiuns, contrà Sol o ignis ficcant qui a bumiditatem trabsn:0 Enfin qu'elles éclairciffent ce que nous auons re marqué de Pline, que les ombres font nourrices ou maraftres par l'effet de leurs projectiōs. PrengB iij 
uons maintenãt la verité de ce principe par l'examen que nous ferōs de la proprieté des ombres \& de leur grande differēce : mais pour nous acquiter de ce dellein auec plus de methode il faut fuppo. fer que, ou les ombres deriuent des arbres ou des animaux, ou des montagres $\&$ des valons : traitós des premieres vn peu au long, \& efleurōs feuIemẽt les autres cóme eftant les moins importãtes.

L'ombre des arbres eft differente par la difference des projections, ainfi que nous auons dit cy-deflus; en effet il y a des ombres qui font froides \& qui infpirentla chafteté, comme celle de l'Agnus Caftus, du peuplier, de lofier, \& du rauie, dont les ombres font nitreufes \& feruent à refroidir les chairs, \& leur infpirent vne qualitéfixatile : il y en a qui delaffent les voyageurs en rependant vne vapeur balzamique, affoupifrante \& humide, qui adoucit \& foulage les nerfs, qui arrefte les fluxions, \& qui ramollit la dureté qui fe fait pendant le chemin par la contufion des iointures. Quelques ombres outre celles-cy, nourriffent \& engraiffent ce quelles couurent, en exhalant des parties oleagineufes \& gluantes, equifees d'vn fel volatil, qui fert merueilleufement à prouoquer la fertilité : il en eft ainfi de ces arbres des Indes, a l'ombre defquels on plante les autresqui ne fçauroient produireautrement. Ces fortes d'ombre en ont quileur font grandement oppofées, qui caufent la fterilité $\&$ qui donnent les maladies, \& qu'on peut nommer iuftement maraftres fuiuant ce que Pline a écrit. C'eft ainfi que Virgile a qualifié lombre du Geneurier, \& les Aftrologues celles 
Des ombresa desparafols.

des arbres qui font fous Saturne, commeles pins qui eftoient de maunaife augure autrefois, \& ceux encore qui portent des fruits noirs, qui ont la figure d'vne tefte de mort ou d'vncafque, ainfi qu'on remarque dans la noix de cyprés. Lucrefle à compris tout cecyen trois vers.

Arboribus primum certis granis vmbra tribut a eft, $V$ fque adco capitis faciant $v t$ fape dolores

si quis eafubter iacuit proftratus in vmbra.

Et certes fi on prend garde que les arbres attirent de la terre des fucs vitrioliques \& nitreux, desfulphureux, des Saturnins, desvenimeux, \& des balzamiques; on ne trouuera pas eftrange qu'il y aye des ombres nuifibles, cōme des ennemies du cerueau, \& des nerfs: que quelques-vnes rendent les perfonmes paralytiques, \& que quelques autres foulagent les maux que celles-cy" font. C.eft ainfi que l'ombre du noyer engourdit les parties, parce qu'elle communique vne huile impure, \& que celle du chaine reftablit la vigueur perdue par la trăfpiration du noyer, parce qu'il répand au dehors des fels quicorrigent vn fouphre inutile, en vn mot qu'il y a des ombres qui réueillent la rage affoupie, des autres qui chatouillent \& excitent à la volupté, quelques: vnes qui prouoquent les douleurs \& la bile, qui tuent les ferpens, comme celle du frefne, ou les hommes, ainfi que le lierre fuiuant Plutarque; enfin il y en a quiarreftent la foudre, qui la repouflent, quiattirent le fang, \& qui fót quantité d'effets tout à fait inconceuables \& furprenants.

Celles qui irritent la volupté font remarquées du Pere Kirker quien donnevne preuue experi- 
mentale dans fon liure de la lumiere, affeurant que lors qu'vn jeune Gentil-homme Romain repoloit à l'emboucheured'vne grotte ombrayée du fatyrion, il trouuoit toûjours fa chafteté affoiblie, jufqu'à ce qu'il eut veu par la figure que cette plante a à la racine, que fon ombre eftoit ennemie de la vertu.

Les ombres qui empefchent l'action de la foudre, n'agiffent que par le moyen desefprits, qui fixent ceux qui fortent de la nue allumée, celles qui prouoquent la bile ont des efcoulemens qui feruent de leuain, \& qui font bouillonner le fang. C'eft fans doute de là que l'hxmagogue fuiuant Galien fait fortir le fang hors des vaines, \& que l'ombredu fureau qui eft en fleur rougit les chairs \& les vifages, \& n'eft bonnequ'aux pituiteux, auff les anciens ne la recherchoient que pour voir par la maturité des grains de larbre, sil eftoit temps de faire vendange, \& s'ils pounoient colorer les Statuës deleurs Dieux.

Cependant,cequ'il y a deremarquable parmy les ombres des arbres, c'eft qu'il y en a des melancholiques, \& d'agreables : celles-là plaifent aux defefperés, $2 \mathrm{ax}$ amoureux, aux taciturnes, \&aux folitaires, quiy racontent leurs martyres, \& ils y laifient leurs chiffres, ou quelques marques de leur douleur, elles fomentent l'atrabile, les influences de Saturne, \& feruent à entretenir le chagrin. Ces ombres font compofées des arbres toufus \& efpais, dont les fueilles ont vn verd obfcur, \& vne confiftence groffiere qui empefche la lumiere, \& qui en interrompt 


\section{Desombres \&u des parajols.}

la clarté : Elles ne fe nourrillent mefme que d'vn fuc efpais \& terreftre : elles ramaffent va air groffier, fous lequel on ne refpire que des vapeurs crues \& impures, \& quelquefois des venimeufes, sily a des plantes au deffous femblables aux mandragores \& aux aconits.

Les ombres agreables procedent des feuilles qui ont vne confiftence tenuë, \& qui fe nourriffent d'vn fuc efpuré, elles donnent paflage à la lumiere qui ne les purifie pas feulement, mais qui s'vniflant auec leur teinture, fait vn verd brillant qui réjouit les melancholiques, qui donne vne humidité bien faifante qui eft jointe auec la fraicheur, enfin qui a efté fi fort eftimé des Poëtes \& des anciens, que les premiers one logé fous ces ombres les Dieux \& les Nymphes. \& que les autres ont erigé des forefts, \& les one confacrées au lieu des temples. C'eft ainfi qu'il faut expliquer le Poëte.

Lucus inV Vbe fuit media, letiffimus vmbis.

L'ombre des montagnes\&des vallées n'eft pas moins remarquable que celle des plantes: c'eft ainfi que l'ombre du Mont-Argée a merité des adorations, à caufe qu'elle procuroit la fertilité, quel'ombre decertains valons eft peftilente, en cachant des mineraux, des eauxcroupiflantes $\&$ des ferpens, \& en empefchant la vertu purifrante de la lumiere. Ie ne f̧̧ay fi c'elt à caufe decela, que pour adoucir la Deeffe Vallina on luy offroit des Sacrifices dans ces lieux fombres \& obfcurs : quelques vns pourtant croyent que c'eftoit pour procurer la fanté aux heetiques, qui fetrouuent bien dans les vallées humides \& 
froides quicontiennent des arbres d'vne mefme nature, dont le fel adoucit \& corrige l'acidité qui eft dans leur chair.

L'ombre des animaux a efté obferuée de quelques fuperfitieux, qui apprehendoient de la fouiller de leurvrine, \& elle auoit impofé aux credules queles chiens eftoient fafcinés par l'ombre de la hiene, \& que les hommes y perdoient leur voix; mais toutes ces ombres font, ou parfageres ou fabuleufes, \& elles ne font rien à nofre fujet: Il faut feulement remarquer, deuant que de terminer ce difcours, que l'ombre du matin eft toûjours plus humideque celle du midy $\& d u$ foir, à caufe qu'elle renferme les vapeurs \& les exhalaifons que la nuit auoit enleuées, qui font que le Soleilqui monte fur l'horifon paroit plus grand, \&d'vne lumiere plus obfcure.

\section{CHAPITRE IV.}

Du Serain. \& del'Atmojphere.

Vifque nous auons obferué le Ciel, le Soleil, 1 \& les autres Planetes, il eft temps dedefcendre plus bas, \& de confiderer dans l'air les meteores qui s'y forment, \& quelles font leurs qualités : \& parce que le ferain.en eft vn des plus ordinaires \& des plus dangereux, il eft propos d'en examiner l'origine, \& de voir ce qu'il peut fur lecorps \& fur la fanté.

C'eft pourquoy il faut prendre garde que 1 a terre contient quantité d'efprits, \& des fels, 
dont les vertus font fort nuifibles : neantmoins elles ne paroiffent point au dehors, que lors que leurs fujets exhalent, à caufe des fermentations differentes, qui les tirent hors de leurs voiles, \& qui les produifent des tenebres à la lımiere, comme Hippocrate nous a montré.

Il faut remarquer d'ailleurs, que le Soleil contribuë beaucoup au detacherent des ces matieres, parce que cet Aftre eft comme le feu, qui fublime, qui fepare, \& qui fubtilife : que fes rayons font femblables à des couteaur, qui diuifent en atomes ce qui fouffre leur violence, qui donnent mefme la legereté, \& font que les particules detachées montent en haut le plus foulent, \& deuiennent le principedes meteores qui nous caufent l'admiration.

Il arriue merme que les rayons efleuent toutes ces petites parties, apres les auoir feparées, qui les fouftiennent, \& les portent dans l'air ainfi qu'vn Cheual vigoureux, qui promene fon. Caualier. En effet, puis qu'ils entrent dans les pores à la maniere des fleches qu'on lanced'vn arc bien tendu, ils pouffent, ils remuent, $\&$ ils detachent enfin les portions, qui font plus fubtiles, \& s'vniffans auec celles qui font volatiles; ils les entrainent dans l'air, en fe reflechiffans, à la façon de ceux qui ayans percé quelque corps auec vn fer pointu, le releuent en hauflant les bras.

Cette fuppofition fait conceuoir maintenant $v$ ne verité fort importante; car les rayons eftans vn is auec les parties qu'ils ont detachées, ils font auccelles ainfi que les eaux fortes \& dif- 
foluantes, quiapres auoir rongé les metaux, \& les auoir reduits en poudre, elles s'y joignent eftroitement ; cette comparaifon fe peut autorifer en deux manieres.

Premierement, parce que ce qui elt detaché a du rapport auec tous les corps metalliques, fur lefquels les eaux fortes agiflent, il participe du mercure, de l'antimoine, \& du vitriol, ou il eft la matiere des mineraux que la terre nous couure, comme de l'arfenic, du plaftre \& $c$. En fecond lieu, parce que comme les eaux fortes s'vniflent fi fort auec les metaux, qu'il faut vn fel qui les precipite, les rayons \& lescorpuro cules fe feparent de la mefme façon ; car comme le Soleil fe charge toújours de nouueaux fels, il quitte fa premiere charge pour fe joindre auecla feconde, fi bien que lespremieres particules fe precipitent pendãt que les nouuelles remontent en haut : il faut partantremarquer que celles-cy ne defcendent pas fi fubitement fur la terre;mais elles furnagent à caufe de la profondeurde l'air, ainfi qu'yn bafton fur les eaux, jufques à ce que le Soḷil venāt à quịtter 1 horifon, elles tombent enfin fur nos teftes, \& font le ferain, qui eft fi mal-faifant en beaucoup de lieux. Mais pour en expliquer la cheuteauec plus de clarté, il faut reprendreceque nous auons dit ailleurs, \& fe Sounenir que le Soleil ne continuè à rouler tous les jours fur le globeque pour feparer inceltamment, fr bien que la nuict deuient comme vn Cahos par le defaut de fa lumiere, les elemens femblent alors retomber dans la confufion, \&e lair fe troune browillé des impuretez quieftoièt 
Duferain, do de l'asmofphere.

inuifibles \& furpenduës. Les Medecins obferuent tous les jours vne idée de cet embarras a un vrines; car elles font claires par la chaleur; mais elles deviennent troubles eftant rafroidies, \& elles depofent leurs fels, ou ce qu'elles contiennent de cras : Ceft ainfi qu'il faut conceuoir l'air chargé de vapeurs \& de fels, pendant les tenebres, il deuient alors efpais, \& fe decharge de cequ'il auoit fouftenu le jour.

Cette decharge au refte fe fait, foit parce que le froid comprimant les pores de cet element, il en efpraint l'atmofphere ainfi qu'à vne efponge; foit parceque les atomes preffées, fe pouffent mutuellement par leurchoc, \& par la pe fanteur des fels; foit enfin parce que les rayons venant à manquer, ills abandonnent les particules qu'ils tenoient rarefiées \& furpenduës, \& aurquelles ils donnoient quelque legereté par leur chaleur, ainfi qu'vn cheual vigoureux qui demonte fon Caualier, \& le fait tomber dans la courfe. Appliquons maintenant tous ces fondemens. au ferain, \& decouurons tout aे fait fa nature.

Ileft affeuré en premier lieu, quele ferain ne deriue quedes particules qui retombent durant la nuit, ces particules viennént le plus fouuente desfels, qui font les corps groffiers \& folides. \& parce qu'elles defcendent de fort haut, \& qu'elles ont vne confiftence, elles s'impriment fur nos teftes ainfi que des petits marteaux, \&à li façon des petites pierres, qui roulant d'vni lieus eminent, font des contufions \& des murtrif cures. 
D'ailleurs, parce que les fels font fublimés du Suleil, ainfi que nous auons déja dit, qui les fubtilife \& les porte en haut, apres les auoir tirés des mineraux, \& les auoir comme calcinés fur la terre, ces fels en tombant percent à la façon des efpingles \& des efguilles, à caufe de leurs figures romboiques \& pointues quelles prennent, ou par la fublimation, ou de reurs fujets, en forte que c'eft d'elles fans doute que la neige a fouuent des floccons en pointe, \& qu'elle paroift en eftoiles. Outre les fels neantmoins, il y a quelque chofe de plus fubtil, qui cit la caufe du ferain : elle confifte aux efprits qui s'éleuent auec les fels, comme nous auons remarqué par le bouillonnement des matieres : or ces efprits eftans repouflés en bas, ils communiquent à nos teftes les qualités de l'arfenic, de lor-pigment, du bitume, du fouphre, \& du nitre, \&c. defaçon que commeils font de prodigieux effets dans la foudre, ils repandent aufi leur malignité en coulant en bas, \& rendent mos efprits ainfi que des effences pures, qui fe corrompent par quelque meflange. Et voila la 1aifon pourquoy le ferain eft fi dangereux encertaines Prouinces; à caufe de leurs mineraux, \& des efprits qui en deriuent, \& pour montrer ce. cy dans l'endroit où nous fommes, il n'y a qu'à obferuer que le terroir contient du plaftre, du nitre \& du fouphre, comme nous remarquons dansles bains, \& dans les eaux de quelques fontaines, fi bien que le Solcil fublime ces matieres, \& en efleue les atomes, \& lesefprits, aidé de la chaleur du fable, qui eft échauf-

fé 
Du ferain, of de l'armosphere.

fé des callines \& des rochers, comme d'vn feu de reuerbere, de forte que ces fels, res atomes \& ces efprits nous communiquent enfin les qualitez de leur principe, \& alterent noftre fanté.

Et apparemment toutes ces conjectures font bien fondées, ti on prend garde que nos jours eftant chauds \& ferains, les pores \& les futures fedilatent, fi bien que la nuict furuenant, le ferain \& les exhalaifös efleuées par l'ardeur precedente, trouuent vne ouuerture fort difpofée, $\&$ impriment au cerueau ce qu'elles ont de venineux Il ne nous refte maintenant à examiner que certains problemes, pour acheuer d'éclaircir $\&$ de terminer ce difcours.

On demande premierement, d'où vient qu'en certains lieux les femmes ayment à demeurer au ferain pour deuenir blanches, \& pour auoir le teint plus beau.

Il faut refpondre que la blancheur empruntée vient ordinairement de ce qui deterge, \& qu'on choifit les chofes acres pour polir le vifage $\&$ le rendre plus pur. Or le ferain fournit quantité de fels, qui eftant portez à la peau, font 1 'effet que les Dames fouhaitent, \& embelliffent leur vifage à la façon deces belles glaces, dont les taches s'effacent par ce qui a de la pointe \& de l'afpreté.

Ondemande en fecond lieu, pourquoy eft-ce que quelques-vns ne reffentent point l'incommodité du ferain.

Il faut direà cela que, ou ces perfonnes ont le crane fort dur, fort folide, les futures fort eftroittes, la chair maifiue, ou bien grande 


\section{Duserain, do de l'armosphere.}

crane delicat, lesfutures larges, \& la peau fort ouuerte \& tranfpirable, comme il arriue à la plufpart des habitans de la Prouince, quife fer uent de calottes à cet effet.

Ia troifiéme difficulté confifte, f̧̧auoir fi la Lune ne contribuë point au ferain, ainfi que quelques-vns ont fouftenu, puis qu'elle eft fi fort ennemie du cerueau, que fes rayons relachent les nerfs, \& rendent les enfans epileptiques : En forte que Plutarque defendoit aux nourrices de les dépouiller fous cet Aftre, de peur que leurs petits corps ne pliaffent à la façon des bois humides. Mais ce qui a obligé principalement les modernes à fe figurer que la $\mathrm{Lu}$ ne eftoit la fource du ferain ; c'eft qu'vn ancien Lyrique a dit que la rofée eftoit fa fille,

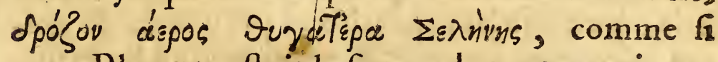
cetce Planette eftoit la fource de tout ce quicou'ela nuit, \& que ce fuft d'elle que le Poete a dit.

-...- Noctis lentus non deficit humsor.

Et que l'antiquité l'eût erigée en Dieu LHo nus, parce qu'elle répandoit le Iupiter froid fur la terre.

-.-- Pofitas vt glaciet nirses Puro numine Iupiter.

Nonobftant ces raifons, il n'eft pas neantmoins veritable que la Lune faffe couler le ferain fur la terre, luy qui eft mal-faifant en certains endroits, quoy que la Lune éclaire \& inGü par tout le monde, quicefle même quelquefois, durant la plus grande clarté de cet Altre, \& qui fair vn effet plus violēt dansvn lieu marefca:

C ij 


\section{6}

\section{Din ferain, of de l'atmofphere?}

geux, \& dans les valées, pluftoft que fur les pleines \& fur les montagnes, aufquelles la Lune prefide, ainfi qu'on lit dans le Poëte.

Montium cuftos,nemorumque virgo.

I. equatrieme probleme eft, pourquoy eft-ce que le ferain fit les veilles, qu'il affoiblit les corps, \& qu'il finit lors que les charleurs font ardentes.

Il faut dire que comme le ferain meurtrit le cerueau, le perce \& l'entr'ouure par fon venin, fon acrimonie \& fa pefanteur, il rend par confequent les efprits tumultueux, \& fait accourir lefang à la partie qu'il a bleffée, de forte qu'il eft impolfible que la nature puiffe trouuer de repos dans ce trouble, qu'elle n'en reffente mefme de la douleur, \& qu'elle n'en deuienne affoiblie, puifque les exhalaifons piquantes \& acides picottent lesnerfs, \& rendentainfi les membres languifrans. Ajoûtons à cela que comme les efprits duferain penetrent par tout, qu'ils font mefme des effets confiderables fur les metaux, eftant femblables aux eaux fortes, ilsouurent par confequent les pores dans la telte qui doiuent eftre bouchez durant le fommeil, pour ramaffer les efprits dans lecentre, de maniere qu'ils roulent par tout, \& font les veilles quine confiftent qu'à leurs mouuemens.

Mais d'ou vient cependant qu'il y a de temps

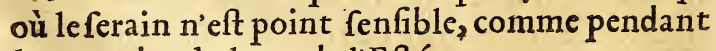
les grandes chaleurs de l'Efté.

Il faut refpondre que cela ne procede qu'à cau: fe des grandes chaleurs, \& des nuits qui font trop courtes, les premieres attenuent \& fubti- 
Duferain, \&o de l'atmojphere.
lifent les particules \& les fels, \& les rendent trop legers \& trop volatils, \& parce que toutes ces atomes ont d'ailleurs vne crudité \& vne indigeftion maligne, elles les cuifent, les digerent, \& les modifient à la façon des fruits qui deuiennent meurs. Et pour ce qui eft des nuits, elles n'ont pas affez de longueur pour les épaiffir ou les repouffer, \& leur imprimer cette pefanteur, qui fait vne partie de leurs effets. Aufr apres le Solftice, lors que les nuits font plus grandes ces atomes deuiennent fenfibles, \& alors on reffent de nouueau le ferain; mais fur tout on voit paroiftre cette rofée qui eft fi nuifible à la campagne, dont la generation merite bien d'eftre expliquée.

C'eft pourquoy il faut remarquer qu'il fe fait deux fortes de diftilation dans le monde, la premiere par le moyen du Soleil, qui eftant comme vn feu, \& ayant efté mis au deffus de la terre, ilfait quelque chofe de femblable à ce qu'on void dans la chymie, ou le feu eftant au deffus des matieres, en fait couler l'humeur oleagineufe en bas, \& caufe cette diftilation, quon appelle vulgairement per decensum. La 2. eft. lors que les fels quifont efleuez en haut, fe rendent liquides par l'humidité de l'air, \& font vne autre diftilation, per decenfum, femblable à celle de fel de tartre, qui fe rend oleagineux dans les lieux humides, \& fous-terrains; car c'eft fans doute de cette façon que la rofée tombe pendant que les nuits font déja longues, \& par les vapeurs, à caufe defquelles les fels deuiennent humides, diftilentça bas à grandes goutes, $\&$

$C$ iij 


\section{$3^{8} \quad$ Du Serain, of de l'atmopphere.}

mouillent los fleurs \& les plantes: \& voila la raifon pourquoy la rofée fe change en cryftaux, d'ou vient fon efprit diffoluant, dont Sengiuodius a dit tant de chofes; pourquoy eft-ce qu'elle rend la terrefeconde, ayant pour fondement le fel: Lnfin d'où vient qu'elle brufle les plantes à la Canicule, nonobftant qu'elle aye contribué à leur production : parce qu'elle perd fon humidité par la chaleur du Soleil, qui eft́alors encore ardente, de façon qu'il ne refte foument qu'vn fel corrofif \& alcalifé, qui ronge les fruits \& les herbes, \& qui obligeoit les anciens à chaumer des feftes, pour empetcher le dégat qui en procede le plus fouuent: c'eft ainfl qu'il faut expliquer Ouidedans fes Faftes.

Flamen in antiqua lucum Robiginis ibat,

Exiacanisflammis, exta daturus ouis.

Adjoultant cetce raifon.

Eft canis, Icarium dicunt, quo fidere moto,

Tota fitit tellus, preripiturque feges,

Procare fadereo canis hic imponitur aris,

Et quarefat, nul nifi nomen habet.

La difficulte du cinquiéme probleme eft, pourquoy eft-ce que les vents empefchent le ferain.

Il faut refpondre qu'ils balient l'air, \& le nettoyent de fon fel \& de fes atomes, qui empefchent leur rectitude, quiles portent ailleurs, arreftent leurimprefion, en les rendant flottantes \& vagues. C'eft ainfi que ies vapeurs de certaines teites allumées agifle nt, eltans comme des vents qui balottent $X$ repouffent le ferain au dehors, ainfi que nous auons écrit cy-deffus.

Le dernier probleme eft, fçauoir files ato- 
Duserain, \& de l'atmiofphere.

mes nitreufes \& falées, quiaboudent en certaines Prouinces, font les nuits de ces mefmes lieux extraordinaurement froides \& incommodes, comme il arriue en Portugal, \& en quelques endroits d'Italie.

La refponfe eft, que le Nitre fert à glacer, qu'il eft la matiere des vents, \& que luy \& le fel armonial font le fondement de la neige, fi bien que les atomes qui en prowiennent peuuent produire vn grandfroid dans la nuit, \& puis qu'elles glacent l'eau, ainfi que l'experience nous montre, elles peuuent bien communiquer à 1'air la mefmevertu, puifque cet Element n'eft qu'vne eau plus fubtile \& plus pure, comme nous expliquerons ailleurs ; \& voila la raifon pourquoy on reffent vin froid au cerueau, lors que la nuit commence à paroiftre; que le crefpufcule eft dangereux en beaucoup de lieux, que quantité des perfonnes cherchent retraite, \& que l'atmofphere fupplée au defaut du ferain: car les corpufcules qui la compofent, meflés fur tout auec les vapeurs des lieux humides, agiffent fur la tefte, foit par leur froideur, par leur acidité, \& par les autres qualités qu’elles ont, fans qu'il foit neceffaire qu'elles tombent d'enhaut, à la maniere du ferain. Et voila tout ce que nous auons à dire des chofes gui font fur la terre. Faifons maintenant vne eftude fur celles qui noustouchent, \& qui font en bas, fans nous prefcrire neantmoins vn ordre particulier, ou vne fuite qui nous attache.

C iiij 


\section{CHAPITRE V.}

Desrafraichiffemens, des grandes chaleurs, du temps counert, $\delta$ du vent coulis.

E foin qu'on a de chercher des rafraichiffe:1 ments en Efté eft fi general, \& les chaleurs alors fon fi incommodes, \& fi ardentes, que nous en poutuons trrer des confiderations tresvtiles à la fanté.

C'eft pourquoy il faut fuppofer que nos chairs s'alterent facilement par lechangement des faifons. Leur moleffe fait qu'elles fe preffent durant l'Hyuert, qu'elles s'endurciffent \& feramaflent, enfin qu'el les nous rendent vigoureux, en arreftant ces efprits balfamiques, qui leur feruent au lieu du fel; mais fur la findu Printemps, \& au commencement de l'Efté elle contribuè à les rendre bouillonnantes \& dilatées, elle les expore aux chaleurs, qui les feichent, les rarefient, \& les fieftriffent, qui lachent leurs ventres, \& elaryiffent leurs qualités, \& dont ellesfont exhaler les effences qui les animent, à peu pres comme il arriue à ces odeurs aromatiques, qui euaporent des vafes qui font mal bouchés. De ce principe on peut maintenant tirer toutes les confequences fuiuantes.

La premiere, que les difpofitions qui s'introduifent dans les chairs, par les chaleurs trop v1olentes, font des degrés de corruption, qui s'impriment facilement aux chairs mortes, \& des 


\section{des grandes chaleurs, ofc.}

commencemens qui s'atachent à celles qui font animées; parce que celles-cy ont befoin de la conferuation \& de l'influence de leurs efprits qui s'euanouïffent par la lacheté des pores, \& à caufe des cauités trop ouuertes par la faifon.

La feconde, que comme parmy les chairs viuantes, les vnes font dans vne parfaite fanté, \& les autres dans la maladie, il eft certain que ces difpofitions font plus fortes \& plus fenfibles à celles-cy, puifque la maladie eft ennemie des efprits, qu'elle les change en vents, fuiuant Hippocrate, \& qu'il eft neceffaire alors de concentrer ce que la nature retient d'effentiel. Et voila la raifon pourquoy les malades languiffent dans les grandes chaleurs, \& qu'il les faut rafraichir auec moderation, de peur de n'efteindre par l'excez les petits efprits qui leur reftēt, pourquioy d'ailleurs les delicats mefme chancelent, \& ont befoin d'vn long repos; enfin pourquoy ceux qui ont les chairs mufculeufes, \& la peau plus denfe refiftent dauantage durant l'Efté, par la concentration deces matieres volatiles, \& par la dureté des chairs,

Il eft donc certain que les chaleurs rendent nos chairs languiffantes \& abbatuës, il faut donc que la fraicheur les affermiffe, qu'elle ramaffe leurs ventres, qu'elle fixe leurs efprits, \& qu'eIle empêche de cette façon leur fouleuement \& leur exolution. Exc'eft auffi ce qu'elle fait:mais par des differentes manieres, que nous examinerons en deftail.

La premiere deriue des ombres dont nous auons écrit cy-deflus, qui arreftent fi fort les 
42 Des rafraichiffermens;

efprits, que les chaffeurs découurent la pifte des beftes par l'odeur, qui n'eft qu'vn efprit pluftort fous les ombres quau Soleil.

La feconde eftoit fort en $v$ fage anciennement; car on difpenfoit pardes canaus, \& on faifoit couler dans les chambres les eaux des referuoirs, ou celles des fontaines \& des riuieres, \& on temperoit ainfi les plus ardentes chaleurs de l'Efté. C'eft à ce fens qu'il faut tourner les vers de Stace.

An piaturata lucentia marmora vena.

Mirer; fo emiffasper cuncta cubilia lymphas.

Et auquel on doit appliquer le deflein d'vn canal de plomb decouuert aux murailles d'vne maifon qui bornoit le Rhône auec cette infcription au deffus.

\section{S. Valerius Surillio, \\ C. Cantius.}

Quoy qu'il en foit cette façon de rafraichir eft la moins dangereufe \& la plus commode; il feroit bon de la renouueller, puifque la clarté, la fraicheur, le murmure \& la cheute de l'eau nous peuuent donner le fommeil, que la faifon bien fouuent nous refure, \& puifque les Medecins ordonnent des fontaines artificielles à ce deffein, en vn mot, puifqu'on peut ainfi abbatre l'émotion des humeurs, des efprits \& des chairs.

La terre fraichement tirée, nous fournit la troifiéme maniere: par exemple, fi on la porte dans les appartemens, fi on a le foin de la chäger, fi on fuit les payfans qui la remuent, fi on la faire le matin, \& fi on la tient quelque temps 
des grandes chaleurs, \&c.

dans la main. Or cette qualite rafraichiffante procede du nitre humide qu'elle contient, qui la rend fleuriffante \& fertile, qui fe communique aux vegetaux, qui donne vne grande froideur aux infectes, qui euapore au commencement du Prin-temps, \& qui diminuë dans les fechereffes trop longues. Auffi la pluye qui les termine, nous la fait fentir en forme d'vn vent agreable, parce qu' elle s'y joint, qu'elle en compofe vne lefíue, qu'elle luy fert de diffoluant, \& qu'elle fait exhalercette fubftance au moindre effort de la chaleur : Et voila la raifon des petits vents frais, qui s'éleuent apres qu'il a pleu, \& pourquoy l'eaurend la terre froide \& fecondeen detrempant ce Nitre, le faifant couler par tout, \& en augmentant cette rarefaction qui le fait la matiere des vents les plus froids, \& le fondement des effets prodigieux de la foudre.

De tout ce difcours on decoure la fource de la vie longue de ce Gentil-homme dans Verulan, qui portoit des gazons dans fes mains, \& quien mettoit toutes les nuits fur fon cheuet, \& fur fon lict; car par ce moyen il donnoit de la fraicheur à fon fang, il concentroit fesefprits tropmobiles, \& il refpiroit ce fecret aliment de vie, que la terre attire de l'air, dont elle fortifie les animaux, \& deuient la mere commune de toutes chofes.

On connoift encore du mefme principe, ce quidõnoit la moderation à ces fameux Romains, qu'on efleuoit de la terre à la dictature, . parce qu'ils temperoient par la fraicheur de cet elemẽt lhumeur quiles brufloit dans leur climat. 
44

Des rafraichiffemens;

Enfin on infere pourquoy les boules de mar: bre refroidiffent, lors qu'on les roule dans les mains, ou qu'on les a plique aux autres parties; car elles ne procedent que d'vne terre endurcie \& liée parvn efprit nitreux \& petrifiant, qui a les mefimes qualités du gafon. Seroit-ce point de la que les os font les membres lesplus froids de nos corps, \& qu'ils foulagent reduits en poudre les inflammations des entrailles, puis qu'Hippocrate au liure des chairs leur donne pour principe la terre? quod quidem, dit ce grand Medecin, ex terra purredine pinguedinem fortitum eft, citißimè offa produxit. Et puis que les Poëtes les font venir des os que Pyrrha, \& Deucalion eurent ordre de ramaffer de cette grand mere des Dieux, \& du monde?

La quatriéme maniere de rafraichir confifte aux feueillages \& aux rameaux, d'ont on fait des pauillons \& qu'on entrelaffe aux feneftres pour bien conceuoir leur vertu.

Il faut remarquer premierement que le rafraichiffement des efprits, ne fe fait mieux que par l'air, par les vents, \& par les vapeurs; or les fueilles, \& les rameaux pouffent des exhalaifons qui portent la froideur de cette humidité nitreufe qu'ils ont attirée par leurs tuyaux, qui fixe les efprits \& les chairs, qui bouche leurs pores, \& fert degluà ce que le chaud a ouuert : \& voila la raifon pourquoy on conferue durant l'efté les animaux égorgés dans les fueilles, \& qu'on empéche ainfi la diffolutiō de leurs chairs; voila d'oú vient que les fueillages, qui tombent en automne, abbatent ce que nous reffentons 


\section{des grandeschaleurs, ơc.}

deschaleurs; en vn mot voila la cau fe pourquoy les pauillons des jardins \& $\mathrm{k}$ des baffe-cours, qui ne font tiffus que de fueilles, nous foulagent pendant lardeur qui nous importune dans la faifon.

II faut remarquer en fecond lieu queles chaleurs rendent les chairs acides, en feparant ce qu'elles ont d'humide, d'oleagineux, \& de doux; de maniere qu'alors les mortes fe corrompent facilement, qu'elles impriment vne aigreur aux bouillös, \& que celles qui font viuantes reffentent des piqueures \& des douleurs. Orcertains arbres renuoyent vn fel volatil \& alcalifé, doux comme le fel de Saturne, qui modere ce quifort de noscorps, quil labbat \& le coagule, \& qui abforbe cet acide que la chaleur fepare des chairs. Et voila le motif quí obligeoit les anciens à porter aux banquets, des couronnes de fleurs \& de fueilles, pour émouffer les vapeurs duvin, dont l'acidité picquote la tefte. C'eft le méme qui infpiroit à Megiftenes dans Anacreon decouurir fon fron de peuplier; \& quifaifoit rechercher aux femmes dans des feftes particulieres, le faule \& l'Agnus Caltus pour y coucher, \& pour moderer par leurs vapeurs rafraichiffantes ce que les reins ont d'acre \& de fort.

La cinquiéme façon de rafraichir procede de 1'air qu'on introduit la nuit par les feneftres, \& les portes ouuertes : il y a partant quelques conditions à obferuer pour agir ainfi.

La premiere que les perfonnes foient jeunes; robuftes \& faines; que le ferain ne tombe point, que les chaleurs foient eftouffantes, que le lieu 
fe trouue preffé, qu'on n'abandonne point les counertes, \& quil ne fafle point de vent ; la raifon de tout cela eft que la trop grande fraicheur du foir fait deuenir pefant, fuiuant les fondements de la Medecine ftatique par la fupreffion de ce qui exhale hors des pores, qui euapore mieux pendant le fomeil. Auffi cette fuprelfion eft la fource des fluxions, aux bras, aux jointures, fur les yeux, \& fur les épaules, elle contribue aux dereglements de l'eftomach, \& elle produit des douleurs qui arriuent fouuent l'efté à ceux qui repolent à découuert, \&qui font expofez à l'air de la nuict. Et veritablement fi on prend garde que les influences de la Lune fe commu. ziquent mieux dans cet eftat, on fe feruira des precautions que nous venons defcrire, puis qu'elles humedent \& rafraiflent, qu'elles font ennemies $d u$ cerueeu $\&$ des chairs, que nous auons befoin des influences du Soleil, par la proportion que noftre efprit à auec fa lumiere. Enfin puifqueles rayons de la Lune eftantra. inaffés dans la concauité d'vn miroir, mortifiene les verrues, \& ramoliffent les durtés : car apparammentil en arriue à peu presainfi de nos membres, qui perdent alors leur vigueur, \& leur formeté.

La fixiéme inaniere de rafraichir, fe fait par les vents; mais par des moyens qui font gran. dement differens, car ou les éuentails les excitent dont nous parlerons cy-a pres, ou les ouuertures quifont oppofées les introduifent, ou bien ils fe gliffent par des canaux. On pratique la derniere façon dans vn certain endroit d'Italie au pied 
des grandeschaleurs, \&c.

d'vnegrande montagnequi poulle inceifammêt desvents;c'eft pourquoy les habitans ramaffêt ces vents, les diuifent en des tuyaux, ainfi que des eaux de fontaine, \& les font couler dans les chambres pour amoindrir la violence des chaleurs. Ce moyen partant eft vn peu dangereux, il peut fupprimer ce qu'il tranfpire, \& fivin vent agreable eft foument nuifible fous l'ombre aux promenades, \& fur le foir, que doit-on prefumer des vents foufterrains?

Le peuple rend les vents formidables, qui paffent des feneftres \& des portes ouuertes, par la froideur qu'il en' reçoit: pour l'expliquer maintenant auec clarté, il faut obferuer comme pour vn fondement neceffaire, que quantité de chofes concourent à la mieux introduire, \& à augmenter les maux qu'elle fait, la delicateffe des corps, la chaleur, la penetration, \&le defaut du mouvement. Les corps font delicats, lors qu'ils font maigres \& percés, qu'ils ont leurs chairs douillettes \& molles, leur fang fubtil \& coulant, \& des efprits qui fe rarefient \& fecondenfent promptement. Or le froid dont nous parlons faifit ces corps, il condenfe leurs efprits \& leur fang, \& ce qu'ils contiennent de rare, il preffe encore leur poictrine, \& déregle leur eftomac, en vn mot, il arrefte à la peau, \&à la furface, ce qui doit fortir du centre au dehors, cependant la chaleur, foit qu'elle procede du mouuement, du temperament, ou de la faifon, en rarefiant l'habitude, luy prepare vn libre paffage, le repos expofe les parties \& les engourdit a diminué leur vigueur, \& arrefte lintiuen- 
ce $d u$ grand principe, qui modere la force du froid, \& quis'excite par l'action, \& lesvents le font penetrer, linfinuent mieux dans les pores \& dans lesveines, ainfi qu'Hippocrate nousenreigne au liuredes vents. Mais pour examiner celujet d'vnftyle plus methodique, il faut decouurir la fource decettefraicheur, puis qu'elle nouseft fi nuifible, \& voir pourquoy ordinaire ment elle fe gliffe auec les vents; neantmoins pour en traitter plus nettement, montrons l'origine des vents qui la portent, \& en fuite nous decouurirons ce qui la produit auec eux.

Confiderons donc l'air comme vne eau grandement fubtile, dont la nature a remply l'vniuers; difonsqu'elle a comme les eaux, des tourbillons, des courans \& des vagues, quelle fouffre des orages \& des tempeftes, qu'elle deuient comme elles bruyante dans les lieux eftroits, \& qu'elle coule inceffammēt ainfi que les mers, \& lesfleuues, pour entretenir leflux \& reflux, qui eft fi general par tout. On reconnoit fon cours en diuerfes façons, comme par la neceffité, par la rarefaction, ou par la contrainte, par les ouuertures oppofées en des endroits, enfin par l'equilibre qui fe doit garder dans le monde. La neceflité paroit en ce que l'air ne doit point croupir, crainte qu'il n'imite les eaux qui fe corrompent par leur pareffe; la contrainte nous montre à trauers des fentes que l'air fait comme les eaux qui paffent par des lieux preflés. Lequilibre eftant perdudans l'atmorphere, l'air prend des courans \& des routes diuerfes, comme il arriue aux tourbillons, 
Des grandes chaleurs, $\sigma_{0} \sigma_{0}$
fi l'air eftant condēfé d'v ne part, il eft rarefié d'vne autre, alorsil augmente fon cours, ainfi qu'on reffent fous les ombres; \& s'il treuue des ouuertures qui fe refpondent dans les maifons, on peus dire qu'il eft deuenu libre, qu'il n'y a rien qui arrefte cette eau, qu'elle a des emboucheures alors pour courir comme les rivieres, \& que les murailles luy feruent de bornes, qu'elles contiennent \& qu'elles ramaffent, qu'elles reglent, \& qu'elles determinent fon cours.

Lt voila la raifon pourquoy le peuple neconçoit l'air ainfi coulant, que fous le nom d'vn vent qui fouffle, parce que le vent eft le lot de la vague de l'air, \& qu'il le nomme le vent coulis, parce qu'alors l'air coule à la façon des Hleuues, voyons maintenant pourquoy il rafroidit ainfi qu'eux. Maisil eft facile à connoiftre que cette vertu rafraichiffante procede de ce quel'air fe renouvelle toûjours en courant, \& qu'il luy arriue comme à l'eau chaude, qu'on rafroidit lors qu'on la change, d'ailleurs il balie ainfi les vapeurs fulphurées, qui allument nos corps $\&$ nos chairs, il deuient vin euentail, qui modere l'ardeur qui nous prefle, enfin il entraine comme les eaux les atomes de l'atmorphere, qui font pour la plufpart humides \& froides, comme on obferue aux Meteores \& dans la nuit. Cette verité decouure pourquoy le vent coulis fait entrer la foudre aux endroits où on le reffent : car clle fuit le courant de l'air, commece qui elt keger eft entrainé de celuy des eaux.

Les bains font la plus propre maniere à nous rafratichir : car elle renouuelle l'eftat où nous 
des grandeschaleurs, doc. pourquoy quelques-vns ne reflentent plus des picqueures apres s'eftre feruis du bain, \& qu'ils ne fouffrent plus les veilles par la concentration deschairs, par l'v nion \& par le retour des efprits, par la diffolution des fels, \& de ces matieresacides que nous auons expliquées ailleurs.

On fe rafraichit en dernier lieu pär les apparzemens fous-terrains, dont l'air froid, groffier \& humide, refferre les chairs, repouffe \& lie les efprits, \& fert à conferuer la vie, en ramaffant ce que nous auons de fubtil : c'eft ainfi qu'il faut entendre le texte d'Hippocrate au 6. des Epidemies, pracalidam naturam intempore calido cubile in aëre frigido incraffat; incalido vero attenuat. C'eft pourquoy les anciens viuoient long-temps, parce qu'ils demeurolent dans des cauernes, les Orientaux mefme refiftent aux grandes chaleurs, en habitant dans les lieux creux, \& fi l'Angleterre a décounert des hommes tous verds, dont la force eftort prodigieufe, ceelf qu'ils demeuroient dans la terre, \& ne pouuoient fouffrir le grand jour.

Et veritablement vne des plus grandes commodités de la campagne, c'eft de taillerdes grotes dans la roche, \& d'y faire couler de l'eau, pendant que le midy nous brufle, \& de fe fouuenir que dans les Pötes, elles doment retraim te au Dieu Somne, \& ne produifent des pauots que pour Iuy.

Il faut cependant obferuer que là \& dans des lieux femblables, on y dorme fort peu de temps, fans foutenir le corps contre les murailles humides, parce qu'elles condenfent les glandes, que $\mathrm{D}$ ij 
la nature a deftinćes pour filtrer les humeurs, \& pour leur domner vn paffage, afin d'en retenir cette pureté, \& ce confentement vniuerfel,dont Hippocrate parle fi foument. Auff ceux qui repofent de cette façon, fur tout fi ce font des perfonnes grofles \& pletoriques, fouffrent des fuxions \& des douleurs, parce que les ferofités arreftées inondent dans les chairs \& dans les parties, que ne pouuant eftre filtrées, elles y trainent ce qu'elles ont de fuperflu, qu'elles fe jettent dans les jointures \& dans les mufcles, qu'elles abondent à ceux qui font pleins, \& qu'elles font ainficette maladie, que le peuple appelle froideur, qu'on ne peut foulager que par des remedes quirarefient; à caufe de la compreffion des pores, \&des glandes, qu'il eft neceffaire de dilater pour faire couler ce qui les engage.

Dece difcours on connoift la fource de l'A poplexie \& des autres maux furprenans, qui faififfent ceux qui demeurent trop à decouuert dans les lieux frais, \& dans ces baffes cours, que le vulgaire nomme des ciels ouuerts; mais parce que ce fujet demande vne explication fort exacte, auançons deux fondemens qui luy donneront vn grand jour.

Le premier, que la plus grande partic du fang monte à la tefte, comme on voit par les ferofités, \& par cette prodigieufe quantité des veines, qui entrent, ou qui enuironnent le cerueau.

Le fecond, que le cerueau contient vne mö̈lle, au trauers de laquelle la nature coule, repare, filtre, prepare \& diftribue incellamment. 


\section{des grandeschaleurs, \&c.}

C'eft pourquoy elle a des conduits, des entonnoirs, \& des ventricules, par ou elle fe decharge, \& elle depofe toûjours. Or à cet effet elle doit eftre rare, poreufe, efparpillée \& legere, à la façon d'vn cotton delicat qu'on a élargi auec les doigts, elle eft ainfi dans la fanté, dans la jeunefle, \& au temps ferain, elle eft opacque dans l'enfance \& dans la vieilleffe, la grande chaleur la dilatte trop fortement, \& fi la froideur luy fuccede, elle la reflerre \& la comprime, elle la preffe \& l'épaifit, en forte que par ce moyen toutes les diltributions finiffent, les détours s'engagent, les humeurs s'arreftent, le cours du fang \& des ferofités fe deregle, il fe fait vne interception, \& vne confufion dans la tefte, qui eft la caufe de l'A poplexie, \& des autres mauximpreueus, \& c'eft icy ce qui arriue dans les lieux frais, apres les affaires \& durant l'Efté, par les raifons que nous auons déduites; de là on void pourquoy les Pletoriques en font plus fufceptibles, parcequeleur fang eftabondant \& groffier, qu'il y a quantité de ferolités \& de nourriture, \& que le froid venant à condenfer la fubftance moëlleufe, l'arrefte facilement, \& fupprime les feparations; on decouure encore la caufe de la Paralyfie, qui furuient à ces mefmes perfonnes, lors qu'elles s'expofent aux lieux frais, leur tefte nue \& trop longuement, par la compreffion d'vn endroit de la moëlledilatée par la chaleur, qui fufpend l'influence des efprits, \& du fuc nerual vers quelques parties du corps. En vn mot on infere pourquoy le rheume rend la tefte pefante, pourD iij 
194

quoy lesventoufes, les petits chiens; \& les re* medes échauffans foulagent les A poplectiques, endilatant tout le cerueau, \& pourquoy le froid tuëles arbres, lors qu'il vient fubitement apres la chaleur, en preffant ce qu'ils ont de mouëleux $\&$ de rare par où la nature coule les fucs qui feruent à nourrir les fruits, les rameaux, les fleurs \& les fueilles; mais nous éclaircirons micux vn jour toutes ces verités, que nous auons feulement ébauchées, fi le lecteur nous fait grace dans cét ouurage, \& s'il nous anime à en compofer vn nouueau. Finiffons donc ce Chapitre par le probleme que nous auons promis d'examiner touchant la nonchalance que nous reffentons dans nos membres, lorfque le temps fedifporé è eftre couuert.

Difons donc que nos efprits font comme des fumées, \& qu'ils font compofés d'vn fouphre fubtil, quiles rend bien fouuent la matiere des fiéures. Or cela fait quele temps pluuieux les épaifit \& les change en eau, ainfi qu'on void de l'efprit du fouphre, quine coulequ'au temps couuert, de maniere qu'ils n'ont plus alors leur 2ctiuité, qu'ils diminuent mefme de leur lumiere, qu'ils ne font plus brillans \& vifs, \& qu'il en eft d'eux comme de la poudre, qui perd fa furce \& fa vigueur fion l'a imbibée de l'eau; les efprits font ainf lorfque la moiteur de l'air les humecte, ils ont peine à gonfler les nerfs \& les mufcles, \& leur mounement eft femblable à celuy de la poudre humide \& groffiere, qui agit foiblement dans les moufquets $\&$ dans les canons. Et voila la caufe de l'abbatement de nos 
des grandeschateurs, oc.

znembres, de la pefanteur de nos teftes, \& des paroles d'Hippocrate dans l'aphorifme de la troifiéme fection; voila ce quifait deuenir noAtre raifon à demy éclipfée, qui rend les oifeaux parefleux, \& nos jambes à demy chancelantes, fi le fommeil ne repare les efprits qui nous viuifient, \& s'il ne reftablit leur lumiere, qui fert à éclairer la raifon. On pourroit adjoufter d'autres reflexions à celles-cy, qui monftrent que noftre corps eft vn hygromettre; mais il eft inutile de les rejoüer apres tant d Auteurs qui en ont traitté.

\section{CHAPITRE VI.}

\section{Des Euentails.}

DVifque nous auons obferué cy-deffus toutes 1 les manieres qui rafraichiffent, le tiffu des matieres exige de compofer vn Chapitre des Euentails que le monde a mis en vfage pour fe defendre des chaleurs. Seruons nous en icy à la façon de ces voiles qui pouffent vn vent propre à faire arriuer au port. Voyons quels effets ils nous caufent, \& confiderons-les comme des chofes qui ne font pas inutiles aux Medecins, puifqu'ils doiuent prendre connoiffance de l'air, $\&$ de ce quile peut changer.

Il fe faut donc foumenir que les euentails font de deux fortes, il y en a des grands qui agitent fortement l'air, \& des petits qui euentent mediocrement celuy qui nous approche. Les pre-

D iiij 


\section{Des Euentails.}

nous efclaire; ce feu fe fait connoiftre par fa chaleur, parce qu'il nous brûle dans les charbons, $\&$ dans les fiéures qu'il demande d'eftre nourry, qu'il s'entretient de ce qu'il a de la graiffe \& de l'huile, qu'il s'efteint par les corps pefans : enfin. parce qu'il jette des fumées, \& fur tout qu'il a befoin d'eftre foufflé.Pour faire voir cette neceffité, obferuons les motifs qui nous obligent à fouffler le feu de nos chambres, afin que nous les appliquions au feu quibrille dans nos cours.

On fouffle le feu par quatre raifons, premierement, pour euenter la cendre qui l'embarraffe \& qui l'étouffe; en fecond lieu, pour détacher les matieres volatiles \& fulfurées, qui demeurent founent attachées dans leurs fujets, \& qui produifent la lumiere \& la flamme; en troifiéme lieu, pour les condenfer, \& pour lesvnir fi elles font trop dilatées : enfin on fouffle, parce que comme le feu eft le couteau de la nature, on doit pouffer quelquefois ce couteau par quelque mouuement impetueux, pour le faire entrer bien auant dans les corps trop durs \& folides, ainfi qu'on fe fert d'vn marteau, ou d'vne maffu pour pouffer le trenchant \& la pointe des fers.

L'art \& la nature fe propofent des mefmes fins pour fouffier ce feu, qui eft l'entretient de nos vies.

La nature remuë le diaphragme comme vn admirable fouffet pour difiper la fuye qui l'obfcurcit \& qui l'arrefte ; par là elle le fait mieux penetrer, ainfi qu'Hippocrate nous montre dans les arteres \& dans les veines, 
elle le condenfe \& l'vnit, s'il eft trop rare \&c trop efpars: en vn mot de cette maniere elle émeut \& elle deftache les parties fpiritueufes \& mobiles, quifont à cefeu, ainfi que les fubtiles, \& les huileufes à la flamme \& au feu commun.

Il arriue neantmoins quelquefois, que le foufflet, auec lequel la nature fouffle fon feu fans relache \& fans laffitude, n'eft pas bien fouuent fuffifant à fatisfaire à ces motifs : On connoit cela par plufieurs raifons; mais fur tout lors que les lieux font trop remplis, \& que la faifon eft ardente; car ainfi la chaleur attenu $\ddot{e}$ exceffuement noftre feu, elle le porte à la furface, elle le diffipe \& le fepare de nos chairs, elle I'efclipfe par les vapeurs qui s'éleuent alors de nos pores, de maniere que le Diaphragme ne le peut pas contenir, ny le moderer entierement. Or l'Art a fait des éuantails, qui fortıfient celuy dont la nature fe fert pour fouffler, leur vent balie les exhalaifons, \& repoufle le feu s'il re porte trop hors du centre, il le ramaffe s'il eft efpars, s'il eft fubtil il le condenfe, \&en le faifant rentrer dans le cœur, il le fait mieux gliffer par tout. Il eft neceffaire maintenant de voir par quelle vertu les éuentails agiffent ainfi.

Certainement ils ne font cela qu'en deux façons, par la fraicheur de l'air \& \& par fa qualité pefante.

La fraicheur vnit, comprime \& repouffe ce qui eft vapoureux \& fubtil, \& fait à nos efprits $\&$ au feu qui nous communiquent, ainfi que l'eau de l'alembic qui epaiffit les vapeurs que la chaleur fait monter en haut. 
Des Euentails.

C'eft pourquoy Sanctorius croit par cette raifon, que les éuentails arreftent les tranfpirations, \& appefantiffent nos corps, ventilabrum probibet tran jpirationem, reddit corpus ponderofius of debilius. à caufe des regles de la Medecine ftatique, dont nous parlerons cy-apres.

La pefanteur fait entrer, joint \& ramaffe ce qui fe dilate \& s'eftend; comme on void de la laine, du cotton, \& des linges que les grands poids tiennent prefiez, de forte qu'il en arriue ainfi de noftre feu, \& de ce que nous auons de rarefié. Il eft queftion maintenant de fçauoir pourquoy l'air a de la pefanteur, \& d'où vient fon froid, lors que les éuentails le foufflent.

Pour ce quieft de la pefanteur, tous les f̧̧auâts ont fait voir par detres belles experiences, que l'air eft naturellement pefant ; c'eft pourquoy il defcend en bas ainfi que l'eau, \& les autres chofes pefantes: Or les éuentails augmentent cette pefanteur, parce qu'ils preffent l'air, \& l'vniffent en le pouffant; ainfi que nous voyons des corps, forsqu'on les bat, \& qu'on les comprime; fi bien qu'alors l'air fait à ce qui eft fubtil, par exempleà noftre feu, \& nos efprits, comme ce que nous auons remarqué de la laine, du cotton \& des draps, \& ce que nous auons dit des pierres, des maffues \& des marteaux.

Pour la fraicheur, elle depend d'vn fondement, qu'il faut premierement expliquer pour donner quelqueintelligence : fçauoir, que l'air eft vne chofe fubtile \& legere, qu'il a vn froid qui luy eft naturel, quille perd par le Soleil, par lefeu $\&$ par les vapeurs de nos membres: 
\& que les éuentails venant à éuenter, \& à pouffer cét Element, detachent toutes ces atomes, ils font place à vn air nouueau, \& nous font alors reffentir le froid, que l'éua poration de nos corps auoit amoindri. On peut conceuoir tout cela par deux exemples populaires : Premierement par l'eau bouillāte, qu'on raffroidit fi on la foufte, $f_{i}$ on la bat, \& fi on la change fouuent, en va mot fi on luy fait ainfi quitter toutes les particules ardentes qu'elle auoit retenuës du feu. En fecond lieu, il en eft de mefme de l'air, dans lequel nous fommes plongés, ainfi que des bains qui nous mouillent. Or le mourement que nous y excitons, nous rafroidit, parce que nous faifons fucceder à vre eau déja chaude, vne portion fort éloignée, quia retenu fa froideur, ainfi qu'il arriue de l'air, lorfque les éuentails le remuent, auec cette difference partant, que l'air éuenté rafroidit mieux que l'eau, parce qu'il penetre \& s'applique par le battement à nos membres, ainfi qu'vn linge qui nous enuironne lors qu'il eft froid, \& parce que d'ailleurs les éuentails le renouuellent inceffamment, \& luy font faire plus qu'à l'eau;ce que nous voyons dans la chappede l'alembic, lors qu'on change cét élement par reprifes, pourdonner du froid aux vapeurs. Mais nous éclaircirons mieux ce difcours au Chapitre fuiuant.

Finiflons feulement par cette reflexion, fçauoir, qu'outre le rafraichıffement, les éuentails nous profitent encore, parce qu'ils purifient l'atmof phere quiborne nos corps, \& qu'ils font vn changement d'air, qui n'eft pas moins vtile 
Dela foule, \&oc.

que celuy qu'on cherche dans les Prouinces, \& dans les endroits éloignés.

\section{CHAPITRE VII.}

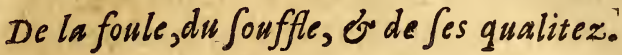

CEn'eft pas fans fujet que les fages ont ordonné qu'on ne fe trouuât point dãs la foule, ç'a efté là vn des preceptes de Pytagore, \& les plus $f$ çauans Medecins n'ont pas défauoüé cette maxime, \& l'ont inferée au rang de celles qui feruent à regler la fanté.

La premiere raifon, qui les a ainfi infpirez, eft tiré dela neceffité que nous auons de refpirer : car tout de mefme que les poiffons ont befoin de l'eau \& que c'eft là leur élement; les hommes ont befoin de l'air, \& ne fçauroient viure fans luy.

La principale raifon de cela deriue de fa fraifcheur; parce que comme il faut ietter de l'eau fur l'alembic pour donner vne confiftence folide aux vapeursqui y font fublimées, il eft neceffaire auffi que l'air attiré des poulmons, tienne par fa qualité froide la place de l'eau, aux diftillations qui fe font dans le cœur, pour rendre les efprits plus denfes, de peur qu'ils n'euaporent par leur grande tenuité. Auffi les Septentrionnaux font robuftes, violents, \& voraces, \& nous auons plus de force en hyuer, nos ventres font plus chands' alors fuiuant Hippocrate, parce que l'air de la faifon condenfe les efprits \& les rend plus épais. 


\section{Dela foule, du fouffle, \& de fes qualitez:}

De tout cedifcoursil eft aifé maintenant de conclurre, que l'air qu'on refpire parmy la foule ne pouuant par fa chaleur reduire les efprits dans cette confiftence folide, il faut par ainfi qu'ils fe diffipent par leur grande fubtilité, \& que leur defaut laifle les perfonnes abbatues $\&$ languiflantes, qu'il les priue du fentiment \& les contraigne de pafmer. Et voila la raifon du fecours, que l'on tire alors de l'eau qu'on répand fur tout le vifage, quifait la fonction du linge mouillé qu'on met fur la chappede l'alembic, dont la froideur retiêt les vapcurs quis'efleuêt: voila encore le motif, qui cblige !e peuple d'ouurir les portes, \& les feneftres pour attirer vn air qui puiffe repouffer les efprits par vne fraifcheur bien-faifante: Envn mot qui luy fait rechercher les vins, les odeurs, \& les parfuns aromatiques afin que leurs efprits reparent $c_{s}$ fubftances fubtiles que la chaleur a fait difiner.

La feconde raifon eft a puyée fur les tranfpigations qui fortent toûjours de nos corps, car fi elles portent l'amour ou la haine d'inclination , fi elles font gliffer les indifpofitions, \& les maladies, cen'eft pas donc merueille $f$ on fait des amiţiés fecrettes dans les lieux rēplis de la foule, fi on y conçoit des aduerfions qui efflatent quelquefois en public, \& fi y eftant entré libre on en fort quelquefois efclaue. Sur tout s'il eftveritable ce que.quelques anciens ont foutenu que toutes les efpeces fe ramaffent dans l'air, \& qu'elles s'impriment en fuitte dans le cœur par la refpiration, \& par la veuë.

Etvoila la caufe pourquoy on eftoufe foument 
De la foule, du fouffle, do de fes qualitex: 63 dans la preffe, car alors l'air fe truuue fi fort brouillé par ce que châcun repouffe au dehors, qui ne peut efuenter la fuye quela chaleur ramaffe inceflăment dans la poitrine, de forte que les efprits font éclipfez, qu'ils fe trouuent couuerts de cendre, \& reffemblent à ces fla mbeaur que la fumée obfcurcit à demy. Auffi on ordonne d'ouurir dans cet eftat les portes \& les feneftres, pour introduire vn air plus pur, on a recours aux efuantails pour bâlier l'air plain d'ordure, \& on donne de l'eau de vie, du vin-aigre $\&$ du vin, afin que ces liqueurs fpiritueufes \& penetrantes diffipent lcs brouillards, détachent les efprits, les rauigorent, \& les ralument, \& fuppléent à leur defaut. C'eftainfi que les femmes fe foulagent, parce qu'elles ont des efprits plus acqueux, plus impurs \& plus foibles, \& déja opprimez par le fuperflu de leurs corps, auffi elles pâment fouuent dans la multitude. C'eft pourquoy Ouide fe mocque de l'empreffement qu'elles ont d'aller toûjours parmy la foule.

sic ruis ad celebrescaftiffima faminaludos

Spect atum venisnt, veniunt $\int \beta e c t e n t u r$ vt ip $\int a_{0}$.

$\mathbf{L a} 3^{\mathrm{e}}$ raifon dépend de ce que dans les lieux grandem ent occupez, il fe fait des fermentations dans nos chairs, \& dãs nos parties, à la maniere à peu prés qu'Hippocrate a defcrite, par la comparaifon des habits refferrés [ $l$. de car.] fi bien qu'il ne faut pas s'eftōner fi on y reffét des fortes chaleurs, fi la nature y détache ce qu'elle a long temps retenu; fi la tranfpiration des membres augmente: fion s'y trouue impatient, inquiet 
64 De la foule, du fouffle, \&o de fes qualitez: \& chagrin ; fi les nuages quifortent de ces emo:tions interieures donnent la trifteffe \& l'ennuy, en obfcurciffant nos lumieres, fi on s'y plaint de 12 pefanteur de la tefte \& de l'accablement du corps; fi les indifpofitions affoupies reuiennent par le foufleuement deschairs, par la multitude quifait les maladies populaires dans les armées; fi l'Auteur de la Medecine ftatique a foûtenu que pour conferuer vn vifage jeune \& vermeil, on deuoit éuiter l'embarras, \& le tumulte des affemblées, où la tranfpiration exceffue fletrit,

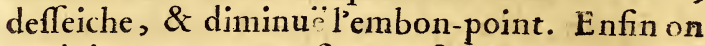
ne doit pas trouuer eftrange fi le moindre froid du dehors s'infinu ë fubitement lors qu'on fe tire de la foule, par la grande rarefaction quidilate le corps, \& rend les perfonnes maigres fufceptibles des qualitez de l'air; ainfi qu'il arriue tous les iours parmi nous.

La quatriéme raifon procede de la pefanteur de l'air; car cet élement prēd cette qualité par les impuretez qui loccupent pendant la foule, fur tout fi elle eft femblable à celle que Iuuenal a fi bien décrite dans fes Satyres.

--Nolis properantibus obftat

Vnda prior, magnopopulus premit agmine lumlos; Qui Sequitur ferit $\int u o$ cubito, ferit affere duro Alter.-...-

Or l'air pefant nous accable \& nous abrutit, le leger au contraire nous éueille, nous rend gays \& plus raifónables, auffi celuy-là eft le principe de cet affoupiffement que nous reffentons dans la multitude, il fait dormir dans les ceremonies les plus faintes, il fait rechercher lors qu'on 
Delafoule, Éc.

qu'on eft dégagé, les promenades \& la campagne, \& oblige les plus fages de fe pofter aux endroits les plus éminents, pour refpirer vn air plus doux \& moins pefant.

La derniere procede du fouffle qui fort \& qui exhale des perfonnes, dont les obferuations font fort importantes, quoy qu'elles paroiffent inutiles à la plufpart. Pour les bien efclaircir,

11 faut remarquer que ce que la refpiration pouffe au dehors, eft comme vn refte, \& vne fumée de cefeu tout celefte, quiépure inceffamment nos humeurs \& nos chairs, \& qui en détache ce quelles ont d'acre, de piquant $\&$ de fort. Or cerefte ne confifte qu'à vn fel vola. til \&a alcalifé par la digeftion des entrailles, qui eft meflé auec vne humidité vifqueufe, par le moyen de laquelle, il s'attache à la fuperficie des corps les plus brillans \& les plus polis, mais fur tout au fer \& aux autres metaux, à la manie re des eaux corrofiues \& diffoluantes, \& voila la caufe pourquoy par le moyen d'vne liqueur renfermée dans vne phiole ronde, fufpendue au milieu du plancher, on congele le fouffle des affitans en forme d'vne barbe de neige, parce que fa principale matiere eft le fel, joint à vne humidité vapoureufe, qui eft la bafe des con gelations.

De tout cela on connoift maintenant pourquoy le fouffle fleftrit les fleurs, \& ternit fouuent les plus beaux ornemens de nos chambres, pourquoy celuy de certains animaux eft tout à fait malin, d'où vient que noitre langue deuient 
quelquefois noire dans les fiéures ardentes, par ce fel tout reuerberé par vne chaleur violente; pourquoy certains alimens nous font les dents noires, fe joignant à ces fels, \& faifant auec eux comme vine ancre; par quelle raifon la faliue eft fi diffoluente le matin, les viandes \& la boiflon $n$ 'ayant point emouffé la pointe de ces matieres fublimées, que la faliue ramafle roufiours: Enfin de tout cela on infere l'effet des fouffles acres \& puants, qu'on refpire dans l'embarras du peuple, quifont aux efprits ainfi qu'aux miroirs les plus beaux, qui penetrent les chairs, qui entrent jufqu'au cerueau par le moyen des nerfs des narines; en vn mot, qui fe repandent jufques aux poulmons \& dans l'eftomach, $\&$ prouoquent ces defaillances, qui arriuent foument à ceux qui refpirent vn foufle fort ou impur. Et certainement li on prend garde que beaucoup des gens populaires refiftent par leur fouffle aux vapeurs du vin, quoy qu'elles tuent neantmoins, \& qu'elles efteignent la lampe, il faut bien qu'il forte quelque chofe de leur poitrine, dont la violence \& la force furmontent les efprits delicats, les fermentent \& les diffipent, puis qu'll en arriue ainfi aux efpritsdu vin, ou du moins qu'il en foit de mefme comme des exhalaifons renfermées, qui étouffent ceux qui en euentent la matiere. 


\section{CHAPITRE VIII.}

\section{Du Bruit.}

7 Out le monde fait tant de bruit, \& tant de perfonnes en veulent faire, tant d'autres s'y plaifent, ou elles l'apprehendent fi fort, que nous auōs crû neceffaire d'écrire fur vn fujet qui eft fi commun \& fi ordinaire, \& de voir fans faire bruit \& fans y pretendre, fi la Medecine nous pourra fournir icy quelques bõnes obferuations.

Il faut fuppofer à ce deffein que le bruit n'eft qu'vn fon fans mefure, qui procede de l'air agité, ou qui deriue des corps folides, lors qu'ils fe choquent parmi eux : de là vient, comme le fon n'elt qu'vn mouuement, ainfi que la raifon nous montre, que le bruit par confequent eft de mefme nature, \& il y a de l'apparence qu'il ne fubfifte que dans la feule agitation. C'eft pourquoy il eft different fuiuant les diuers mouuemens, leurs milieux, \& les fujets qui les reçoivent; par exemple, il eft aigu, fombre, grondant, importun, éclatant \& rude, fi le mouuement fe fait promptement ou auec lenteur, deloin, de prés, ou d'vne diftance mediocre, en cercles, en angles, ou en lignes droites, dans l'air, dans l'eau, fur des corps pefans ou mobiles, \& dans des organes figurés divne differente façon. Cette fuppofition nous oblige d'en auancer vne feconde.

Sçauoir \& que comme lebruit eft vn fon \& ti ij 
vil mouuement, on ne le peut mieux conceuoir, que parce qui explique les fons \& les mouuemens, qui ont du rapport auec luy : Or il n'y a rien qui fafle mieux cela que les chofes fpirituelles \& lumineufes; feruons-nous donc d'elles, \& de leur éclat, pour découurir la nature du bruit. Et veritablement le bruit fe refpend comme elles dans vn moment, on le ramaffe dans des tuyaux à la façon de la lumiere, il fouffre comme elle par les corps concaues, rabouteux, inegaux ou polis, il entre mefme, \& penetre par toutà la maniere des efprits, \& c'eft de là qu'il va jufqu'à l'ame, qu'il s'vnit à fes facultés, qu'il inquiette les demons, \& qu'il caufe du trouble jufques dans le fond de nos cœurs.

On connoift de ce principe, que le bruit eftant vn mouuemēt, \& ayant du rapport aux efprits, il eft affeurement pourneu comme eux, d'vne energie, \& d'vne vertu impulfiue, dont les effets font merueilleux: \& certesc'elt par elle qu'il remuë l'air qu'il a rendu dans la mer Egée, fi nous ajoûtons foy à Plutarque, des petites Ifles flotantes qu'il agite, fuiuant les Medecins, nos organes \& nos humeurs, qu'il fait trembler les membranes, les nerfs, \& les fibres; \& fur tout qu'il confond ou qu'il poufle fortement nos efprits. Nous prouuerons cela ailleurs, tirons feulement de tous ces fondemens des confequences à noftre ordinaire, \& propofons ce qui fera neceffaire à la fanté.

La premiere, que le bruitagitant nos efprits par a faculté impulfiue, il eft a ces petites flammes ainfi que le vent à la lumiere, tantolt il 
les opprime, ou feulement il les émeut, tantoft il agit a la maniere des foufflets, qui étouffent vn petit feu, ou qui en éuentent lescendres, \& tantoft il leur fait comme à vn grand brafier, quis'allume \& qui jette des eftincelles, fi on en fouffle les charbons. De tout cela on peut conjecturer pourquoy le bruit eft fi importun aux contemplatifs, aux atrabilaires, \&auxbilieux, puis quils ont des efprits fubtils, qui tremouffent à la moindre fecoufle, qui fe diffipent au moindrebruit, \& qui perdent leur recticude, $\&$ fe portent hors de leurs routes, s'il eft rude $\&$ trop violent : Et voila le motif qui pouffe toutes ces perfonnes à fuir le tumulte, \&à chercher la tranquillité quiles fait éueiller facilement a la maniere des chiens, \& des animaux d'vne merme nature, parce que le bruit remue leurs e prits volatils, qu'illes tire fubitement des endroits où ils fe ramaffent dans les tenebres, \& leur donne le mouuement qu'ils auoient à demi perdu. C'eft dece principe que nous fommes fort fenfibles au bruit dan's cette Prouince, \& qu'v $\Omega$ homme de qualité mort depuis vn certain nombre d'années, paruft iniultement ridicule au public, parce que fa doctrine, fon temperamment, \& fa grande application à l'eftude, auoit rendu fe efprits fi fubtils \& fi deliés, que le moindre bruit les agitoit, à la façond'vn feftu, lors qu'il eft le jou 't du zephire; qu'il fdifoit rouler ces Aftres hors de leurs fpheres, \& quil les tiroit hors de la fituation, où l'amea couftume de les ranger, lors quelle conçoit. C'eft ainfi que le bruit fait perdre les '-lles idées, 


\section{0}

\section{Du Bruit.}

qu'il oblige les fçauants à s'en efloigner, qui les porte à la folitude, \& à fuir l'embarras du public.

Iien eft partant bien au contrairedes payfans, des mariniers, \& de tous ceux qui font mecaniques, dont les efprits font grofiers, \& difficiles à eftre troublés par l'agitation du dehors, de forte que leur fommeil eft paifible pendant le bruit, \&que leur application ne fçauroit eftre interrompuë par le tracas, \& par letumulte.

Suiuons les mefmes reflexions, \& appliquons les aux malades. En effet les vns apprehendent le bruit, \& s'en trouuent indifpofés, \& les autres ne le craignent point, \& ils l'exigent s'ils veulent eftre deliurés de leurs maux. Ceux-cy ont des indifpofitions qui appefantiffent les efprits, qui les changent en vents, comme dit Hippocrate, qui les engourdiffent \& les rendent fuligineux, de forte que lé bruit moderé leur fait vne impreffion fort petite, \& que le violent eft alors neceflaire pour remuer ces efprits eftouffés, pour les degourdir, \& pour diffiper leurs nuages, pour faire couler ainfi les humeurs, \& pour y exciter vne tempefte dans vn calme tres-dangereux. C'eft ainfi que les Toupinembours traittent ordinairement leurs malades, \& qu'ils tachent à les releuer par des clameurs, \& par des bruits. Il y en a neantmoins qui font biendifferents deceux-cy; car ils craignent le bruit, \& en font grandement émeus; non feulement parce que leurs efprits affoiblis font comme ces petites lampes, qui s'étouffent au moindrevent, non feulement parce que la 


\section{Du Bruit.} grande chaleur les rend fouvent trop fubtils $\&$ legers; mais d'ailleurs parce qu'ils s'agitent, \& qu'ils deuiennent impetueux dans les maladies, qu'ils fe choquent \& qu'ils fe font tumultueux; de maniere qu'ils exigent la ferenité dans la tempefte quiles trouble, laquelle partant eft rendue plus forte par la violence du bruit.

Et voila d'où deriue la mort, ou les rechuttes; fi le bruit eft trop importun ; car il diffipe les efprits, ou il les tire hors de leurs mefures; il empefche les fermentations \& les crifes, en les brouillant, \& il leur fait promptement remefler \& confondre ceque la nature vouloit feparer à loifir.

Qu'on nes'imagine point au refte quele bruit n'eft pas affez fort pour émouuoir \& pour agiter nos efprits; caril fait le mefne que la mufique, dont nous parlerons cy-a prés, \& il en eft de luy comme du mouuement des ennemis, qui fait trembler de bien loing vn dés, qu'on aura mis fur vn tambour: de mefme il eft aifé au bruit d'agir ainf fur nos efprits, foit parce qu'il eft vn mouuement affez fort, \& qui émeut l'air qui leur eft contigu, foit parce que les efprics font tenus, \& dans des agitations perpetuelles, \& quicoulent fur nos membranes comme fur autant de tambours que la nature a tendus en diuers endroits de nos corps.

On découure de ce dif́cours l'effet que le bruit produit à nos oreilles; car comme elles contiennent vn efprit, qui fert de milieu aux harmonies \& aux fons, il arriue que le bruit le brouille s'il eft confus, qu'il le pouffe s'il eft al-

$$
\text { E iiij }
$$


gu, de maniere que les oreilles nous cornent fouuent a pres les clameurs exceffiues, \& qu'il a peine à le remuer s'il eft doux \& fort éloigné. 11 agit d'ailleurs fuiuant fa confiftence; car ill'émeut difficilement s'il eft cras \& fuligineux, \& il l'agite puiffamment $s^{\prime}$ il eft fubtil, \& $\mathrm{s}^{\prime}$ il eft rare, c'eft pourquoy les febricitans fe plaignent du moindre bruit qu'ils entendent, \& Mippocrate [In Coac. ] ordonne alors de prendre garde qu'ils ne tombent dans la fureur, parcequ'apparemment leur grande chaleur a rendu cét efprit extraordinairement rarefié, ce qui marque la mobilité \& le tumulte de tous les efprits influants.

La ferondeconfequence eft fondée fur le rapport que le bruit a auec la lumiere, de là vient que comme la lumiere brille mieux pendant les tenebres, que le bruit incommode pendant la nuit; que comme vne lumiere éclatante bleffe la veué, vn bruit extraordinaire penetre les oreilles trop for tement ; que comme vne lumiere tremouffante fait de la peine à la veuë, il en eft ainfi des oreilles pour ce qui eft du bruit inegal, \& qui d'ailleurs n'imprime point vn effet fenfible s'il eft éloigné, ou s'il eft petit à la façonde la lumiere, qui ne fçauroit éclairer dans vne diftance trop grande.

La troifiéme confequence depend de la figure des mouremens \& des fons, \& parconfequent de celle du bruit. En effet tout de mefme que quelque chofe de rabouteux incommode lattouchement, que les faueurs piquantes alterent le goût, \& que les vapiurs acres font mal à la 


\section{Du Bruit.}

veuè, il en arriue ainfi des bruits, les aigus \& les perçans ont du rapport aux faueurs pıquantes, ils vont en angles \& en pointes, comme les fels qui font les faueurs, les confus brouillent l'air à la façon de l'eau agitée; de maniere que cette inegalité fait aux oreilles ainfí que les figures rabouteufes à l'attouchement. Et voila la raifon pourquoy les bruits confus \& tumultuaires qu'on entend aux foires \& aux marchés font mal à la tefte : pourquoy nous nous rebutons de ceux qui fe font de la fcie, des charrettes, \& des couteaux : Enfin pourquoy eft-ce que les fons agreables appailent la douleur \& l'importunité, qui procede du bruit. Car tout de mefme que le lait, \& les liqueurs addouciffantes moderent le fentiment des chofes quipiquent, en oppofant à leurs angles leurs parties rondes \& polies; on peut dire que la Mufique, \& l'harmonie émouffent la pointe \& l'afpreté desbruits, par la mefure \& l'égalité de leurs cercles, \& par l'ordre qu'elles donnent à nos efprits.

La quatriéme confequence fe tire de la conftitution des nerfs qui font aux oreilles, puifque nous auons remarqué que la difpofition des organes rendoit lesbruits fort differens. En effet comme la nature a tendu le nerf de l'oüye dans fon organe comme dans vn inftrument raifonnant, elle a voulu que fa groffeur, fa lafchetté, fa tenfion, \& fes impulfions differentes contribuaffent à la difference des fons \& des bruits : c'eft pourquoy tout ainfi qu'vn inftrument eft defagreable, lors que fes cordes n'ont point vne tenfion proportionnée aux ac- 
74

Du Bruit.

cords \& aux mouuemens qu'on leur donne, it en arriue de mefme des bruits qui font hors de la proportion du nerf des oreilles, qui l'agitent, \& quile remuent fans mefure, \& qui font comme lors qu'vnignorant fe veut mefler de pinfer les cordes d'vn Luth. C'eft de là quion découure la raifon pourquoy ceux qui aiment la Mufique apprehendent fi fort le bruit, \&qu'on void que tout ainfi que les voyageurs foulagent Ia laffitude qui procede de leur vitefle, par des pas lents \& mefurez, que le bruit eft temperé pareillement par l'harmonie, parce qu'elle regle ce nerf, \& le remue auec ordre \& paifiblement. Et voila la fource de la peine que nous auons des bruits difcordans d'vne multitude confufe, à caufe de l'agitation inegale du nerf, fur tout s'il eft delicat \& fenfible : C'eft pourquoy l'vni-fon eft agreable, parce que fon mouuement eft vniforme, \& qu'il n'imprime point aux nerfscette laceration, qui procede des tons inegaux. C'eft icy encore la raifon pourquoy le biuit des ruifleaux eft agreable à la campagne, parce qu'il donne vn branle regulier, \& toûjours vniforme aux nerfs; enfin pourquoy cerraines perfonnes fe plaifent à des bruits differents fuiuant la proportion des nerfs, qui font atuec eux ou le dia pente, ou le diapafon, ou quelque chofe de femblabe.

On connoift de ce difcours qu'il n'y a point de bruit qui donne plus de peine aux nerfs, que celuy qui eft éclattant \& aigu; car comme le fon aigu ne deriue que des agitations promptement 


\section{De Bruit.}

redoublées, d'où vient qu'à cet effet il faut des cordes fubtiles, dont le mouuement eft plus prompt, il en eft anfi des nerfs, qu'vn femblable bruit esbranle fubitement \& auee-viteffe, fur tout s'ils font fubtils \& minces, \& sits font fecs \& tendus, ainfi qu'il arriue aux bilieux \& aux malades, dont à caufe de cela leur oreille eft fi delicate:c'eft pourquoy ces perfonnes fe treuuent indifpofées par l'émotion furprenante dubruit aigu, qui agite trop vitement \& trop fenfiblement leurs organes, \& qui ébranle fans mefure, ce qui doit eftre pouffé auec moderation. Auffil furuient vn effet bien remarquable de cette émotion; car comme les nerfs deriuent du cerueau, \& comme ce font eux, ainfi que nous venons d'écrire, quifont pouffés trop promptement par les bruits éclatans, ils communiquent par confequent leurs indifpofitions à la fource dont ils procedent : ils ébranlent ainfí le cerueau, \& font dire à ceux qui fe pleignent des bruits aigus, qu'il femble que leur tefte s'ouure par le milieu, ou qu'on y met quelque fer, dont la pointe perce leurs moëles; parce que les angles du bruit piquottent les nerfs' \& que ceuxcy refpandent ce mauuais fentiment jufques dans le fond du principe. Il eft mefme certain que les parties voifines fe reffentent de cette impulfion, ainfi que la telte; mais pour bien entendre cela,

Il faut prendre garde que les chiens, par exemple, ouurent les oreilles, \& les remuent aux bruits furprenans; qu'ils jettent fouuent des efclats de voix, \& qu'ils dilatēt alors leurs paupie- 


\section{$7^{6}$}

Du Bruis.

res: la raifon de cela eft, parce que le nerf des oreilles eftant meu du bruit, vin de fes rameaux, qui eft inferé dans les lobes, les fecouë \& les fait remuer, il en eft ainfi d'vn autre aui fe termine aux paupieres, afin que les yeux \& $\&$ les oreilles faflent fentinelle, \& que ceux-là fe tournent du cofté d'où deriue le bruit : de là vient que comme vn troifiéme rameau penetre au fond de la langue, il fait mouuoir cette partie, \& il eft la caufe deseflans que ces animaux pouffent en fuitedu bruit. Et fans doute c'eft par la connexion des nerfs des oreilles, auec ceux qui font aux genciues, qu'on grince des dents au bruit du liege \& des Charrettes, commec'eft par les dents quion entend mieux les inftrumens, fi on les introduit dans la bouche : difons le mefme des grands bruits qui lachent le ventre; car le nerf des oreilles, \& toutes les parties qui l'enuironnent, ont vn rapport particulier auec les entrailles: c'eft pourquoy la fuppreffion du ven. tre fait les parotides, comme la lacheté les refout, de forte qu'il ya de l'apparence que le bruit quifecoué le nerf porte cette impreffion encore plus bas, \& remuë aufi les boyaux.

La cinquiéme confequence fe prend du fondement que nous auons fuppofé touchant la difference des bruits par la figure des organes; car celle des oreilles fert beaucoup à augmenter les bruits: c'eft ainfi que les lieures s'éueillent au moindre mouvement des chaffeurs, parce que l'emboucheure de leurs oreilles eft en forme parabolique, \& que cette figure ramaffe merueilleufement la lumiere auec le fon, c'eft de là que 


\section{Du Bruit.}

certaines concauitez du mont Etna, \& du Caribde refonnent fi éponuantablement au bruit de la mer \& des vents, que le peuple \& lesignorans y ont logé les demons, \& ont rendu ces lieux formidables.

La derniere confequence fe prend de l'efpece du bruit en qualité de mouuement, dont la nature differente fait des impreffions remarquables; en effet quelques bruits font aux organes de l'oüye, comme lors que nous nous gratons, leur frixion les rend agreables, \& fait que nous entendons auec plaifir les grillets, les grenouilles, \& certains autres animaux.

Et c'eft là tout ce que nous auons pû obferuer fur le bruit, qui jultifie le grand Hippocrate dans fes Epid. qui ordonne de confiderer les clameurs \& le bruit. Et affeurement c'eft icy vne matiere des plu's importantes, parmicelles que les Medecins expliquent: foit pour conferuer la fanté ; foit pour la redonner fi elle eft perduë; foit pour empefcher les fymptomes qui fe fouleuent par le bruit. C'eft à cette fin que les bilietx \& les febricitans doiuent fuir les bruits aigus, comme les melancoliques ceux qui font fombres; qu'on fe doit feruir des bruits aux letargiques, \& aux malades qui ont perdu le fentiment, \& que toutes les perfonnes qui ont leurs corps \& leurs ames bien compofées le doiuent éuiter, \& fe fouuenir que ce fera vne des felicitez des bien-heureux, d'adorer eternellement dans le filence, celuy qui eft venu au monde paifiblement \& fans faire bruit. 


\section{CHAPITRE IX.}

\section{Des Habits.}

TOutes chofes ont des habits, les Hebreux 1 en donnoient à Dieú, qui ont pour couleur les tenebres; Trifmegifte luy en a fait de tout lumineux, \& de tout brillans. Platona dit que rien ne defcendoit du Ciel qui he fût fous des counertures; la nature a reueftu les animaux, \& fes plus belles productions, \& l'Art a taillé des veftements aux hommes pour le befoin qu'ils en auoient. Cette neceffité eft fi preffante qu'elle a obligé les Barbares à fe couurirde fueilles dans les deferts, \&à endurcir leurs corps dans la glace \& dans les riuieres.

\section{Durum i ftirpe genus, natos ad flumina primum}

Defer imus, Saroque gelu duramus \& vidis.

Et qu'elle a fait immaginer aux Rabins que le premier pere dans fa nudité auoit la peau femblable à la corne de nos lenternes, parce qué la niatiere des ongles la plus épurée s'eftoit neceffairement répanduë pour le veftir. Mais pour faire voir l'importance des veftements d'vie maniere plus folide,

Il faut fuppofer quel homme tire fa perfection parmy les chofes animées de fa grande mediocrité, auffi les eftremitez luy fontincommodes, \& les qualitez extrangeres de l'air, des faifons, \& du temps le iettent fouuent dans l'excés. C'eft ainfi que les chaleurs ounurent fes chairs, que le 


\section{Des Habits.}

froid preffe fa poitrine, \& que les vents, le fec, \& l'humide detruifent fon temperament. Il a donc efté neceffaire qu'il employât fon induftrie pour refifter à tous ces maux, \& pour conferuer cette mediocrité exquife qui le rend foible \& delicat, mais le chef-dœu ure de ce monde. Et c'e't certainemēt ce qu'il a fait en fe couurant des veftements quile protegent, \& le muniffent, qui le preferuent des faifons, \& qui luy font ainfi que l'efcorce eft aux arbres, l'efcaille aux poiffons, \& les depouillesaux infectes. Cependant parce que parmy ces habits les vns font pefants, où legers, \& que quelques autres fontd'vne confiftence mediocre; il a deu fe feruir de ceux-cy pour paffer aux extremitez $\&$ des autres dans les grandes chaleurs, \& dans les froidures exceffiues pour obferuer cette mefure qui fe détruiroit fans cela. C'eft pourquoy Hippocrate au liure des eaux, enfeigne que les Afratiques font toûjours reueftus d'vne mefme façon, parce qu'ils ne fouffrent point dans leurs climats ces interruptions, \& ces varietez furprenantes, que les peuples d'Europe preuiennent par la diuerfite des habits. Et voila la rasfon generalle qui a fait rechercher les veftemens aux hommes : confiderons-les maintenant en particulier par leur pureté, par leur choix, par leur matiere, \& par leur forme; en vn mor par les circonftances qui s'y attachent, \& qui peuuent efclaircir ce difcours..

La formedes veftemens fe tire de leur proportion, \& de leur iuftefle auec nos parties, parce que la fructure du corps leur doit feruir com- 
So

Des Habits.

me de moule: \& fi Vitreuue prend d'elle le modelle desbaftimens, il eft bien plus raifonnable de l'obferuer pour la façon de nos habits. C'eft donc vn caprice bien dangereux de fe mettre à la gefne lors qu'on s'habille; l'experience fait voir que les enfans qui prennent vne robe neufue perdent l'appetit dans la preffe où ils fe treuuent, \& les Scytes deuiennent fteriles, fi nous croyons à vn fçauant, \& demeurent long-temps fans manger, fuiuant les relations du fameux Hippocrate, [ Lib. de ä̈re, aquis of loc. ] parce qu'ils fe ferrent eftroitement.

Mais que dirons nous des filles qui ont tant de foin de preffer leur poictrine, \& dont Terence s'eft joüé, en les comparant à des joncs: fans doute par là elles fe procurent bien des maxx. Quoy! Hippocrate n'a-t'il pas enfeigné que la poictrine eft dediée au Soleil, qu'à cét effet elle contient vn fang bouillant, \& femblable à des eaux bruyantes, de forte qu'il doit rouler dans des canaux, \& dans des lieux fort eflargis?

Faut-il donc deftruire vne œconomie fi jufte? ¿\& parvn eftroiffiffement oppofé, doit-on violer vne proportion qui deriue de la Prouidence? Non, que ces perfonnes s'en defabufent, voulant meurtrir par vne figure affectée, ce font elles mefmes qui fe meurtriffent, \& qui preparent des feux, que la contrainte fait rentrer de mouneau dans leur cour. Le fang preflé \& l'air des poulmons reffemblent $a$ ors à ces vagues, qui fremiflent dans les écueils, les efprits rompent leurscanaux, \& produifent les anevrifmes, la bile 
bile s'irrite par la compreffion, \& elle altere la douceur, qui eft vn de ces beauxattributs qu'on fouhaite toûjours aux filles. Cependant l'ame ne la f̧̧auroit regler dans la confufion où elle fe void enyagée, elle agit à la maniere de ces habitans, qui ne peuuent eftaler leur mefnage: enfin elle fe treuue fi preffée dans cet eftat, qu'elle foufpire quelquefois à la façon dont parle Seneque, c'eft à dire de l'afthme par la compreffion des poulmons.

Nonobftant tous ces maux, neantmoins ce fexe n'a pûfe corriger de cette mauuaife coultume. Les filles des anciens auoient des bandelettes de pourpre, appellées Strophia par Ouide. qui leur feruoient a ramaffer leur fein.

Vrebant animum dure, ftantefque papille,

Et quas adfringens clauderet vna manus.

Martial fe mocque d'vne femme ruftique parce qu'elle eftroiffifoit fes mammelles auec des attaches de pèau.

Taurino poteras pectus conftringere tergo,

Nam pellis mammas non capriffatuas

On lit dans les anciennes Coinedies.

Non fimilis eft Virgo Virginum noftrarum, quas matres ftudent demiffis bumeris effe, vincto peitere, $v t$ graciles fiant.

Et les modernes rient de ces femmes Barbares, qui achetent des ceintures rouges, pour amoindrir la groffeur de leur corps.

L'ouluerture des habits eft également incommode, auffi le nom de veftement eft tiré du Latin velando, parce que les habits ne font que pour counrir le corps. C'elt pourquoy l'Auteur F 
82

Des Habits.

de la Medecine Statique a compofé deux A pho: rifmes fort remarquables fur ce fujet; il dit au premier, qu'on fera rarement malade dans les changemens des faifons, fi les varietés impreueues treuuent les habillements peu ouuerts : \& au fecond, il fouftient que celuy qui eft bien couuert euapore librement, \& par ainfi il deuient plus leger, bene munitus veftibus melius iranjpirat, or redditur minoris ponderis. La raifon decela eft, parce que le froid ne repouffe point au dedans les exhalaifons ordinaires, dont la fuppreffion fait le poids, comme nous montrerons vn jour.

- Le choix des habits roule entierement fur les Aftres, qui doruent auoir quelque place dansce Chapitre; puifque S. Thomas a creuau Liure de la deftinée qu'il ne les y faloit pas negliger. En effet les veftemens font $f i$ fort fujets à la Lune, \&celle leur caufe de fi grands changemens, que les Ægyptiens fous le nom d'Ifis, luy ont attribué l'inuention des eftoffes, \& que les Aftrologues ont ordonné de la joindre $2 u$ figne du Lyon, lors qu'on vouloit choifir des habillemens pour la guerre, que les anciens Heros ont tirés des Lyons, \& des animaux les plus fiers.

De tout cela on void la raifon de ce qu'Hippocrate auance fur la fin du Liure des Vierges, lors qu'il dit, que les Preftres Grecs perfuadoient aux filles, dont les couleurs eftoient abbatués, de confacrer à Diane leurs habits; car ce:te Diuinité eft la Lune, qui prefide fur les veftemens, fur les filles, \& fur ce qui ternit 
Des Habits

l'éclat \& la pureté de leur teint : ce grand homme ajoufte neantmoins qu'elles eftoient feduites, \& que les Preftres profitoient ainfi de 12 richeffe de leurs a tours.

Outre la Lune on a creu encore important d'obferuer l'eftoile de Venus, parce qu'elle eft la fource des graces \& de la pureté, deux qualitez quidoiuent eftre infe parables des veftemens; C'eft pourquoy les Pytagoriciens s'habilloient de blanc fous la direction de cet Aftre, des femmes luy offroient leurs ceintures, \& Iule $\mathrm{C}_{\boldsymbol{x}}$ far luy confacra vn jour fa tunique auec fon manteau.

La pureté des habits eft encore fort neceffaise. Pour labien expliquer,

Souuenons-nous que les habits deuiennent rouillés par les tranfmiffions des parties, ous bien par les écoulemens des corps qui leur font contigus; C'eft ce quia fait dire à Pline que les robbes des funerailles n'eftoient jamais percées de teignes par la contagion des corps morts; \& qui a obligé les Romains à quitter les tuniques que les fouris auoient infectées, comme nous lifons dans S. A uguftin [au l. de la Doct. Chr.] cum veftis à foricibus roditur (dit ce S. homme) plus rimere cos fuspicionens futuri mali, quàm prefens daminum dolere : vnde illud sleganter dictum eft $\mathrm{Ca}$. tonis, qui cum effet confulsus à quodam qui fsbi à o. ricibus evofas caligas diceret, refponditt non effe illud monftrum, fed verè monfrum babendum fuiffe, $\sqrt{1}$ foo rices a caligis roderentur. Quoy qu'il en foit,

Nos parties communiguent va fouphre, \& vn fel volatil, qui font difcerner aux chiens les F ij 
34 Des Habits.

veftemens qui font à leurs maiftres, qui leur impriment, \& les maladies \& les odeurs, qui les faliflent \& les engraiffent : enfin qui leur. lailfent vne matiere ennemie de nos efprits, comme les nuages le font de la clarté du Soleil, \& de la lumiere : c'eft pourquoy les anciens ne receuoient des veftemens que des perfonnes releuées, \& ils n'affiftoient aux ceremonies quauec des veftemens tout purs.

Cafta placent fuperis, puracum vefte verite,

Et manibus puris fumite fontis aquas.

Les corps contigus fouillent les habits, enrependant pareillemét des tranfmiffions qui comsnuniquent leurs qualités. Ces tranfmifions s'arreftent dansla tiffure, parce que le microfcope reprefente les filamens entrelaffez, ainfi que le gril des feneftres, de forte qu'ils donnent entrée aux écoulemens eftrangers. C'eft pourquoy les draps s'en jmbibent sils font fulphureux, comme on void par l'exemple de l'huile, \& ils en font penetrez silis font acres, fubtils \& rongeans. Les efprits des corps peftileñs agiffent de cette maniere; car ils ont du rapport aux eaux fortes \& à l'arfenic $b$ de maniere qu'il les faut éffacer par d'autres efprits, \& qu'il eft neceffaire d'auoir des parfuns, dont les particules pointuës faffent aux filets ainfi que des couteaux \& des poinçons, qui raclent, pouffent ou detachent les matieres embarraffées.

Hen eftoit de mefme des corps ladres qui infectoient les Iuifs dans l'ancienne loy, leurs tranfpirations fe gliffoient dans les filamens, \& rongeoient les eltoffes les plus époiffes, elles im- 


\section{Des Habits.}

primoient ces prodigieufes taches qui croilfoient infenfiblement, parce que le tiffu leur feruoit de filtre, \& qu'elles eftoient fi penetrantes qu'elles creufoient les pierres, \& qu'elles obligeoient à demolir les baltimens.

On découure de ce difcours pourquoy dans les maladies Epidemiques on recherche les habits ferrés; carils n'embarraffent point les vapeurs, du moins ils ne leur donnent pas vne entréequi foit fi libre.

On connoift encore pourquoy le ferain purifie les veftemens, parce que les fels alcalifez \& nitreux, qui s'efleuent dans l'atmof phere, font comme des autres parfuns, ils détachent, abforbent, metamorphofent, ou ils adouciffent les fels acides, que les parties y ont enuoyés; mais fur tout ils s'y vniffent, ils les emportent, ou ils s'y joignent, \& ils font refulter,ainfi vne nature indifferente, comme on void parlemêlange du Tartre auec l'efprit du Vitriol.

C'eft de cette façon qu'on peut ofter les taches des linges, qu'on efface l'ancre parlecitron, que le fauon attire l'huile, \& que certains parfuns corrigent les venins les plus forts.

La matiere des habits deriue des peaux, ou des plantes. Pour commencer maintenant par les peaux, il faut voir quel eft le principe de leurs qualités, afin que nous le puiffions ajufter à leur veftemens.

Les yrands hommes du paffé ont pris ce principe bien hautement, ils l'ont eftabli fur l'ame du monde, qui void \& quiregit par tout : ils ont fouftenu qu'elle fe communiquoit à la façon des 
corps lumineux, que fes portions les plus brillantes donnoient la vie aux animaux, qu'elles traçoient dans leurs parties les myfteres de l'auenir, \& qu'ainfi elles decouuroient aux Augures ce que les deftinées tenoient de caché.

Ils ont pourtant enfeigné que la mort étouffoit leur clarté, fi bien qu'elles n'imprimoient plus alors, que des veftiges confus des notions qu'elles auoient eues, \& qu'il ne reftoit parconfequent aux peaux qu'vne fimple vertu de produire lesfonges, \& de troubler par desillufions. Et veritablement c'eft à ce deffein que les Deuins recouchoient fur elles, pour eftre infpirés en dormant, comme nayant plus qu'vne fumée dece feu qui les animoit, quinefert qu'à la production desphantofmes.

Il faut pourtánt déueloper les peaux d'vne autrefaçon, \& fuppofer deux fondemens, qui donneront beaucoup de clarté aux reflexions qui en dependent.

Le premier eft, que les chofes mortes \& feparées, lors qu'elles font vnies à celles qui viuent, retiennent encore quelques reftes, qui viuifient en les appliquant, ou quiattirent ce que celles cy contiennét de mauuais ou de bon. C'eft ainfi que le fcorpiō efcrafé guerit fa morfure; que la chair d'vn corps mort attachée à quelque partieviuante, fait vne reuulfion des humeurs, \& que la peaudes animaux produit des effets admirables, ainfi que nous verrons bientof.

On doit fuppofer en fecond lieu auec Hippocrate, que les peaux font animées de l'influence 
du grand principe, c'elt à dire, qu'elles reçoiuent, qu'elles terminent, \& qu'elles font reliechir les efprits vers le cour, qu'elles font d'ailleurs le fujet de ce cercle ou le fea imite les Aftres, 'qu'elles s'imbibent de ce qu'il y a de plus effentiel dans le corps, quielles retiennent le fel \& les exhalaifons des entrailles; enfin qu'elles criblent, \& qu'elles fepárent tout ce qui vient de la troifiéme digeftion. De ce fondement on tire quantité de rentexions importantes.

La premiere, que les peaux font ordinairement chaudes, \& feiches à caufe de l'acrimonie des fels, \& de l'impreffion des efprits. Cette acrimonie les rend propres à échauffer \& à diffoudre, \& l'imprefion des efprits les rend balfamiques, les fait femblables à l'onguent d: fympathie, au fang, \& au crane des animaux, en vn mot elle leur donne la faculté de fortifier ceux quilanguiffent fi on les y enueloppe tout chaudement.

La feconde, que les peaux retiennent les fels ardens \& alcalifez qui eua porent des parties par vn ordre de la nature, \& parvne grande neceffité; car ainfi elles peuuent refoudre la glu de diuerfes matieres, qui deriuent des digettions, \& qui fe coagulent à la furface, \& elles feruent à diffiper quantité d'humeurs vifqueufes \& froides, qui fe ramaffent dans nos iointures, \& qui embarraffent nos chairs.

La 3. que les peaux font comprifes fous deux efpeces : celles des animaux qui font doux, humides \& gras, font fouples, ramollitiues \& balfamiques, parce que les tranfirations qu'elies F iiij 
eboiuent ont de sëblables qualitez:mais celles des animaux coleres, voraces $\&$ forts, ont cette faculté penetrante, \& cette acrimonie dont nous auons déja parlé.

Ia 4. que ces dernieres prouoquent l'appetit, \& aident à la digeftion, parce qu'elles refpandent des fels qui ont quelque chofe d'acide, \& qui augmentent la vertu que les Medecins attribuent aux efprits de nos eftornachs : c'elt parces fels aufi que les peaux fe rongent fouuent entr'elles, que les plus acres furmontent les douces, comme la peau du loup celle dagneau, \& qu'elles foulagent ceux qui font meurtris par les cheutes, ến diffoluant le mauuais fang, que la contufion a fait rejaillir hors des veines.

La derniere, que les peaux des beftes égorgées font preferables à celles des animaux morts de langueur, parce que les premieres font toutes fpiritueufes \& chaudes par les bonnes influences qu'elles ont euès, \& les dernieres font laches, froides ramollies, par le defaut des efprits, par la foibleffe du grand principe, par les mauuaifes humeurs, \& par les tranfpirations corrompues.

Et c'eft lá tout ce que nous pounons dire des peáux, \& par confequent des veftemens qu'elles fourniffent; neantmoins parce qu'à parlér proprement, leur vage n'elt que chez les Barbares,'\& parmy les Septentrionnaux; obferaons feulement en détail les pieces des peaux, dont les Medecins font enuironner nos parties, lors qu'elles ont quelque indifpofition chronique. La peau de l'homme a de qualitez excellentes 


\section{Des Habits.}

elles procedent du carractere des efprits, \& du mefme principe, par lequel la mumie, le crane, \& le fang ant de fi grandes facultez; aufíles ceintures qu'on fait de nos peaux preparées foulagent la colique, feruent à la matrice, à l'accouchement difficile, à la goutte, \& aux grandes douleurs. Ie ne fçay fi c'eft à caufe de leurs admirables qualitez, que les Gnofticiens efcriuoiēt fur la peau des petits enfans, qu'ils la mefloient dans des compofitions eftranges, \& que quelques-vns employoient heureufement les mêbranes du foetus, qui font comme des autres peaux.

La peau de loup guerit la colique, \& prouoque l'appetit en exhalant quantité d'efprit qui rendent cette befte vorace: ce font eux qui luy donnent le pouuoir d'enrouer, fi nous croyons aux Philofophes, \&qui pouffent des fels alcalifez \& acides, quiimpriment à fa dépouille la vertu d'adoucir la goutte à la maniere de l'eau de chaux, de l'efprit du vitriol, du fel \& du nitre.

Les peaux du renard ont des tranfpirations fort acres, de maniere qu'elles amollifient les duretés, qu'elles refoluent les humeurs des paralytiques, \& qu'elles excitent la foif. C'eft pourquoy les Bacchantes fe couuroient ordinairement de la defpouille d'vn renard: d'oú vient qu'elles font appelées de Perfe Bafarides, parce que Baffaris en langage de Thrace fignifie vn Renard.

Il eft ainfi de la peau des vautours, parce qu'ils aiment à manger les renards; \& dont les euaporations font ardentes, c'eft pourquoy elles prouoquent lappetit, \& font mieux cuire l'aliment dans le ventricule. 
La peau des lieures eft bien oppofée aux pre: cedentes. Pour bien entendre cela,

On doit obferuer que les animaux font ou courageux ou timides, \& que tous impriment à leurs peaux vn caractere des agitations qui fe foûleuent dans leur coeur : la raifon de cela eft parce que ce membre eftant le grand principe, qui influë par tout le corps, il s'arrefte, \& fe determine dans la derniere des parties, \& ily depofe des efprits, qui y grauent les idées des paffions qui fe forment dans l'interieur. Et certes fi elles paroiffent aux humeurs, on ne doit point douter qu'elles n'éclatent dans les depouilles : \& fi le fang du lieure, par exemple, guerit de la dyfenterie lors que les chiens ont effaré cet animal, que doit-on prefumer de fa peau, que la crainte fait toûjours fremir, ainfi qu'Ariftote remarque, à caufe de fon temperament?

De ce principe on connoit premierement que la peau des lieures arrefte le fang, qu'elle empéche la fermentation des humeurs, \& qu'ellerafroidit, quoy que le peuple s'imagine, parce qu'elle engourdit les efprits, qu'elle les lie \& les repoufle, \& qu'elle leur infpire ie ne fçay quoy de proportionné à la peur.

Secondement que la peau des animaux rapaces appaife les douleurs, \& addoucit la matrice irritée, parcequ'elle communique vne efpece de terreur aux efprits qui a ppaife leur fureur, qui furmonte, \& qui modere leur tumulte; car elle deriue d'vn principe qui eft la fource de la force, du courage, \& de la fierté, qui fait que nous 
zpprehendons quelquefois par vn fecret preffentiment la peau de quelque animal dangereux, lors que nous y portons ou la main ou la veue.

Et voila le fondement des grands remedes qu'on peut tirer de châque animal, \& du chois qu'on fait de leurs membres lors qu'on veut foulager quelqu'vn: par exemple, pourquoy les priapes du cerf $\&$ celuy du taureau font excellens, d'ou vient qu'on cherche le crane \& le fang des perfonnes fuppliciées, pourquoy la main d'vn homme mort efface les marques que la mere imprime à fon fruit: en vn mot on tire de ce principe des lumieres pour efclaircir vne infinité des queftions.

Les plantes font les premieres que les anciens ont employées pour fe veftir : mais deuant que parler des habillemens qu'elles nous donnent, examinons leurs differences, afin de mieux connoiftre la nature des veftemens qu'on en peut tirer.

Les plantes font produites des animaux \& de la terre où elles croiffent fur les herbes, fur les arbres, \& fur leur troncs; celles qui font tirées des a nimaux, font les plumes, les poils \& les laines: la terre nous fournit le chanvre, le cotton \& le lin; \& les Indiens ramaffent quantité de filamens des rameaux \& de certaines fueilles, qui furmontent la delicateffe des laines, \& la pureté de la foy. Nous tirons aurefte de toutes ces plantes des veftemens à nous couurir; voyons quelle eft leur nature, \& quelles qualitez on leur peutdonner.

On prend des plantes que la terie porte des 
linges deliez ou grofier, comme le cotton, le lin \& le chanvre: le cotton échauffe \& deffeche nos corps, le chanvre a des facultez qui ne leur font pas bien faifantes, le lin rafroidit, ramolit $\&$ humète\& il eft fi propreà nous veftir, que quelques anciens s'en habilloient, fuiuant le Poëte, dans la Ville, \& en la campagne.

Ridelis ventos boc munere tectus or imbres,

$V$ el fic in Tyria Syndone tutus eris.

Pour traitter maintenant des linges d'vne maniere methodique, propofons icy quelques obferuations.

La premiere, que les linges retiennent grandement ce qu'ils ont de vegetatif : c'eft pourquoy ils font fujets comme leur principe a la Lune, a u Soleil \& à l'eau, \& ils s'vniffent par la reffemblance aux fucs, qu'on efpraint des fruits \& des herbes, comme on voit par les marques des cerifes, des grenades \&c.

De là on connoilt pourquoy les linges éboiuent les tranfpirations de nos corps; car comme elles font ou oleagineufes ou falées, elles imbibent ces plantes mortes, comme les engrais, qui font compofez des mefmes fubftances, les entretenoient lors qu'elles viuoient : c'eft pourquoy les Romains qui n'auoient point de linge, fe lauoient fouuent dans leurs bains, pour mieux détacher ces matieres qui s'arreftent à la furface, fi le linge ne les reçoit.

La feconde eft, qu'on conpoift par le linge la conftitution d'vn chacun; car ceux quile faliffent promptement ont des humeurs oleagineufes \& grafles, dont la fuye ternit 12 blan: 
Des Habits.

cheur, elle difpofe mefme aux fiéures ardentes, elle eft la matiere des feux folets, qu'on a veu fur le menton \& fur la barbe; enfin elle produit ces animaux qui fourmillent foument fur les draps. La raifon de cela eft, parce qu'elle retient quelques veftiges de la vie, ayant paflé parmy leschairs : c'elt pourquoy ces veltiges ne donnent qu'vn eftre bas, à la façon d'vne lampe qui fume, dont on ne void paroiltre qu'vn foible rayon de clarté, \& voila le principe de la generation des rats dans les greniers, fi on met parmy les bleds des haillons imbus de nos tranfpirations.

Difons en de mefme deceux qui vfent grandement leur linge; car cela procede des exhalaifonsacres \& fortes, qui en feparent le tiflu, qui l'ouurent, \& qui le defilent: Ceux-là font ordinairement chagrins, ils ont leurs chairs dures \& feiches, vn temperament ardent, \& des humeurs atrabilaires, \& ils deuiennent fort malades lors qu'il fe fait vne compreffion de ces reftes dans linterieur.

La troifiéme nous enfeigne pourquoy la lexiue nettoye le linge; car l'afpreté des cendres en détache le fouffre, \& leur alcali vnit à foy les fels acides que nos chairs y ont répandus : ainf fi on diftile du linge imbu de la lexiue, il n'en fortira qu'vne matiere vifqueufe \& yluante; parce que la falée demeurera jointe à la portion alcalifee, dont les cendres font compofées.

Parmy les plantes qui deriuent des animaux, il n'y a proprement que les laines qui nous donnent des veltemens; pour voir maintenant leur 
nature, il nous faut éclaircir deux poincts : le premier, fi on peut ranger les laines parmy les plantes; \& le fecond, quel eft le principe qui leur donne l'accroiflement.

Ariftote nous deuelope le premicr : cet efprit merueilleux efgaleaux plantes, les cornes, les plumes, les poils \& les laines; il dit des premieres, qu'elles ont du rapportaux bois, \& il ne doute point que la nature vegetable ne foit auff bien aux fecondes qu'à toutes ces fleurs agreables qui efmaillent le bord des ruifleaux. En effet les laines ont vne racine que le microfcope fait voir, elles font fur les chairs \& fur les dépoüllles comme les herbes fur la terre, elles y font arroufées de mille ruffeaux, \& illes faut quelquefois couper afin qu'elles foient plus fecondes, comme on fauche les campagnes les plus fertiles, afin qu'elles fleuriffent mieux.

Ileft donc certain que les laines font au rang des plantes; mais parce que les eaux qui les arroufent, \& les terres qui les produifent font toutes chaudes \& allumées, elles leur donnent trois qualités qui font trop importantes pour les oublier : La premiere eft, que les laines font entortillées à caufe de leur fechereffe \& de leur chaleur, ainfi que Galien remarque des poils: C'eft pourquoy les veftemens qui en deriuent nous communiquent les mefmes qualités, \& ils nous preferuent contre le froid.

La feconde, que les laines font impures, \& que cette impureté fe communique à leurs habits : la raifon decela eft, parce qu'elles efboiuent l'́gout, \& le fuperflu des humeurs, de 
Des Habits.

forte qu'elles font femblables aux herbes qui fe nourrillent aux marais. De là vient aufi que ces reftes que les laines abforbent, \& qu'elles impriment aux draps, confiftent à vn fel piquant, \& à vn fouffre que les digeftions ont fait acre, qui eltant tous deux joints à nos chairs, \& s'infinuant dans nos pores, feruent de leuain à ces charbons qui prennent le nom du pays, \& qui procedent de ces exhalaifons ardentes, que la chaleur éguife de nouueau dans nos corps.

La troifreme qualité de nos laines confifte à la couleur qui leur eft naturelle; car nonobftant que nous les ayons rangées parmy les plantes, elles ne font pourtant jamais vertes. Pour montrer la raifon de cela, il faut remarquer que la couleur verte eft douce, temperée \& mediocre, qu'elle tient le milieu parmy les couleurs, \& qu'elle paroift fur les plantes, parce que leur digeftion reduit l'eau dans vn parfait temperament.

C'eft pourquoy lors que cette digeftion eft trop forte, les plantes perdent leur beau verd, \& prennent vin blanc, vn rouge, ou quelque teinture efleuée, qui marque l'excés dans les premieres qualités: cela eftant ainfi, on void que le verd ne fçauroit paroiftre fur les cheueux, ny fur les laines, à caufe de l'acrimonie de leurs rujets, \& de la chaleur de leurs matieres, qui les rend femblables à ces plantes bruflées par lardeur de la terre, ou par la force du Soleil: c'eft pourquoy elles font noires, ou bien elles jauniffent; \& elles reprefentent ce que la fecherefle nous fait couper. 


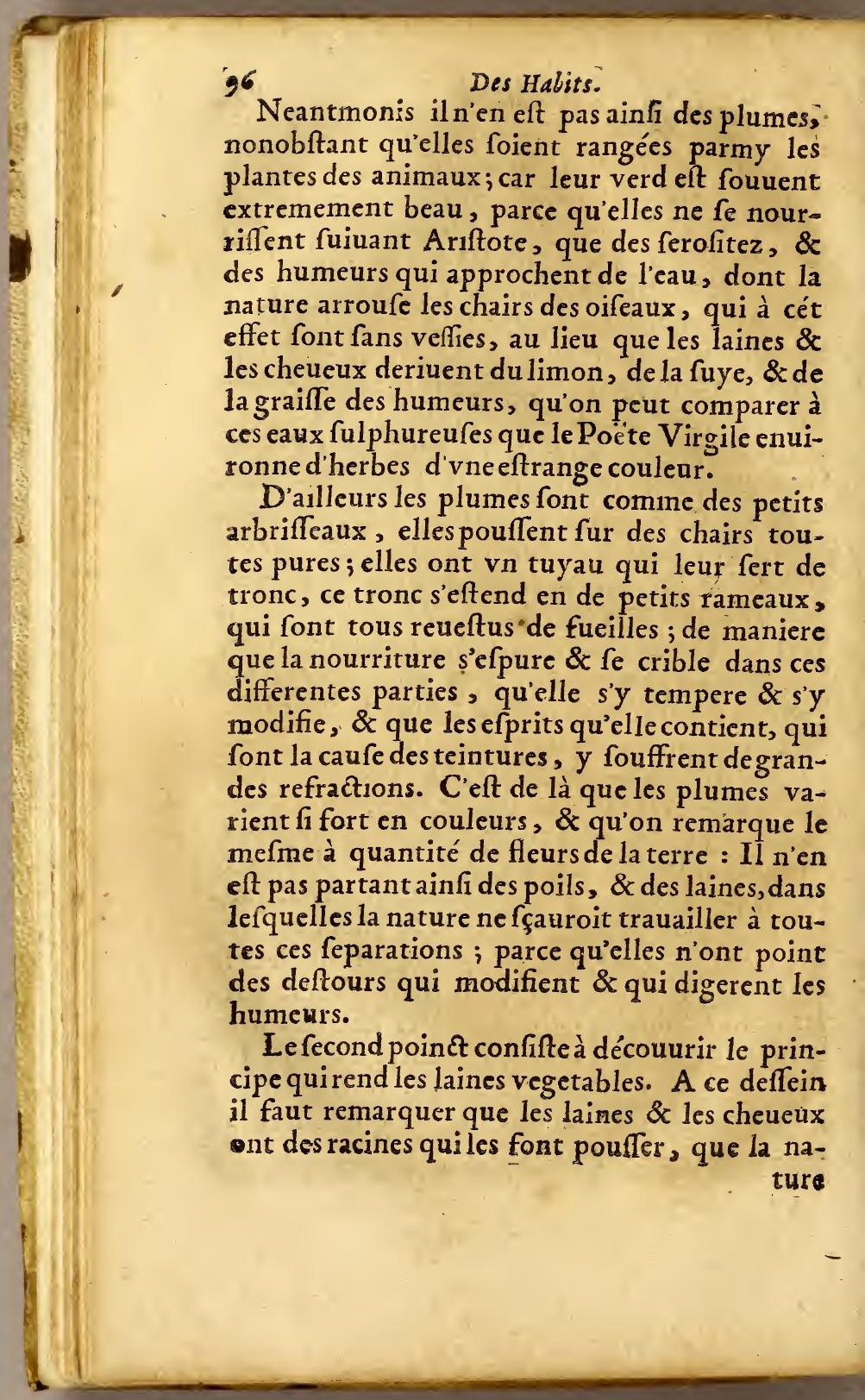


Des Habits.

ture a inferée dans les peaux, \& qu'elle a animées d'vn rayon de l'ame vegetãte. C'eft par elles que les petits agneaux naiflent auecleur laine, les oifeaux fouue nt auec leurs plumes, \& le reftedes beftesauec leurs poils, \& que la Medecine diuife les cheueux en connaturels \& en d'autres qui furuiennent. Or toutes ces racines attirent toûjours, elles preparent vn aliment, ainfique les plantes, quifait augmenter les lais nes, \& leur donne l'accroiffement. Voyons maintenant la qualité de cet aliment, \& fous quel genre on le doit mettre.

Il y a de l'apparence que cet aliment n'eft qu'vn fuc, que la chaleur naturelle des brebis tire des plantes qu'elles broutent, ce fuc renferme les efprits de ces vegetaux, eftant porté vers la furface, il fe metamorphofe en laine à caufe de la proportion, \& 11 fe change en des plantes qui ne font differentes des premieres qu'en confiftence $\&$ en couleur; jofemefme dire qu'elles font les mefmes, qui refufcitent, \& quife renouuellent fur la peau. Et certes fi les vies font immortelles, \& files formes ne perif: foient jamais, comme les plus fçauants ont enIeigné; fi tout fe fait par vn cercle ça-bas, \& par ce tour \& ce retour des tenebres à la lumie. re ; fi fuiuant Hippocrate c'eft le mefme de rejoindre \& de feparer, d'engendrer \& de corrom. pre; fi la veritable image des plantes apres tant defeparations, paroift de nouueau fur la cendre à la moindre chaleur du feu : pourquoy ne prefumera-t-on pas le méme du fuc vegetable que la cuite aura preparés, qui troumera la chair \& la 
98

Des Habits.

peau comme des terres animées, là oú il reprendra fon ancienne nature par vne femblable refurrection.

Et veritablement il faut que cela foit, puis que les laines prennent les qualitez des herbes, qu'elles changent fuiuant leurs efpeces, \& fuiuant la conftitution du pays; ainfi qu'on lit dans Martial.

Velleribusprimis Apulia, Parma $\int e c u n d i s$

Nobilis, Altinum tertua laudat ouis.

Auffiles plantes delicates produifent la toifon fubtile, \& elles luy communiquent les qualitez des riujeres \& des ruiffeaux.

On void de ce fondement que la foye n'eft atre chofe qu'vne planterefuf́citée, \& vin retour des parties fibreufes des fueilles dont on nouryit lesvers à foye, à cét effet elle eft jaune, oui elle eft verte, parce qu'elle reprend la couleur deplante, ou bien la teinture des parties interieures qui font aux meuriers; aufi cette herbe refufcitée a des proprietez excellentes, elle eft rafraichiflante \& cordiale, elle fert à l'érefipelle, \& à la fquinance, fi on employe vn de fes filets, auec lequel on aura eftranglé vn ferpent. Quion ne troure point eftrange au refte. que nous rangions la foye au rang des plantes; car l'obferuation de Doncan fait voir qu'elle a vneame vegetante : cét Auteur remarque qu'vn. filet de foye qui fermoit vne playe fur le fourcil d'vn bleflé, croifloit fi fort toutes les Lunes, qu'il le faloit couper à la maniere des cheueux, parce qu'sl prennoit fon accroiffement des os comme d'vne terre, que la chaleur naturelle 
Des Mafques.

échauffe ainfi qu'vn Soleil, \& que les ferofitez humectent ainfi qu'v ne pluye. C'eft de là qu'on a veu fleurir vn prunier fauuage fur la poitrine d'vn berger, \& qu'oria tiré des pois verds de l'oreille de quelques-vns.

\section{CHAPITRE X.}

\section{Des Mafques.}

$\mathrm{N}$ ne fçauroit aflez admirer cette demangaifon eftrange, qui porte depuis tant de fiecles les hommes à fe déguifer; quiinfpire les Barbares à jaunir, à découper, ou à preffer leurs nez \& leurs teftes; \& qui pouffe les perfonnes les plus galantes à cacher leur maintien fous des figures furprenantes, \& à le couurir de mafques hydeux. Certainement on ne pourroic jamais trouuer vne raifon affez folide, pour éclaircir d'où vient que les Metamorphofes nous plajfent fi fort, qu'il en a falu amufer l'antiquité la plus feuere;\& que nous aimons les men . fonges de nos vifages, aufí fouuent que ceuss de nos cours. 11 y a de l'apparéce quel'imagination contribuè à tout cela; \& qu'elle prend vn fi grand plaifr à la production des phantofmes, qu'elle a entretenu depuis long-temps les peuples, \& les nations les plus ciuiles à faire des mafques, ou à admirer leurs façons. Quoy qu'il en foit, pour écrire maintenant furcette mat ixe auec l'ordre, que nous auons ioujours fuiui, confiderons la caufe des mafques, leur

$$
\text { G ij }
$$


100

Des Mafques.

origine \& leur motif : \& voyons fi la Medecine nous pourra fournir quelques regles pour les mefnager.

Comme Mercure regit les hommes, ainfi que nous auons fait voir ailleurs, affeurement il les a portés à mafquer: en effet c'eft luy qui eft 1e Dieudes fourbes, quis'elt toûjours déguifé pour feruir Iupiter dans fesamours, \& qui eft 1'Auteur des fables \& des menfonges; \& vn mafque eft juftement définy dans Seneque, cùm pra fe fert aliquid, quod non eft. Aufi les Dieux ne furent deliures de loppreifion, \& de l'infulte des Geans, que lors que Mercure les euft reueftus de figures horribles, \& tous les Aftrologies font d'accord qu'il donne aux mafques cette éloquence concertée, pour feduire, \& pour piper agreablement.

On infere dece difcours, que comme Mercure deuien i mauuais par la contagion des planettes infortunées, il caufe anfi bien du defordre, fuiuant la complexion des mafques qui ont $d u$ rapport auec elles; car fi ces mafques font melancoliques \& Saturniens, Mercure choifit par-: my-eux les jaloux, les efpions, les poltrons, \& les traiftres, il rend ces perfonnes folitaires, hydenfes, ennemies des femmes \& des enfans, il les fait marcher fans lumiere auec des armes. dangereufes pendant la nuit: enfin il leur infpire des defferns, qui n'ont pour but que de nuire à quelqu'vn. Que fi au contraire ceux quile maiquent font reyis de Mars, c'eft à dire, s'ils font échauffezde la bile : c'eft alors que Mercureles rend entreprenans, tumultuaires \& hax. 


\section{Des Mafques.}

dis, qui les fait deuenir infolens \& fuperbes, \& qui les pouffe à paroiltre liberaux \& pompeux, afin d'éblouïrl'e!prit foible de quelque femme; Par la raifon que nous auons obferuée que Venus aime Mars, \& que Mars s'accommode à fes influences; de forte que les mafques qui luy font foûmis, four fe mieux infinuer auec elle, fe courent fouvent, \& fe parent de fes atours.

L'origine des mafques égale prefque celle de I'vniuers; car les hommes fe font pleus toûjours. aux reprefentations comiques : foit parce que la plufpart ont aimé à publier les vices, \& à décrier leurs femblables, ou que quelques-vns ont pris plaifir à faire valoir la vertu. Or tous ceux-là prefque s'habilloient en Satyres, \& $x$ ils couuroièt leur vifage d'vin mafque, pour parler auec liberté. On a long-temps obferué ce maintien dans les Comedies de la Grece, \& de l'ancienne Rome, ainfi qu'on lit dans le Poëte.

Nil illi larua, aut tragicis opus effe cotburnis.

De façon que les Acteurs eftoient obligez d'ofter leurs mafques deuant les fpectateurs quine paroiffoient pas fatisfaits; mais il faut conliderer encore l'origine des mafques d'vne maniere pluséloignée : car les peuples de la campagne, apres auoir ramaffé leurs fruits, \& fur tout ayant coupé leurs raifins, \& fait leurs vendanges, fe diuertiffoient à compofer des chanfons ruftiques, \& ils fe couuroient de mafques, ou ils barbouilloient leurs vifages de moût, \& de boü̈ pour les chanter. Les mafques dont ils fe feruoient eftoient faits de bois ou d'efcórfes.

$V t$ tragicus cantor lignotegit ora callato.

$G$ iij 
102

Ou bien de fueilles de figuier, \& de celles du Bardana, appellée perfonata à caufe des mafques, parce qu'on l'employoit fouuent à mafquer. Et voila la maniere auec laquelle les anciens folemnifoient les Bacchanales, \& ils honoroient le Soleil fous le nom de Bacchus, comme eftant le pere desfruits; voila la fource de leurs mots piquants \& de leurs fatyres, qui eftoient des effets de la gayeté que le vin \& l'abondance infpiroient à lame, \& qui ont du rapport aux caffades du carnaual : enfin voila ce quia donné jour au fçauant Cafaubon d'expliquerces figures, quireprefentent vn chariot conduit par vn mafque, qui void verferduvin, \& qui eft enuironné de Satyres : à peu pres fuiuant le Poëte, quienfeigne qu'alors les mafques fe failoient porter.

-....- Et plaufris vexiffe Poëmata Thefpis,

Qua canerent, agerentque peruncti facibus ora.

Les motifs que les hommes fe propofoient pour faire leurs mafques font fort differens; car ils eftoient portés à cela par la religion, par la politique, par l'amour, par la fafcination, par Iacrainte, \& pard'autres fins que nous expliquerons en particulier.

La fafcination eftoit grandement apprehendée, \& tout le monde f̧̧ait que les anciens ont éuité certaines perfonnes, parce qu'ils croyoient que leurs regards feichoient les hommes, fletriffoient les herbes, \& amaigriffoient les agneax.

Nefcio quis teneros oculus mibi fafcinat agnos.

C'eft pourquoy pour éuiter ces maux, ilsopporoient à leur veué, ce qu'il y auoic de fale, 


\section{Des Mafques.}

de defagreable, d'extraordinaire \& de rebutant, qu'ils appelloient res turpes, parce quainfi ils pouuoient deftourner les infuences malfaifantes, qui procedoient des yeux \& de leurs a peets. De là on void la raifon pourquoy les triomphateurs voiloient leurs vifages, parce qu'ils apprehendoient le regard de quelque enuieux.

C'eft encore là le principe de l'eftime que le peuple auoit aucrefois pour la peau du front de la hiene, dont la vertuarreftoit la fafcination fi on faifoit vn mafque de cette defpouille. Enfin on connoit de tout cecy pourquoy les Marfeillois mafquoient fi fouvent, parce qu'ils auoient appris dans la Grece que certains regards eftoient dangereux: c'eft pourquoy ils employoient tout ce qui eftoit furprennant \& fans forme, qu'ils comprennoient fous les noms de $\beta$ «re, $\mu \alpha x \varepsilon \lambda r_{\text {, }}$ que Saumaife fur Tertullien dit auoir donné le nom aux mafques, dont la figure eft cftrange, \& au rang de ces chofes que Varron a nommées resturpes, côme nous auons remarquécy-deffus.

La peur obligeoit les Dames Romaines à fe feruir des mafques, pour efpouuenter les enfans lorfqu'elles eft oiêt im portunées de leurs pleurs. C'eft ce qui a fait dire à Plutarque au Liure de 1'Exil, qu'il les faut donner à manier à ces petits, afin qu'ils fe raffeurent, qu'ils s'en jouent, \& qu'ils n'en foient pas effarés. Et certainement cela eft fi veritable, qu'vne mere chaffoit fon enfant de la chambre, en luy prefentant vin mafque, de peur qu'il ne découurit les libertís fecrettes dont elle fauorifoit on courtifan; \& que le peuple Romain effrayoit en public la jeunerfe, G iiij 
304

Des Masques.

en faifant paroiftre des mafques, qui auoiene la gueule ouuerte, quimontroient les dents, \& tiroient la langue, \& dont la figure reprefentoit vne Gorgone, vne femme vieille, ou quelque animal formidable. Ces mafques auoient des noms eftranges : on les entendoit par Iamias, Grumias, Sillas, Brudalichas, Mormolichia, Oxidontas, ou bien fous le nom de Manducus:c'eft pourquoy les nourrices prononçoient ces mots pour en menacer leurs petits, comme les noftres parlent du loup, du renard, des cornes, des vieilles gens.

La politique a mis pareillement en vfage les mafques, vn Roy d'Ecofle s'en feruoit de Iumíneux pour épouuenter fes fujets : aux Antilles 1e peuple à certaine fefte paroift la nuit tout éclatant des yeux de coccuye, pour imprimer la terreuraux eltrangers: L'Empereur d'Ethiopie nefe mötreen publicquecaché fous vn mafque, \& dans la Guinée les Roys jugent, \& les Aduocats plaident mafquez, pour parler librement; \& dire fans contrainte ce qui peut jultifier leurs parties.

La religion a fait valoir les mafques; car les Grecs, \& apreseux les Romains ont creu qu il en faloit honorer les phantomes, qui paroiflent fi fouvent dans les deferts, dans les maifons, \& aux fepulchres: C'eft pourquoy Apulée a dit au liure du demon de Socrate; qui verò propter adaerfa vita merita, nullis bonis Sedibus, incerta vagaticne, feu quodam exilio puniuntur; inane terriculamentum bonus hominilus, noxium autem malss, id genus plerigus Laruas perbibent, d'ou fans doute 
le nom de Larua a pris origine, larea à laribus, \& d'où on peut tirer l'intelligence de Plaute.

Laruatus AEdelpol bominem mifcrum, mendicum queritat.

C'eft pour ces phantofmes que les Romains \& les Grecs auoient inftitué les Feftes, Feralia, silicesnia, ou fuiuant Iamblique, on faifoit des expiations auec des mafques, en forme de fquelet; comme on remarque dans Petrone, \& c'eft pour eux qu'il faut entendre encore Hippocrate au Liure des fonges, où il ordonne d'appaifer les heros, aprés auoir veu pendant le fommeil des figures horribles, \& d'vne couleur appron chante aux mafques: Ie ne f̧̧ay fi pour abjurer ces phantormes, les Egyptiens couuroient des mafques le vifage de leurs mumies, \& fic'eft d eux qu'ilfaut entendre le paffage de Pline, au 22. de fon Hiftoire. Equidem ea forma gratia ritu〕queperpetui in corporibus fuis aliquas externarum gentium, $v$ ti berbis quibufdam aduerto animum, illiniunt certe alic alÿs faciem; in populis Barbarorum famine, mare $q u$ ue etiam apud Dacos \& Sarmatas corpora fus infcribunt ; Britannorum coniuges toto corpore illits, quibufdam in jacris, nuda incedunt, eAtbiopum coloremimitantes

L'amour a fait rechercher les mafques autrefois auff bien qu'aujourd huy : C'eft pourquoy. Plutarque remarque qu'A lcibiade eftant amoureux, laifla derober fa vaiffelle dans vn banquet, par vn mafque dont il eftoit aimé ardemment, c'eft à caufe de cela d'ailleurs qu'on void furdes pierres precieufes, fur les medailles, \& aux anneaux des Cupidons deguifez en des diffe. 


\section{6}

Des Mafques:

rentes manieres, fur tout en Satyres couronne $\vec{z}$ de pampres, \& des raifins : Et que nos ancierines Dames auoient reglé aux mafques, par des preceptes quion lit encore, la maniére de faire l'amour.

Enfin les malques ont feruy dechiffresaux anciens, ils en grauoient d'ænigmatiques fur leurs anneaux, \& fur leurs cachets, ils en imprimoient fur leurs boucliers en forme de vieilles $\&$ de furies, ils en mettoient en grand nombre fur les murailles de ieurs maifons, qui reprefentoient des vifages de jeunes hommes, des-vieillards, ou desfemmes ridées, fuiuant les diuers endroits par où on les confideroit.

Et voila toutes les obferuations que nous auons pû faire touchant la fin \& l'origine des mafques: voyons maintenant ce que la Medecine nous pourra fournir la-deffus. Et veritablement elle doit confiderer les mafques, puis qu'on lit dans le Liure des alimens, illitus, vnctio, nuditas, integumentum totius or partis, c'eft à dire, qu'il faut confiderer l'onction, la nudité, \& les enuelopes des parties, au rang defquelles on comprend les mafques, \& celles de tout le corps en general. Pour faire voir donc, fuiuant Hippocrate, l'effet queles mafques peuuent caufer,

Il faut remarquer en premier lieu, que Dieu a fait briller fur le front vne certaine grace, \& qu'il luy a imprimé des traits, qui rendent Thomme aimable, \& qui le font refpecter jufques parmy les animaux. C'eft pourquoy il a voulu que cette partie fuft à découvert, \& qu'on ne la tinst point cachée; mais que ce fust cette 


\section{Des Mafques:}

feneltre ouuerte, que Nomus auoit fouhaitée pour penetrer dans l'intericur.

Il faut remarquer en fecond lieu, que les'vapeurs des parties baffes montent ordinairement au vifage, que ce membre a beaucoup d'efprits, c'eft pourquoy il eft à découuert pendant que nous couurons les autres, qu'il eft vn racourci \& vn abregé des parties qui nous compofent, \& qu'il a vne liaifon eftroite auec le cœur, \& auec ce qu'il y a de plus noble dans noftre corps.

11 faut remarquer en troifiéme lieu, que le vifage a vne peau deliée, \& fort tranfparente, que fa delicatefle eft plus grande aux femmes, qui la poliffent encore mieux, que c'eft à caufe de cette tenuité, que les paffions y impriment leurs caracteres, que les poulmons \& le foy y font refléchir leur rougeur, qu'on y void des changemens fi prompts, \& que le froid, le chaud \& l'humide $y$ font penetrer leurs vertus jufques dans le fond des entrailles.

On void de tout cela les mauuais effets que nous poutons receuoir des mafques, puis qu'ils couurent ce qui doit eftre découuert, qu'ils efchauffent ce quirefifte à la froidure, qu'ils ajoûtent à vne peau tranfparente \& fubtile,vn corps qui eft folide \& pefant; qu'ils renferment les vapeurs, dont les parties fe dechargent, \& qu'ils fouillent aintice qui doit auoir vne tresgrande pureté. Et voila la raifon de ces maux de tefte, de ces rougeurs, \& de ces enleueures, qui faiffifent ceux quimafquent fourent, voila encore la caufe de la fureur de ce mafque, qui deuinft fol fubitement, \& quibattit fa maiftref: 
308

Des Mafques.

le dans vne affemblée publique, parce que l'enuelope de fon vifage auoit allumé fes efprits \& fon fang: Voila encore la caufe des fuffocations de matrice, quiaffligent les femmes marquées, par la connexiondu vifage, \& par les ramas que les mafques font des vapeurs : Enfin voila ce qui rend les mafques effoufflés, foit par la chaleur du vifage, dont l'influence fe porte aux poulmons, foit que la voix eft fi fort contrainte, qu'on a creu que le nom de perfona deriuoit de perfonando, à caufe de l'alteration qu'on remarque dans la parole, qui bleffe par confequent les organes qui feruent à fa production.

\section{CHAPITRE XI.}

Des Baftons.

$\mathrm{N}$ ne fçauroit mieux combattre l'erreur qui s'eft gliffée bien auant dans le monde, qu'auec vn balton : fçauoir, qu'on doit attendre la décrepitude pourfe fouftenir fur vn bafton, \& que d'en agir autrement c'elt vne veritable habitude. Detruifons ce paradoxe par les principes d Hippocrate, \& pourdiuertir le Lecteur, eftendons-nous vn peu au long furcefuject; marquons-y auec vn bafton les ænigmes de quelques vieux. Auteurs, \& obferuons-y les maximes que la Medecine a enfeignées; joignons-y les couftumes des peuples quife font feruy du bafton, ne fuiuons pas fur cette matiere vne regle particuliere, mais traittons la à baftons rom- 
Des Baftons.

pus; apres tout, imitons les voyageurs, dans le chemin que nous allons faire, qui employent fouuent le bafton pour s'empefcher d'eftre laffés.

On a toujours appliqué le bafton à diuers vfages; les perfonnes qualifiées portoient ordinairement vn bafton dans Athenes, pour monftrer leur eleuation. C'eft pourquoy Demoltenes a. fort bien obferué trois chofes qui donnoient de lenuie, \& qui faifoient murmurer le public, la. démarche graue, la voix efleuée, \& vn bafton entre les mains : fans doute parce que le bafton eft vne marque dominante, comime Cafaubon monftre fur Athenée; \& ainfi qu'on lit dans Plutarque aux vies de Licurge, \& de Nicias. C'eft à ce deflein aufí qu'on honoroit les Senateurs d'vn bafton d'yuoire dars la vieille Rome, qu'on obligeoit lesLicteurs à porter des verges deuanteux, \& qu'on donnoit vn bafton 2 ceux quideuoient commander aux armées.

Nonobftant tout cela, neantmoins quelques Philofophes ont rendu le bafton l'inftrument de leurs fantaifies. On f̧̧ait que L $x$ lius \& Scipion s'en diuertiffoient à la maniere des enfans. qu'Alcibiade furprit ainfi le fameux Socrate, \& qu'Horace a dit de quelques-vns.

eAdificarecajas, ploftello adiangere mures.

Ludere par impar, equitare in arundine longas

si quem delectet barbatum, amentia verfer.

Les gens de debauche abufoient du bafton auffibien que les Philofophes, elles n'alloiene jamais au cabaret qu'auec vn bafton bruflé par lebout; parceque fuiuant Scaliger. les portes 
S10

Des Baftons.

eftoient fi efleuées, que la jeuneffen'en pouuoit pas noircir le frontif pice auec la main, de forte qu'elle traçoit auec cebafton, ce que le caprice luy fuggeroit. On explique ainfi les Vers du Poëtc Catulle.

-.-.- Namque totius vrbis

Frontem taberne Scipionibus fribam.

Les Cynicques prenoient le bafton pour fai-

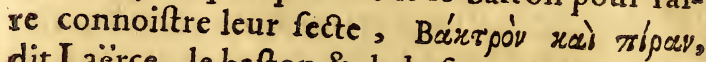
dit Laërce, le bafton \& la beface tenoient lieu de leurs armoiries. C'eft pourquoy on lit dans A pulée, Diogeni \& Aniffenipera do Baculus, quod Regibus Diadema; quod Imperatoribus Paludamentum, quod Pontificibus Galerum, quod Litwus Auguribus: Et parce que fuiuant $\mathrm{L}$ ucien, les Cynicques difoient qu'ils imitoient Hercule auec leur bafton. le mefme Apulée ajoufte : similizer aduerfus iracundiam, libidinem, ceteraque animi monftra, Crater Hercules fuit, qui malitiam perdomuit feminudus of claua infignis.

Les Bergers portoient le bafton pour combatre les beftes farouches, pour grimper les lieux efcarpez, pour faire des jeux, \& pour montrer leur gratitude, c'eft ce qu'on lit dans les Bucoliques. At tu fume pedum, quod, me cùm seperogaret,

Non tulit Antigenes, of erat tum dignus amari,

Formo fum paribus nodis atque are Menalca.

Ils le courboient au refte en forme de croce; de maniere peut-eftre que $c^{\prime} e f t$ de là que $\mathrm{l}^{\prime} \mathrm{Eg}$ life a tiré les croces, pour les donner à ceux, qui font nos vetitables Pafteurs; fi nous n'aimons mieux les faire venir du bafton recourbé, aues lequel les Augures indiquoient le ciel aux Gentils, 


\section{Des Baftons:}

puis que Meffieurs les Prelats qui les portent, nous feruent de guides vers ce lieu bien-heureux, \& nous le montrent par leurs difcours, \& par leurs exemples.

Les Poëtes recitoient leurs Pömes en tenant $v \mathbf{n}$ bafton de laurier, comme Paufanias dit d Hefrode, parce que le laurier eft confacré à A pollon, que c'eft ce Dieu qui infpire dans la Poëfre, qui rend ceux quila cultiuent des Prophetes \& des Deuins, aufquels il eft important d'auoir fon fymbole, \& fa marque, auffi les Poëtes eftoient

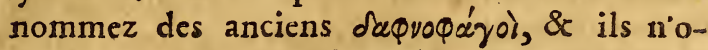
foient paroiftre aux Comedies fans vn bafton, ou bien vn rameau de laurier : c'eft pourquoy Suetone exagerant la confufion que Neron receut fur le theatre, auance ces mots : In quodam. tragico actu, cum elapfum baculum citò refumpfiffet. Parce que cet Empereur en recitant laiffa tomber vn femblable bafton de fes mains.

Il eft partant veritable que les anciens appliquoient le bafton de laurier à d'autres vfages; car ils croyoient par là de refifter aux fafcinations, \& de preuenir les dangers \& les maladies: de la vient qu'ils portoient cebaftonen public s'ils craig noiêt, ou s'ils auoient éuité le poifon \& les traiftres, \& s'ils auoient preueu leurs deffeins; parce que le bois de laurier eft aromatique \& folaire, qu'il forifie le cœur, \& qu'il attenuë fi fort lefprit, fuiuant quelque fuperfitieux, qu'il luy defcouure l'aduenir, \& les chofes les plus fecretes.

Les ruftiques n'alloient iamais fans vn ba: Iton à la campagne 
Baculumque tenens agrefte finiftra.

$\mathrm{Sa}$ figure eftoit recourbée pour marquer leur abbaillement, à la difference des baftons des Nobles quieftoient tout droits. Les arbres qui ont la vertu de tuer les ferpens, en donnoient la matiere; c'eft d'eux que les Egyptiens tiroient leurs baftons, quils confacroient apres à Mercure entrelaffez de deux dragons.

Les \$aints habitans du defert rendoient leurs baftons miraculeux, comme on efcrit du bafton d'Helifée, leur forme neantmoins eftoit grandement differente: les Coptites, par exemple. en auoient qui reprefentoien vn marteau, non feulement pour defigner la liaifon des parties du monde, les trois dimenfions, \& les quatre elemens que l'amour tient toûjours vnis; mais encore pour voir inceflamment la figure de la Croix, que les Hebreux, qui auoient vne connoiffance fecrette du myftere de la Paffion, montrerent aux Egyptiens fous le carabtere du Tau, comme vn figne tres-falutaire: de maniereque leur A pis en eftoit marqué, \& qu'on le voyoit ordinairement aux baftons des anciens Peres de l'Egypte qui fçauoient l'origine; \& l'excellence de ce fymbole.

Les voyageurs Grecsfaifoient compofer leurs baftons à la façon d'vnemaflue, pour fecouèr les arbres chargés de fruits, pour fe deffendre ou pour attaquer : apparẽment la maffuëd'Hercule eftoit vn bafton de cette figure, \& on peut croire que c'eft fur fon modele qu'on a tourné la pomme de nos baftons. A ce propos les Hollandois remarquent que les Sauuages du Capverd 


\section{Des Baftons:}

verd s'arment ordinairement de baftons efpio neux, qu'ils coupent des arbres fans fueilles mais qui font heriffés d'efpines, \& dont les branches fe terminent en des maffuës, qui feruent d'appuy \& de defenfeà ces Barbares.

Les voyageurs portoient encore des baftons creux pour y cacher des armes, \& pour y mettre du vin ou de l'eau : c'eft ainfi que les Brafiliens employent leurs grands rofeaux lors qu'ils voyagent, \& c'eft à cefens qu'il faut appliques les vers $d$ Ennodius.

Vtimurinclufo, per fraudes, enfe bacillo, Mors ligni tunicis quam bene suta latet, Subfidium portas, quo cunctis terror baberis, Pacificum eft nobis quod necat obfequium.

Ils en auoient encore qui cachoient des chiffres, \&des lettres enigmatiques, [Vigenere, ] \& dont la matiere combuftible fuppleoit au defaut du fufil : les Veftales allumoient leur feu facré auec des baftons de cette maniere, lors qu'elles 1e trouuoient efteint.

Cependant, puis que sous fommes fur les baftons des voyageurs, il ne fera pas hors de propos d'examiner s'il eft vray ce que quelquesvns nous auancent, qu'on peut choifir des baftons qui ont la faculté de delaffer, \& d'amoindrir la.peine qu'on reflent pendant qu'on chemine. Pour terminer cette queftion auec methode, il faut fuppofer que la laffitude deriủe de diuers principes: En premier lieu, de la diffipation des efprits, que le long trauail a produite: En fecond lieu, de la continuelle agitation des fibres, des tendons \& des mufcles, \& de la con 
ist

\section{Des Baftons.}

tufion des joinctures, qui fe froiffent \& fe meurtriffent par vn mouuement trop long. Cela eftant ainfi,

Difons hardiment quion peut trouuer des baftons qui delaffent : Premierement quelquesvns par des projections cordiales, peuuent efueiller \& fortifier les efprits, ainfi que Garcias remarque du'bois Aromatique des Malabares. D'ailleurs il y a des baftons qui refpandent des vapeurs rafraichiffantes \& humides, propresà adoucir à la façon du laiet, \& à ramolir ce qui eft endurci par la laflitude. Quelques-vns merme euaporent vre qualité ballamique, quidonne à certaines herbes la vertu de foulager les voyageurs, sils portent leurs racines fufpandues firr la poictrine; enfin d'autres pouffent je ne fçay quoy d'affoupiflant, qui appaife la douleur, \& ce fentiment incommode de la contufion \& de la fatigue : c'eft ainf, fuiuant quelques vns, que le tabac delafle, l'eau de Iunipara dans les Indes, \&c.

Les Romains difpenfoient en donnant vn bafton, les Gladiateuts de leur exercice; c'eft fur cela qu'on doit entendre, $r u d e m$ accipere, $\sigma$ rude donari, \& qu'il faut expliquer l'allufion du Poëte Horace.

spectatam fatis, donatum me rude quaris,

Macenas iterùm me antiquo includere circo.

Ie fçay que Lipfe neantmoins conçoit autrement ce bafton; car il veut que ce rudis ait eu la figure de nos efpées pour exercer les Gladiateurs nouices, ou bien celle de nos baftons pour feparer les ardens \& les efchauffez, ou pour ani-. 
mer les poltrons, \& pour battre les laches dans la mellée.

Les Bacchantes fouftenoient vn bafton de ferule, qui auoit vn fer au bout tout entrelaffé de fueilles de lierre: C'eftoit, dit Cafaubon dans fon traitté de la Satyre, pour éuiter les bleffures, \& le tumulte qui fe foufleue quelquefois parmy ceux que Bacchus infpire, \& qui font porfedés du vin.

Les Indiens font des baftons, dont les par? ties feparées fe choquent, \& fe heurtent à la façón de deux animaux irrités, elles ont vne faculté proportionnée à celle des diuers poles qu'on void dans l'aimant, de maniere qu'il eft impolfible de les vnir : C'eft pourquoy elles ont feruy aux Magiciens à faire paroiftre autrefois des ferpens qui fe battent.

Les Medecins tenoient anciennement deus fortes de baftons; car les vns eftoient furt polis \&e lesautres tout plains de neuds : ceux-cy marquoiert les grandes dificultés qui fe rencontrent dans la Medecine practique; \& ceux-là faifoient voir l'empire que les Medecins ont fur 1 a mort, 3 monftroient que res perfonne, eftoient les veritables fouftiens de la vie.

Lesconuiés fe feruoient d'vn bufton de Mir' the pour battre la table en cadence aprés le repas, [Saumaise in lil. de Pallio] lors qu'il n'y auoit point d'inftrument : c'elt pourquoy ils y joignoient leurs chanfons \& leurs voix \& tachoiet.t à fe diuertir ainfi parmy eux. Les Sacrificateurs portoient les mefmes baltons ; maisils conceuoient vn mauuais prefa: H ij 
(16

Des Baftons:

ges'ils les laiffoient couler de leurs mains dans Ie Sacrifice, \& deuant le peuple.

Les vieillards s'appuyent du bafton pour foutenir leurs corps qui tremblent; il eft queftion s'ils s'en doiuent feruir a bonne heure, ainfi que nous auons propolé cy-deffus.

Il faut dire pour vuider cette dificulté, que les petits corps n'ont pas befoin fi fubitement du bafton; mais quil eft neceflaire que les perfonnes âgées, dont la taille eft auantageufe, s'y foufticnnent fans differer. Pour faire voir cela, il n'y a qu'à confiderer l'A phorifme du grand Hippocrate, quiveut que la grandeur fort inu. tile \& onereufe aux vieillards, qu'elle les faffe chanceler, \& les rende fujects aux cheuttes, \& qu'illeur foit par ainfi effentiel qu'ils s'appuyēt fur vn bafton. Et certainement ce fecours a paruimportant durant tous les fiécles; car les anciensfaifoient prefent à leurs enfans de leur baAton, rur la fin de leur vie, pour leur tefmoigner le bien qu'ils en auoient receu, \& qu'eux mefmesen deuoient attendre. Et Hefiode pour authorifer cette verité, apppelloit l'homme.

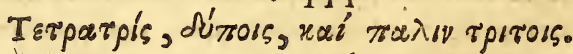
Quadrupes, bipes, orurjum tripes.

Ce que le $S$ phinx a reduit en wigme, en propofant vnanimal, qui marche le matin à quatre picds, à deux à midy, \& à trois fur le foir. Les Aftrologues ayant confideré cela, \& que les vicillards d'ailleurs eftoient fort difpofés à tomber fans le bafton, fe font appliqués à compofer des baftons fous certaines conftellations, qui geuuent empefcher les cheutes de ces perfon- 
ines affoiblies, à la manier e du bafton queTiretias receut de la Déefle Minerue, de qui le Poète a dit,

\section{-....- Baculum dat deinde porentem,}

Tirefla magni, qui quosdam Pallada nudam

\section{$V i d i t$......-}

Suetusinoffenfos, baculoduce, tendere greffus."

Ces baftons font de coudrai, dont on couppe fort bas les branches, lors que le Soleil entre dans l'Aries, s'il nous faut ajoufter foy à l'Agneau, à la façon de ceux qu'on taille rous le ligned'Aquarius, pour découurir les eaux cachées, \& des autres qu'on tire du frefne, pour arrefter l'hxmorragie, lors que le Soleil joint à la Lune, fetrouue auec le Belier. C'eft de cette maniere peut-eftre que les Egyptiensfaifoient leurs baftons merueilleux contre les infectes; que le Berger d'Agripa gardoit fon troupeau, laiflant feulement ion baiton, \& que les Platoniciens ont dit, qu'il y auoit certaines matieres qui attiroient, \& qui ramaffoient les plus belles vertus des Aftres, contre les maladies \& les dangers.

\section{CHAPITRE XII.}

\section{Des Caloties.}

T A façon de nos calottes n'eft pas fi moderne, 1 puis que les Romains en faifoient de flet? ou dedrap.

Iritus pilea Jute de lacernis.

H iij 


\section{8}

Des Calottes?

Qu'vn Auteur a dit delles, Capita calceatas \& que les Garamantes fe feruoient de la moitié d'vn œuf d'Auftruche pour fe couurir à leur defaut. Il y a mefme de lapparence que les chapeaux des anciens leur eftorent femblables, \& que le nom Galerus ne deriue que de $\tau \tilde{\eta} s$ yeñ̌s, ceft à dire des belettes, dont fuiuant Voffius, on adjuftoit ainfi les peaux. Neantmoins la tradition nous apprend, qu'il n'y a pas quatre vingts ans que les calottes font en vage dans la Prouince; ce qui a fait lou pçonner à quelquesvns qu'elles eftoient onereufes \& inutiles, puis qu'on les auoit negligées depuis long-temps. Examinons les raifons de ceux-cy; mas premierement celles des perfonnes quiles autorifent, \& trouluons vin temperament qui ferue de regle, \& qui acheue cette differtation.

En premier lieu, il eft certain, ainfi que nous venqns d'écrire, que les anciens reueftoient leurs teftes de peaux à la maniere de nos calottes, comme on remarque par les medailles \& par la ftatu $\ddot{d u}$ grand Hippocrate, par le titre dont quelques Autheurs ont qualifié l'ancienne Rome.

\section{Permittis puto Roma pileata.}

Et parce que Piine, Plutarque \& Salufte, or: donnerent de falu $r$ les perfonnes de marque, en tirant de la tefte les calcttes \& les bonnets: il bien qu'on peut perfuad $\mathbf{r}$ par là l'vfage des caloites, apres le temps, les ficcles, \& lis Dieuxqui prefident à la fanté.

En fecond lieu, n'eft-il pas veritable que nos teftes font foument trop couuertes, que 
leur delicateffe les expofe au changement de l'air, que le froid leur eft ennemy, quele ferain eft dangereux en diuers endroits, \& par confequent qu'il eft neceffaire d'employerl les calottes pour les munir contre ce qui les menace au dehors? En effet c'eft là le veritable moyen quiles peut preferuer desfluxions qui nous importunent; car comme il fe fait vne continuelle diftillation dans nos corps, \& que le cerueau condenfe les vapeurs qui montent, il eft afleuré que la froideur de l'ạir augmẽte cette compreffion, \& qu'elle fait les diltillations plus frequentes, fi les calottes n'empéchent cette qualité malfaifante, \& fi elles n'efloignent les impreffions decet element. Mais d'ailleurs ne faut-il pas que le culte Diuin, que la ciuilité $\&$ la bien-fceance nous faffent foument découurir au froid, auvent, \& aux lieux percés \& humides? Or les delicats, les infirmes, les chautes \& les conualefcens publient auec éloge l'auantage qu'ils reçoiuent alor's descalottes, fuiuant les vers de Pö̈te Ouide.

Arguat \& macies animum, nec turpe putaris

pileolum nitidis impofuiffe comis.

Auff la Medecine adjoufte de remplir leur entredeux de poudres odoriferentes \& cephaliques, lors qu'il eft neceflaire de fortifier la memoire, d'augmenter la chaleur, de conferuer les efprits, \& de reftablir la fanté.

Cependant voicy des raifons bien folides qui deftruifent les precedentes. Card'ou vientque l'vfagedes calottes eft fi moderne parmy nous? Quoy! Le climat auroit-il changé depuis foi- 
is Des Calottes:

xante ans, la conftitution de nos corps feroit. elle fi differente, n'y auoit-il pas à l'autre fiecle des hommes tranf pirables comme aujourd'huy, le monde eftoit-il moins expofé à l'air, \& ce qui eft de plus remarquable, n'y auoit-il pas d'hyuers aufi rigoureux, \& des faifons également inconftantes ?

Adjouftons encores à ces raifon's ce que nous fçauons des Italiens, \& ce que nous auons leu dans Platon, dans Plutarque, \& dans Herodote. Les peuples d'Italie laiffent la tefte des petits enfans fans bonnet, quoy qu'elle fojt encore fort tendre. Heredote remarque que les cranes des Egyptiens furent trouuez apres la bataille durs \& folides : Ceux des Perfes au contraire friables \& fort tenus, parce qu'ils fe couvroient de calottes, \& que les Egyptiens alloient toujours à decouuert. Plutarque obferue ainfi ces fameux capitaines, Annibal \& Mafiniffa, nonobftant la neige, les montagnes \& les marais : Et Platon commande à fes Citoyens de ne couurir jamais la tefte \& les pieds : Varron affeurant en fuite de ce grand homme, quil ne fut ordonné de fedécouurirdeuant les Dieux \& les Magifrats, que pour rafroidir lecerueau, \& 1 accoultumer aux diuers changemens du temps. Et certes, sil elt vray, dans Hippocrate, que cette partie foit vne ventoufe, \& qu'elle attire eftant échauffée, les exhalaifons qui font au deflous, leschapeaux joints aux calottes peuuent augmenter fa chaleur, \& fublimer ces euaporations ardentes, qui font la matiere des feux folets, dont Faber a veu briller les 


\section{Des Calottes:}

cheueux d'vne fille, \& que Virgile nous fait admirer dans fes Vers.

\section{Ecce leuis fummo de vertice vifus Iiili}

Fundere lumen apex. -.....

Auffi c'eft ce qui oblige les habitâs de Borneo; de faire aller leurs femmes fans cheueux, fans bonnets, \& fans crefpe, crainte de n'échauffer leur ceruelle, dont le feu infpire à ce fexe des eftranges emportemens.

Et voila le fondement de ceux qui ne f̧̧auroient fouffrir les calottes, qui balancent ce que nous auons dit cy-deffus. C'eft à nous maintenant à decider la queftion, \&à declarer ce qui fera plus conuenable.

Difons donc hardiment que les calottes fone fort vtiles, \& que l'homme eftant vn arbre tranfplanté, \& hors la terre qui luy auoit efté donnée, il doit conferuer fa racine, quieft renuerfée $\&$ à découuert, à la maniere de ces plantes eftrangeres, qu'on couure, \& qu'on foigne durant l'hyuert. Il eft mefme effentiel de fe fouuenir que nos corps ont des parties qui reprefentent les regions qui font au midy, comme le cour \& la poictrine ; \& d'autres qui ont du rapport à la zone froide, comme la tefte \& le cerueau, de maniere qu'il faut auoir foin de moderer la froideur de ces membres, \& de les changer en des zones temperées, en les courrant de calottes \& de bonnets.

Il y a mefme à remarquer que la plufpart de nos maux ne deriuent que des tranfpirations arreftées, que la tenuité y rend le cerueau fort fujet, \& que pour éuiter les maladies 


\section{2}

Des Calottes.

quiluy viennent de ce principe, il nous faut fer? uir de calottes, pourueu qu'on prenne garde aux regles que nous allons eftablir.

Ceux qui ont les cheueux efpais, la tefte chaude, quantité d'exhalaifons \& d'efprits, quiboident fort, qui necraignent point le ferain, qui font jeunes, vigoureux, \& robuftes, ne doiuent pas s'accoultumer aux calottes, \& v́n fimple rheume ou quelque indifpofition legere ne les doit pas obliger à s'en couurir, fuiuant ce que Celfe commande; ne in fecunda valetudine aduer $\int$ prafidia consummantur, ó ne in iuuenili at ate Senilis adhibeantur auxilia.

Les maigres, les delicats, lesflö̈ets, lestranfpirables, ceux qui ont les futures larges, \& le crane ouvert, qui font chauues \& ne portent point de perruques, feront fort bien des'en munir, pour preuenir les maladies. C'eft pourquoy les efclaues faits afranchis, portoient autrefois vn bonnet fur leurs teftes rafées.

Ego hodiè rafo capite caluus accipiam pileum.

Et Cefar ne promenoit jamais dans vn air libre, qu'il n'euft reueftu fa tefte de quelque calotte, parce qu'elle eftoit à demy dépouillée de rescheueux.

Cetteconfitution eft ordinaire aux perfonnes de la Prouince, il faut donc cóclurreque generalement parlant, les calottes leur font neceffares, qu'elles leurferuent de ciment, contre les changemens \& l'inconftance des faifons, contre les inegalitez des jours, la froideur des vents, la rigueur deshyuers, \& la force du ferain, qui fait vn grand nombre d'aueugles, \& d'épileptiques cheznous. 
Les courtifans qui demeurent ordinairement à defcouvert, qui font expofez à vnair froid \& humide, où il y a des riuieres \& des marais, doiuent employer les calottes: aufi Nicephore dit au liure dixiéme, que les vieux courtifans portoient autrefois des bonnets; \& les relations modernes nous apprennent que les Mofcouites faifant leur Cour, fe feruent de la dépouille du Boramets, pour arrefter les iniluences humides\& froides, qui les incommodent dans leur climat.

Ceux qui font obligés a faluër foument, fe peuuent couurir des calottes, pour éuiter le changement du chaud au froid, \& toutes ces inegalités furprenantes, qui rendent fujet le monde ciuil aux rheumatifmes, \& aux fluxions: C'eft pourquoy les Turcs, qui n'oftent jamais leur turban, n'en font que fort rarement attaqués, \& les Iaponois ne faluënt que du pied, peut-eftre pour fe conferuer par la tefte.

Les voyageurs fe trouueront fort bien de couurir ainfi leur cerueau, à caufe des nuits, de la neige, des vents \& des pluyes. Les Romains quialloient à découuert dans la Ville, en agiffoient ainfi, ils fe couuroient des chappeaux lors qu'il faloit aller en campag ne ; Ciceron appelle à cét effet leurs courriers, Tabellarios Petafatos; \& Vitreuue dit, que les foldats alors enuironnoient leurs teftes de peaux.

Les perfonnes âgées, qui ont leur tefte couuerte de neige, la doluent reueftir des calottes, parce que cette partie reprefente alors les montagnesdu Sepien ricn, \& qu'ellefedecharge en bas, commeles montagnes fur les plaines, \& 
124

Des Calottes.

dans les valées. Et quoy qu'on remarque des vieillards, qui ne couurent point cét endroit de leurs corps, c'eft qu'ils ont des difpofirions particulieres, qui ne font point de confequence; ils ont du feu, ils ont le cranedur, \& la peau callufe, ils font robuftes, \& charneus, leur tefte eft rempliede bile, \& elle pouffe des fuméesqui moderent le ferain \& le froid, comme nous auons montré ailleurs. En effet c'eft à ceux-là dans leur jeuneffe, à qui Celfe defend les calottes, il leur ordonne mefme d'y jetter fouuent de l'eau froide, pour endurcir le crane, \& pour abattre la chaleur.

* Si les calottes appaifent les infirmités ordinaires, on les doit continuer, il eft mefme befoin de confiderer leur grofleur \& leur confiftance, crainte qu'elles ne foient pefantes, ou inutiles par leur grande legereté.

Il ne refte maintenant qu'à voir pourquoy il y a fi peu de temps que les calottes font proprement en vage dans la Prouince, \& doù vient qu'on les auoit abandonnées en diuers lieux. Difons donc que la fource de cela ne deriue que de la difference des hommes des fiecles pallés, auec ceux quife trouuent dans celuy-cy. Les premiers eftojent d'vne conftitution plus robulte, \&ils auoient leurs membres plus maffifs \& plus grands, ainfi qu'on void par la difference des armes : ceux d'aujourd'huy font plus Plouèts, amolis peut-eftre par le luxe, \& par les delices, ou bien parce que les chores degemerent inceffamment; mais fur tout par l'éducation, dont le pouuoir eft admirable, car c'eft 
Des Caloties.

elle qui relache l'efprit, \& qui ramolit les parties, aufi-bien comme elle en augmente la force, \& qu'elle en reftablit la vigueur. De là vient auff que ce fiecle a des hommes rufés \& fubtils, qui font moins francs, plus entreprenans, \& moins folides; mais qui ont vn efprit plus aigu \& plus efclairé : ils font au refte plus inquietés des hypocondres, \& l'attrabile les rend extenués \& fans chair, les fait pafles \& fans couleur, fi bien qu'il les faut fouftenir, par le moyen de l'art \& de l'induftrie, comme les anciens fubfiftoient par leur nature, \& leur propre temperament; ceux-cy auoient des efprits plus efpais, à la façon de la flamme qui brufle quelque corps groffier, ceux-là au cone traire l'ont fort rare \& fort delicat, \& femblable au feu de la paille : c'eft pourquoy il fe condenfe \& fe rarefie facilement, \& reprefente l'air renfermé dans les Thermometres, qui marque par fes alțerations la diuerfité des faifons : il en eft ainfi des hommes delicats ausjourd'huy, leur cerveau eft la figure de la partie fuperieure du Thermomtere, les efprits en font l'air, \& ils s'eflargiffent ou fe condenfent à fa maniere, fi les calottes, ou quelque artifice ne produit vne efgale chaleur, qui modere les changemens \& la varieté des temps. 


\section{6}

\section{CHAPITRE XIII.}

\section{Des Perrugues.}

Ts anciens n'ont pas ignoré les perruques; Diomede le Grämairien dit qu'elles feruoiè deuant les mafques à deguifer les premiers comediens, \& on lit dans quelque Po te que les chapeaux faits de cheueux eftoient l'ornement de plufieurs perfonnes.

Tenuia non illum candentis carlafa lini,

Non auro depicta chlamys, non flaua galeri

casaries, pictoque iunant fubtegmine bracce, Pour aujourd'huy nous remarquons vine figrande varieté des cheueleures empruntées, que nous auons jugé à propos de voir fi elles impriment quelque qualité, \& fi ceux qui s'en couurent en peutient receuoir quelque bien \& quelque profit. C'eft pourquoyafin de proceder auec la methode que nous gardons dans ce volume,

Pofons pour premier fondement, qu'il faut que les cheueux ayent quelque faculté remarquable, puis qu'on les dedioic à la Forceautrefois : que Scylla donnant les cheueux de fon pere, rendit Minos victorieux: que Didon refifta dans Virgile jufques à ce qu'on luy eût coupé facheueleure blonde

Nondum illi flauam Proferpina vertice comam

Abfulerat, figioquecaput damvauerat orco.

Que Sanfon deuint impuiffant apres quivne femme l'eut rasé; \& puis qu'Ariftote cnfei- 


\section{Des Perruques.}

gne que le defaut des cheueux elt vne marque d'auarice, \& vn figne de courage abbatu.

Et certainement files cheueux font au rang des plantes, ainfi que nous auons monftré, ils ont par confequent leurs vertus comme elles; ces vertus font à leur maniere, ou bien cachées, ou conneuës, \& elles fe treuuent aux perruques parce qu'elles ne font que des cheueux que la galanterie \& l'artifice entrelaflent adroitement; de la vient qu'il n'eft befoin maintenant que de defcouurir toutes ces proprietez aux cheueux afin de les obferuer comme vnies \& ramaflées aux cheueleures dont nous parlons.

Les qualitez connuës des cheueux font la chaleur \& la feichereffe, elles procedent des matieres ardentes, volatiles, \& fulphurées, qui fe fubliment, ou qui fe feparent aux digeftions, \& quidonnent aux cheueux le pouuoir d'efchaufer le cerueau. C'eft pourquoy la nature en a couuert les animaux du Septentrion pour les preferuer de la glace; elle nous infpire dans les chaleurs d'en retrancher la quantité, \& elle à obligé par la mefme raifonles Romains à rafraichir leurs cheueux dans le Tibre, \& à les confacrer aux Fleuues.

\section{........ Tiberino in gurgite mergis,}

Mane caput bis terque

Les qualitez cachées furuiennent aux cheueux de leur nourriture \& 2 des membres quiles produifent : Voyons commecela fefait, \& appliquons le tout à noftre deffein.

II faut donc remarquer que les cheueux ont vne racine, qu'ils font concaues \& poreux; qu'ils 
128

Des Perruques.

font la fonction des filtres dans nos parties; qu'ilsattirent ce que les humeurs ont dimpur; enfin qu'ils s'imbibent de ce qui eft oleagineu $x_{\text {, }}$ \& des reftes de la dernierecuite: De là vient que lors que l'attraction des cheueux eft languifrante, \& affoiblie, ce qui eft de fuperflu retourne, \& infecte le fang, il trouble la tranfparence des efprits, \& il ternit l'efclat de la veuë; envn mot il corromp, \& altere fi fort le laict, que Democrite difcernoit par fon goût le laict d'vne cheure noire de celuy d'vne blanche; \& que le larct d'afnefle, par exemple n'eft iamais fi bon que lors qu'on a decraflé le poill de cet animal, \& qu'on a empeché par là le retour de toutesces matieres impures.

Cependant ce n'eft pas feulement le limon des humeursqui remplit les cheueux, \& quifent à leur nourriture, mais les efprits s'y ioignèt encore, \& ils y portent la teinture du tempera. ment \& des chairs, ils y donnent leurs coloris comme on remarque aux bilieux, \& anx melancholiques, \& ilsy grauent lescaracteres des paffions qui fe foûleuét dans les cours : $c^{\circ}$ eft ainfi que la peur blanchit les cheueus, que les laines des brebis effarées du loup fe corrompent, que la colere fait dreffer les poils, \& que l'amour \& l'efperance metamorphofent leur nature. Cela eftant ainfi, on infere de ce principe les qualirez cachées que les cheueux prennent des membres; carils contiennent vn extrait de tout nofrecorps, ils reçoiuent cette munie dont les Chimiques difent merueilles, \& ils retiennent d'elle eftant feparés vne fympathie\&vnefaculté magnetique 
magnetique quia du rapport aux parties quiles ont produits, \& affeurement c'eft à caufe d'elle que les poils des animaux gueriffent, fi on les met fur les morfures; que Paracelfe penfe les poils quion a arrachez des pieds \& des jambes, d'vnonguent fym patique pour guerir la goutte; \& que quantité de Medecins tranfplani ent les maladies violentes, en faifant aualer des cheueux. Maisce quifait encore voir que les cheueux font des aimans, \& qu'ils conferuent ainf vne liaifon auec les corps dont on les tire : c'eft qu'ils ont le pouuoir d'infpirer l'amour, \& d'entretenir fon empire, bref, de donner vne inclination particuliere ou generale, aux perfonnes aufquelles ils feruent d'ornement. Cela eft fi veritable, que la feruante de Milon dans A pulée, ramafloit les cheueux coupés à ce deffein; que les parens conferuoient ceux des morts autrefois, pour entretenir leur tendreffe : que les Demonographes parlent de beaucoup de malefices par les cheueux, que les anciens les employoient à faire des philtres, \& qu'on lit dans l'Apolos getique du fameux A pulée.

Philtra omnia vndique irruunt

Anthipates -.....-

Trochus, pili, vngurs renic

Radicula, berbe, furculis.

Sauri, illices, bicodule, bire

Nientium dulcedines.

Les cheuetux ont donc pour leurs proprietés connuës, la feichereffe \& la chaleur, \& vne faculté magnetique pour les cachées : il faut donc que les perruques ayent des qualités fem- 
Des Perruques.

par vn Auteur moderne. C'eft Bartolin, qui remarque qu'vn Chirurgien ayant fufpendu les cheueux d'vn bleffé à la tefte, de laquelle on auoit arraché la peau, ces cheueux partant eftoient fujets par interuale aux mefmes indifpofitions de cét homme, ils marquoient par leurs changemens, les progrés de l’âge, \& les alterations du corps, faifoient voir parr là l'accord \& la correfpondance qu'ils conferuent auec le principe dont on les fepare, \& monftroient. euidemment, quece que nous auons proporé du magnetifme des perruques, ne doit pas paroiftre fi furprenant: neantmoins pour l'autorifer auec plus d'éclat, vuidons quelques dificultez quifemblent en obfcurcir la certitude.

La premiere eft, que les cheueux dont on compofe les perruques, font pour l'ordinaire tirés des femmes; mais que partant ces perfonnes eftant inconnuẹ̈s \& éloignées, il eft impoffible que leurs cheueux puiffent incliner àl'amour, \& determiner ceux quis'en parent.

Il faut refpondre que cela pour le particulier eft veritable; mais que neantmoins il y a de l'apparence que les cheuetix de cette façon pouffent à la galanterie \& au plaifir, qu'ils amoliffent \& effeminent, \& qu'ils oftent les belles ¿dées que la force de l'efprit pourroit fug erer. Pour preuue de cela, il n'y a qu'à confiderer que seux qui affectent à fe reueftir des perruques, deuiennent le plus fouuent laches \& amoureux, qu'ils recherchent d'eftre oififs; courtifans \& joüeurs, qu'ils aiment la delicateffe \& les cheuclepres blondes \& parfumées, que lés Aftro. I ij 
is

Des Perrugues.

logues ont foumifes à Venus \& à fon pouuoir: en effet toutes les femmes d'Italie, \& de beaucoup d'autres endroits, ont grand foin de colorer ainfi leurs cheueux, \& les Poëtes couronnent Cupidon d'vne femblable cheueleure, lors qu'il veut embrafer les cours. Auif Clement Alexandrin a appellé les hommes reueftus d'vne pareille maniere, mererricios, Tertulien s'en eft moqué au liure du manteau, \& Ouide a dit d'eux.

Sint procul d nobis iurenes ve femina compti.

Nous pouuons confirmer cecy par vne raifon qui eft tirée de nos principes; car fi nous nous Counenons que les cheueux retiennent quelques veftiges des agitations de nos ames, \& qu'ils ont vn grand rapport aux parties de la generation, dont les maladies les font tomber, \& dont les ćmotions font croiltre la barbe, il y a à croire par confequent qu'ils retiennent par là quelque vertu propreà infpirer les fentimens dont nous parlons, à la maniere des plumes de certains oifeaux, \& des poils de quelques animaux, qui reprefentent nos cheueux fuiuant Ariftote, \& aufquels Pline attribuë le mefme pounoir.

La feconde difficulté conlifte, en ce qu'il eft difficile de croire que les cheueux puiflent conferuer quelque vigueur eftant couppés, puis qu'ils font feparés de leur principe, \& qu'ils perdent l'influence de leur nourriture $\&$ de Jeur fujet.

Difons que l'experience fait voir le contraire; car ceux qui font les perruques recherchent les cheueuxanimés \& viuans, parce qu'ils confer- 
Des Perruques.

uent leur efclat\&leur fuftre, qu' ils viuent d'euxmefmes, \& qu'ils font commeces plantes qui de:meurent vertes, vigoureufes \& fleuriflantes; \& qui feruent à la medecine, quoy qu'arrachées de leur terroir. Ce qui narriue pas des cheuedx morts, qui perdent leursfacultés, leurs efprits \& leurs forces, par la contagion \& les maladies: enfin par la corruption des parties, qui ont contribué à leur production. C'eft pourquoy les anciens n'attendoient pas la mort pour prendre les cheueux, \& pour les confacrer à A pollon, à la Santé, \& à la Icunefle.

\section{CHAPITRE XIV.}

Des Hommes, de leurs differences, of de lo vertis de leurs tranfmiffions.

Es hommes ont befoin des hommes, il faut Lqu'ils empruntent leur langue \& leurs mains, ils ne fe fçauroient paffer parmy eux de communiquer dans le monde, \& leur commerce eft fi general, que nous pounons appliquer. icy ce qu'Hippocrate a dit des Medecins au premier de fes aphorifmes, qu'il n'eftoit pas feulement neceffaire de fe confiderer en particulier; mais qu'il faloit encore obferuer les chofes eftrangeres, \& les perfonnes dont nous fommes enuironnés. C'eft pourquoy, comme noftre deffein nous oblige d'examiner ce quieft a l'entour de nous, il eft à propos par confequent de voir la nature, \& les differences de l'homme,

$$
\text { I iij }
$$


134

Des Hommes, \&c.

de marquer les effets que fon abord nous fait fentir, \&de tirer les confequences que nous jugerons conuenables à ce fujet.

Difons donc en premier lieu, que toute la natire eft reprefentatiue, que toutes chofes enuoyent des projections, \& fe répandent au dehors, queles formes font destumieres, qu'elles ont des influences \& des rayons, que les animaux exhalent vn fel volatil qui communique leur teinture, \& que l'homme quieft fpiritueux \& folaire, jette toujours des tranfmilfions, \& refpand fesqualitez ailleurs : on les connoift fur les plantes, fur les mineraux, \& fur les hommes, ainfi que nous découririrons dans la fuite de ce difcours.

En effet les plantes reflentent ce qui euapore de nos parties, puis que les herbes mimeufes perdent leur verdure, \& ramaflent leurs fleurs \& leurs fueilles, à la moindre application de nos mains, que quelques fruits ne font jamais fi vermeils \& fi beaux, que lors que certaines gens en fement la graine, \& puis quil y a des arbres dans les Indes qui feicheroient, \& ne fçauroient produire, fi leshommes n'y habitoient premierement au deffous.

Les mineraux fouffrent aufi bien que les plantes, nonobftant leur confiftence $\&$ leur dureté ; ils retiennent la contagion qui éuapore de nos mnembres, ils reçoiuent les tranfpirations acres \& fortes, qui fortent foument de nos corps : ce font elles qui diminuent les monnoyes à la façon des eaux regales, quipercent mefmeles lunettes qu'on expofe ordinarementauxyeux, \& qui 


\section{Des Hommes; doc.}

nous obligent à nettoyer les vafes les mieux polis \& les plus brillans, s'ils ont feruy fur tout à quelque perfonne malade. Et voila pent-eftre le principe de la vertu de ces deux fameux Sici-? liens, qui ouwroient les ferrures, fuiuant Cardan, par la feule approche du coude, voila la caufe qui fait fieftrir les fenfitiues, voila enfin ce qui falit \& qui change les bijoux les plus efclatans. Auffi par là ils marquent les changemès. \& les reuolutions du petit monde, cöme les $\mathrm{Hy}-$ grometres font les fignes de celles du grand. C'eft de cette maniere que leurs fels s'imbibent, feichent oufe rendent humides, que leur fuperficie fe ronge, \& que leur éclat fe ternit; on remarquecela aux coraux qui paliffent, aux perles qui s'obfcurciffent, \& aux opales, quifuiuant. Boèce, montrent les indifpofitions a venirs parce que le fel volatil qui exhale des pores, \& qui acquiert foument de la crafle, de l'acrimonie ou de l'afpreté, altere ces pierres precieufes, \& agit fur leurs fels, à la maniere du fuc de berberis \& du limon, ou de quelque liqueur pareille. Les hommes reçoiuent le mefme de leurs femblables, ainfique les plantes \& les metaux; car ceux-cy font glifler fur eux les maladies, l'amour, ou la haine : c'elt par leurs efcoulemens que Platon, \& les plus grands Philofophes orit: vieilly, parce qu'ils eftoient abordés d'vn grand nombre de difciples jeunes, vigoureux \& robu . ftes : c'eft encore de là que les Medecins font fouuentrecherchés, \& que nous fommes contrains de prendre yarde aux perfonnes qui nous. approchent, de peurqu'elles ne foicat fembla- 
136

Des Hommes; Co:

bles à ces eftoiles remarquables par leursinfluen: ces, \& par les afpects qu'elles ont.

On tire de cefondement le choix qu'on doit faire des valets \& des domeftiques, l'inclination qu'on a pour quelques-vns en particulier. la necellité qu'il y a de ne point coucher les petits enfans auecles vieillards, dont les vapeurs picquotent \& feichent. ces corps tendres \& de* licats, par leurs qualités mordicantes, l'importance d'ailleurs de leur choifir des Precepteurs $\&$ des nourrifles d'vne bonne conftitution : enfin on decoure du mefme principe, la fource de ces facultez merueilleufes, qui font affeetées à desfamilles, qui ne deriuent fans doute que de pareilles tranfinifions, ainfi on void pourquoy les Pfylles refiftoient aux ferpens, pourquoy quelques-vns anciennement iettoient du venin par la bouche; \& pourquoy d'autresguerifloiēt la douleur de rate, en touchant cette partie du bout des doigts; mais pour micux faire voir cela . il faut confiderer les hommes en particulier. obferuer les tranfmiffions quiviennent de leurs differences, \& y joindre en fuite quelques remarques qui découuriront leur nature, \& les qualités qu'elles ont.

Les hommes font fort grands ou petits, noirs, blancs, bafanés, oliuaftres ou jaunes, ou en partie noirs \& blancs : ils ont d'ailleurs des figures qui les diftinguent, \& qui montrent leurs qualitez, eftant vnies à leurs teintures naturelles.

Les nains, c'eft à dire les petits, ont des tranfpirations malignes: Faifons voir la nature de leur principe, \& ainfi nous découtrirons leurs 


\section{Des Hommes, \&e.}

maluuais effets. Et veritablement la plufparts des nains, comme remarque Verulan, viennent ainfi par artifice : \& on fait d'eux, dans leur enfance, ainfi que des chiens qu'on veut rendre petits. Or la naturefe trouuãt preffée de cette façon, elle n'agit alors quauec peine, \& auec contrainte, \& il en eft de la chaleur naturelle icy, comme de la flamme dans vn fourneau de reuerbere, ou à la maniere de ces effences fort actiues, qui bouillonnent dans des vafes, \& dans des alambics trop eftroits; auffi les nains par la compreffion des efprits, \& par la confufion des matieres, exhalent fouuent de leur bouche, vnair fi puant \& fi fort, qu'on en propofe quelques-vns, dont le fouffle fondoit le beurre; ils font d'ailleurs fi ardens, par la concentration de leur feu, qu'ils pouffent de tous coftez des parties fpiritueures \& alumées, quiles rendent lubriques \& lafcifs, en forte que c'eft fans doute par leur contagion que Iulia deuint amoureufed'vn nain : ce font elles encore eftant: retenuës qui les font hardis \& coleres : C eft pourquoy on les cachoit autrefois dans des patés, à l'ouuerture defquels ils fautoient promptement fur la table, \& attaquoient les affiftans.

Raifonnons tout autrement des perfonnes d'vne grande ftature, ou la chaleur eft moins ardente, les humeurs plus épurées, \& par confequent les tranfpirations moins acres, \& les efprits plus détachés; aufi leur fanté en eft meilleure, leurs mours plus douces, \& ils approchent dauantage de la complexion de ceux qui font entre la petiteffe \& la hauteur. 


\section{Des Hommes, óc.}

Les hommes noirs, c'eft à dire les Moies, exhalent je ne fçay quoy, quilesdoit iendrele rebut de ce monde. Pour montrer la verité decette propofition, faifons vne anatomie de ces perfonnes, \& découturons leur complexion, \& 1 a fonrce de leur teinture.

Il faut donc obferuer que les Mores font melancoliques \& Saturniens : cela fe remarque par la difpofition de leur corps, par leurs mœurs, \& parleur fortune; car ils font pauures, timides, folitares \& vagabons, ils ne s'occupent quaux peaux, au beftail, \& à trauailler à leurs terres, ils font opiniaftres \& mal faifans, diffimulés, cruels \& traiftes, ils deuiennẽ t lycan hropiques, $\&$ cherchent les cadaures dans les tombeaux : ils s'appliquent mefmeà la magie, \& ils font fi jaloux desfemmes, que les peres paffent l'éguille aux parties fecrettes de leurs filles, de peur qu'elles ne perdent leur chafteté. Or toutes ces qualités font voir que Siturne domine fur ces peuples infames, \& que l'atrabile eft l'humeur principale quiles entretient. Auff c'eft elle qui les colore d'vne noirceur efpouuentable, \& qui infecteleur peau de la façon que nous la voyons. Pour monftrer cecy auec ordre, prenons ce fujet dans fa fource, \& difons en premier lieu, queles hommes ont vne certaine latitude dans leur efpece qui les partage par degrez: C'eft pourquoy les vns poffedent le milieu, \& les autres en déclinent \& s'en éloignent, les couleurs au refteles diftinguët, \& nous marquent leur difference, en forte que c'eft à ce deffein quion void des hommes noirs, desblancs, des bafanés, des. 


\section{Des Hommes, \&C.}

oliuaftres \& des jaunes, \& de ceuxquifont partagés. Or toutes ces couleurs ne font que des lumieres, elles procedent des efprits, d'où toutes nos teintures dériuent, qui fouffrent par les humeurs, par la confiftance des parties, \& par quantité d'autres moyens leurs differentes refractions.

En effet les hommes fonc blancs par la pureté des efprits ä̈riens, qui ne trouluent point d'embarras qui puife éclipfer leur lumiere, parce que la blancheur en approche dauantage par deffus les autres couleurs, de forte qu'elle marque vne refraction moderée, \& vn defaut de quelque matiere quifoit propre à ternir faclarté. De là vient que les hommes blancs font les plus parfaits, \& que leur approche eft bien faifante, parce qu'ils ont vne pureté plus exquile, vne portion plus lumineufe, \& qu'ils approchent mieux de la lumieredu Soleil. Hippocrate au liure des fonges a connu cette verité, il a eftabli pour vn prognoftic falutaire de fonger dans les maladies, d eftre couuerts d'habits fort bläcs, parce qu'ily a de l'apparence qu'ainfi il n'y a aucune humeur groffere, quiembarraffe les efprits, qui les reflechifle, \& qui les rompe ; enfin qui les repoufle hors de la furface, où ces eftoiles viuantes on couftume de s'arrefter.

Siles hommes blancs font dans la perfection, il faut donc que les noirs, qui leur font oppofés endéclinent, \& queles Moresayent je ne fçay quoy qui arrefte la viuacité, \& qui empefche la lumiere de leurs efprits, qui luy faffe fouffrir desrefractions, \& quila rende femblable à celle 
140

Des Homanes, ors.

des lambeaux qu'vne fumée épaifle barbouille. Voyons maintenant le principe de tout cela; mais obferuons en premier lieu le fentiment de ceux qui ont éflearé cette matiere.

Poltel a creu que la noirceur des mores proce. doit de la malediction que Cam auoit attirée fur res defcendans, apres qu'il cut decouuert fon pere. Quelques anciens ont fouftenu que le Soleil eftoit le peintre quidonnoit aux mores leurs coloris, que la fource de la lumiere eftoit la caufe de leur teint de tenebres, qu'elle imprime ainfi la noirceur aux voyageurs, qui font haflés, quecieft d'elle que les Orientaux, \& ceux du midy portent la liurée des flammes, \& quec'eft $\dot{z}$ cette fin que le Poete a dit parlant de Phaëton.

Sanguine tum credunt in corpora fumma vocates Atbiopum populos nigrum traxife colorem.

Cefentiment partant fouffre de fortes objeetions; car le Septentrion a d'habitans quifont auffi noirs que ceux du midy, il y a mefme des Meridionnaux blancs, quoy que leurs voifins coient noiraftres, on en remarque dans Sumatra quelques-vns qui font partie blancs \& partic noirs, \& les Hollandois obferuent dans la Guinée, que les Mores font rougeaftres jufques à la feptiéme année, qu’apres cet âge ils deuiennent noirs, \& qu'ils paroiflent jaunaftes dans leur. vieillefle, nonobltant qu'ils foient toujours efclairés du merme Soleil. C'eft pourquoy à bien confiderer les chofes, \& à les examiner dans leus fond, il eft certain que la noirceur de ces peuples vient pluftoft de leur nature particuliere, qu'elle procede de la generation, quielle donne. 
Des Hommes, Go. qualque matiere qui fait les refractions que nous venons d'écrire, qu'à cét effet Herodote a creu que l'humeur genitale des Mores eftoit noire, que Paufanias dans Plutarque a fait vne Venus noire, \& vine blanche, que les blancs \& les noirs mellés enfemble, donnent à leurs defcendans vne couleur claire \& blanchaftre, \& qu'on 2 veu vn enfant né divn More, \& d'vne Francoife, qu'il n'auoit retenu de fon pere que le bout du membre viril tout noir. Voyons donc ce que les noirs tirent de leur naiflance, \& quelles font les difpofitions qui leur imprament leur couleur. A ce deffein,

Il faut reprendrece que nous auons déja dit : fçauoir, que les Mores eftoient Saturniens, \& malancoliques, que leur rate les dominoit, \& que ceftoit elle quirendoit leur fouffle puant, $\&$ lesportoit à aimer le vinaigre auec auidité, \& les fucs de mefme nature. Decefondement on peut probablement conclurre que ces gens ont leur couleur de ce vifcere, qui les rend femblables aux fcorbutiques, \& à ceux qui ont l'ictere noir; car il depofe fur la peau d humeurs melancoliques \& bruflées, qui luy impriment la teinture des furoncles \& des charbons, qui font des refractions auxefprits, qui y roulent, comme dit Hippocrate, \& qui metamorphofent leur lumiere à la noirceur que nous y voyons.

Neantmoins pour expliquer encore cecy d'vne maniereplus exacte, il faut remarquer que la ratte contient vne acidite naturelle, qui a du rapport au vitriol: Or lors que cette acidité eft abondante, ainfi qu'apparemment on la doit 
142

Des Hommes, \&oc?

fuppoferaux Mores, elle fe mefle auec la partic la plus acre, \& la plus piquante du fang, qui eftant proportionnée au vin efpais \& groflier, fait comme vn ancre naturelle qui noircit les lieux où elle eft; qui brouille les efprits \& les emoufle, quidonne aux Mores dans Petronne vn teint de tenebres \& de la nuit, \& que la nature pouffe toûjours à la furface, ainfi qu'on peut prefumer par la fueur continuelle, qui fait que les Mores puent fi fort, \& certes cela elt fi ve. ricable, \& la naturea vn fi grand foin de pouffer ce méflange à la furface, que les Mores ont leur chair, \& toutes leurs entrailles fort blanches \& delicates, \& qu'il n'y a que leur epiderme qui foit noir. De forte que lors que la picotte en a rongé quelque partie, on le void auec des taches blanches, \& on eft furpris de remarquer favarieté. Dece principe, il eft aifé maintenant d'en tirer les confiderations qui fuiuent.

La premiere, que les Mores ont en quelques endroits la peau fort calleufe, à caufe de l'acidité qui fixe, \& qui endurcit; fur tout fi elle eft: iointe de quelque humeur alcalifée.

La feconde, quelle noircit la peau fans agir ainfi fur les chairs \& fur les vif́ceres, à la façon de cette ancre furprenante compofée d'vn acide \& d'vn fel piquant, qui penetre l'épaifleur d'vn gros liure fans faire impreflion au dedans.

La troifiéme, que la diuerfe digeftion, \& le mélange qu'elle fouffre rend les Mores rouges, ou iaunaftres en certain temps de leurvie, comme dans l'enfance \& dans la vieillefte, \& qu'elle fait ainfi la diuerfe couleur.des peuples. les 
rend oliuaftres, \& bafanés, \& partage en deux teintures les infulaires de Sumatra.

La quatriéme, que coulant à la fuperficic, \& fe meflant auec vn fang impur elle rend la tranfpiratió des Mores tres-mal faifante, \&leur abord tres dangereux. A uffic cef de là que quelquesvins on affeuré que les Mores auoient la vertu de falciner par leur regard, \& qu'elle deriuoit de leurgang, parce qu'il fert à la Marie, \& qu'eftant tiréde ceux qui ont la ligne menfale fort longue \& fort large, produit des fonges, \& fait trouuer de trefors cachez : c'eft le Pere Eugene qui le remarqué, \& c'eft là encore lobferuation des plus fçauants Orientaux : Au refte ce quiautorife la contagion, \& limpureté de ce fang; c'eft le maunais regime de ces barbares iuftitié par Hippocrate au liure de l'epilepfie, là où ce grand Medecin affeure queles habitans del:Affrique Meridionale qui font pour l'ordinaire noirs, font mal-fains, \& affligezde l'epilepfre, parce qu'ils viuent de cheures \& de quantité d'autres animaux fort vilains. Et voila tout ce que nous pounons dire des couleurs; confiderons les maintenant lors qu'elles font iointes auec des diuerfes figures. La couleur \& la figure differente deshommes nous font de grandes impreffions: \& certes files peintures \& les portraits agiffent fenfiblement fur l'imagination, \& ficettefaculté lors qu'elle eft emeue a gite puiffamment les efprits, les parties, \& les humeurs qui y font contenues, que doit-on prefumer lors qu'elle a pour objet des Images viuantes \& animées, dont laction, la figure \& le coloris s'arreftent à la 
344 Des Hommes, ofe.

veue, \& faifffent viuement nos cours: auff voila la fource de la complaifance \& du rebut que nous conceuons dans le monde, de la joye que nous auons en voyant certaines perfonnes, des fouhaits que nous faifons pour elles \& des bonnes, ou des maunaifes idées qu'elles nous infpirent à leur abord: Et veritablement l'ame en tire d'exemplaires, \& des copies qui fe reflechiffent dans nos efprits à la façon dece qui fe fait aux plus belles glaces, \& qui nous portent à des actions dont le fuccez eft fouuent furprenant. C'eft de ce fondement que Campanelia tire vne obferuation tres-importante aux Phyfionomiftes: fçauoir qu'on prend les penfées, lesinclinations, \& les couftumes de ceux dont on fe reprefente fortement les façons, que c'eft là l'vnique moyen de reuffir dans les affaires $\&$ de penetrer dans l'interieur de ceux aueclefquels ont les veut negocier.

On conclud de ce difcours, pourquoy $Q$ uintilien a exageré le déreglement de quelques vns qui aimoient à voir des valets d'vn teint, \& d'vne figure extraordinaire. Illa quacumgue deflexa funt, tanquam exquifitiors miramur, non aliter quàm diffortis aut quoque modo prodigiofis corporibus apud quofdam maius eft pretium, dit ce Pere de l'eloquence. On connoit encore pourquoy le peuple Romain auoit des perfonnes qui faifoient profeffion d'embelir les efclaues deuant que de les expofer en public, pourquoy il prenoit des enfans hardis \& bien faits, qu'il nommoit des delices, parce qu'il croyoit que leur bonne"mine contribuoit à la fanté, qu'elle reiouiffoit leurs femmes 
Des Hommes, dor.

femmes dans leur domeltiyue, \& qu'elle leur fournilloit vne belle figure dans la conceptiou: Stace a parlé de ce fujet

Non ego mercatus pharia de pupe loguaces

Delicias, doctumque fui conuitia mili,

Infantcm, linguaque fimul Jalibusue proseruus

Dilexi.-.-.--

De tout cela il eft aisé de déueloper la caufe de 1 'auerfion qu'on a pour les vifages blémes \& 2 batus; \& le fondement qui a obligé Hippocrate, Galien, \& Virgile d'ordonner qu'vn Medecin fût dans l'embon-point, \& d'vne maniese agreable; au contraire de Platon qui le veut toûjours maigre \& défait, afin qu'ayant experimenté fur foy les maux, il les gueriffe mieux fur les autres.

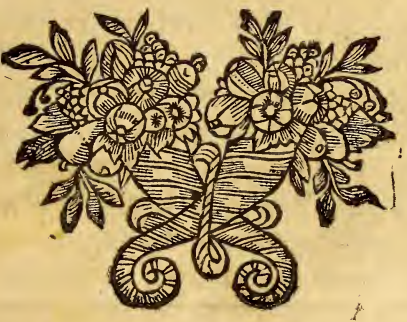




\section{6}

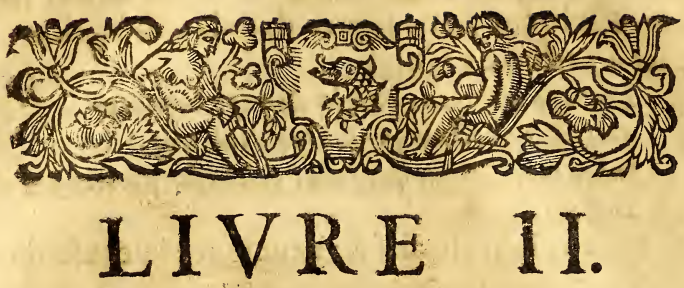

Des chofes que nous receuons, $E$ qui pafent dans nos parties.

Frir 国 PRES auoir traitté de ce qui nous H. eft exterieur, \& de ce qui nous enui1. 2. 2 qui s'introduifent dans nos corps, \& d'examiner leurs vertus. Neätmoins comme ces chofes font prefque infinies, \& que nous compoferiōs vn gros, volume fi nous vouliós efcrire de toutes en particulier. Nous ferons par confequent le choix de quelques vnes, que lecaprice ou la volupté ont mife en vfage depuis quelque temps, \& quela Medecine n'a pas exaatement obferuées.

\section{CHAPITRE I. \\ De l'oeuf.}

$\mathrm{CI}$ toutes chofes deriuent des cem $\mathrm{fs}_{\mathrm{s}}$, ainfi que Sles fçauants nous monftrent les anciens en ont fait naiftre leurs Diuinwer, s'ils ont con- 
De roenf.

tefté dans Plutarque leur anciennetéfur la pozle; il nous fera bien permis de commencer cette feconde partie par l'œuf, \& d'en tirer des reflexions profitables \& falutaires, puis que les Au. gures en prenoient pour le prefent, \& pour ce qui eft à venir.

\section{Labra moues tacitus, recutitaque Sabbata palles,}

Tuncnigri lemmures, ouoque pepicula rapto.

C'eft pourquoy il faut fuppofer comme vn fondement neceffaire, ce qu'Hip pocrate a auncéau fecond de la façon de je viure. Volucrum ous validum quid, nutriens, \&o inflans babent; validume quidem quoniam animalis generationem continent; uutriens, quód boc in pullis lact is rationem babet; inflans quia exparuamole in magnam diffunditur. Les œufs desoifeaux, dit Hippocrate, ont quelquechofe de fort, de nourriffant, \& d'inflatif: de fort, parce qu'ils contiennent ce qui fert à la genera. tion : de nourriffant, parce que cela tient lieu. delaictaux poulets: d'inflatif, parcequ'il groffit de peu, il fe rend tumide, \& prend vne eftenduë plus vafte. Examinons maintenant vn" pet au long ce qu'Hippocrate n'a expliqué quedans peu de mots, \& propofons nos fentimens fur les œufs, \& fur leur nature, en nous feruant du texte comme d'vn principe, \& d'vne bafe tresrolide.

Les $œ u$ fs contiennent quelque chofe de fort; parce qu'ils font deftinés pour la generation, que tout ce qui eft viuant en procede, \& que les plantes, les oifeaux, les poiffons, \& les quadrupedes n'ont pour commencement que les oufs, les graines ne font que des oufs, aufi: 
148

De l'oeuf.

bien que la pluipart des fruits \& des bulbes: il en eft de mefme de la femence des infectes, \& des poiffons, les quadrupedes dans la matrice font juftement comme dans vn œuf, compofé de diuerfes matieres, \& s'ils font produits continuellement dans le monde, c'eft quece monde eft vn œuf enuironné du ciel, ainfi que du blanc, $\&$ qui a pour jaune la terre. Si donc tout prefque deriue des œufs, il faut qu'ils contiennent quelque chofe de fort, de vigoureux, \& d'énergique, quidonne l'eftre \& lecommencement à tant de belles productions: il faut, di-je,qu'ils foient doüés d'vne grande vertu, \& queceux des poules la poffedent d'vne maniere plus exquife puis qu'ils femblent les plus parfaits, \& comme la regle de tout le genre. Et certes autrefois on a fi bien admiré leur force, qu'on l'a crevé quelque chofe de Diuin \& de releué, \& vnrayon de l'ame du monde, on s'eft figuré mefme qu'elle donnoit aux œufs vne faculté d'effacer les crimes, \& de purifier lecorps, \& le Poëte a dit

- Nifi fe centum luftrauerit ouis,

Et Xerampelinas veftes donauerit ip $\int$.

Et Ouide a pres celuy-cy.

Et veniat qua luftret anus, lectumq; locumq;

Praferat, or tremula fulphur, \& oua manu. Les $\propto u f s$ ont encore fuiuant Hippocrate, quelque chofe de nourriffant, qui tient lieu de laict aux poulets, à cét effet on doit fappofer que comme il y a des animaux qui viennent dans les flancs de leurs meres, attachés ainfi que les arb:es à la terre, il y en a auffi qui font engendrés autrement, qui font produits dans vn lieu fe- 


\section{De l'oenf.}

paré, \& qui ne demandent qu'vne fimple chaleur influente pour pounoir efclorre \& fortir. De là vient aufli que comme les premiers eftant mis au jour, s'attachent encore aux mammelles, $\&$ font à peu prés, dit Hippocrate, ce qu'ils ont fait dans les entrailles de leurs meres: Ceux-cy au contraire trouuent dans les matrices feparées, vn aliment quiles entretient, '\& dontils fe nourriffent, deuant que de pouuoir manger. Les oufs font ces matrices feparées, \& les poulets font ces a nimaux qui y troulenr par confequent vn laiit \& v ne nourriture excellente, fuiuant le texte que nous auons mis cy-deffus. Et affeurement cette verité paroift aux legumes, qui font des oufs, ainfi que nous auons marqué; lés feues par exemple, ont des membranes, vn germe, \& quelque chofe de tendre \& de delicat, qui fert de premiere nourriture at nouueau fruit, de peur qu'vn plus groffier, \&vn plus materiel, n'en empefche l'accroiffement; il en eft tout de mefme du bled \& des bulbes, c'eft pourquoy ils pouffent fouvent à la moindre chaleur, quoy qu'ils ne foient point fur la terre, \& des oufs des poules par confequent, qui font compofez. d'vne excellente maniere.

Les oufs fuiuant le texte, s'enflent encores, fe gonflent, \& fe dilatent, \& peu de chofe dans leur fubftance prend vn notable accroiffemē $i$.La raifon de cela eft, parce qu'ils font deftinés pour la generation, deforte qu'ils fe doiuent dilater à la moindre chaleur, \& s'efleuer ainfi que la pafte: c'eft pourquoy ils on tbefoin d'vn leuain comme clle, \& d'vne matiere qui foìt difpofée à cet effet.

$$
\text { IK ij }
$$


Expliquonsmaintenant ce leuain, \&voyons de quelle nature eft cette matiere.

Le leuain confifte aux efprits, qui fe trouuent dans toutes les femences, \& par confequent dans Jes œufs, qui tiennent le premier rang parmy elles, ce font eux qui les rendent feconds, \& quileur donnent la vigueur qu' Hippocrateleur attribuë; mais fur tout qui les efleuent, qui les dilatent, quiles eftendent, \& leur donnent vn degré de fermentation. Ces efprits au refte fe trouuent renfermés dans vn poinct que le vul. gaire a ppelle le germe, de là ils fouleuent toute Ia fubitance de l'œuf, ils enuirominent de trois cercles le lieu quiles centient, \& quiles renferme, \& enfin ils rarefient le blanc \& le jaune, \& leur impriment l'idée de l'ouurage qu'ils ont euẻ de leur principe, ainfi que fur va moule, \& fur de la cire.

Cependant la matiere contribuëbeaucoup au Souleuement dont nous parlons, parce qu'elle eft fulfuré \& vifqueufe, molle, gluante, \& remblable à la pafte; \& dont on tire vin huile qui fait voir qu'elle fe dilate, \& fe gonfle facilement. Et voila la raifon pourquoy eft-ce qu'il faut boire apres les ceufs de poule; caril eft neceflaire de diffoudre la gluë de cette matiere, \& d'empefcher qu'elle ne foit adherante \& tenace, \& qu'elle ne s'arrefte aux chemins. Tirons maintenant de ces principes des confequences à noftre façon:

La premiere, que le peuple fait fort bien d'ofter le germe aux oufs, deuant qu'on les prenne, parce qu'ils n'ont plus ainf $f_{2}$ ny la force, 


\section{De l'oenf.}

my le leuain, qu'ils perdent leurs ef prits \& leur energie, \& qu'ils n'ont plus ce pouuoir qu'Hippocrate leur a donné : en effet ils font alors inutiles à la generation, \& reduits dans cette mediocrité exquife, qu'on doit rechercher aux alimens de cette nature. De là on void qu'on ne doit pas tant eftre exact à chercher les oufs frais, \& qu'il eft bon que leur qualité feminale, aे qui Hippocrate donne la force, \& le vulgaire la chaleur, ait relachéde fa vertu.

La feconde, qu'il ne faut pas s'eftonner que beaucoup fe trouuent mal par l'vfage des oufs: car leurs eftomachs font comme des matrices qui agiffent furces femences d'vne differente maniere, tantolt ces parties endurciffent les œufs par leur chaleur; ou bien elles les fouleuent $\&$ les eftendent, ou bien elles en alument le foulfre, \& caufent ainfi des naufées \& des deuoyemens furprenans. Et voila la raifon pourquoy les oufs des poiffons deuiennent bien fouuent nuifibles, \& d'où vient que quelques vns ont en auerfion la boutargue, \& tout ce que les Grecs ont entendu par $\omega \alpha \dot{\alpha} \tau \dot{\alpha} \rho$ stres.

La troifiéme eft, que les cuifs ont vne faculté grandement nutritiue, puis qu'ils feruent de laict au orfeaux, dont les chairs font ordinairement delicates. D'examiner maintenant quelle eft la partie qui fere dars l'ouf de laicz aux poulets, c'eft ce que noftre deffein ne nous fçauroit permettre, feulement on peut direque les modernes ont obferué contre Hippocrate, que c'eftoit le jaune qui tenoit ce rang, qu'à cet effet on voyoit jaunir les poulets, que dans peu $\mathrm{K}$ iiij 
Is

De loeuf.

de temps on ne remarquoit plus de blanc dans leur cocque, \& qu'on trouuoit foument l'autre humeur dans le gofier \& dans l'eftomach de ces animaux. Le blanc neantmoins contribuë quelque chofe 2 leur nourriture, on peut croire qu'il eft comme le premier laict, auff bien que la premiere matiere, \& qui eft la portion la plus donce. C'eft pourquey on l'employe comme le laict aux infammations, aux brufleures $\&$ au douleurs. Et voila dans peu de paroles ce que nous aucons confideré fur les $œ u$ fs en general, \& particuilerement fur ceux des poules. Faifons cionc quelques reliexions fur les accidens qui les changent fouuent, ces accidens procedent de leur generation \& de leur nourriture, ainfi que nous allons monftrer, \& queles f̧̧auans modernes obferuent.

La nourriture les altere \& les metamorphofe 11 fort, quec'eft d'elle qu'on remarque les differentes couleurs des oufs de la ville, \& de la campagne, elle les fait mefme deuenir tout brillans, \& Glauber, Rofembergius, \& quelques autres nousenfeignent de leur donner la couleur de l'argent ou de l'or, de les rendre vtiles ainfi aux vieillards, aux afforblis \& aux malades, fi on donne aux poules les quinteflances de ces metaux, ou fi on mefle leurs fueilles auec leur pafture, lors que le Soleilentre dans l'Efcriuice, ou dans le Lion, en vn mot, lors que les chaleurs font ardentés; car on void ainfí dans peu de temps le ventre des poules tout éclatant de jaune \& deblane, on linbferue peint d'vn verd merueilleufenent agreable, qui réjouit la veıë, \& 


\section{De loeuf.}

qui fait prefumer que les ocufs, \& tout le refte des entrailles eft imbibé fortement de cettenourriture precieufe.

La generation fait encore des alterations re marquables, anfi les poules noires produifent les œufs d'vne maniere differente des blanches, \& s'il eft vray ce que Licetus affeure, que les poules de la campagne s'accouplent quelquefois auec les afpics, on trouue là le principe des ferpens, qu'on a veu fouuent dans les œufs, \& de la vermine qui ronge leur cocque, \& tout ce qui y eft contenu.

\section{CHAPITRE II.}

\section{Des PoifJons.}

D Vifque l'eftomac par le long vfage des vian1 des, exhale quelque fois vne ma uuaife odeur, qu'il reflamble ainfi aux grandes cuifines; qu'il rebutte lcs delicats, \& qu'il leur fait fouhaitter fouuent le carefme, puifque d'ailleurs les chairs des poiffons ont quelque chofe de vifqueux qui fert de glu à la maigreur, \& qui émouffe l'humeur picquante des bilicux, \& des diffipables: il n'elt pas donc malà propos d'en manger pour l'entretien de la fanté, \& de fuiure les anciens Grecs qui inuitoient le peuple à cela par lesfons des cloches, \& par leurs ordonnances publicques. Il $y$ a pourtant quelques precautions à obferuer que nous examinerons par articles.

La premiere, que l'v fage des poiffons foit mo- 
54 Des Poiffons.

deré, quion fe fouuienne que ce font desanimaux attachez à la proye, que leur voracitéles rend impurs, qu'ils ramaffent ainfi quantité de fel dans leur fiel, \& d'humeurs inutiles \& abondantes dans leurs parties, que ceft ce qui les rend ordinairement difficiles a l'eftomac, \&ce qui a obligé les anciens Medecins de ne les accorder qu'auec peine aux malades, \& aux conmalefcens. Auffi Pythagore qui aimoit la pureté les auoit interdits à fes difciples: Les Egyptiens n'ofoient les offrir à leurs Dieux : \& les Grecs faifoient loger ceux qui les faloient hors des Villes, comme ne s'appliquans qu'à preparer de mauuais alimens.

La feconde, que le poiffon foit grandement frais. Athenée fait voir limportance de cecy, par vne couftume bien eftablie qu'il appelle Nopesy rpnos', vne loy dior. Il dit que les Grecs obligeoient les vendeurs de poiflon de demeurer droits dans le marché, afin que la grande laffitude les forçât à vendre promptement leur marée. Mais pour monftrer la neceflité de cette or donnance auec ordre,

Il faut remarquer que les poiffons font compofés de deux fublta nces, l'vne eft gluante, froi. de \& vifqueufe, quife conferue quelque temps. \& qui fait qualifier les poiffons frais, \& l'autre eft oleagineufe, elle contient quantité d'efprits, \& deuient fenfible a pres que la pourriture a metamorphofé la premiere. L'oleagineufe paroift par l'huile puante qu'on tire abondamment des poiffons, par l'acrimonie de ces animaux, lors qu'ils viennent à fe corrompre, par la lumiere 
Jont ils brillent durant la nuict, \& lors qu'its cherchent les femelles, qui deriue apparemment des efprits vnis auec vne humeur fulfuré \& parquantité d'autres raifons qu'il eft facile deremarquer. Il y a feulement deux reflexions à faire fur cette fubftance huileufe, qu'on ne doit pas oublier en-cét endroit.

La premiere, quec'eft elle qui rend quantité dé poillons ennemis de la voix, des poulmons $\&$ de la poictrine. Fernel obferue cela fur les anguilles \& fur la muge, lors qu'il dit : Rara eff. admodum vera perineumonia, banc tamen Hippocrates tradit vinolentia potiffmum fieri, $t \mathrm{~km}$ pifcium, vt mugilum os angurlarum efu, quibus pingue aliquid ineft bomini infersfflimum. C'elt aufli par l'abondance de cette graifle ou de cette huile, qui fe gonfle, quis'allume \& qui fe dilate facilement, que la muge eft vn poifton des plus lubriques, \& que les anciens la confideroient comme la marque de la volupté : c'eft pourquóy s'ils auoient furpris vn adultere, ils choiffifoient des petites muges, \& les faifoient gliffer dans leur derriere, pour punir leur brutalité, par vnanimal d'vne remblable nature.

-...-. Necat hic ferro, Seccat ille cruentis

Verberibus, quofdam Machos \& inugilis intrat. Et Catulle apres Iuuenal.

Ab tum te miferum, malique fati, Q e em attractum pedibus, patente porta Percurrent raphanique mugilesque.

L'autre reflexion elt que cette partie oleagineufe dont nous parlons, exhale quantité de vapeurs dans la nuit, qui deriuent de fon foulfre 
is 6

Des Poiffons.

quibrufle, \& il en eft d'elle fans doute comme de l'huile dont on entretient la lumiere, de laquelle on void fortir vne fumée fort épaiffe, \& on flaire vne mauuaife odeur. Or il arriue de là que ceux qui mangent quantité de poiffon le Foir, parles exhalaifons qui en procedent, font troublésinceflamment des reueries, \& des fonges, les anguilles leur reprefentent des ferpens, les feiches tigurent des tenebres dans leur idée, ondit mefme que les langouftes leur font voir desgaleres, parce qu'elles flottent, \& fendent l'eaù à leur façon, \& qu'elles en ont fourni le modelle; enfin chaque poiffon fait quelque chofe d'approchant, \& on peut croire que la digeftion fait à thuile deces a nimaux, \&aux vapeurs qui en procedent, ce qu'on nous dit de certaines lampes, \& ceque les Chimiques obferuent dans la cendre des rofes \& des œillets. Le peuple d'Iflande confirme fort bien tout cecy ; car comme il ne vit que de poiflons, qu'il n'entretient \& n'allume fes lampes qu'auec de l'huile de balaine, qu'il fe fert mefme des os dece möfre marin pour en faire des fiéges, \& d'autres meubles ordinaires, il fe reprefente toujours durant la nuict des naufrages \& des tempeftes, \&il s'imagine d' eftre incellamment dans la mer.

Il eft donc certain que les poiffons abondent en huile: c'eft pourquoy lorsqu'ils ne font pas frais, \& qu'ils ont perdu leur humeur gluante, cette huille paroift \& fe fait fentir, elle deuient acre \& maligne, elle altere le foy \& efleue la peau, mefme elle a fait deuenir quelques-vns ladres, \& on prend garde que c'eft de là qué:es 
Des Poiffons.

is 5 peuples ICthiophages prennent la plufpart de leurs maux. Il nous refte maintenant apres tout cela de vuider deux queftions, dont la decifion eft affez difficile; mais auffi affez diuertiflante \& aflez curieufe.

La premiere eft, touchant vne obferuation remarquable que feu Monfieur Merindol à faite dans vne de fes differtations. Là ce f̧̧auant homme nous dit, que l'vfaged'vn gros poiflon que le vulgaire du Martiguesa nommé l'Ange, qui eft de la yroffeur d'vn thon, \& au nombre des fquatines, embellit la gorge, \& la fait enfler, qu'il donne aux tetons vne dureté conuenable 2 la naturelle; enfin qu'il lesbourfoufle \& les efleue, lors que la maigreur ou les maladies les ont fleftris. Cette obferuation eft confiderable, \& on ne la doit point reuoquer en doute, à eaufe de la doctrine, de la probité, \& du merite de fon Auteur : Voyons en la caufe en peu de paroles, afin que nous examinions l'autre difficulté, qui eft également furprenante.

Il faut donc dir en premier lieu, que beaucoup des poiffons ont v ne faculté inflatiue, ainfi on lit dans la Cofmographie de Theuet, que la plufpart de ceux du Septentrion font de cettefaçon, on remarque d'ailleurs que les Syriens auoient A pua \& Mœnides, qui enfloient commeles premiers, \& qu'on croyoit eftre lesDiuinités de ces peuples.

\section{Incufsere Deos inflantes corpora.}

Dit Perfe , \& Martial auecluy.

Iuro per syrios tibi tumores.

Il fe faut fouuenir d'ailleurs que certains ali: 
is

Des Poiffons.

mens affectent certaines parties, \& que l'ange peut faire ainfi des mammelles; \& les efleuer en fuite par vndegré de fermentation \& de cuitte, qui déueloppe fa vertu pluftoft à la gorge qu'en d'autres endroits, on void cela au gofier que quelques alimens grofiffent, \& à l'of teocolle, quiaffermit \& épaiffit les os. Et certes cette raifon n'eft pas efloignée, fi on fait reflexion que le poiffon, dont nous efcriuons icy, a vne humeur gluante \& vifqueafe, qui sarrefte parmi les deftours des glandules, qui les embarrafle \& les bouffit; qui peut agir ainfi dans celles qui font aux mammelles, \& faire le mefme que cette abondance de viandes cruës, \& de differente qualité, defquelles Hippocrate a dit au recond des Apidemies, ex aduliis, Ev potibus bumeri, \& mamma tumefcunt, quia ex victus intempevavitia flatus incrementums capiti addust donec offa firmitatem acceperine. Adjouftons à tout cela que quantité de poiffons augmentent le laict, que d'autres irritent la matrice, \& que cette partic ayant vn grand rapport aux mammelles, on ne doit pas douter qu'elle n'y imprime ce qu'elle reçoit, \& que ce ne foit par là, ou par l'autre maniere quel'ange y porte fa vertu, qui les dilate \& quiles efleue.

L'autre obferuation eft tirée du Pere de Rodes, qui affeure dans fes voyages Oriêtaux, qu'eItant dans la Cochinchine il apprit d'vn Cathecumene, que les poiffons qui font déuorés, \& qu'on trouue dans le ventre des autres, eftant mis fur le gril, preferuent leftomach de ceur qui les mangent, des fouleuemens \& des naw- 


\section{Des Poiffors.}

fées qu'il reffent ordinairement fur la mer ; que luy mefme s'en eft feruy fort heureufement, \& qu'il a paffé ainfi les mers les plus orageufes des Indes. Cette experience eft beaucoup importante, \& il eft bon dechercher quelque raifor qui l'autorife, \& qui infpire le monde d'en mienx obferuer les effets.

On peut donc dire fur ce fujet, que tous les animaux tués, deuorés, \& qui meurent d'vne mortviolente, ainfi que nous auons remarqué ailleurs, reçoiuent vn notable changement dans leurs efprits, \& dans leur fubftance. Ce changement confifte d'auoir vne faculté d'éfacer, d'eftreindre, \& de repouffer : Enfin de fupprimer \& d'arrefter ce qui irrite, ce qui coule, ou ce qui fe produit audehors: c'eft ainfi que le fang du lieure couru $\&$ déchiré des chiens guerit de la dyffenterie, qu'on recherche le crane des hommes pendus, \& que les mains des noyés effacent les marques que les meres ont imprimées fur leurs petits. Cela eftant ainfi, il ya de l'apparence que les poiffons pourfuiuis, attaqués \& engloutis, peuuent imprimer par la peur à l'eftomach deceux qui les mangent, vne qualité qui l'arrefte, qui le fixe, qui le lie, \& qui le fufpande, en vn mot, qui le rende infenfible, \& qui empefche les fouleueméns qui deriuene des vapeurs, \& de l'agitation de la mer, \& voila la raifon pourquoy fuiuant Harthmanus, les poiffons pris dans le ventre du brochet fer= went à l'incontinence d'vrine.

Outre cette raifon on peut conjecturer, que comme le fel marin roulé dans la bouche ema : 
160

Des Poifforts.

péche les émotions de la tourmente, comme l'eau de la mer beué fuiuant quelques-vns, fait le mefme, l'efprit du fel, \&c. queles poiflons deuorés peuuent acquerir vne vertu femblable dans le ventre des autres poiffons, \& prendre vine faculté magnetique qui ramalle, \& qui attire toutes les exhalaifons picquantes qui irritent fouuent les entrailles : on peut mefmedire encore que puis qu'il y a de l'ap parence que l'eftomac des poiffons eft muny abondamment de l'acide qui anime, qui fortifie le ventricule $\&$ quiluy donne l'appetit ( c'eft pourquoy les poiffons font voraces \& toûjours auides, \& necraiynent point l'emotion continuelle des flots)que dis-je, cette acidıté fe communique aux poilfons deuorés, que le gril l'attenu $\ddot{~ \& ~ l a ~ d e ́ u e l o p p e ~}$ qu'elle corrobore noseftomacs dans la mer, \&e comme nous auons remarqué \& nous montrerons plus au long, que l'acide abforbe \& adoucit ce qui eft alcalisé, \& qui picquote par fon acrimonie; il eft probable que cette acidité communiquée fait le mefme aux vapeurs quis'eleuẽt toûjours de la marée qui prouoque les foulleuemens, \& qui font fortir iufques à la moindre goutte des humeurs inutiles qui font contenuës dans nos parties.

\section{CHAPITRE III.}

\section{Des Fruits.}

Dur conceuoir la nature des fruits, il fase 1 examiner leurs differences, afin de décou, urit 
Des Fruits.

urir les qualitez qui font affectées à chacune en particulier.

Les fruits font oleagineux, terreftres, efcumeux, fpiritueux ou falins, ils participent du laict, du miel, du vin, ou du fuccre, ils retiennent quelquefois la faculté des mineraux; enfin ils ont vne nature qui eft meflée, \& qui ramaffe les vertus qui fe trouuent efparfes, leurs efpeces \& toutes leurs differences.

Les glands, les chatagnes reffemblent à leur mere; car elles font terreltres, pefantes \& groffieres : c'elt pourquoy on les reduit facilement en farine, \& elles font nuifibles à l'eftomach par leur confiftance maffiue, aulfi le feu feul les peut reduire dans la mediocrité, encore engendrent elles apres la cuite des obftructions par leurfaculté adfringente, \& il y à à s'eftonner. pourquoy eft-ce que les femmes n'en font $g$ randement alterées, quiaiment les chatagnes apres le repas, \& durant la nuit.

Les fruits oleagineux font de deux fortes. Les vins ont vne hulle douce, agreable \& fubtile, quiramolit les parties, \& qui fertà la poictrine de lenitif; mais dont l'excez caufe la chaleur \& le feu, par l'embrafement de cette fublance. Les amandes, les piltaches \& les pignons font decét ordre, \& ce fruit dont le fuc battu fout: nit aux Indiens vne efpece de beurre excellant, Les autres ont vne huile plus acre, plus épaille, \& moins moderée: La noix tient le premier rans dans ce genre, d'où vient qu'elle gafte la voix, en imprimant à ces organes quelque chofe de gluant \& de cras, qu'elle s'alume d'aillecurs, 
162

Des Fruits.

qu'elle échauffe \& qu'elle deffeiche, \& qu'elle prouoque fi fort l'appetit par fa pointe, qu'on en regaloit le peuple aux Feftes les plus folemnelles de la Grece, \& de l'ancienne Rome. C'eft ainf que Schaliger a expliqué cette infcription,

Incrementa pueris curie

Et

sparfionem mucum dent.

De tout cela on void la raifon pourquoy l'a mandier refifte fi peu, \& qu'à la moindre chaleur il poufle fes fleurs delicates; car l'huile de l'amandier eftant plus fubtile, monte, \& fe rarefie plus pramptementque celle du noyer, qui eft crafle, vifqueufe \& gluante; mais auff la moindre froideur fur prenante la condenfe, l'épaiffit \& la repouffe, \& luy fait abandonner vn fruit qu'elle auoit à demy ébauché.

Les fruits fpiritueux \& falins fe trounent ordinairement aux arbres champeftres, \& à ceux que la nature pouffe fur les rochers \& dans lesbois, ils procedent d'vne fubfance nitreufe \& fubtile, par le moyen de laquelle ils deuiene nent quelquefois venimeux, acres \& purgatifs, \& femblables à ceux dont Pline a dit dans fes Epiftres, cum ne filue quidem, horridiorque natur facies Medicina careat, ils ont méme bien foument vnequalité corrofiue, ainfi qu'on remarque de l'ananaschez les Indiens, qui ronge le fer par $\checkmark$ ne faculté diffoluante, \& par des efprits penetrans. Ces efprits font le principe des fiéares intermitantes à la campagne, commenous montrerons vn jour.

Les fruits qui ont vn fuc efcumeux, ou bien 
quireffemble à la baue, font or dinairement mal rans, parce que leur matiere eft aflez impure. \& mal digercé, \& qu'elle les rend molafles, \& les difpofe à la corruption. C'eft de là que certaines pefches dans la Perfe, \& quel yues abricots chez nous, font les féures intermitanies, \& que le fruit du fauon dans les Indes eft fort nuif ble à l'eftomach, parce qu'il eft fi fort efcumeux, qu'eftant battu dans l'eau, il donneau linge par fon efcume, vne blancheur fort agreable.

Les fruits vineux font ceux là dont on efpraint vnehumeur quibouillonne, \& que h feimentation change en vin : c'elt ainfi qu'on prepare le cidre, le poiré, le vin des palmes, desraírins \&rce de là vient qu'ii faut manger fort mediocrem nt de ces fiuits, de peur que la quantité ne les fafte bouillir dans nos flancs, comme s'ils eftoient dansla cuue. Sur cefujet on peut refoudrecette queftion fil long temps agitée, fçauoir, s’il faut boire du vin ou de l'eau apres auoir mangé des fruits. Car les terreftres, les aqueux, les fanguins, les efcumeux ix les oleagineux exigent du vin, ainfi qu on obferue a pres les chatagnes. les pefches, les noix, les amandes \& lesolures; \& pour ce qui ett des vineux, on peut boire du vinapreseux, fileur quantité eit petice, fil'eo ftomach eft foible, \& sil faut corriger ce qu'ils ont dhumide \& de froid; mis il faut prendre del'eau lors qu'on s'en charge, pour moderer le fe't, \& pour abattre les vapeurs。 qui s'efleuent de leur bouillonnement.

Les laicteux, comme les figues fraiches, nour I. ii 
164

Des Fruits.

riffent, lafchent, adouciffent, \& font pectoraux; mais ils font bien fouuent la matiere de la vermine, \& leur excez difpore les humeurs à la corruption.

Les fruits qui participent du fuccre ou du miel, marquent vne cúte excellente; car en moderant les qualités pafiues, elle faitvn firop de leur fuc, \& donne aux melons, par exemple, $\&$ à d'autres fruits vne douceur charmante. L'art tache d'imiter cette parfaite digeftion; car apres auoir cuit les fruits verds, elle les joint au niel, ou au fuccre, \& les trempe dans vne liqueur quiapproche du fuc naturel. Au refte on doit prendre garde de ne fe pas trop gorger de cesfruits; carils cachent vn fel picquant que la chaleur de nos eltomachs deueloppe, qu'on void paroiftre au deffus de quantité des fruits en forme de fuccre, que le peuple des Medecins a nommé bile, quirend la carfe purgatiue, \& qui prouoquela dyflenterie aux Indes, \& en quelques lieux du midy, où la chaleur l'attenuë, \& le fubtilife, \& ou les fruits de cette nature font abondans.

Les fruits qui ont la faculté des mineraux la cirent par le moyen de l'arbre, ou bien ils reçoiuent de la digeftion quelque chofe qui luy approche; on void la premiere à quelques raifins de la Hongrie, qui font peints d'vn jaune brillant, \& qui ont les pampres dorées, parce qu'ils prennent leur nourriture dans des lieux qui cachen des mines d'or \& d'argent; $\&$ voila la raifon pourquoy il y a des vins qui font malfaifans, qu'ils caufent la goutte, \& des indifpo- 


\section{Des Fruits.}

fitions opiniaftres, parce qu'ils portent auec leurs efpritsceux de quelques mineraux que les raifins ont attirés. Les fruits ont encore des facultés approchantes \& analogues : par exemple, quelques-vns ont du rapport au vitriol par leur acidité penetrante; ils fixent, ils rafroi. diffent, \& ils purifient ainfi que luy ; mais ils nuifent à la poistrine: on peut metire fous cét ordre les oranges \& les limons. C'eft pourquoy leur fuc efface ies taches de l'ancre, parce que fon acidité abforbe l'alcali des gales, quı tenoit, \& qui arreftoit le vitriol, \& dont la liaíon fait la noirceur qu'on void à l'ancre.

Les fruits mixtes, c'eft à dire d'vne differente nature, font pour l'ordinaire fort tẽ perés, on void cela aux griotes, aux grenades \& aux cerifes, quifont compofées du vin \& de l'eau, aux prunes, qui ont l'eau, le miel ou le fuccre, \& à quantité d'autres fruits qu'il feroit fuperflu de nommer.

Outre toutes ces differences, il faut encore adjoufter celles qui deriuent de la confiftance des fruits, \& des diuers degrés de leur maturité.

Les fruits dans leur confifance font durs, mols, ou ils font dans l'égalité, \& au milieu deces deux natures; les durs fe conferuent longtemps, ils font pour l'ordinaire, ou oleagineux ou terreftres, \& poffedent leurs qualites. Les mols fe corrompent facilement, le microfcope y découure ordinairement vne quantité de vermine; on les vend aux enfans, qui en fouffrent des fiéures \& d'autres maux. Ouide remarque cela dans l'ancienne Rome, oùion eftaloit ces. L iij 
fruits à demy corrompus a la ruë facrée: C'eft pourquoy en fe moquant il dit,

si zibi mil dederit facra roganda via eft.

Les fruits qui paricipent des mois \& des durs fe peutent conferuer quelque tcmps, commè les pommes \& les poires, \& on ne doit pas appiehender fi toft ce qu on void arriuer aux mois.

Enfin on doit obferuer aux fruits les trois temps qui feruent à leur nourriture:au premier, par exemple, ils ne reçoiuent qu'vn fuc impur \& mal digeré, quiles rind apres folides: au fe. cond, ils c nont vna demy preparé, qui les fait chez nous la matiere des fieures, à la campagne, \& durant deux failons de l'annéc : \& au troifiéme, ils en contiennent vn quicontribue à leur excellence, pourucu que l'excez ne les rende maunais.

A pres toutes ces differences, finmons ce Chapitre par vne refiexion profitable, qui nous aidera a mieux connoiftre la nature \& la veru des fruits en general. Les fruits font des ceufs, ainfi que nous auons éfleuré cy-deflus, puis que la plupart font d finćs pour faire des produations nourelles. Or ces ocufs ont comme les autres quelque chofe de fort, cienourriflant, \& d'inflatif, ils ont quelque chofe de fort par le moy $n$ de leurs efprits, \& des femences qu'ils contiennent, par ces efprits ils ont la couIeur \& le gouft, \& le pouuoir de paffer à des gezeratiós nounelles : $c^{\prime e f t}$ par cux que les pommes renettes ont diuerfes figures fur leur efcorfe, \& les cerifes cellés du cerilier dans leur noyeau; enfinceft par ces efprits que les fruits bouillon- 


\section{Des Fruits.}

sent dans nos entrailles, \& y excirent des fumées, \& la chalẹur : l'odeur mefme quils ont en deriue, auffi c'eft d'elle que les beftes connoiffent la bonté des fruits en flairant, \& qu'vn enfantefleué dans la foreft noire, découuroit les vertus \& les qualitez des champeftres, les tranfpirations qui en fortoient, \& le temps qu'on. pounoit les cueillir.

Les fruits ont quelque chore dinflatif : c'eft pourquoy ils fe gonflent foutent, \& fe dilatent dans nos ventres, la chaleur leur fert de leuain, ellerarefiece firop naturel, dont la nature les arroufe, leur miel s'eftend par fon moyen, fa vifquofité s'atenü̈, \& demaridant vne plus grande place, elle bourfoufle l'eftomach. Cela arriue ordinairement lors qu' on mange les fruits en quantité, ou trop chauds, \& trop fraichement pris de l'arbre, parce qu'ils retiennent encorecette vertu fermentatiue qui les augmente, \& quilesentretient fur le tronc.

Les fruits unt encore v ne faculté nourriflante parce qu'ils ont du miel, du fucre, de l'huile, ou du vin, que beaucoup ont vn fuc balfamique, quia pour principe les fleurs, \& qui prouient d'vne quinteffance filtrée, preparée \& cuite dans leurs deftours, dans le tronc, \& dans les racines, ou bien dins les fueilles \& dans les rameaux; cette quinteflance fe trouue fi fort épurée, qu'elle eft dans vne parfaite mediocrités quirend les fruits fort delicats, mais corruptibles, \& qui les proportionne à la pureté de nos chairs : c'eft ainfi que les chofes les plus exquifes viennent de la terre, \& que noltre nourriture 


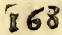

Des Fruits.

ne fe prend que de là. Cependant les fruits font quelquefois nuifibles, lors que durant les fecherefles, le Soleil \& l'arbre abforbent vn aliment acre \& trop fort, \& qu'ils éboiuent la terre, comme l'enfant qui efpreint en fucçant les mammelles prefque taries : alors quantité de fels fe fubliment \& montent en haut, ils fletriffent les fruits, \& ils oftent à leurs chairs ce qu'elles ont de fucculant \& d'humide, ils les remplifrent de quantité d'infectes, ils les font la matierede la bile, \& le fujet de la chaleur, ils égalent leurs efprits à l'eau forte; \& juftifient le Poëte quidit au 3. de l' $x$ neide.

-..-- Tum fteriles exurere sirius agros.

Arebant terra, \&o victum Jeges agranegabat.

Cela arriue fouuent chez nous pendant l'Efté, dont la chaleur ne brûle pas feulement les fruits, leur miel, \& leur fuccre; mais elle détache les fels venimeux \& cauftiques des terres arides \& rablonneufes, quifont le principedes maladies populaires, qui nous arriuent fi frequemment, oule ventre fe déregle, la foif nous preffe, \& le corps eft en feu; \& voila la raifon pourquoy, fi la pluye furuient, elle arrefte les progrés deces maux, parce qu'elle détrempe les fels, qu'elle en émouffe la pointe, qu'elle entraine, \& qu'elle laue \& diffoud ceux de l'air, qui meurtriffent nos chairs, allument noftre fang, s'introduifent dans nos pores, \& caufent des accidans qui ne peument eftre calmés que de la fraicheur \& du bain. C'eft ainfi que les changemens de faifon nous profitent, comme nous montrerons ailleurs. 
Il refte feulement à obferuer fur les fruits vnechofe aflez remarquable, fçauoir quion void aux prunes, par exemple, lors qu'elles font nouuellement cueillies, comme vne pouffiere quiles couure, \& quiles bla achit, que le vulgaire a nommée la fleur; \& quifert de preuue de leur pureté \& de leur fraicheur. Or on a pris garde que cette fleur ne deriue que de quantité de petits filamens d'vne blancheur brillante, qui fortent du fruit d'vne maniere delicate, que le microfcope fait voir, \& que les doigts rompent \& détachent : C'eft pourquoy les prunes perdent leur fleur lors qu'on les manie founent.

\section{CHAPITRE IV.}

Des Fruits verds.

C'Eft quelque chofe de bien remarquable; que l'appetit qu'on a de manger des fruits, \& le foin que la nature a eu d'en produire de tant d'efpeces pour le farisfaire \& le contenter: Porphire au liure de l'abltinence, \& des Sacrifices, a creu que c'eftoit là la veritable nourriture des premiers peuples, \& a fouftenu que les $S a-$ crifices des fruits eftoit plus agreable aux Dieux que ceux des animaux. Primi qui animalibus vefci caperunt penuria frugum animalia inuaserunt, prius enim terre fructibus vescebantur. A uffic'eft fans doute cette inclinatio fo forte qui fait rechercher auec empreffement les fruits qui font encore verds. quiles fait défricher par vn dereglement eftran- 
270

Des Fruits rerds.

ge, \& qui oblige quantité de perfonnes à les tranfporter à des Villes fort efloignées pour en cirer vn grand profit. Faifons voir icy l'effet qui peut arriuer de ce defordre, \& fi nous pouuons, detruifons vne coûtume qui eft la caufe detant de maux : A ce deffein il fe faut feruir d'Hippocrate, \& de la doctrined'Ariftote; Hippocrate enfeigne comme vn fondement trescertain qu'ily a des facultés aux mixtes, que ce fontelles quiles font aigres, picquans ou falés, que leurs excés nous font malades, \& que ceft a cette fin, que comme ce qui eft feparé nous trouble, la nature trauaille toujours à les adoucir ou à les meller: or il arriue qu'elles fe treuuét aux fruits verds fans temperamment, \& fans mellange, ainfi quon remarque par les faueurs * par le gouft; il eft donc certain qu'elles nous produifent les maladies, \& qu'elles font la fource de ces indifpofitions populaires qu'on reffant fur la fin du pintemps, \& au commencement de l'efté : c'eft pourquoy Hippocrate dans le liure de la diette affeure que les fruits qui s'auancent trop caufent les fieures \& les diarrhées, parce quils n'ont pas acquis affez de moderation dans. leurs facultez, quils approchent des fruits verds, \& qu'ils ont befoind'vne mediocritě plus srande.

Tout cecy eft authorisé par les preceptes, \& par les enfeignemens d'Ariftote : Ce grand PhiIofophe afleure dans fes Meteores que la cuitte neft qu'vne perfection, que cette perfection confifte à la reduction des qualitez paffiues, $8:$ que fansclle les chofes font ou trop molles or? 
trop folides \& trop pefantes, \& elles ont des facultés qui alterent nos eftomacs: Or qui ne void que les fruits verds n'ont pas acquis cetce perfection qu'Ariftore demande, que leursfaculrés n'ont pas attcint cet temperaminent, qu'elles reflemblent à celles qu'Hippocrate propofe \& qu'elles font les principes \& l'origine des mefmes effers. Et certainement tout cela eft fi veritable, que cieft par cetie raifon que les fruits verds font a la choleur naturelle comme lebois verd dans le feu, ils nefont là que des vapeurs \& de la fumée non plus queluy, \&x ce font eux qui obfcurciffant ainfi les efprits, jettent fi fort les femmes qui en mangent abondamment, dans 13. rriftefle, que c'elt ce qui a peut-eftre obligé les Afrologues à les ranger fous Saturne, \& à les foumertre âfes influences : on peuidire mefme que comme les fruits verds par le deffaut de cuitte ne produifent qu'vne humeur verdaftre dans les veines, qui irrite \& gui picquote inceff:mmen: par fon acrimonie \& par fon aigreur, il arriue par confequent que cette humeur produit les maladies qui deriuent de l'acide qui eft hors de l'eftomac, \& qui fe treuue eftranger dais les vafes, qu'elle eft d ailleurs comme vis aiguillon quirend les femmes inquiettes \& chagrines, qu'elle leur fait des obfructions, qu'elle abbat par fa mali hite l'efclat \&la beauté qu'elles ont; enfin quelle leur fait deuenir vne tefte aufi verte que les fruits qu'elles mangent font verds: mais ce qu'il y a encore à remaryuer c'eft qu'elies en viennent maigres \& deflechées, parce que cette humeur eltant terreftre, elleeft 
oppofée à la partie oleagineufe \& aẻrienne quj fait la graifle, \& l'embon-point, par fon acrimonie meime elle la ronge \& la penetre, \& a dix rapport au vinaigre, à quion donne la proprieté d'amaigrir. Tous ces fymptomes nous fontiuger que les anciens y auoient pris garde: carils ne mangeoient iamas des fruits s'ils n'en auoient offert les premices: C'eft ainfi que Pline au troifiéme chapitre recommande la religion, des Romains, non deguftaffe eos vina, aut nouas fruges prius quàm Sacerdotes libaßent primiti.s. Or ces premices eftoient tirées desfruits déja meurs; c'eft pourquoy ils les offroient aux Dieux domeftiques, à ceux des jardins, \& à A pollon, d'ont la chaleur viuifianteles acheue \& les perfectionne; les filles eftoient choifies pour les prefenter dans de corbeilles, afin d'apprendre à celles qui aiment les fruits de n'en rechercher que des meurs, c'eft d'ellesce qu'on lit dans le Poete Calphurnius, Has que poniferi laribus confueuimus horti Mittere primitias of fingere liba Priapo, Rorantes fauos damus \& liquentia mella, Surquoy il y a à s'eltonner pourquoy lesfem: mes \& les filles mangent vne fi grande quantité des fruits verds, pourquoy elles ont cét appetit \& cette inclination déreglée, \& d'ou vient qu'elles n'en font pas pour l'ordinaire fi promptement incommodées que les hommes, nonob. fant qu'elles foient plus delicates, \& que leur eftomac foit moins fort.

Pour ce qui eft de lappetit, on peut dire qu'il ne procede que de la varieté d'humeurs que les femmes \& les filles ramaflent dans leurs 
eftomacs \& dans leurs entrailles : ces humeurs cruës \& impures ont du rapport au charbon, au plâtre, à l'alun, \& à beaucoup de femblables matieres; elles contiennẽt fouuent vn felimpur qui approche du nitre que la crudicé a mis dans les fruits verds; c'eft pourquoy 1 lles infpire à l'imagination des femmes enceintes \& des filles mal colorées, qui contiennent quantité defucs, qui n'ont pas eu leur maturité. Et voila la raifon du profit que ces perfonnes tirent des coraux, de l'acier, \&e des yeux d'écriuiffe, qui precipitent ces fels acres \& fuperflus, qu'ils en abbatent \& en alentiffët lapointe, qu'ils les entrainét auec eur, enfin qui les occupent, \& les adouciffent $\&$ en empêchent l'actionfur les parties \& dans l'eftomac: de cecy on connoit pourquoy les femmes fouffrent plus facilement les fruits verds que les hommes : car affeurement ces alimens terreftres occupent les difloluans qu'elles ont : on peut mefne croire que leur acidité les corrige, comme les Chimiques nous montrent par l'huile de tartre \& de vitriol, qu'ils en font mefme amolis \& qu'ils perdent par la diffolution, la dureté de leur confiftence folide, ou bien, fi on veut, qu'ils quittent leur acidité \& ce qu'ils ont d'acre, \& d'auftere, comme il arriue des liqueurs penetrantes, qu'on modere lors qu'on les vnit; cela partant n'arriue pas toujours, fur tout lors qu. l'excés s'y trouue, ainfi que l'experience nous fait voir. 


\section{4}

\section{CHAPITRE V.}

\section{Du Melon.}

T E Melon eft fi excellent, qu'il femble que Lla nature l'ait choifi parmy tous les fuits de la terre, pour y grauer fon caractere, \& pour tracer fur fon écorfe fon chiffre, \& lis veritables marques de fon amour. Vous diriez mefme qu'elle a eu jaloufie dans $f_{a}$ production, qu'elle en a fait vnfruit pipé, vn ambigu, \&vnagreable myftere, \&qu'elle la cache fous des apparences incertaines \& furprenantes, afin qu'on re trompalt fouvent. Neanimoins nous ne fçaurions apprehender icy cette furprife, qui eft partant fi ordinaire : puis que c'eft noftre deflein de penetrer dans lintericur du melon, fans nous arrefter à l'ecorfe, \& que ncus n'auons pas feulement refolu de flairer ce fruit, de levoir, \& de l'embraffer; mais encore de l'ouurir, d'en goufter, \& d'en faire 1 anatomie. A cet effer,

Il faut fuppofer que les genres font comme des lignes que les efpeces comporent \& partagent diuerfement, \& qu'ellesen fon les milieux, les commencemens \& les termes, à la maniere deces points, auec lefquels la mathematiyuea propof́é fes fondemens. De là vient que cells qui font au milieu, tenant également quelque chofe des autres qui font éloignées; e.les font ainfi dans vne grande moderation, que 


\section{Du Melon.}

Thomme, par exemple, eft le plus temperé parmy les a nimaux, le verd parmy les couleurs, \&c Ie melon entre les fruits, \& leurs differences, parce que la nature leur a donné cét ordre, \& a mis vn chacun dans vne diftance égalemert éloignée de leurs extremités. Pour faire voir cela du melon,

Il ne faut que confiderer ce que nous auons dit cy-deffus; fçauoir que la cuite, fuiuant Ariftote, eftant vne perfection, \& cette perfection ne confiftant qu'à la reduction des qualitez paffiues, dans vae grande mediocrité : il eft donccertain que le melon la poffede auec excellence, caufe de fa parfaite digeftion, \& qu'il eft par confequent dans l'équilibre, dans l'égalité, \& dans l'éloignement des extremités de fon genre, comme toutes les efpeces qui font dans le milieu dont nous parions. Il eft maintenant necellaire de faire voir, \& de preuuer par des raifons \&e par des fignes, que le melon fe troutue dans vne parfaitecoction.

Et certainement cela n'eft pas fort difficile, \& il n'y a qu'à voir les differents attributs du melon pour connoiftre fa digeftion. Car premierement, le bon melon doit eftre pefant; parce que la pefanteur eft vn effet de la maturité, qui reduit les eaux \& les parties llateufes. qui fe trouuent ordinairement aux fruits verds, en vn fuc femblable au firop: elle donne vne confiftance \& vne épaiffeur à ce fuc, qui eft la caufe de la pefanteur, \& elle y adjoufte vn fel fucrin, qui fert de beaucoup à l'augmenter. D'ailleurs elle fepare la portion la plus folide, 
\& la plus terreftre, pour fournir vne écorfe d ce fruit, qui a befoin d'eftre coutuert à caufe de fa grande delicatefle : c'eft pourqouy elle en augmente la pefanteur, \& elle aide à découurir la maturité \& l'excellence du melon. Neantmoins elle impore le plus fouuent, \& elle fait voir qu'vne chofe d'vne nature fi capricieufe, eft la veritable figure des amis d'apparence, \& du temps qu'on a beau embraffer, prefler, \& porter jufquesau vifage, \&qu'il fautentamer, $\&$ ouurir pour en connoiftre les defauts.

(v. En $\mathrm{recond}$ lieu, le melon doit auoir vne odeut charmante, vnéclat vermeil \& brillant, \& vne douceur aiguifée d'v ne pointe qui éueille l'appetit, \& quilechatouille. La raifon de cela eft, parce que l'odeur deriue de l'abondance, \& de la pureté des efprits, qui fe font produits dans la cuite, l'éclat elt vin effet de la fermencation \& de la chaleur, qui eft neceffaire à la maturité: c'eft pourquoy le vin \& le fang, qui brilient d'vne couleur pareille, font dans cette parfaite coction, queleur bouillonnement \& leurs efprits ont augmentée : Enfin la pointe \& la douceur procedent de la reduction des qualités paffiues, \& d'vne digeftion fiexacte, qu'ellea meflé également l'eau \& le fel, le foufre \& le nitre, à la maniere de l'artiran, qui joignant fur le feu la liqueur au fuccre, en fait vne confit ure exquife, \& donne vn degré de chaleur qui la cuit, \& qui laffaifonne ainfi que nous auons obferué du firop.

En troifiéme lieu, le bon melon a festranches en nombre impair, parce que l'efprit qui le meurit 


\section{Du Melon.}

meurit, \& quile fait croiftre, cuit fes humeurs parfaitement : \& il imite en luy la chaleur naturelle de nos parties, qui ne digere dans les maladies \& dans la fanté, dans les crifes, \& lors qu'elle engendre, qu'en fuiuant vn ordre \& vn temps inefgal.

Il eft donc certain que le melon eft dans vne cuite parfaite, que les Grecs l'ont fort bien

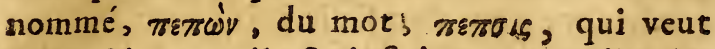
direcoction, qu'il eft ainfi dans vne mediocrité fort exacte, \& par confequent qu'il fe trouue dans le milieu, \& dans l'éloignement des axtremitez que nous auons obferué cy-deffus. De tout cela on peut tirer facilement vn grand nombre de confequences.

Premierement, qu'il ne faut pas s'eftonner fi le melon eft fi delicat, eftant reduit dans vre moderation fi precife: filuy \& le verd agréent l'homme, parce qu'ils font tous d'vn melme rang, \& d'vne mefme égalité : fi on trouue peus de bons melons, parce qu'il eft inal-aifé de les rencontrer dans le point que leur mediocrité demande : fi ceux des pays chauds font preferables, à caufe de la digeltion : fi les pluyes \& la varieté des faifons les corrompent, parce qu'ain I ils tombent dans l'extremité, \& fe tirent de leur mefure; comme l'homme fe porte par la mefrme caufe dans l'excez; ou dans le defaut : fi on doit confiderer le terroir qui les porte; car eftans attachés à la terre par leur nourriture, ainti quel'enfant au ventrc de fa mere parfes vaiffeaux, ilschangent comme luy fuiuant la nature. de cette terre: C'eft pourquoy lors qu'elle eft 
engraiffée \& humide, elle les rend fades \& malfaifans, comme fa feichereffe les priue de leur chair fucculente: Si on doit prendre l'occafion pour couper les melons, de peur qu'ils ne fe changent par la longue cuite, \& quils ne s'alterent par l'abondance de leur fuc : fi ceux qui exhalent l'odeur des courges font méprifables, parce qu'ils n'ont pas vne parfaite mediocrité, \& qu'ils approchêt d'vn fiuit qui ne peut acquerir fa moderation que du feu : Enfin fi les petits melons font ordinairement meilleurs que les gros, parce que la cuite en eft meilleure, les efprits plus refferrés, que l'aliment ne les accable point, \& que leur nourriture n'eft pas fi abondante ny fi diuerfe. Il refte maintenant voir qu'elles font les facultés des melons, \& ce qu'ils peuuent faire lors qu'on les mange.

Certainement il ne faut pas douter qu'ils ne nous foient fort conuenables par leur cuite parfaite, par leur proportion, \& par cette mediocrité qui les fait femblables à nos chairs; leur douceur d'ailleurs les rend fauorables aux poulmons \& au foye, qui s'en rafraichit \& quiles abforbe, la rate mefme s'en abreuue facilement, jufques là qu'elle s'efleue, s'endurcit \& fe gonfle, lors qu'on en mange fans mefure : enfin tout le corps s'en trouue fort bien, les reins s'en reflentent plus dégagés, \& les paffages de l'vrine plus libres : ainfi qu'Hippocrate a remarqué dans le liure des affections. La raifon de celaeft, parce que les melons ont quelque chofe de diuretique \& de penetrant, par le moyen du nitre qu'ils ont de la terre : c'eft pourquoy ils 
acquierent de luy le pouuoir de nettoyer les lombes, la matrice \& les reins : de luy ils donnẽ vne eau qui decraffe \& qui embellit le vifage, ils pouffent le fable \& en empefchent le progrés \& temperent fi fort la chaleur des entrailles par ce nitre, qui eft mellé auec l'humidité, qu'on peut dire que la nature les a produits feulement à ces fins, dans les grandes chaleurs de l'année, \& qu'elle en a fait à ce deffein porter à des arbres dans les pays Orientaux. Il faut pourtant prendre garde que les vieillards n'en abufent point; car leur eftomach s'en déregle, \& le nitre, dont nous parlons leur caufe des diarrhées difficiles a fupprimer, en relachant \& irritant leur ventricule, \& agiffant fur leurs membranes, ainfi que lors qu'ils impriment leur marque fur les linges. plus déliés.

\section{CHAPITRE VI. \\ Des Fraijes, of des Ajperges.}

E s Auteurs qui ont admiré la production Lurprenante du lierre, quirampoit contre les cornes d'vn cerf viuant, n'ont point impofé au public: puis que les belles afperges pouffent parmy les cornes de mouton \& de bœuf, qu'elles deriuent fouvent de leur pourriture, \& que c'eft dans leur proprefubftance qu'elles iettēt mieux leurs racines, \& prennent leur accroiflement. Et certainement cela neft pas inconceuable, puis que ces cornes ferment zux engrais, qu'elles. Mij 
180 Des Fraifes, of des apperges.

ont quelque chore de fulphureux, qui for tifie grandement la nature vegetatiue, puis que les Aftrologues ant rangé les afperges fous les influences de l'Aries, \& puis qu'elles aiment le nitre dont les cornes font pourueues abondamment. Auffi c'eft de ce nitre que ces plantes font aperitiues \& penetrantes, qu'tles mondifient les reins, pouffent le fable, nettoyent la rate, purifient le foye, prouoquent l'appetit, foulagent la goutte, embelliffent le teint, \& rendent la peau plus polie, parce qu'elles precipitent hors des veines, \& par les vrines, à caufe de leur fel nitreux, tout ce qu'ily a d'acre, \& de fuperflu dans le corps.

Toutes ces qualitez ont obligé les anciens à rechercher auec empreflement, \& à donner vn prix aux afperges, ou bien à les qualifier de quelque chofe de Diuin. En effet Varron les a appellées les verges Diuines; \& ç'a efté auec vne huile toute parfumée, que lesRomains nōmoient prspor des Grecs, que, fuiuant Cafaubon, cet honnefte homme les faifoit feruir à fa table. oleum in lucubrationem seruauimus, quod in asparagos totum legitime vertamus. Cependant il y a deux chofes à obferuer fur ce fujet.

La premiere, que les afperges cultiuées ont des facultés moins excellentes, que celles des autres que la campagne nous produit, parce que les cham peftres font plus actiues \& plus nitreufes, comme l'experience fait voir, \& ainfi que l'etimologie du nom nous enfeigne, parce qu'il femble qu'elles foient dites, ajparagi, quafi in asperis virgultis nati. 
Des Fraijes, of des Asperges. 18 .

La fecondechofe qu'il faut obferuer eft, qu'on doit manger les afperges auec mefure, parce qu'autrement elles fe metamorphofent en bile, \& elles fourniflent vn fuc ardent, qui eft propre à la ramaffer : c'eft pourquoy on a couftume de les corriger auec le vinaigre pour en moderer la chaleur, \& pour empefcher qu'elles ne foient la matiere des humeurs qui nous alument, \& qui bouillonnent dans nos parties.

Les fraifes font cultiuées ou champeftres. Celles-cy eftoient en vfage autrefois, l'A pulée en a fait l'eloge, Ouide a dit d'elles.

Arbuteosfoetus, montanaque fraga logebant, Et qua deciderant patula louis arbore glandes.

Et Virgile auec ce Po te.

Qui legitisfores, \& humi nafcentia fraga.

Parce qu'ils ont creu tous deux qu elles ettoient la viande du fiecle d'or, \& qu'eilles contentoient la fimplicité de fon peuple.

Les fraifes cultiuees font fort en vfage aujourd'huy en France, en Efpagne \& en Italie. Pour conceuoir leurs qualités, il faut obferuer leur gouf, leur odeur, \& leur confiftence.

Leur confiftence eft mole \& gluante, \& elle fait vne pafte dans l'eftomach : c'elt pourquoy Fontaine a creulors qu'on mangeoit abondamment les fraifes, quecette pafte eftoit la fource des fiéures malignes \& peftilentes, parce que par fa gluë, elle faifoit les obitructions, \& bouchoit les veines, qu'elle produifoit des himeurs corrômpues, qu'elle emouffoit la pointe, \& arreftoit la mobilité des efprits.

Leur odeur a infpiré le nom Latin fraga, d'où $M$ iij 
[82

Des fraifes: 80 des Afperges.

rans doute le François a efté tiré, fraga à fragando; elle marque au refte des efprits affez abondans, qui prouoquent quelquefois la fueur à ceux qui İe gorgent des fraifes, \& qui impriment à leur peau, par leur qualité impulfiue, certaines taches vermeilles; que Bartholin dit auoir obferuées founent.

Leur goult confifte à vne douceur éguifée d'vne acidité moderée, fans laquelle la faueur des fraifes feroit fade, \& elle auroit quelque chofe de languiflant. Or cela fait voir que les fraifes cachent vne qualité qui eft analogue aux vertus du vitriol, qu'elles ont comme luy la faculte diuretique, que par là elles nettoyent 1a bile, purifient le foye, \& en rafraichiffent le fang, qu'elles foulagent les bleffés, excitent l'appetit, \& feruent aux hemorroides, enfin qu'elles donnent vne eau pour les yeux, pour Ia goutte, \& pour la politeffe du teint. On void de ce difcours que les fraifes peuuent caufer les fiéures malignes, comme le fçauant Fontaine a remarqué, Ii on s'en remplit fans mefure, parce qu'elles peuuent introduire vne acidité dans les veines, qui eft la matiere \& le principe de ces maux.

\section{CHAPITRE VII.}

Des Champignons, fo des Truffes.

C'Eft vne chore bien eftonnante, que ce qui eft fouuent vn refte \& vn effet de la corrup: 
Dès Champignons, \& des Truffes. tion, foit employe aux feftins les plus delicats, \& aux banquets les plus maynifiques : il n'y a rien partant de plus ordinaire aujourd huy, on ne fçauroit feruir vn mets, qui ne foit enrichi deschampignons, \& anciennement mefme c'eftoit ce qu'on recherchoit dauantage dans la debauche.

-..--.-Qui radere tubera terra,

Boletum condire, Eo eodem iure natantes

Mergere ficedulas didicit, nebulone parente.

Examinons donc les qualitez que les champignons peuuent auoir; mais pour le bien faire, confiderons premierement leur naiffance $\&$ leur origine.

Les champignons font produits, \& fortent de diuers principes. En premier lieu, ils deriuent des fujets quife corrompent \& qui finiffent, parce que leur diffolution eueille vn efprit, qui tache de faire vn effort pour reprendre fes premieres routes, \& pour reftablir vn corps qu'il va perdre, ou qu'il a perdu. C'eft ainfi que les anciens on dit que rien ne periffoit, que toutes les vies eftoient immortelles, \& qu'elles fe conferuoient parmy les metamorphofes \& les debris : \& voila la raifon pourquoy on void fortir des champignons des vieux arbres, de leur fuc $\&$ de leurs racines ; car leur faculté prefque mourante ne pouuant rién faire d'acheué, elle degenere auecfon fujet, \& s'exerce à produire desinfectes, de la mouffe \& des champignons, à la maniere des fongofités, qu'on void s'elleucr fur les viceres \& fur les chancres. C'elt ainfi qu'il faut entendre Hippocrate, lors qu'il dit M iij) 
184 Des Champignons, of des Truffes. queladiffolution elt la mefme que la generatio \& que le meflange, \& qu'il y a vn rapport \& vne proportion entre toutes les deux, difcerni idem ac commifceri, commifieri idem atque difcerni, Ge.

En fecond lieu, les champignons font engendrés de ía terre, à la façon des callofités \& des verruës, qu'on void éleuer fouuent fur nos chairs; foit par ce qu'ellecontient, ou qu'elle fe mefle auec les plantes \& leurs racines corrompu"s, c'eft pourquoy il y a quantité des champignons dans les boccages \& dans les prés : foir à caufe de certains ef prits qui s'efleuent de fes entrailles, \& qui ont le pouuoir de produire les champignons: Soit parce que la terre s'épuifant à la maniere des femmes par des generations frequentes, elle engendre ces auortons : foit enfin parce qu'elle eft grafle en quelques endroits, qu'elle abonde en foulfre \& en nitre, \& que c'eft là la matiere des productions dont nous parlons: en effet c'eft ainfi que les engrais leur feruent, que les pluyes nous les font voir en detrempant le fei de la terre, que la Lombardieeft feitile en champignons, \& que fon terroir gluant en nourrit des gros, dont les vertus font formidabless, fuiuant le Poëte.

-....- Minus ergo nocens erit Agripina

Boletus, fiquidem vnius pracordia prefirt.

Que la mer rouge en fournit quantité à lon bord à caufe d'vne humeur oleagineufe \& falée, que ceft ce fel qui les petrifie tous ainfi que les coraux qui y naiffent en abondance; qu'il leur en fait produire des nouweaux, ces champignons 
Des Champignons; of des Truffes.

eftant humectés de l'eau douce, qui reduit en acte le fel : en vn mot qu'on void dans lescimetieres fouuent des champignons d'vne prodigieufe apparence, parce que leur fond eft imbibé d'vne matsere glutineufe, qui procede de la corruption de nos chairs.

Surce fondement, on peut rendre raifon de ce que Camerarius, Belle-foreft, \& quelques Auteurs nous auancent, touchant ces apparitions merueilleufes, que les Egyptiens obferuent dans les grandes chaleurs, fur vne eminence va peu éloignée du Caire, où on enfeuelit quantité des morts : car ces Barbares 凤dmirent là des bras, des jambes, des mains, \& des teftes qui fortent fubitement, \& quidifparoiffent bien toft, \& appellent cet endroit le lieu de la refurrection. Or toutes ces figures font des veritables champignons qui fefont promptement à la façon de nos vulgaires, leur forme procede de ce qui refte des cadaures que la chaleurviolente a fublimé, \& qui paroift à la maniere de ces ombres, que les Chimiques détachent de la cendre des plantes \& des arimaux.

Peut-eftre mefme, qu'il y a dans ses lieux certaines femences cachées qui produifent des champignons de cette efpece, puis qu'on en void dans laHollande en forme de membre viril, que beaucoup de plantes ont la fignature \& le caractere de nos parties, \&qu'vn champig nō qui reprefentoit vne main s'éleua au fiecie paffé de la corruption du bois fur $v n$ theatre, \& effara tout vn pays.

Leschampignons naiffent encore fuiuant l'or. 
dre, \& le deflein de la nature: l'eftrevegetatif commence par eux, ainfi que le fenfitifa pour principe lesinfectes, ils en font les premiers degrez, c'eft pourquoy ils ont leurs femences qui les diuifent en efpeces, \& quelques-vas d'eux peuuent, eftre mangés auec moderation, parce que leurs efprits les adouciffent, \& les moderent par l'effort de la digeftion, comme il arriue aux vegetaux; neantmoins la nature n'en demeure pas là, elle donne encore vn degré plus haut à deschofes fi rauallées, \& elle s'en fert pour remplir le vuide, \& l'interuale des efpeces, \& pour ne paffer des plantes aux animaux fans quelque milieu. C'eft ainfi qu'elle fait des champignons qui font au rang des zoophites, \& comme vn refultat de ce qui vegete, \& de ce qui a fentiment; quelques champignons de la $\mathrm{Ca}$ labre font de cet ordre, ils exhalent vne odeur de mufc, mais dez qu'on les touche, ou qu'on les rouille de nos ordures, ils rentrent dans la terre $\&$ fortent parvnautre endroit : il en eft de mefmedes boyaus marins, des éponges, qui font au rangdes champignons zoophites comme les potirons de Calabre, du phal hollandique quireffemble à la partic fecrette, \& qui fe tumefie lors qu'on en approche les doits, \& de quantité d'ambigus femblables qu'on remarque au bord de la mer: Auffils paffent fouaẽt aux animaux, \& montent à vn degré plus fnblime; car les oireaux qui font en grand nombre aux rinages d'Ecoffe commencent par des champignons, ces champignons fe metamor phofent en vers, \& ces vers en des canards qui fe plongent toujours 
Des Champignons, to des Truffes:

dans l' eau pour y crouuer leur nourriture.

Apres auoir examiné l'origine des champignons, voyons quelles font les qualitez qu'ils impriment à ceux qui les aiment; difons donc qu'ils n'en peuuent communiquer que de tresdangereufes, \& tres-nuifibles, puis qu'ils ne font qu'vn refte de ce qui meurt, ou qui pourrit, $\&$ qu'vne fimple liaifon des efpeces: qu'ils ne procedent d'ailleurs que de ce qui eft cru \& mal digeré, qu'ils fe trouuent fort éloignés de now fre temperamment \& de nos principes, quil y en a de venimeux qui bouchent nos canaux, qui font ennemis des nerfs, \& caufent la paralyfie; qus font quantité defumees qui offufquent la clarté des efprits, qui deriuent d'vne huille impure qui eft contraire au ventricule, enfin. qui ont vn fel acre \& picquant, \& qui pouffêt vnevapeur maligne quifait le vertige $\&$ qui produit le mal caduc. C'eft pourquoy Martial s'eft trompé infalliblement, lors qu'il a. preferé les champignons aux truffes.

\section{Rumpimus altricem tenero decortice terram,}

Tuberabolet is poma fecunda damus.

Puis que les truffes chatouillent l'appetit auffi bien que les champignon's, qu'elles ont le mefme rang, \& le mefme vfage; examinons leurs qualitez de la mefme maniere, \& découurons leur origine pour faire mieux conceuoir leurs vertus.

La generation des truffes a fort partagé les Auteurs; quelques-vns fe font figurés quielles font produites d'vne terre nitreufe, \& d'vne humeur vifqueufe, \& gluante qui l'vnit \& la ioint 


\section{8}

\section{Des Cbampignons, of des Truffes.}

par hafard, ils fe font imaginés pour cela les rumeurs \& les enleueures de nos parties quife font d'vne congeftion; ils ont creu que cette humeur couloit des arbres \& des racines, que c'eftoit icy la raifon pourquoy il y auoit quantité de truffes dans les bois, \& qu'on y trouuoit quelquefois de la monnoye en les ouurant, ou quelque autre chofe d'étrainge, qui s'eftoit rencontré fortuitementlors que la matiere fecondenfoit.

Quelques autres neantmoins ont donné aux truties pour pere les tonnerres \& les éclairs, ils ont fait ces filles de la terre les filles du ciel mum. tiné, \& fi Iuuenal a exaggeré fur l'excés des feitins \& de la débauche, c'eft apres auoir dit en parlant d'elles,

\section{Faciant optata tonitrua canas.}

Plutarque a tâché de trouuer la raifon d'vne origine fi furprenante, mais apres luy les plus Içauans ont enfin découuert que c'eftoit l'eau nitreufe, \& remplie des eiprits des nu s fulmi. nantes \& allumées, qui feruoit de diffoluant \& de lewain, \& qui prouoquoit la vertu feminale destruffes, pendant que la foudre luy imprimoit la confiftence $\&{ }^{\prime}$ la dureté à la maniere de ce qu'elle fait bien fouuent au vin, à quelques animaux qu'on a trouués roides \& empierris, à nos humeurs, \& à des arbres.

Il y a partant de l'apparence, que la nature a eu deffein de former les truffes auff bien que les champignons, qu'elle leur a donné leur rang \& leurordre, \& que c'eft auff par elles qu'elle a voulu tracer les fondemens de l'eltre 
Des Champignons, do des Truffes.

\& du genre vegetatif: Il y a de fi fortes conjectures qui authorifent ce fentiment, qu'il ne reftera aucun fcrupule au lecteur lors quilles aura obferuées.

En effet fil les truffes d'Egypte font de bulbes qui produifent de belles fleurs : fi les noftres ont de filamans que le Microfcope découure, pae le moyen defquels elles prennent leur nourriture à la façon des plantes de mer: Si les Indiens mangent do fruits foûterrains qui ont leur gouft \& leur figure; fi la nature leur a prepare leurs faifons ainfi quaux plantes $\&$ aux fleurs: Si les truffes de l'Amerique multiplient partar gées en diuers endrcits; fi celles-là auec les noftres rempliffent les vuides parmy les genres, en font les ébauches \& les crayons, \& font à leurs efpeces comme les nombres fimples à ceux qui font quarrés \& cubiques; qui doutera par confequant que les truffes nayent pour principe vne vertu femmale \& feconde, qui les engendre \& qui les forme à proportion des arbres \& des arbriffaux, \& qui les faffe les cömencernēs de la nature vegetable comme nous auons remarqué. Il eft donc certain que les truffes font au nombre des plantes, qu'elles ont comme elles vn efprit qui les engendre \& qui les diuife en efpeces, qui en fait des femblables aux cornes, aux limaçons \& à d'autres chofes, \& quiles digere fi bien, qu'il leur imprime vne odeur agréable qui les fait remarquer de bien loing. Voyons maintenant de quelle façon cet efprit les engendre, \& de quelle nourriture il fe fert pour les faire augmenter \& pour les groffir. 
\$90 Des Champignons, dr destruffes.

La nourriture elt v ne humeur graffe \& vifcide, qui a du rapport à l'aliment des champignons, qui deriue comme luy du fuperflu \& du refte des plantes, qui fe filtre dans les filamans dont nous auons des ja parlé, \& quilie les parties falées des truffes à la maniere de la glu: c'eft pourquoy le lieu oi lestruffes font engen. drées eft d'vne couleur blanche \& cendrée, parce que la matiere graffe qui donne la couleur obfcure eft employè à faire croiltre ces tumeurs, auffi elles fecorrompent facilement par la vifcofité de l'aliment qu'elles attirent, \& cette cor ruption contribuëà les engendrer de nouueau.

Pour fairevoir cette generation, il faut obferaer, que comme les truffes s'engendrent au commencement de T'automne, elles finiffent \& $\mathrm{re}$ corrompent au printemps : la raifon decela eft parce que la terre venant à fe fermenter, elles rouffrent vne diffolution \& vn relachement dans elles mefmes, leur humeur gluante euapore \& fe flêtrit alors, \& elles perdent ce qui leur fert de glu, ce quiles affermit \& quidonne leur confiftence. Or comme la corruption eft vn acheminement à vne production nouuelle, l'experience fait voir que les truffes qui finiffent ainfi, fe metamor phofent en de papillons, \& que ces animaux fortent en fuitte d'où les Iruffes font rama flées; de forte que reuenant sur la finde l'efté, ils y rapportent vne femence quileur a feruy de principe, qu'ils ont digerée dans leurs petits corps, \& qui reftablit les truffes ì demy feichées par la corruption \& par la chafeur, c'eft ainfi que les papillons produifent 
Des Champignons, \& des Truffes.

fouuent les herbes $\&$ les infectes, en preparant les graines quirefteroiêt d'ailleurs impures : c'eft ainfi que les habitans du Dauphiné connorfent les lieux abondans en truffes, lors qu'ils y voyẽt reuenir en automne quantité de ces papillons, qui les couurent \& les picquotent; parce qu'ilsy deporent ce qu'ils en auoient retiré, qui renait de nouuéau dans la terre, \& qui luy fournit vn leuain : enfin c'eft de cette façon que les moucherons des figuiers champeftres de la Grece:s venant à mordre les figuiers domeftiques $\&$ cultiués en prouoquent la maturité $\&$ en produifent l'abondance, \& donnent au fruit vne tendreffe \& vn gouft excellent, en infpirant à l'arbre vne vertu prolifique \& feconde, $\&$ en faifant commeles mouches ordinaires qui picquant les chairs. elles y produifent leurs petits vers.

Voila nos conjectures fur la generation des truffes : Voyons maintenant quelles facultez elles ont. Or il eft certain que leurs vertus fon $t$ plus nuifibles que profitables, puis que les truffes font dans les tenebres $\&$ hors du foleil qu'elles ne font que des veftiges de la nature vegetable, que leur aliment elt groffier, qu'elles abforbent ce que la terrea de fuperflu à la mas. niere de nos glandes, qu'elles fe corrompent facilement, que leur fubftance gluante gonfle la rate, fait les melancholiques \& leur caufe des obftructions, qu'elles degenerent en vers \& fe changent fouuent en pierre, \& que c'eft cette forte de pierre qui produit eftant arroufée quantité de champignons par vne proportios 
192

Des Oublies.

naturelle; en vn mot puis qu'elles engendrent les vents, \& que par leur moyen elles font enne. mies de la temperance, fuiuant le Poëte.

Semina nulla damus, nec Jemine nafcimur vllo, sed qui nos mandit femen babere putat.

\section{CHAPITRE VIII:}

\section{Des Oublies.}

Voy quece foit par diuertiffement, \& par vn caprice, qu'on mangequelquefois des oublies, \& qu'il femble d'ailleur's qu'vne chofe fi legere \& fi delicate ne fçauroit imprimer quelque qualité remerquable, il nefera pas neantmoins hors d'ouure d'en faire l'examen dans peu de mots, \& de voir quelle eft leur nature fuiuant l'ordre que nous auons propofé cydeffus.

Le nom d'oublie dans Rodiginus deriue du

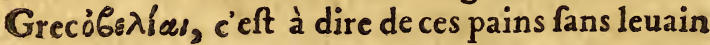
qui ne couftojēt autrefois qu'vne obole, \& qu'on auoit accouftumé, dit Galien, de prefenter aux Idoles pour marque d'vne grande veneration; quelques modernes partant le font venir d'obelus qui fignifie broche, à laquelle les anciens rotiffoient ces pains apres les auoir meflez auec le sniel, \& les aromates, pour les faire entrer au rang des mets, que les Grecs on nommés

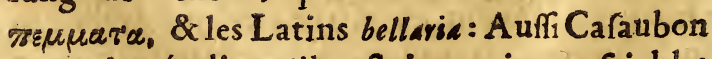
fur Athenée dit qu'ils eftoient minces, friables \& redoublés à la façon de nos oublies, \& qu on les 


\section{Des Oublies.}

les trempoit dans le vin comme eux pour res nouveller la débauche, \& pour châtouiller l'ap. petit apres le repas.

Quoy qu'il en foit, partant il y a de l'apparence que nos oublies font fort differentes de celles-là, que leur confiftence n'eft pas fi maifiue ny fi pefante, \& qu'on ne lesa pas inuentées dans des fiecles fort efloignez: le premier que nous auons pû découurir, eft celuy du bon Roy René, qui fe feruoit des oublies comme de Rebus eltanten prifon, \& qui en faifoit la figure fur les murailles de fa chambre afin de montrer par ì qu'on l'auoit entierement mis en oubly. Pour découurir maintenant leurs qualitez, \& les biens, ou les maux quelles nous peuuent faire: voyons quel eft leur meflange, leur matiere, \& leur forme, \& auec quoy \& en quel temps on les prend ordinairement.

Leur forme reprefente vn cornet, à la façon de cellesd'Athenée, elle ne fait aucun effet, vous diriés feulement qu'elle marque quion veut cor. ner des nouueaux excez, \& inciter les débauchez à faire vne nouuelle charge : c'eft pourquoy on a toûjours prefenté les oubies aux Bacchanales anciennemèt; \&Clement $A$ lexandrin les a ob. feruées ainfi, parlät de la folẽnité de ces filtes, libag; multis difincta vmbilicis, placenta, asq; papanera. Leur matiere elt la pafte qui n'elt pas leuee; fi bien qu'elle a les mefmesvertus du pain faris leuain. Orce pain a trois qualitez, il prouoque a la volupte, il engendre vn fuc melancholique, $\$$ il fait des obftructions \& produit des vents.

La premiere eft publiée par les fçauans, par $1 a$ 


\section{Des Oublies.}

raifon, \& par l'experience : la raifon nous en: feigne que le pain fans leuain eft le fujet de beaucoup devents, ainfi que nous monfrerons cy-apres, \& qu'il a vne vifcofité quile gonfle dans nos entrailles, de forte que rempliffant les lombes, \& gonflant les parties voifines, il fait ces emotions qui font opposées à la vertu. C'eft de là que la purée, les legumes, la croufte de pafté \& les tartes agiffent; que Didimus a dit * au rapport de Langius, in vniuer am panes absque fermento facti efficaciffimi funt ad venerem, \& qu'on a tiréle prouerbe, fine Baccho, \& Cererefriget Venus.

Mais quoy, me dira-t-on, d'où vient donc que dans Plutarque les Preftres d'Ifis, \& le Flamendialis dans Rome fe nourrifloient de pain fans leuain pour entretenir leur continence?

Ileft aiséàxépondre que ceux-cy confideroiēt pluftot lá figure que la realité, \& comme le leuain eft le fymbole du changement, de l'emotion \& de la pourriture, ils vouloient fignifier par là qu'il faloit s'abftenir de tout ce qui eftoit la marque de l'impureté ; c'eft pourquoy ils ne mangeoient point du fel, qui eft le leuain general de ce monde : Et les Iuifs pratiquoient $f \mathrm{l}$ bien cela dans l'ancienne loy, qu'on lit dans Rabi Ben-Efra fur le Leuitique, qu'ils deffendoient d'adoucir les pains qui n'eftoient pas leués, parce que le fucre, \& le miel mis en abondance, ontvne pointe qui fuppléeau defaut du leuain; c'eft pourquoy elle modere vn peu la paftedont on fait les oublies, qui feroit d'ailleurs plus mal-faifante.

Le fecond effet du pain fans leuain confifte à 
produire la melancholie, à caufequ'il avne fubfance terreftre, froide, pefante \& grolliere, qui le rend femblable, ou du moins le fait la veritable inatiere decette humeur. Sur quoy on peut expliquer icy le probleme de Rafis qui a donné de la peine à tous les f̧auăs : Pourquoy eft-ceque le pain fans leuain dirninuéle coeur \& le foye : car par fa pefanteur \& par fa confiftence gluante, il émouffela pointe des efprits, les engourdit. les enueloppe \& les é touffe; \&rend ainfi le cour petit, c'eft à dire, il en diminue la chaleur, \& la force \&ilen abbat la vigueur : adjoûtés qu’il eft aidé en cela de la melancholie, dont il eft le veritable principe; parce que cette humeur bourfouflant la rate, infpire la timidité \& diminue le coeur, le foye, \&les autres parties, en excitant l'accroiflement \& l'attraction de celle-cy.

Enfin le pain fans leuain eft la fource des vents : car les efprits du froment qui nefont pas lachez par le leuain, demeurant comme liez dans vne pafte gluante \& maffue, fe rarefient enfin dans le corps, dont la chaleur les attenuë, \& les dilate; \& parce que ces efprits font ordinairement mal digerés, par confequant ils font flateuxa \& deuiennent le principe des vents.

Le pain fans leuain a donc les trois qualitez precedentes, il y a de l'a pparēce par ainfi qu'elles fe trouuent aux oublies, \& certainement elles produifent comme eux la melancholie fi on en mange trop fouuent, les Aftrologues ont rem. connu cela puis qu'ils les ont rangées fous Satur: ne, \& qu'ils ont obferué que ceux qui les vendent ont de cette planette d'eftre infortunes

Nij 
comme elle \& de trauuailler dans la nuit, d'eftre mal traittez, d'eftre trompeurs, fales \& amys desrats, qui font des animaux Saturniens, enfin d'eftre batus, \& de gaigner au jeu pardes rufes \& des adrefles. Les oublies dailleurs font encore les obftructions, \&engendrent les vents ainf que les pains fans leuain : car comme on les mange ordinairement auec l'hipocras, il fe fait par ce mêlange dans 1 eftomac v ne pafte feniblable à la colle, qui eft fort nuifible apres le repas, qui eft le temps de cette debauche, \& qui eftant entrainée toute crü par l'hipocrasou par d'autres boiffons penetrantes, dans les entrailles, 8 \& dans le foye, deuient la matiere des vents, bouche les parties, arrefte les efprits \& fait les obftruetions, \& caufe les vents: on infere de là la troifieme vertu des oublies, puis que les vents la produifent, comme nous auons marqué cydeflus: \& c'eft peut-eftre par cetteraifon, qu'on fait les oublies lors que Venus, \& Bacchus triomphent des hommes, \& que ceux qui les vendent, les diltribuent de nuit en difant des chan. rons qui funt contre la pureté.

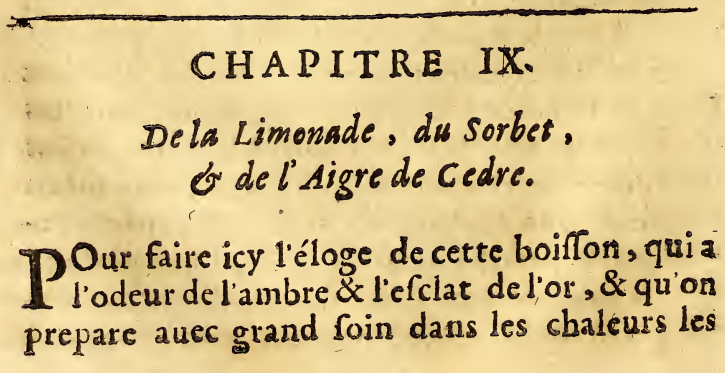


plus ardentes, il n'eft pas befoin d'eftre infpiré du Dieu d s beuneurs, \& dauoir fonenthoufiafme, elle n'elt pas de la débauche puis qu'on la peut offrir aux vierges les plus innocentes, \& les plus fobres fans craindre d'offenfex leur pudeur : aufi elle coule de ces pommes d'or qu'on prefente fouluent aux plus belles, fans que leurs femblables en deuiennent ias loufes, \& fans qu'elles foient obligées de paroitre comme autrefois. Examinons donc auec briefueté toutes les qualitez quelle polfede, \& voyons de quelle maniere fon vfage peut eftre propreà la fanté.

Lefuc da imon a trois qualitez, il fortifie le cour \& en éloigne les venins; \& les ixhalaifons peftilentes, it pouffe le fable \& nettoye les reins, enfin il rafraichit le fang, \& le foye, il tempcre la bi.e $\&$ les vapeurs qui en deriuent: ii fau donc que la limonade, qui n'eft quela liqueur de ce fruit, al terée feulement par le fucre, que, dis je, elle agiffe de la melme maniere, \&e qu'elle faffe des femblables effets : faifons voir mainienant que ces trois facultez fe trouuent zu fuc de limon.

Tout le monde eft daccord, que le fuc du limon eit excellent pour arrefter les imprefions qui difpofent les reins à la pierre, non feulement parce qu'il s'oppofe à la bile, qui eft las fource de ces maux fi les hæmorroïdes ne la vuident, non feulement parce qu'il penetre toutce qui eft petrifié ainfi qu'on void aux perles, aux co:aux, \& aux yeux d'écriuiffe; mais encore parce qu'il abforbe ces matieres picquantes s $N$ iij 


\section{8}

Dela Limotade, du Sorbet, cue.

tartareufes \& falées, quis'empierriffent promprement à la façon de ce qu'il fait à l'ancre, lors que fes tâches s'impriment aux draps. Le fucde limona donccette vertu, il faut par ainfi qu'elle foit à la limonade, \& qu'elle profite par confequant à ceux que la pierre \& le lable ont embarraffez.

Le fuc de limon a encore la force de fortifier le cour \& d'en repouffer le venin; les Medecins authorifent cela par le frop de limon qu'ils employent à la pefte \& contre les fiéures malignes, \& la ature nous l'éfeigne par la figure du coeur, qu'A thenée au cinquiéme liure a fort bien remarquée au limon, comme le caractere du fecours que ce fruit donneà la plus noble de nos parties; d'ailleurs l'hiftoire qui fuit eft vne preuue conuainquante de la verité que nous auançons. La derniere pefte de Rome fut vn pretexre à quelques femmes de Calabre pour venir affifter en apparence cette grande Ville : mais en effet ce n'eftoit que pour faire vn commerce de Aeur poifon;ces méchantes en compofoient d'vne maniere qui caufoit les mefmes fymptomes que 1a maladie, c'eft pourquoy elles s'en feruoient fort adroitement pour fatisfaire les maris jaloux ou les femmes quigemifloient fous leur tyrannie:ce poifon au refte eftoit ainfi qu'vne eau elaire \& brillante, \& la quantité de fes goutes faifoit vn effet plus long ou plus court; neantmoins il fut découuert par adreffe, celles qui ledonnoient furent executées à mort, \& les courmens ioints aux remords de la confcience leur firent déclarer ce venin, auec le fuc de limon 


\section{De la Limonade, du Sorbet \&.c.}

qu'elles oppofoient à fa violence comme fon veritable ennemy. On ne doit donc pas douter de Ia vertu contre les venins \& contre la pefte, \& on doit prefumer qn'elle fe touuc auec excellence à la limonade que nousbeuuons, puis qu'elle eft du mefme principe, \& qu'elle deriue du fuc de limon.

La troifiéme qualité du fuc de limon, eft de rafraichir le cour:, le fang, le foye \& toutes les humeurs ardentes; en premier lieu parce quece qui eft acide empêche l'inflammation \& l'embrafement des parties oleagineufes \& fulphurées qui fe ramaffent en abondance dans la portrine $\&$ dans le foye: c'eft pourquoy les Medecins meflent l'efprit de vitriol aux juleps, la nature a répandu vne acidité dans le fouphre, \&on foulage l'erefipele \& les autres tumeurs bilieufes qui deriuent d'vne huile embrasée, par le vinaigre, \& par l'oxicrat.

En fecond lieu Hippocrate, au liure de la diete des maladies aiguès, dit que ce quieft amer eft penetré par les acides, defquels il eft enfin rafroidy \& fixé, \& reduit dans vne confiften-

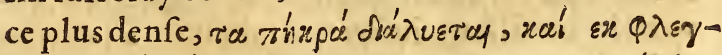

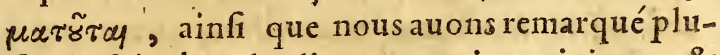
fieurs fois dans les liqueurs qui precipitent, \& dans l'vniö qui fe fait de l'huile de tartre auec l'efprit du vitriol, \& c'eft fans doute ce qui faitie fuc de limon en s'vniflant auec la bile, qui eft vne humeur amere \& brûlante, dont il arrefte la mobilité \& le volatil, \& donc il metamorphofe le fouphre en phlegme, \& l'amertume en douceur; difons en de mefme des autres humears

Niiij 
quiluy reffemblent, \& auec laquelle elles ont quelque efpece de proportion : \& voila la raifon pourquoy les modernes foutiennent que le fuc aigrelet du pãcreas adoucit le chile, \&le rend plus é pais\&plus blanc; pourquoy lechägemèt de fon aigreur eftla fource des maladies, \& par quelle raifon on firingue des fucs acides dins les veines lors quion veut fixer la trop grande fluidité du fang. Ileft donc certain que ie fuc de limon rafroiditles parties, \& les humeurs bouillonnantes qu'elles contiennent : il faut donc en dire de mermedela limonade, \& conclurre que l'arbre qui a lor furfon fruit, l'argent fur fesfleurs, \& le verd de l'emeraude parmy fesfueilles, fournit encre l'ambroiliequi appaife la foif, chaffe le venin, empche le rable, fortifie le cour, tempere lefoye \& modere fa chaleur violente. Il nous refte maintenant à vuider quelques objections pour donner plus de iour à cette matiere.

On nous auance que ce quieft aigre eft ennemy de l'eftomach, qu'il fait euaporer la melancholie: qu'Hippocrate a dit des acides que ce qui eftoit noir en eftoit fublimé, \& qu'il en deuenoit bouillant iufques à monter à la tefte.

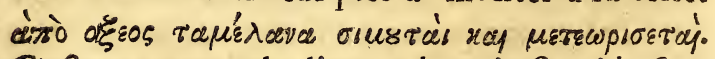
C'eft pouoquoy la limonade qui eft acide fera les mermes impreffions, \& caufera des femblaLles effets, elle amaigrira mefme en fubtilifant, \& ắnfielle fera nuifible aux perfonnes de la Prouince qui ont la reichercfle, la melancholic \& la maigreur.

II faut répondre en premier lieu, que ce qui eft aigre n'elt pas fi contraire à nos eftomachs, 
De la Limonade, du Sorbet boc.

puis que la nature n'en conferue la vigueur que par vn efprit aigrelet, que ce font les acides qui leur procurent l'appetit, \& d'ont on affaionne nos meilleures viandes, quileur feruent de diffoluant \& de leuain, \& qu'il ne faut apprehender que l'excés dans l'vfäge des chofes de cette nature.

Il faut répondre en fecondlieu, pour ce qui eft du paffage d'Hippocrate, qu'il peut arriuer que la limonade remuera la melancholie; mais auffielle la conuertira en phlegme comme la bile, \& elle condenfera fon volatil par l'vnion qui fe fait ordinairement deschofes aigres auec celles qui font alcalisées, ainfi que la Chymie fait voir.

Il faut répondre en dernier lieu que le grand $v$ fage de la limonade peut amaigrir en alterant les humeurs fulphurées qui feruent à la graifle, \& à l'embon-point: C'eft pourquoy on employe le vinaigre pour diminuer la grofleur exceffue descorps; \& les liqueurs aigres profitent aux fiéures ardentes, où le fouphre a coûtume de s'allumer: de là vient que les maigres doiuent boire la limonade moderamment, \& qu'il eft neceffaire qu'ils la meflent auec l'eau froide, a fin que par ce temperamment, ils compofent vne boiffon agreable d'unt le gouft ait du rapport au diapafon, ou à que!que excellente harmonie : il eft partant bon que les vieillards, les pulmoniques, les effouflés, \& les hectiques s'en abftiennent, \& qu'ils prennent ordinairement ce qui fera plusincraffant \& plus lenitif. Difons le merme du forbet, \& des autres boiltons aigrelettes qui procedent du limon, de fes efpeces, ou de 
202

Se la Glace?

quelqu'autrefruit approchãt, \& appliquös-y le difcours que nous auons fair cy-deflus: On doit neantmoins obferuer fur tout cecy de ne fe yorger point apres le foupé de ces liqueurs rafraichiffantes comme on a couftume de pratiquer, car ainfi elles relachent l'eftomach, interrom pent la cuite, détrempent l'aliment \& en empêchent leleuain.

\section{CHAPITRE X.}

De la Glace.

Voy que la nature ait composé l'homme auec harmonie, \& qu'elle l'ait reduit dans vne grande mediocrité; neantmoins il fe porte toûjours aux excés, il en fait fes plaifirs, fes vo.. Juptez, \& fes delices, \& il détruit par leur mayen cette proportion reguliere quile rend l'ouurage le plus admirable de l'vniuers : C'eft ainI qu'il fe plait à des violens exercices, qu'il fe nourrit de viandes trop douces, trop falées, ou trop piquantes, \& que pour appaifer la foif, il joint le froid au chaud, l'hyuer à l'efté, \& la glace aux boiffons les plus temperées. Cet exceza enté exaggeré par les plus honnêtes gens de I'antiquité, \& par quantité d'Auteurs modernes, II bien que nous ne ferons que l'efleurer, afin de n'interrompre le deffein que nous voulons fuiure dans cet ouurage : mais pour faire cela auec clarté confiderons la glace lors qu'elle eft mife abondamment, ou bien lors qu'on l'employe auec 
mediocrité, \& dans la mefure; \& voyons fi elle peut eftre raifonnablement accordée dans la fiéure, \& dans les autres maladies du feu.

Pour commancer donc par la glace prife extraordinairement, \& fans regle :ie dis hardiment: qu'elle eft tout a fait mal-faifante \&cennemie da la fanté. Pour eftablir ce paradoxe, quidans le temps ou nous fommes effarera beaucoup le le.: steur, il nous faut appuyer fur des raifons qui foient certaines \& conuainquantes.

N'eft-il pas veritable, fuiuant tous les plus rçauans Medecins, que la coction du ventricule eft femblable à celle qui fe fait dans le pot qu'on appelle vne elixation, \& dont on tire dubouillon excellent pour la nourriture de nos parties? Orne fçait on pas que l'eau chaude eft meilleure à celle-cy que la froide, que la froideur comprime l'aliment, \& qu'elle empêche l'expreffion de fon fuc, \& l'attraction de fateinture, qu'elle en bouche les pores \& en arrefte les efprits; enfir qu'elle abbat la chaleur, \& diminue cette perfecion des qualitez paffrues fur laquelle Ariftote a eftably la veritable digeftion; \& voila ce quia infpiré Hippocrate au 6. des Epidemies, de dire. refrigeratio qua in ventre continentur indurat, coitus gua in vensre continentur indurat. Et certainement II pour' épreindre quantité d'huile des oliues \& des autres chofes femblables, il fe faut feruir d'eau bouillante dont il faut arroufer le marc: fi les Chimiques pour tirer la teintute, \& l'effence de leur matiere, les macerent dans l'eau tiede ou grandement chaude; pourquoy eft-ce quela nature ne demandera-t-elle pas le mefmedans nos 
204 Dela Glace.

eftomachs pour prendre de l'aliment ce quily de plus gras, \&de plus huileux, \& pour feparer cette cfience fubtile quidoit compofer nos efprits \& entretenir nos vifceres.

Que l'on ne mobjecte point que l'eau à la glace s'échauffe enfin dans l'eftomach; car fion nourrit d'eau froide le pot, nonobitant que le fcu la faflebouillante, elle imprime partant à la viande vne odeur fade \&vn mauais gouft, \& elle amoindrit l'effet \& la perfation qui procede de la cuitte; que doit-on donc prefumer lors qu'on ne verfe pas feulement dans le ventricule de l'eau froide, mais de la glacée, \& lors quion veut nourrir ainfi va aliment fort delicat, \&.eul ment échaufe d'vne chaleur fort moderée?

Dailleurs Hippocrate n'appelle $t$ il pas dans fon liuredes eaux \& de l'air, leselixcru 's\&dures lors qu'elles font trop froides, qu'elles font foûterraines comme les eaux des puys, ou bien lors qu'elles deriuent de la neige, \& de la glace; des mines, ou bien des rochers? ne veut il pas que ces eaux foient nuifibles, qu'elles troublent le bas ventre, qu'elles refiftent à la digeftion: envn mot qu'elles s'oppofent à la chaleur quia peine à les furmonter \& à les reduire ? Or l'eau la glace par artifice, n'eft elle pas proportionnée d̀ la naturelle? \& fi les eaux des puys font difficiles, fuiuan Hippocrate, que fera-ce lors quion les aura refroidies auec excez? Rt quels biensen tirerons-nous dans la ville, nous qui ne beuuons que des pareilles eaux? auff ce font ell s qui par leur crudité deuiennent bien fouuent la fource de nos maladies; \& quiles rendent 
opiniaftres, parce que la glace les fait deuenir indomptables, \& improportionnées à la force de nos eftomachs: \& voila la raifon pourquoy les fçauants Medécins confeillent aux delicats. leau bouillie, ou la tizane, s'ils fe veulent preferuer des maux que la campagne leur caufe fouuent par laqualité de fes eaux.

En troifiéme lieu, pour digerer parfaictement les viandes dans le ventricule, ne faut-il pas que la faculré commence par deux preparations neceffaires, par la diflolution, \& par vne fermentation exacte, afin que les alimens deuiennent rares \& ouuerts, quils fe reduifent en petites parties, \& que la chaleur natua relle les penettre plus fortement? C'eft ainfi qu'on reduit le bled en farine, qu'on diffout la Earine dans l'eau, \& qu'on fe fert du leuain pour en rarefier la pafte deuant que de la mettre au feu: qui doutera donc que ce qui empêche dans nos eltomachs, que ces preparations ne s'y farfent, n'interrompe la digeftion, \& que la glace n'agiffe de certe maniere, puis que fon froid ex. ceflif arrefte les leuains \& les foufleuemens, qu'il engourdit les efprits qui font deftinés diffoudre les viandes, qu'il les fixe, les concentre \& les épai.fit , \& qu'il les rend femblables aux couteaux dont la pointe eft émouffée.

En quatriéme lieu, linterieur du corps fuiuant Hippocrate, eft tranfpirable \& tout ouuert, il eft plein de petits détours, \& de mille pcres afin qu'il y ait vn confentement general, confluxus vnus, confpirctio vra, dit ce grand homme, que l'aliment fe diftribue, qu'il s'épure, 
qu'il fe crible inceflamment, \& que le grand principe faffe couler fes influencés jufques à la derniere partic: Or la glace en endurciffant, en fixant, en comprimant, \& en preffant, n'empêche-t-elle pas cette liberté \& ce dégagement des membres : n'arrefte-t-elle pas ces tranfcolaions; n'eft-elle pas vn obftacle au confentement general; ne rend-elle pas linterieur des entrailles plus denfe, \& eftant prife deuant \& apres le repas n'eft-elle pas la caufe de la difficulté que la nature trouue à diftribuer l'aliment? En effet $f \mathrm{l}$ lefroid rom $\mathrm{p}$ : les veines, les comprime \& les endurcit, en forte que nous auons veu vne homorragie du bas ventre auec les extremitez froides tuer vn homme qui auoit beu à la glace dans la débauche, fans y eftre premierement accouftumé; que doit-on croire donc des vafes qui portent lechile, qui les reçoiuent, quil'infinuent, \& qui en feparent le fuperflu? Et voila peut-eftre le motif qui a obligé les Romains à boire long temps chaudement ou à tenir del'eau chaude auff bien que de la froide dans leurs feAtins; voila ce que les Moines ont confideré au temps de $S$. Bernard lors qu'ils preparoient leurs boiflons au feu, ainfi que les Chinois pratiquent \& quelques autres peuples de l'Orient : enfin voila ce qui fait que la plufpart des habitans de PAfrique qui ne fçauroient boire autrement, ne pouuant auoir ny glace, ny neige, que dis-jes ils font d'ailleurs fort robuftes \& vigoureuz.

En cinquiéme lieu, fil'hömeeft dans la medio: crité, fi fa vie confifte dans la chaleur, \&que toutes les facultez naturelles lexigent; s'il eft folaire 
$\&$ fi les chofes aromatiques feruent à le viuifier ; ne doit-on pas auouër hautement que le grand froid luy eft contraire, \& que la glace eft ennemie des principes dont la nature l'a compofé, qu'elle fait vn hyuert de fon corps, \& que fon feu eft alors à la maniere du Soleil lorfque la terre eft couuerte de neige? Enfin fi le froid, ruiuant l'A phorifme, eft ennemy du cerueau. de la poitrine, des dents \& des nerfs, de l'eftomac \& des membranes, il faut neceffairement que les Medecins defendent de boire à la glace, puifque ces parties font les infruments des principales facultés, puifque l'appetit deriue des nerfs, que ce qui entretient nofre vie eft renfermé dans la poitrine, \& que la glace peut: grandement alterer tous les organes dont nous parlons. Il eft donc certain que le boire à la glace nous eft extremement nuifible, c'eft à dire lors qu'il y a de l'excés, \& lors qu'on a peine d'en pouuoir fouffrir la froideur: la moderation par tant eft tres-vtile \& tres-profitable, comme nous allons faire voir.

En effet, la fraicheur. que la glace moderée imprime arrefte les efprits qui fe portent trop hors du centre, vers la furface, dans la force de nos chaleurs; elle leur donne quelque confiftence \& quelque épaiffeur, elle fixe:leur mobilité, \& empêche que ces efrences n'euaporent; d'ailleurs elle affermit les chairs, \& ce qu'il y a de plus important; elle modere le bouillonnement \& la fermentation dela bile \& du fang dans les veines, quieft le fondement de beaucoup de maux: \& voila la raifon pourquoy la glace fait 
dermir \& qu'elle a calmé les maladies populaires de l'Efpagne, \& del'I talie.

En fecond lieu il faut remarquer que nous fommes affligez pendant l'efté d'vn flux de ventre affez rude \& affez importun dans cette Pro. uince, non pas feulement comme quelques-yns s'imaginét, par vn ramas d'vne humeur piquante \& bilieufe; mais fur tout, parce que l'eftomach deuient alors trop lâche \& trop ouuert, qu'il a peine à fe ramaffer, \& à fermer fes orifices, \& qu'il déuient femblable à ces cuues qui font toutes pleines de fentes lors qu'on les expofe au fo1eil. Or la glace affermit ces parties,elle leur dónne le moyen d'embraffer mieux les alimens, de mieuz contenir les efprits, \& d'empêcher qu'ils I'euaporent \& de bien acheuer la cuitte, qui eft imparfaite fans tout cela: Et voila la caufe que l'apperit eft reuenu à quelques-vns apres auoir beù̀ la glace, \& que leur indigeftion a efté finie, rouvent contre le fentiment, \& l'efperance des plus excellents Medecins.

En troifiéme lieu les grandes chaleurs defmélent ce qui eftoit mellé, fubtilifent ce qui auoit la confiftence, \& feparent inceffamment, ou bien elles dilatent, elles ouurent \& elles rarefient toûjours. Or fuiuant Hippocrate au liure de lancienne Medecine, ce qui eft feparé eft la fource de beaucoup de maux, ce qui eft ouvert reçoit, ou fe décharge fur les parties, \& ce qui eft rarefié occupe vn lieu plus vafte \& plus grand, il le bourfoufle \& luy caufe founent vne douleur tres-violente : ' \& c'eft icy la raifon des maladies qui furuiennent durant l'efté, fi la glace moderée 
moderée ne s'oppofe à leur violence; car alors elle reflerre les parties \& empêche leur effufion, elle contient les humeurs dans leurs bornes $\&$ dans leurs mélanges, \& comprimant ce qui ef volatil, elle arrefte ces rarefactions, qui font le principe des vents. Et c'eft icy la railon pourquoy quelques-vns fe font gueris des coliques fon vfage, \& quils ont concentre ainf tous les efprits \& les matieres volatiles qui mugiffent dans nos entrailles, ou qui montent dans le cerueau. On preulue cette compreffion par vne experiencecertaine : car comme l'eau contient quantité de fels volatils, quil en fort toûjours de la terre durant l'efté, \& que l'air cn eft tout rempli. la glace dans l'hyuert les ramaffe, \& les preffe fi fort, que nous admirons foument fur elle la figure desherbes \& des fleurs, comme Quercetan a fit voir du fuc de l'ortie \& de fa lixiue glacée, parce qu'elle eft dans les efprits falins, que la chaleur la rend inuifible, \& que la glace l'épaiflic.

Il eft donc veriable que l'vfage de la glace dans la m diocriténouselt necelfaire, \& que fon excez deftruit nos temperaments \& nos corps: c'eft pourquoy prefcriuons icy quelgues obferuations \& quelques pieceptes, qui empêcheront le déreglement de quelquesovns, \& qui feruiront à conduir e les autres.

Que ceuxqui ont l'eftomach fioid, delicat \& mince, fe feruent de la glace auec grande modezation.

Que les vieillards s'en abfiennent du tout, \&e qu'ils fe fouviennent que leur feu s'euanonit infenfiblement, que leurs parties sendurcilfent, 
\& que le froiden agmente la dureté.

Difuns en de melmedes femmes enceintes, \& des filles qui ont les páles couleurs, qui doiuent confiderer que le froid com prime les veines, qu'il fufpend leurs ordmaires écoulements, \& qu'il caufe les obftructions, fi nous croyons à Erafiitrate.

Que les pareffeux, les nonchalands, \& les fedencaires ne boiuent que fort peu à la glace; a u contraire des perfonnes entreprenantes qui font toûjours dans les affaires \& dans l'action, parce que le trauail augmente la chaleur, que l'agitation aide à la cuitte, \& que le mouuement fait mieux gliffer ce qu'Hippocrate a nommé dur \& indomptable dans fon liure des eaux \& des lieux.

Queceuxqui boiuent des eaux de puys, ou de celles qui font fouterraines, obferuent que dans Hippocrate, elles font affés difficiles, fans qu'il foit befoin que la glace en augmente la crudité : c'eft pourquoy ceux-là puiferont des eaux defontaine, ou ils prendront de l'eau bouillie à la maniere des Romains, ainti qu'ont remarqué fur le nom decocta, quantité de bons Auteurs.

Que les perfonnes quin'ont chez elles quedes eaux échauffées par la terre, par la faifon, ou parle Soleil employent librement le fecours de la glace pour les rafraichir doucemẽt : C'eft ainfi que les Siciliens \& ceux de Calabre en agiffent, \& que les eaux chaudes des Indes tuent foument les voyageurs; parce que fuiuant Hippocrate les eaux decette nature fe changent en bile, qu'elles déreglent l'eftomach, \& caufent les inflammations des entrailles. 
Que les hômes qui ont l'eftomach charneux \&e le foye bruflant, qui aiment le vin, \& les viandes picquantes boiuent librement à la glace: autrefois on pratiquoit cette façon de vie auec fuccez, le Po"te l'a remarquée,

Dum domini ftomachus feruet vinoque ciboque,

Frigidior getulls petitur decoct a prainis.

Que ceux qui font conltipés s'en abltiennent, nous en auons donné la raifon, \& il eft inutile de la réioüer maintenant : difons le mefme de ceux qui ont la poitrine foible $\&$ les deris cariées $\&$ chancelantes, fuiuant l'aphorifme. On doit partant confiderer que fi les dens font malades aे caufe d'vne humeur chaude, rongeante, \& falée, quicoule dans les petites arteres que la nature a inferées à leurs racines, ce qui arriue fouuent aux bilieux, \& à ceux qui ont les cheueux rouges . dont à cét effet les morfures fon fort malignes: fi dis-ie cela arriue ain fi, la glace fera tres-profitable aux dens, \& fon froid tem perera la pointe. Jardeur \& la fubtilite du fang.

Qu'on fe founienne de mettre l'eau à la glace pluitot que le vin,

Maßilia fumos mifcere niualibus vndis,

Parse puer -.... dit le Poëte.

Suiuant lintention de ceux quiont inuenté le meflange du vin \& de l'eau, pour corriger la crudite de celle-cy par les efprits, \& la chaleus de celuy-là ; car la vigueur \& la force du vin deuiennent languiffantes par la glace \& parle grand froid, ainti que les Hollandois ont foument obferué dans leurs diuers voyages vers Nosse zenibla. I'excepte partant icy les vins tumuls.

$O \mathrm{ij}$ 
tueux \&piquants, qui ennyurent \& qui mon: tent promptement à la tefte.

Qu'on ne boiue pas apres le repas fi fouuent \& de fi grands traits à la glace; car ii ii'y a rien qui trouble dauantage la digeftion, qui interrompe mieux l'effet des efprits \& de la chaleur influente, \&qui rafroidife pluftot ce que la nature auoit commancé d'échauffer: Il faut partant dans cette rencontre, \& dans tous les preceptes que nous auons prefcrit, auoir égardà la couftume, comme Hippocrate nous a enfeigné.

Que ceux dont l'ouie eft foible, ou bien dont les oreilles fouffrent des indifpofitions, $\mathrm{fe}$ moderent dans l'vfage qu'ils font de la glace; il ne faut que lire Hippociate, pour eftre viuement perfuadé de la certitude de ce precepte; car on trouue ces mots dans le 6. des Epidemies fection 7. valde frigidum velut nix, \& glacies venas rumpere, \& tußes excitare folet, hum orum vero collectiones facit, quales funt oblonga circa aures eminentia, à Satyrorum fimilitudine Pharea dicte; aut rotunda, arborum quarundam tuberculis fimiles, qua gongrone vocantur. Et veritablement cecy eft auctorisé par les Hollandois de Noua Z mbla, qui fe pleignoietdans vn pays extremementfroid, des enle. ueures, qui leur faiffloient l'endroit qu'Hippocrate nous a marqué: Voyons maintenant fi nous pourrions trouuer quelque raifon de ce fymptome. Seroit-ce point parce que le froid preffe les glandules voifines : qu'il empêche là le paffage \& la tranfcolation des humeurs, \& qu'il y fixe ce qu'elles ont de fubtil \& de rare: C'elt pourquoy quelques-vns ont creu que le 
De la Glace.

goittre des Sauoyards ne procedoit que de l'eau de neige . laquelle prefle \& endurcit ces parties fpongieufes, \& les groffit de quantité d'hus meurs, jufques là qu'elles en dépofent vne partie dans les cauitez, \& qu'elles en rempliffent les chairs ; feroit ce point encore parce que lors $q$ quon boit à la glace, le froid eftant introduit au centre du corps repouffe aux extremitez \& juf ques à la circonference, c'eft pourquoy il reduit les matieresaux emonctoires de la telte \& delas poitrine, \& fait ces grandes tumeurs qui embarraffent les oreilles, \& qui enuironnent le col; \&e certes cela n'eft pas difficile à imaginer, fi on prend garde au rapport du bas ventre auec les oreilles, fi on fe founient que les purgatifs foulagent, ou gueriffent la furdité, que les parotides procedent fouuent de la fupprelfion des parties baffes, que le froid comprime \& endurcit, \& qu'Hippocrate a dit, biliofis liquidis ex aluo prinsuns defcendentibus, deinde ftercorofis, coma fuperueniens tumorem ad aures facit; peut eftre a caufe de 12 diftribution des veines, que cét excellent homme a enfeignée dans fes oeuures, laquelle contrio. bueà porter jufques là les humears ou à y intro. duire le froid. Et voila en peu de mots ce qu'on peut dire de la glace dans briefueté que nous nous fommes proposée : voyons maintenant fi on la peut accorder aux febricitans, \& à ceuxqui font affligez de quelque indifpofition quiproce: de d'vne ehaleur trop vehemente.

Il eft facile à répondre à cette difficulté fi nous fuiuons, \& fi nous reprennons nos routes: Did fons donc premierement quele boire à la glace

O iij 
$2 \times 4$

sil eft moderé, elt excellent dans les fiéures \&: dans les maladies du feu : premierement parce que la fiéure eft vne colere de l’efprit qui eft Inutiné dans le cœur, qu'elle eft vn effet de l'impetuofité extraordinaire qu'il fait dans nos membres \& dans nos veines, \& que la glace peut arrefter la fougue, \& la violence de fon émotion.

En fecond lieu parce que fuiuant Hippocrate, le feu dans lesfiéures furmonte l'eau, ignis irruit in extremitatem aqua, de façon qu'il eft neceffaire de luy oppofer la glace \& le froid pour arrefter fon mouuement.

En troifiéme lieu parce que ce feu dans la violence qu'il fe donne fe détruit foy-mefme apres auoir brûlé le corps; de forte que par le boire frais, il faut faire vn hyuert dans nos membres \& vin Septentrion, comme luy les rend pro. portiounés à la zone corride, humanus animus, dit Hippocrate, ad morrem víque perpetuoproducitur, guod fi vna cum morbo incensus fuerit, tum ip fe corpus orians depajcitur.

En quatriéme lieu parce quil tempere la bile $\&$ arrefte le fang qui bouillonne, \& qui roule grands flots dans les fiéures, qu'il abat les va. peurs, appaife la douleur de tefte, fixe les matieres fubtiles, \& refifte à la pourriture qui eft prefque le fondement de tous les maux qui font aux humeurs.

Si partant on prefume de boire à la glace auec excez dans les fiéures, çeft ce qui eft directement ópposé à la raifon \& aux regles de Medecine. En effet ne fçait-on pas que le froid lie les efprits quideiuent faire toutes les digeftions, lesfer- 
mentations, tous les mouuemens, \& les crifes dans des maladies femblables? qu'alors ces efprits fe changent en vents, dit Hippocrate, \& que cette metamorphofe eft augmentée par le froid; que c'eft luy qui bouche \& qui conftipe. \& que partant la plufpart des fiéures fe gueriffent par le ventre lache \& qu'elles ont pour principe les obftructions: qu'il eft d'elles comme des inflammations exterieures, qu'on ne doit pastraitter par vn froid violent; \& que lecorps eft vn theatre qui ne f̧̧auroit fouffrir le grand froid, \&la grande chaleur, qui font des combattās fir rudes?

Deuant que de finir ce chapitre, examinons dans peu de paroles, le problemeque Valefius a auancé fur les Epidemies; fçauoir fi on doit mettre les fruits a la glace comme on fait ordinairement l'eau \& le vin.

On peut dire doncen premier lieu qu'il eft propos de rafraichir mediocrement les fruits, foit pour empêcher leur bouillonnement dans leftomach, pour arrefter leur fermentation \& lageneration de la bile', foit pour en diffoudre \& pour en feparer le fel impur que les fruits atirent dans les chaleurs \& quiles rend la matiere des fiéures, foit pour temperer le foye \& le fangs foit pour tuer vne prodigieufe quantite de vermine, que le microfcopedecouure toûjours dans les fruirs: C'eft ainfi que Diphylus aimoit les cerifes dans Athencé, \& que les Lfpagnols rafraichiftent les leurs. Neantmoins on peut dire en fecond lieu que les fruits extraordinair ement glacés font tres-nuifibles, non feulement parce

( 1 iiji 
Sis

\section{De la Glace:}

qu'ils introduifent vn froid trop fixe \& trop attaché, non feulement parce que ce froid fléerit $\&$ ride les membranes,

-...- Penetrabile frigus adurit,

qu'il empêche la tranfpiratio quire doit faire par tout le corps, \& que fuiuant la Medecine ftatique, celle des fruits eft tres-difficile; mais d'ailleurs parce que les fruits ne font jamais meilleurs que lors qu'ils font cuits, \& que la glace partant leur imprime vne qualité qui s'oppofe encore mieux à la chaleur \& à la force des entrailles: iadjonte que les nerfs du ventricule \& de toutes les parties fouffrent de là par vne confpiration mutuelle. C'eft pourquoy fuiuant Boontius, les Indiens qui fe gorgent de fruits glacés, fouf frent foument vne efpece de paralyfre fort opi: niatre, qu'ils appellent Beriberi.

\section{CHAPITRE XI.}

\section{Du Tabac on fumée.}

Dorbien confiderer ainf le Tabac, \& remap1 quer dans peu de mots fes qualitez \& fa natute, il faut diuifer cechapitre en autant de diuers articles que nors ferons des reflections.

Premierement il y a à s'eftonner que la fuméc ait toûjours amuséles hommes: car les Thraces dans Mela, prenoient plaifir à brufler des herbes pour en obferuer le parfun, les Babyloniens faifoient le mefme de certains fruits pour fe preparer à la danfe, on expioit les crimes par la fuEmée parmy les Romains, c'eft elle quiferuoit de 


\section{Du Tabac es fumée.}

fondement à la Capnomantie, \& 1a plufpartdes gens d'aujourd'huy s'appliquent fi fort à voir \& à refpirer la fumée qui fort du tabac, qu'on peut dire fans hyperbole que leur vie n'eft qu'vne fumée, \& qu'elle fait le fujet de leurs penfées \& le comble de leurs plaifrs. Voyons maintenant d'où deriue cette inclination fi puiflante qui porte les hommes à la fumée, d'où vient que celle du tabac leur plait, quel eft fon pouuoir \& fa force, \& de quelle maniere elle agit. Mais pour fare cecy auec fondement, propofons la reflexion fuiuante.

Il faut donc obferuer en fecond lieu, queles hommes aiment des chofes qui font partant bien elloignées de ce tem peramment, \& de ce milieu où Dieu a posé leur nature: C'eft ainfi que les Turcs fe plaifent au Maflac qui les fait deuenir furieux; que les Chinois eftiment le Thé qui trouble le répos que le fomeil leur donne: que les Orientaux recherchent l'AJja fatida, que le Betel meflé auec la chaux eft le delice desIndiens, \& que le Tabac en fumée compofe prefque le plaifir de tous les peuples de la terre, nonobftant fon acrimonie, fa malignité, \& fa puanteur. Tout cela fait prefumer fans doute que la plus grande partie du genre humain eft hors de la mediocrité que fon exellence demande, \& qu'elle ne fe porte à des chofes exceffiues \& hors de la moderation, que par quelque proportion \& quelque rapport : \& voila la raifon pourquoy: quelques-vns boiuent volontiers l'eau de vie, le vin picquant \& le vin fans eau; d'où vient qu'ils cherchent le fel, le haut gouft \& lesviandes poiurées; que les doux, les delicats \& les 
218

Du Tabac en jumée.

raifonnables ne peuuent fouffrir le tabac; que les Ordonnances l'ont prohibé, parce qu'elles ont reglé les emportements de ceux qui en vfent, fuiuant le principe, que les mours de l'ame fuiuent le temperament de nos corps: enfin voila la fource de ce que nous auons obferué, fçauoix qu'il n'y a que les foldats, les matelots les foux, Ies faineants, \& ceux dont l'humeur leur donne quelque proportion aux Barbares, qui fe parfument du tabac, \& qui fe diuertiffent à voir fa fumée, parce qu'ils fe trouuent dans l'excés. Nous auons partant pris garde que les perfonnes melancholiques \& atrabilaires la refpiroient plus volontiers, à caufe qu'elles font toutes remplies d'humeurs ardentes, de vapeurs acres \&d'efpritschauds, ainfi qu'elle, quila leurfont fouhaiter, \& la leur rendent agreable, à la maniere de la croufte brûlée \& des viandes feiches qu'on defire lors qu'on a le foye chaud \& le fang bilieux. Il eft donc certain que les hommes qui font dans l'excés aiment le tabac, mais principalement les melancholiques \& les atrabilaires. C'eft pourquoy cela nous fournit vne reflexion qui n'eft pas moins neceffaire que la precedente.

Car comme les preneurs de tabac font pour lordinaire d'vn temperamment adufte \& bruflé, ils ont par confequent, à caufe de leur feu, vne imagination fort viue quiles déregle \& qui les occupe le plus fouvent, \& leur prefentedes reueries \& des continuelles vifions. En effet, tantolt ils grondent contre 1 Eftat \& peftent contre les Miniftres; tantoft ils s'erigent en cenfeurs du public \& ils declament contre le fiecle; tantoft ils conçoiuent des deffeins fans apparence \& 


\section{Du Tabac en funsée:}

fansfondement, pour lefquels ils abandonnent leurs affaires; en vn mot tantolt la fantaifie leur propofe des bagatelles fi legeres, qu'elle les amufe à la fumée \& à remarquer fon mouuement, \& certes on peut dire qu'ils imirent en cela les femmes oifiues quicontent les poutres du plancher, ou bien les replis de leurs iupes, \& qu'ils font femblables aux enfans qui admirent vne carte couppée que le vent fait tourner en rond: faifons partant quelque reflexion fur cette application fi friuole, \& voyons fi nous pourrons découurir le principe qui arrefte ainfi l'imaginatiō de ceux-cy\&de laplus gräde partie des hômes.

II faut donc fupporer que la viede l'homme . auffi bien que celle des plantes, n'eft qu'vn. mouuement perpetuel, \& qu'elle ne s'entretient que par des mouuements tres-juftes : car l'ame fe meut inceffamment, fes facultez ne font que fes mouuements ordinaires, les efprits s'agitent toûjours, \& leur repos fait les maladies, ou il efte caufe de la mort.

Il faut fuppofer en fecond lieu, que tous nos'corps font pleins de fumée, qu'il en exhale ordinairement au cerueau, qu'il en fort de tous coftés des pores, \& de l'habitude, que nos entrailles fument toûjours, que la fumée eft vn effet des feparations \& des cuites, \& que les efprits qui defcendent \& qui montent dans nos parties, en imitẽt le mouuement \& reprefentēt fa figure.

Il faut fuppofer en troifiéme lieu, que l'ame prend plaifir à voir au dehors vne image de l'œconomie qu' elle exerce dans tous nos membres, c'eft ainfi qu'elle fe plait à la mufique qui eft vine ombre de l'harmonie quelle obferue dans fes 
fondions, qu'elle aime à confiderer les ruifteaux parce qu'ils figurent les humeurs qu'elle fait couler dans nos veines, \& qu'elle occupeà tout cela l'imagination \& les fens. Cela eftant ainfi, il y a de l'apparence que les hommes s'arreftent à voir la fumée, parce qu'elle eft dans le mouuement, que ce mouuement a quelque ordre à la maniere de ceux de l'ame, qu'il reffemble à ceux de nos vapeurs \& de nos efprits, qu'il marque à la phantaifie ce merueilleux mênage qui fe fait continuellement aux parties, où tout eft plein de la fumée, \& qu'il eft vncaractere des exhalairons \& de brouillards oú nofte ame s'enuelope \& fe déuelope toûjours; de là vient que comme les atrabilaires ont vn feu qui détache inceffam. ment des vapeurs, qu'ils ont quantité d'efprits \& vne imagination expreffue, ils soccupent par confequent à confiderer la fumée, \& ils font determinés à celle du tabac parfón acrimonie \& par fa chaleur. Il en eft de mefme des foux qui ont cette faculté vigoureufe, \& leur temperament dans l'excez; enfin les faineants \& les populaires, les foldats, \& les mariniers ont des inclinations égales, parce qu'ils font pour lordinaire d'vne pareille conftitution. Au refte tout cela ne doit pas paroiftre fort eftrange, fi on prend garde que les yeux fe plaifent à la fumée comme les oreilles à certains bruits, latouchement à certaines frixions inutiles, le gouft à des faucurs piquantes, \& l'ame à des reueries \& àdes vifions. 11 nous faut maintenant examiner quels effets la fumée peut produire fur l'efprit, fur les humeurs \& fur les nembres, \& voir en particulier ceux quidériment de la fumée du ta: 
Du Tabac en fumée.

bac : mais pour nous bien conduire encecy, il eft neceflaire de confiderer la nature des parfuns \&les matieresqui les cópofent, puis qu'on fait va. parfun de la fumée du tabac, \& que les parfuns ne font que les chofes allumées quifument, cóme on void du tabac bruflé. Le parfun eft vncōpofé d'vn fel volatil, d'vn fouphre que le feu fubtilife, en vin mot de quantité d'efprits que la diffolutiô fait monter, \& qui portent les vertus \& les facul. tez de leurscorps: de là vient qu'il penetre par tout, que fon odeur eft tres-fenfible, quil efface limpreffion des maladies \& des venins, que ra fubtilité l'v nit \& l'applique à nos efprits, que les anciens ont creu qu'il auoit du pousoir ainfi fur nos ames, \&qu'il pouroit ayir fur les Intelligēces \& fur les demons : \& certes nos ceremonies ordonnent dans les exorcirmes, des prieres $\&$ des parfuns, Procle, Tamblique, Porphyre \& tous les plus grands magiciens les employoiẽt dans letars mylteres, ils fe feruoient du parfan du foye de Cameleon brulle fur vne tuille contre la foudre. \& ils croyoient que certaines fumées auoient la faculté de nous faireProphetes \& de nous inf $p^{i-}$ rer le futur. Pour nous, voicy de quelle maniere nous confidererons le parfun.

En premier lieu eftant vne chofe fortactiue? fort déliée \& fort penetrante, ou reprefentant des nuages \& des brouillards, elle change la fituation des efprits, elle les obfcurcit, ou bien elle les netoye \& les épure, ẻlle efface leursidées, ou elle les rend plus diftinctes, elle brouille les efperes ou elle les remuë \& les confond, brefelle les excite eftant affoupies \& elle fournit ainfi des pensées differentes \& des phantônes à l'imagina- 
222 Du Tabac en fumée.

tion \& à la raifon.

En fecond lieu, elle altere ainfi cet efprit qui fert, pour parler auec Platon, de lien \& de chariot à l'ame, tantoft elle s'oppofe à faclarté, quelquefois elle luy fait ainfi que les fons quiremuant l'air en diffipent les orages \& les tempeftes, tantoft elle l'é paiffit, l'attenuë, ou le rarefie extremenient, \& de cettefaçon elle produit dans l'ame l'éleuation \& l'enthoufiafme, ou vr profond engourdiffemēt. Etvoila fans doute la raifon qu'il y a des parfuns qui caufent l'amour, la haine \& la compaffion, qui portent à la fureur, ou au fomeil, qui chaflent les demons, en corrigeant la malignité des vapeurs \& des humeurs melancho. liques; enfin pourquoy eft-ce quion parfume dans les Eglifes, \& qu'Orphée dans fes hymnes compofe quantité des parfuns pour difpofer aux influences de Saturne, de Iupiter, \& du Soleil.

En troifiéme lieu les parfuns agiffent plus direetement fur les corps, il n'y a pour cela qu'à lire Hippocrate, \& on verra quilles ordonne pour. Ia conception, pour la matrice, \& pour quantité de fesmaux; on fçait d'ailleurs, qu'ils feichent, qu'ils attenuènt \& qu'ils échauffent, que le cerweau \& la poitrine en reçoiuent du bien ou du mal, \& que c'eft par leur moyen que les Romains découuroient la conftitution des efclaues. Il eft donchors de doute que les parfuns ont desgrandesvertus fur nos efprits \& fur nos parties, \& quele tabac en fumée les poffede par confequent comme eux, puifqu'il eft au rang des parfuns, de ceux, dis-je, qui feruent prefque à tout le monde. Il eft temps maintenant de les découurir \& d'obferuer celles qui font impreffion fur nos 
corps, \& les autres qui agiflent fur lesefprits, \& indirectement fur nos ames: Et pour commencer par les premieres, la fumée du tabac émouffe l'appetit $\&$ modere la faim preflante, peut-eftre parce qu'elle eft ennemic de l'eftomach, que I'experience fait voir qu'elle le prouoque en toutes les manieres, qu'elle luy imprime vne teinture iaune, comme les diffections ont montré, \& qu'apparamment elle eft opposée par fa qualité fulphurée, à cette acidité que la nature a cachée dans le ventricule pour luy faire fouhaiter l'aliment.

La fuméedu tabac, fuiuant Scroderus, empê-che d'ailleurs de piffer au lit, peut-eftre parce qu'elle feichelecorps, \& en abforbe les ferofitez. abondantes; ou bien qu' elle eft cnnemie des reins \& qu'elle fufpend leur ouurage : ceft pourquoy on la crost opporée à Venus, \& on dit qu'elle elt contraire à la generation, peut-eftre auffiparce quele fel volatil du tabacs'vniffant auec celuy de l'vrine le coagule \& l'adoucit ainfi que nous auons dit plufreurs fois; de forte qu'on peut tirer la raifon de là, pourquoy la fumée du tabac foulage les vieux maux de tefte, qui ne dériuent pour 12 plufpart que des fels acres \&e mordans $\&$ des humeurs aigres \& chaudes.

La fumée du tabac efface bien fourent l'impreffion des venins, \&la teinture de la pelte : voila pourquoy elle tue la vermine, les coufins, \& quantité d'autres infectes qui exhalent quelque chofe de venimeux, fans doute en effaçant par fon fel \& par fes efprits, ainfi que beaucoup de parfuns, les atomes malignes \& contagieufes qui fe repandent fur les meubles \& qui font $m \hat{e}=$ 
lées dans l'air, il y a mefme à croire quelle les fixe \& les corrige à la façon que nous auons marquée cy-deffus, ou bien qu'elle les refout, les nettoye \& les diffipe : de forte que c'elt par fa faculté acre, difcuffiue \& penetrante, quielle guerit la furdité \& qu’elle polit les dens \& les rend luifantes \& blanches, fi on l'introduit par vn entonnoir.

La fumée du tabac eft tres-nuifible \& tres malfaifante aux poulmons, non feulement en empêchant la fraicheur de loir, qui les rafraichit \& quiles tempere, non feulement en les remplif. rant de la fuye \& de la fumée, quoy qu'ils foient deftinésà euenter ler fuliginofités du cour; mais encore en chaufant, en rongeant \& en penetrant des parties fi delicates, \& que la Medecine tâche de reftablir, ou de conferuer en leur donnant vn air tout pur. Sur quoy il faut remarquer que la fumée du tabac fe refpend facilement à la poi. trine; car comme l'expiration la repoufre au dehors, \& fait ainfi reflembler la bouche à vne four naife quifume, l'inf piration au contraire l'introduit \& linfinuë librement : C'eft pourquoy on remarque par l'ana tomie que les prenneurs de tabac ont fouuent la poitrine fleftrie, excepté lors qu'elle eft eflouflée du flegme \& de quantitéde Terofités, parce que le tabac la deff iche auec tout le corps; que fon fell'endurcit \& en diminué lhumide, \& la rend femblable aux jambons \& aux harengs enfumés, qui fe conferuent au défaut de l'humidité, laquelle eft le principe de la diffolution \& de la pourriture. Le cerueau fouf fre les mefmes qualités, c'eft pourquoy on void void 


\section{Du Tabac en fumbe.}

foutient tarir par la fumée du tabac les eaux de cette fource abondante: res nerfs d'ailleurs s'en irritent fi fort, qu'ils caufent les conuulfions, les tremblemens \& les vertiges à ceux qui n'ont pas accouftumé le tabac: C'eft de là qu'on a obferué qu'ils pafmoient fubitement apres en atoir ref. jiré la fumée, dont la puanteur s'arreftoit aux pieds fort long temps, parce qu'elle fe gliffoit par les nerfs, comme par autant de tuyaux, ver les parties quicommuniquent à la tefte.

Lafumée du tabac agic fur les efprits, \& in. directemẽt fur l'ameà la façon des autres parfüs: pour eftre bien perfuadé de celail fut remarquer que les fueilles du tabac s'alument facilemët parce qu'elles font oleagineufes \& fulphurées ; \& qu'elles guerillent les vlceres, font vomir \& éternu $\ddot{e}^{-}$, effacent la gale \& piquent la langue, parce qu'elles contiennent vn efprit fort acre \&e vnfelde mefme façon: Il y a doncdel'apparence que la fumé fait les mefmes effets, \& qu'elle contient ainfi que les autres parfuns, ce fouphre, cet efprit \& cefel: par le fouphre elle eft narcotiyue $\&$ affoupillante, elle a du raport à la iufquiame \& à l'opium, elle excice des ronges \& brouille l'imayination comme luy, elle amoindrit ainf aux criminels la terreur des fupplices, \& aux foldats la crainte des combats: c'eft par là qu'elle delaffe les voyageurs en occupant leur phantaifie, qu'elle abrutit les hom mes en affoibliflant leurs efprits \& qu'elle les ietredans des pensées inutiles \& fuperflues, à la maniere des fumées que les fiéures font monter à la tefte, \& des vapeurs de la mandragore, \& de l'eftramoneum: 
elle obfurcit encore parce moyen les petites lumieres qui brillent dans le cour \& dans le cerueau, qui feruent de charsot à l'ame; \& il en eft d'elles foument, comme de cet efprit dont Hippocrate parle dans fes predictiós, \& lors qu'il décrit l'iflu è funefle des maladies;car tantoft il l appelle

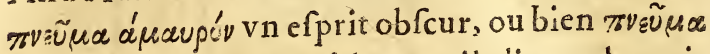

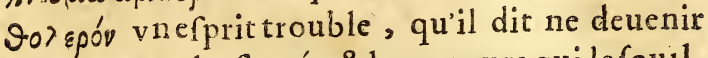
ainf que par les fumées\&les va peurs quile fouillent \& le rendent impur, quil'ofufquêt \& l'embarraffent; enfin quile font deuenir charbon, ou tout à fait remblable à la fuye: La fumée du tabac fait de mefmede nos lumieres, elle les obfcurcit \& les confond, elle leur ofte ce titre qui les rend,fuiuant Ariftote, proportionnées aux eftoiles, \& elle iette l'ame dansles tenebres en enuelopant ce chariot qui la fait rouler, fuiuant Platon, des eftoiles iufques dans nos corps: \& voila la caufe pourquoy la plufpart des prenneurs de tabac sabrutiffent; \& d'où vient que ceux qui commencent fe trouuent foument furpris d'vn éblouiffement \& d'vne diminution de fentiment, de raifon \& de veué.

La fumée du tabac par fon efpritacre \& fon fel picquant peut encore faire le mefme à l'ame, que le vin, l'eau de vie \& les liqueurs qui enyurent: Auffi elle rend lesPreftres des Indes furieux, elle anime ainfi les foldats, elle rétablit le courage \& infpire au Po te de dire,

Denique niä̈reum flammis conuer $\int a$ vaporem,

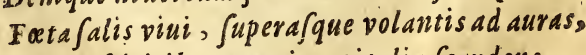
Irauia fpiritibus mentis capitolia fcandens, supplensenta nora exhauftis animalibus infert. 


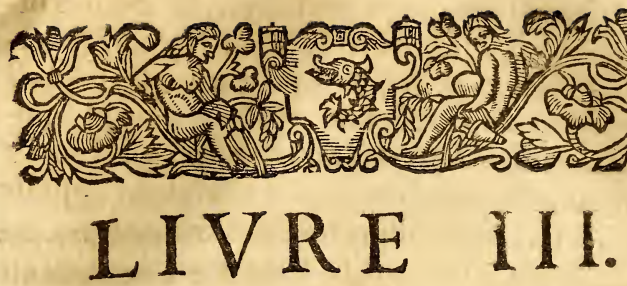

Des leux, E des Exercices, on de la Gymraftique moderne.

E Liure eft le plus important, \& le plusvtile de ce volume, puis qu'il enfeigne à regler les actions, \& à prendre (1.2)

les mouuemens auec ordre:Hippocrate a elte le premier qui nous en a donné le deffein, $\&$ on lit dans vne des parties de fes ouurages: bomo fanus effenon poteft, nifa etiam laboret, oportet autem, velut par eft, Medicum laborum vim pernof so cere, tum naturalium, tum eorum qui pervim funt, o qui ex iftis, carnes in augmentum praparant. A uff apres luy, beaucoup de Medecins on trauaillé à connoiftre la nuture des exercices, \& on void dans Iaubert, Mercurial \&c. la maniere de les pratiquer. Neantmoins comme ces honneftes gens ne fe font appliquées proprement qu’à la grime naftique des anciens qui nous eft maintenant inutile: Nous auonsiugé à propos d'examiner la moderne qui contient nos ieux, nos diuertifemens \& nos plaifirs, \& de prendre garde aus maux, \& aux biens qu'elle mous peut faire. 


\section{CHAPITRE I. \\ Des Exercices en general.}

A Fin de mieux fuiure la route de ceux qui A ont traité de l'ancienne gymnaftique, il eft neceflaire de faire feruir ce chap ptre pr liminaire à la gymnaftique moderne, \& d'y examincr en general la nature de l'exercice, fes difierences, ies effets, \& les caufes qui les produifent, ou quiluy tiennent lieu d'inftrument.

L'exercice en yeneral eft vn mouuement de I'ame, ou du corps, ou bien de tous les deux enfemble, Platon l'a confeillé de cette façon : c'eft pourquoy il dit quil ne faut pas reflembler aux boiteux, en exerçant l'efprit fans les membres, \& qu'il eft fort à propos, par exemple, qu'on mefle les pensées, qui font les promenades de l'ame, auec les promenades que nous pratiquons di fouuent pour le corps.

Les differences de l'exercice deriuent de diuers principes; car ou l'ame s'exerce fimplement, ou elle remuë les parties, c'eft pourquoy on partage l'exercice en celuy de l'ame, ou du corps; ou bien certains organes s'exercent feulement; \& de là on prend l'exercice des yeux, des poulmons, des bras, de la langue \&c. D'ailleurs, ou le mouuement en eft rude, ou moderé, \& on tire de ce fondement l'exercice quieft violent, ou mediocre : Enfin ou les jeunes s'exercent, ou les vieillards; les hommes, ou les femmes; dans des lieux couuerts, 
Des Exercices en general.

zabouteux, ou vnis; par l'impulfion narurelle, ou par le branle d'vn corps eftrange, \& par beaucoup d'aixtres moyens qui font la difference des exercices, \& qu'il eft fuperflu d'écrire icy.

Les exercices font importans dans leurs fins, \& dans leurs effets; car ils donnent la fanté, ou ils affermiflent les membres : voilla pourquoy Galien a donné à châque maladie vn exercice particulier, \& Zenophon n'a faic exercer les Perfes, $\&$ les anciens $n$ ont erigé leurs Gymnafes, \& ne les ont confacrés à Apollon, qui eft le Dieu de la Medecine, que pour conferuer la vie aux hommes, ou bien pour les rendre plus forts. Neantmoins pour mieux eftablir cette verité, il fe faut reffouuenir que, ou les exercices font violens, ou bien ils font doux \& mediocres, les doux font à nos êprits \& à leur lumiere à peu prescomme lors qu'on fecouë vn flambeau pour le rendre plus clair, ils agiffent fur nos parties ainfi que I'artifan, qui roulant vn fer, le polit \& en tire la roüille, \& rendent nos humeurs femblables à ces liqueurs, quine font iamars plus tranfparentes qu'a pres qu’on les a remuées \& qu on les a batuës longtemps: Il en eft partant bien au contraire de l'exercice qui elt rude, car il xcite vne tempefte dans les humeurs, \& brouille \& confond ce que le doux auoit épuré, il en vuide le pur auec linutile, \& verifie ce qu' Hippocrute a auancé dans le fixiéme des Epidemies, queceux qui s'exercent fans eltre purgez fouffrent des v1ceres a ux jambes, \& vn tranfport des matieres par tout leurscorps; ilarriue mefine, quecomme fuiuant cet Auteur, le feu que nous auons

P iij 
a couftume de faire trois cercles, ce feu neantmoins eft contraint alors d'interromprefes routes \& fes contours, mefme par l'agitation il furmonte l'eau \& deuient ardent, ignisirruit in $e x-$ eremitatem aqua, enfin il fe diffipe "̋́ il s'euapore, fur tout aux maigres, aux dinipables $\&$ aux bilieux, \& auctorife ce qu'on lit dans Epictete, que l'homme eft v ne lampe que le moindre vent \& le moindre excez eftuuffent fouuent; bomoeft lucerna in ventopofita. Et voila la raifon quia obligé Hippncrated: qualifier l'exercice du mot grec rovics parce qu'il lignifie tantolt douleur, tantoft trauail, quelquefois peine \& maladie.

Les chofes qui produifent, ou quiconcourent aux exercices, nous font propres, ou eloignees; les propresfont l'ame, le corps, les efprits, \& tous les organes; les eftrangeres comprennent tout ce que nous employons du dehorsà nous exercer, comme le mail, les charres, les cheuaux, les carroffes \& quantité d'autres infrumens que nous examinerons cy-apres.

L'ame comme vin premier mobile dans les exercices, roule facilement tout lecorps, émeut librement les reflorts de cette merucilleufe machine; neantmoins elle fuppofe que les organes foient difposés à receuoir fés mouuemens: de là vient que s'ils font trop fecs, ou trop humides, s'ils ont la pefanteur, ou la lacheté, ils font incapables d'executer les ordres de cette maitrefle, $\&$ d'eftre les infrumens de fes actions. Autr les anciens, pour donner aux membres vne flexibilité conuenable, deftinoient à châque exercice vn aliment particulier; \& on void que le choix 
Dos Exercicesen general.

que nous faifons de ceriains jeux, ne procecie fouuent, que d'vn fecret preffentiment de notre conftitution naturelle, qui fait que nous gaignons, ou nousperdons, que nous fommes chagrins, \& nous nous rebutons des exercices qu'on nous propofe, par la facilité, ou par la peine que nousconceuons à les executer. Et certainement comme la plufpart des exercices fe font, ou en lignesfpirales, ou circulaires, ou en arcs, ou en angles diuers; comme dailleurs fuiuant Hippocrate, il y a des parties qui couppent, dautres qui pouffent, \& d'autres quireprefententla fcie, que châcune d'elles a des ventres \& des cauitez, dont il eft dangereux de changer la figure; il arriue que les exercices qui font côtraires à tout cela font fort laborieux \& fort nuifibles, ou du moins ils ont peine à faire vne impreffion d'habitudeà ceux quiles pratiquentferieufement lors qu'its n'ont pas la veritable difpofition, ou qu'ilschangent leursinftrumens.

Le corps eftant eftroitement vnyà l'ame en fuitle branle, \& les mefures, \& s'exerce, ou fe remlë plus ou moins à la façon d'vn nauire qu'vn pilote gouuerne, \& qu'il pouffe viguureufement dans les flots; En effet l'ame agit ainfi par fa nature, comme le pilote parfes regles, \& le corps eft poutueu à la maniere du nauire, de voiles \& de cordages, \& prend levent aufí bien que luy; tout cela fe void dans les exercices violens ou mediocres, comme nous allons faire voir.

Les efprits font les vents qui enflent nos voiles \& qni pouflent noftre nauire; car is ont leur Piiij 
vertu impulfue comme les vents, ils fe gliffents par tout a leur maniere, \& on ne fçauroit pratiquer aucun excrcice, qu'ils ne penetrent dans les membres $\&$ dans leurs détours, qu'ils ne ten. dent \& qu'ils ne gonflent les parties, qu'ils ne leurdonnent la force, \& ne leur infpirent la vigueur. Et voila la raifon pourquoy Hippocrate les nomme des corps impetueux, Ta $\sigma \omega \mu a r a ́$

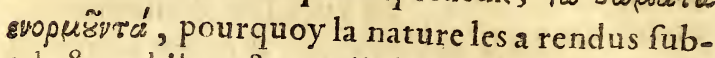
trls \& mobiles, \& qu'elle les a placez à des lieux́ d'ou deriae le mouuement : de là on tire quantité de reflexions remarquables. Sçauoir que les malades ne peuuent ordinairement s'exercer, parce que fuiuant Hip pocrate, la maladiecorrompt, ou fait degenerer les efprits \& qu'elle les change en fanie; que l'exercice trop long \& trop violent abbat les forces, parce qu'il fait euaporer les efprits; que les maigres, les bilicux \& les delicats fe laffent bien-tôt par la dîipation deces flammes; qu'ils oni befoin du fommeil pour les reparer. qu'ils tombent facilement dans des fiéures longues, ou courtes, foit par la chaleur que l'exercice excite aux efprits, ou bien par la tempefte qu'il produit en les agitant dans les vcines; enfin que les pefans \& les parefleux ont befoin de s'exercer foutuent, pour remuer \& pourallumer les efprits de peur qu'ils n'eftouffent par le poids des humeurs, à la maniere du feu qui eft accablé de la cendre.

Les mufcles font les voiles dece nauire, qui font tendues \& bourfoufées des efprits dans les exercices comme de vents fort fauorables \& quelques fois impetueux, c'eft pourquoy ces voiles 
feruent à route l'oconomied ds corps, elles ont descauitez fuiuant Hippocrate, toutesremplies de particulesfort fubtiles, \& elles contiennent des tuyaux quiportent les vents, \& quiles leur difribuent par tout. On tire de ce principela difference des exercices; car tout de mefmequ'on ramaffe les voiles dans les nauires, ou qu'on les eftend pour aller plus vifte, ou doucement; il en arriue ainfi des mufcles dans les exercices, dont la diuerfité procéde de leur contraction ou bien de leurgrande extenfion.

Les nerfs \& les fibres font les grands \& les petits cordages qui aident à mouuoir le nauire, \&c qui font necelfaires à faire exercer noltre corps. C'eft pourquoy il faut foument que ces cordages deuiennent roides \& tendus, \& quils s'entrelaffent \& s'entrecoupent, afin d'exercer les parties par des differentes façons; \& voila laxáifon de l'interfection admirable des nerfs que l'a natomie nous montre, des figures diuerfes des fibres quion obferue parmy nos chairs, \& du motif qui obligea Hippocrate d'ordonner à fon fils de prendre connoiflance de la geometrie, \& d'en étudier bien les principes.

De tout cela on peut tirer des confequences importantes, f̧̧auoir que les nerfs entrelaffés ne font pas feulement la fonction des cordages, mais encore celle de ces vis aueclefquelles on éleue des grands poids, \& on remue des machines; que les poids que ces cordages, ou ces vis efleuẽt dans les exercices caufent diuers fentimens aux parties par les differ ntes tenfions, lefquelles font à peu pres femblables à celles qui font 
diuerstonsaututh, ou à d'autres pareils infrumens; que les hommes qu'on appelle nerueux font fort propres aux exercices, c'eft pourquoy les animaux les plus agiles ne paroiflent compofés-que de nerfs; que les exercices trop opiniâtres caufent de douleurs tres-fenfibles par vne extenfion trop rude, ou par vne torfion, \& vne firuation trop preflante; que les poftures quion prend dans les exercices, laiffent fouuent vne impreffion fort longue, qui diminue les diuertifements, \& les plaifirs par vn changement forcé des angles \& des lignes dans les mufcles, dans les fibres \& dans les nerfs, qui eft opposé à l'arrangement $\&$ à la connexion veritable : bref qu'on void arriuer de là dans les mouuements extraordinaires des exercices \& des jeux, des luxations, desfractures, des douleurs aux jointures \&c. parce que la plurpart des membres fouffrent des mouuements quileur font oppofez.

Enfin tous les organes du corps coucourent à produire les exercices, il feroit neantmoins trop long de les prendre tous en détail, le lecteur fe contentera donc de deux obferuations remarquables.

La premiere que les chairs contribuent beaucoup, \& s'alterent grandement dans les exercices; car fielles font dures, elles durent long temps, \& fouffrent librement le trauall, \& fi elles font moles \& lâches elles, ne peuuent refifter à fa violence; ainfi les Efpagnols, par exemple, font plus penibles \& s'attachent plus que les François parce qu'ils ont leurs chairsdures\&mufculeufes, c'eft pourquoy les Caraibes qui en mangent 


\section{Des Exercices en general.}

Courent les trouuent auoir moins de gouft que celles des noftres, qui leur paroiffent fort tendres \& fort delicates.

La feconde que les organes font exercez par ious les objets qu'ils reçoiuent, parce que la faculté qu'ils ont ne les f̧̧auroit apperceuoir, \& eux d'ailleurs ne pourroient imprimer vnverie table fentiment, s'ils ne produiloient dansles parties des mouuemens particuliers, qui leur font comme autant d'exercices; c'eft ain'f que l'oreille eft exercée par les fons qui ne font que des mouuemens; que les efpeces vilibles en iettant des rayons exercent les yeux; que les efprits des odeurs agiffent ainfi au cerueau, \& vers les procés mamillaires, enfin que la langue \& les autres membres font emeus en fouffrant \& en receuant leurs objets. De tout cela on peut tirer les reflexions fuiuantes, f̧̧aùoir que le mouuement trop prompt, trop violent, ou trop inegaldes objets exerce trop fortement, \& il eft directement contraire àla faculté \& à fon organe; ainf. vne lumiere qui efclate fubitement, ou qui tremouffe, \& qu'on agite, bleffe \& donne vn mauuais exercice nos yeux, les chofes inefgales font le mefme aux inftrumens de l'attouchement, \& les odeurs trop penetrantes s'infinuent trop viuement dans le nez \& vers les membranes:on peut daflleurs inferer du mefme principe que les mouuements des objets laiflant leurs veftiges aux parties molles qui compofent le cerueau $\&$ les nerfs, ils leur donnent fouuent des impreffions fixes \& permanentes; que quelquefoisles nouueaux veftiges effacent les premiers, que les 
humeurs les reçoiuent à la maniere de l'eau qui Fait quancité de cercles par la cheuted'vn corps folide, \& que les derniers cercles troublant les premiers, alterent leur cours dans les vafes, \& rendent les exercices les principes de beaucoup de maux. Et voila la raifon pourquoy lesioueurs qui s'appliquent à des jeux violens deuiennent coleres, ou fe mutinent bien fouuent, qu'ils crient ou ferendent malades, parce que les hus meurs tranquilles contribuent à la prudence, fuiuant Hippocrate au liure des vents, \& que leur trouble eft la fource des indifpofitions que nous reflentons; fi nous n'aimons mieux dire que l'emportement peut deriuer des mouuemens extraordinaires du corps, qui font conceuoir à l'ame des penfées de mefme nature, puifqu'elles ne fonique des mouuemens, \& qu'elles fe fouleuent en fuite de ceux des objets, des efprits, de nos humeurs \& $\mathrm{x}$ de nos organes; qu'elles durent même dans le fommeil, qu'elles conferuent Ieur ayitation, à la manie de quantité de corps

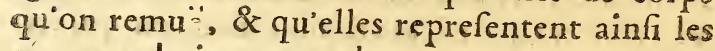
exercices du iour precedent.

\section{CHAPITRE II.}

Reflexions particulieres, \& generales fur les Exercices des Enfans.

Dercices que d'examiner en particulier les ex: portant de faire quelques obferuations genera. 


\section{Des Exercices des Enfans.}

les, qui nous découurent leurs effets.

La premiere eft, qu'il y a trois tempsde l'ane née ou les enfans reffentent des alterations \& des changemens, le pintemps, l'efté \& l'hyuert : car comme pendant le printemps \& l'efté, toutes chofes fortent des tenebres à la lumiere, c'ef alors que les enfans deuiennẽt turbulents \& fougueux, qu'ils courent, qu'ils fe tourmentent $\&$ qu'ils s'agitent, qu'ils deuiennent maigres \& effouflés, que leurs humeurs fe rarefient, \& que leurs efprits reflemblent à ces refforts qui entrainent leurs machines en fe détechant: Il en eft partant bien au contraire de l'hyuert de la fin \& du commencement de l'automne, où les enfans ont vn mouuement plus reglés oủileurs humeurs font plus tranquilles, ou leurs efprits deuiennent efpais, \& reffemblent à ces refforts qu'on a peineà faire joùr.

On tire vne confequence de ce principe; f̧̧auoir, que puifqu'au printemps, \& durant l'efté lesenfans font difpofez aux mouuements, \& que les exercices y font compris, il faut donc qu'ils foient alors bien doux, \& bien moderés de peur qu'ils ne faflent mouuoir exceffuement les organes, \& qu'ils ne difipent ce qu'ils ont de tendre $\&$ de flouët. On peut garder vn aurre coûtume en hyuert, où les chairs des enfans deuiennent plus dures, les humeurs plus tranquilles, les efprits moins tumultuaires \& majns capables du mouuement.

Lafeconde obferuationeft, que les enfans ont le cerueau fi mol \& fi glutineux, qu'à cette fin Ariftotel'a compare a la cire, Hippocrate 
238

Des Exercices des Enfans.

la crefine, \& que de là l'efpine du dos a vne confiftence parcille, eftant commevn autrecerueau. Et voila la raifon pourquoy les enfans n'ont ny efprit ny jugement, parce queles efprits, \& les facultez font dans leur tefte comme dans de la glu \& dans de la colle: voila encore pourquoy ils font flexibles, \& ils plient fi librement par la confiftence de leur efpine \& par la tendrefle de leurs nerfs, qui prennent la teinture de leur principe; de forte qu'ainfi ils rendent les parties friables dans cet âge \& improportionnées aux grands efforts. Par cette obferuation on doit prendre garde que les enfans n'exercent pas fortement leur cerueau, qu'ils nele brouillent pas pardes agitations exceffiues, qu'ils ne fouffrent pasdes grands poids, \& qu'ils ne plient pas fortement leur efpine, dont la mauuaife difpofition eft la fource de beauccup de grands maux.

La troifiéme obferuation eft que la pefanteur, \& la legereté du fang ont leurs degrés\&leurs differences fuiuant le fexe, l'àge \& le temperament: Aisfi par la Medecine ftatique les bilieux, \& les enfans ont vn fang plus leger, comme les pituiteux \& les melancholiques l'ont plus folide. plus efpais \& plus denfe. Or le fang leger exige des mourements doux \& reglez; le pefant au contraire des plus violens $\&$ des plus rudes, afin que les efprits de celuy-cy fe remuent, \& de peur quel'autre ne bouillonne, \& ne forte hors de fes vaiffeaux. De là on voit que les enfans doiuent éuiter les mouuemens, \& les exercices quifont penibles \& continus, que c'eft par là qu'ils fe diffipent, qu'ils fouffrent fouuent des feignées 
dunez, \& qu'ils deuiennent infolens \& impetueux par le remuëment, \& par l'agitation de leur fang, qui fe foûleue facilement à caufe de fa confiftence.

La quatriéme eft fondée fur ce qu'il n'y a rien qui auance la vieilleffe, que la dureté de nos chairs : c'eft pourquoy fi on pounoit ramolir vn vieillard, on auroit trouué le moyen de le remettre dans la jeuneffe : Auffi c'eft ce qui a obligé la nature de faire la chair des enfans mole, tendre \& douillette, afin que leurs parties fe dilatent comme les rameaux, \& qu'elles puiffent éboire \& mieux abforber l'aliment. De ce fondement on tire deux confequences infallibles; la premiere, que les exercices feichent \& qu'ils endurciffent les chairs, qu'ils les preffent \& les rendent mafiues, \& auancent ainfi nos jours; la feconde, que celles des enfans en deuiennent folides contre l'intention \& l'ordre que la nature a toûjours eftably dans nos corps: on conçoit de là pourquoy les Lacedemoniens faifoient exercer leurs enfans, car ils vouloient rendre leurs membres durs, \& propres à refifter dans la guerre, \& à fatiguer dans le grand trauail.

La cinquieme roule fur ce qu'il faut prendre garde aux parties qui s'exercent \& à la connexion qu'elles ont: car ainfi elles entrainent, \& elles emeuuent leurs voifines, \& les portent à concourir aux mefmes actions : or cela arriue principalement aux enfans à caufe de leur delicatefle : la petiteffe de leur corps, \& la legereté de leur fang y contribuent d'ailleurs grandement, \& les rendent femblables à ces machines qui s'ébranlent 
toutes lors qu'on les remue par quelque endroit. On infere de là, qu'il faut auoir foin des bras aux enfans, à caufe de la liaifon qu'ils ont auec la poitrine; quon doit moderer le grand mouues ment de leurs iambes, de peur quil ne brouille trop leur cerueau, \& qu'il eft à propos d'agir ainfi fur tout le refte de leurs organes. Appliquons maintenant toutcecy pour feruir d'exem. ple à quelques exercices qui amufent ordinaire. ment les enfans.

La Toupie, appellée des Grecs $\beta$ vobira, agite affés fortement les enf $n s$, parce qu'elle exige d'eux vn mourement infatigable. Cieft pourquoy Virgile s'eft ferui d'elle \& de fes tours pour expliquer les tourbillons.

Cer quondam torto volicans $\int u b$ verbere Turbo.

Quem pueri magno in gyro vacua atria citcums

Intenti ludo exercent: slle actus baber $\hat{a}$

Curuatis fertur Spatïs, ftupet infcia turba.

Impubifque manus miraba volubsle buxum:

Dant animos plaga.

Ie premier effet qu'elle produit c'eft d'affoiblir le cerueau aux enfans, \& de les difpofer au vertige, parce qu'elle brouille la tefte \& qu'elle agite les efprits, qu'elle emp $\hat{e}$ che leur rectitude en les faifant tourner en rond, \& qu'elle ne reprefente aux yeux que des objets qui roulent tôfiours.

Le fecond effet de la toupie eft d'ćchaufer les petits enfans, $c^{\prime}$ eft pourquoy ils s'en diuertiffent durant lefroid pour adoucir fa violence, \& pour dégourdir leurs efprits.

Le troifiéme eft de rendre flexible $\&$ de plier 
Des Exercices des Enfans.
trop lefpine du dos, contre le deflein de la nature, quil'a renduë exactement perpendiculaire afindedreffer tout le corps: aufi les enfans qui s'appliquent trop à la toupie, courent rifque dalterer leurs reins, de deuenir boffus, ou de prendre vne fituation recourbée, à la façon des jeunes arbres, dont on enlaffe les rameaux.

Le ieu des noix \& des amandes exerce fort moderément les enfans; aufí de tout temps on leur a permis cet exercice. Ainfi on lit dans Ouide,

Quatuor in nucibus, non amplius, alea tota eft cum fibi fuppofitis additur vna tribus

On obferue le melme dans Perfe.

-..--Nucibus, of facimus quacunqua, relictis. Cùm Sapimus patruos....-

On it que l'Empereur Galienus encore petit ioüoit de cette maniere auec des pommes; \& oa n'a qu'à confulter Philon au liure de la creation du monde, \& on verra clairement l'idée \& l'antiquité de ce mefme ieu. I quiparmmtellygit, lsfu quodam vulgatocognofcet: qui nucibusludunt, folent poficis primò tribus in plano quartam fupcrimponere in formam pyramidis.

Maintenant l'effet de l'exercice des noix eft de mouuoir mediocrement les bras, \& par confequent la poitrine; parce que, comme nous verronscy-apres, elle a vne grande connexionauec ces membres. Et voila la raifon pourquoy les en. fans crient, tempeftent \& fe brouillent parmy eux, en fe diuetiffant aux amandes; parce que leurs poulmons s'échaufent par les fecoufes que le diaphragme reçoit des bias; de fortequ'il fau

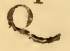


242

Des Exercices des Enfans?

quelquefois ietter de l'eau des feneftres pour efteindre le feu, \& calmer l'emportement deces petits ioüeurs, qui s'allument. On peut dire quel yue chofe de femblable du ieu des offellets, dans lequel les filles exercent leursbras, \& employent leurs mains à ietter \& à receuoir des petites pierres : car ainfi elles exercent leur poitrinè̀ Ja manicre des enfans, elles l'échaufent \& la foûleuent : c'eft pourquoy elles chantent ordinairement a pres auoir ioùe quelque temps. Il eft partant veritable que les alterations qu'elles reçoivent alors font fort douces \& fort moderées. Voila pourquoy les peres auoient vn foin tout particulier d'amufer leurs filles de cette façon; ils leur donnoient d'offellets d'yuoire au defaut des pierres, que les Latins appelloient ofellata,

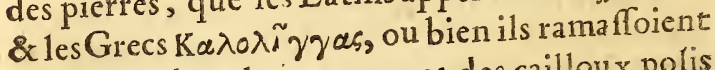
pour elles dans leurs voyayes des cailloux polis \& luifans, \& qui auoient la figure ouale. Ouid. -..--Medo grata puellis Munera fert illi, conchas, terctefque lapillos.

Dece difcours on peut deueloper vne difficulté, qui eft fondée fur la plainte des femmes \& fur le trauail qui les occupe tous les iours; car elles exercent ordinairement leurs bras à filer, ou à deuuider, \& elles affeurent que cette application fufpend foutuent leurs écoulemens periodiques, qu'elle remuë la matrice, \& la fait bien fouuent monter. Or il faut refpondrè̀ cela, que leur opinion n'elt pas mal fondée, \& qu'ily a de l'apparence qu'elle roule fur l'experience, \& fur la raifon. En effet les bras par la connexion de leurs norfs, eftant agités exercent fortement les reins 
\& les lombes, de forte quainfi ils peuuent émouuoir la matrice, dont les ligamens aboutiffent en partic vers ces endroits, \& donner anfi vn panchant aux humeurs, qui diuertira leur cours ordinaire.

On peut encore découurir des melmes principes (car nous fommes fur lexercice, \& fur les mouuemens des bras) ce qui arriue aux enfans, lors qu'ils roulent la neige, \& en jettent les pelotons, puifque comme la projection fe fait là auec force, elle exerce pareillement leurs parties vitales, \& elle fe fert de la neige pour les échauffer. Difons en de mefme des filles quife joünt quelquefois de cette maniere; car outre qu'elles fouffrent par la froideur de ce qu'elles ramaffent vne interception de leurs vuidanges ordinaires, \& que le nitre de la neige, ride \& ef. face la beauté de leurs mains, elles font d'ailleurs plus expofées aux effets de la proiection, \& elles excitent vne fi grande chalcur dans leur poitrine, qu'elles en communiquent le feu foumentà ceux. qu'elles frapent de leurs pelotons tout glacez comme quelques-vns en ont foupiré fuiuane le Poëte.

Tranfibam frigens, vidit me Celia, rifit, Et mea compreffam icffit in ora niucm, Non nix illa fuit, ropto fed qualis ab Euro Arentes calamos vrere flamma folet. Tunc arfi infelix, funt bec miracula, poffuis In media fieri flammea tela niue.

La fronde exerce les bras d'vne façon fi violente, qu'elle a ferui principalement aux pafteurs, aux infulaires, aux foldats, \& aux Barbares d'A-

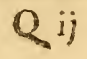


244

Des Exercices des Enfans.

frique; \& que les payfans l'ont jugée fi proprè les deffendre, que pour ne la quitter point, ils l'ont employée à renfermer leur pain, comme leur tenant lieu de beface, ou bien à prendre des poiflons à la façon des rets.

Funda iam verberat amnem.

Neantmoins les enfans s'y font prefque de tout temps appliqués; car on fçait queles habitans des Baleares ne leur permettoient point autrefois de manger des oifeaux, s'ils ne les auoient tuez à la fronde, fuiuant Virgile \& Stace.

Stupea torquentem Balearis verberafunde,

Roboraque. So grawidas funde Balearis babenas.

Voyons maintenant les maux \& les biens qu'elle leur fait, puifque les anciensont confacré à A pollon \& à Ef fculape tout ce qui eft lancé des mains, \& puifque la fronde eft vn des plus frequens exercices de la jeuneffe turbulente.

A ce deflein il faut fuppofer que dans toutes les projections le corps tient lieu de bafe \& de centre, \& que les bras font comme des lignes qui en portent les inflü̈nces \& la vertu: il fautre. marquer en fecond lieu, que les projections fe font en arcs, \& qu'au plus les aresfont eftendus, au plus les projections font violentes: C'eft pourquoy les bras longs pouffent plus vigoureufemèt que les cours; mais leur impetuofité eftencore plus grande lors qu'on y adioûte la fronde, qui tennant vne plus grande eftenduë, fais le demy cercle plus long; \& voila la raifon pourquoy on prend des raquettes au jeu de paume, pourquoy les bras frapent plus vigoureufement lors qu'ils fe portent au dedans, \& d'où vient que lesens. 


\section{Des Exercices des Enfans}

fans ont befoin de la fronde à caufe de la pet 245 de leurs bras \& de la briefueté de leurs corps. Les frondes donc font la force $\&$ la vigueur de l'impulfion, il faut par ainfi qu'elles exigent des bras vne impetuofité plus grande, que les bras dans cet eftat agitent les nerfs, \& qu'ils ébranlent tout le corps auec la poitrine; \& certainement cela eft fiveritable qu'on a veu founent les petits frondeurs faifs d'vn tremblement continuel, qu'on les a remarqués tous moittes \& tous effouflés, \& que leurs crieries \& leurs huées n’ont procedé fouvent que de l'émotion de la refpiration trop forcée, fuiuant les principes que nous auons déja effleurés. Ceft pourquoy il y a à șeftonner d'où vient que Platon dans le troifréme de fes loix confeille aux femmes vn exercice fi penible, de fortequ'on ne fçauroit excufer ce grrand homme fi on ne croyoit quila entendu parler des Herö̈nes, \& des robuftes, pluftot que de celles qui font douillettes \& delicates.

Ily a d'autres mounemens, outre ceux dont nous auons déja examinéla nature, qui detiēnent les enfans, \&qui en exercent les membres, comme la courfe, la danfe \& toutes fes efpeces; mais nous en écrirons dans des chapitres particuliers.

\section{CHAPITRE III. \\ De la Paume, \& du Mail.}

T E ieu de paumea paru fort agreable auxanciens, c'elt pourquoy ils ont aimé à s'endi. 
uertir à pied, à cheual, dehors \& dedans leurs Colleges; \& pour fe mieux fatisfaire ils l'ont exercé en des fí diuerfes façons, que pour fuiure noftre deffein, \& pour euiter la longeur, nous n'examinerons icy que ce ieu qui eft en vfage, \& qu'on a couftume de pratiquer maintenani parmy nous.

On doit donc remarquer en premier lieu, que le ieu de paume porte du centre à la furface les humeurs auec les efprits; quill les y poufed'vne maniere tumultuaire \& impetueufe; qu'il les brouille la, dans le fond du corps $\&$ dans leurs vailleaux; \& quil produit ainfi la chaleur, \& cette rougeur clatante qu'on void paroifte fort founēt fur le vifage des ioüurs. La raifon de cela eft, parce que dans cet exercice le mouuement fe fait toujours en auant, de forte que les efprits vant à la fuperficie, mais d'vn cours violent $\&$ precipité, au lieu que fuisant l'ordre de la natu$r e$, ils y coulent fans trouble, auec mefure, \& fans confufion. On tire plufreurs confequences de ce principe.

Sçauoir qu'on fuë en ioüant, ou apres auoir ioüé à la paume, par la dilatation des pores, par le mouuement des efprits, \& par l'agitation des humeurs vers la circonference des parties: qu'on fe fait froter dans vn lit, foit pour decrafler la peau, pour ramollir les membres, \& pour détacher de l'habitude ce que l'émotion y a répandu: que le froid furprenant auqueton s'expore dans cet eftat penetre alnrs bien auant dans lecorps, \& caufe ces maladies dangereufes qui deriuent des alterations, \& des changemens impreueus: 


\section{De la Paume, o du Mail.}

que la paume eft ennemie de la tranfpiration, \&e nuifible apres le repas, parce qu'elle excite vne tempefte aux humeurs, \& dans les entrailles, de forte quelle fait depofer à la circonference ce qui eft cru allec ce qui eft cuit, ce qui eft fubtil auec les matieres groffieres, à la maniere de la mer orageufe, quiiette à fon bord de l'eau meflée auec de Therbe, des coquilles \& des poiffons. Et voila la raifon pourquoy la paume affoiblit les ycux, \& qu'elle eft contraire aux maladies de la tefte: car elle fecouë les efpeces \& les nerfs optiques, elle remué les tuniques \& les humeurs, elle en diminuë la tranfparence en y precipitant des corps eftrangers, \& elle confond ce que le cerueau a de plus tendre \& de plus coulant : c'eft pourquoy on lit dans Horace,

Lufum it Macenas, dormitum ego, Virgiliufque; Nam pilâ lippis damnofum eft ludere, crudis.

Il faut remarquer en fecond lieu, qu'on lance les bales tantoft en angles, ou en lignes droites; qu'on eft contraint de les receuoir, \& de les repouffer dans leur reflexion, \& dans leur retour; qu'on doit preuoir \& attendre leur cheute, \& qu'à cet effet on eft contraint de ramaffer les mufcles, de plier le corps \& les ioinctures, de donner des fecouffes aux lombes, \& de prendre diuerfes pofturcs à tout moment. Delà or void pourquoy les Medecins ont creu que la paume difpofoit à la goute; d'où vient qu' Artemidore a enfeigné qu'elle infpiroit des fonges de plaifir \& devolupté, \& qu'vn moderne a fouftenu que par fon moyen on fe preferuoit de la pierre, mais qu'on iettoit fur les articles les humeurs \& les 


\section{De la Paume, or du Mail.}

bées \& circulaires,auec vigueur, \& le coup fe fait d'yne maniere prompte \&fubite. De tout cela on tire plufreurs confequences.

La premiere, que ceux quiont le mail \& les bras fort longs ont vn ieu plus auantageux, parce qu'alors la percuftion fait des arcs plus grands \& des cercles plus eftendus. La feconde, que la vitefle \& la force du mouuement ébranlent le corps, \& l'agitent $f$ fort, que lors qu'on prend mai,ou qu'on manque la boule, on tourned'vne manicre rude \& fort incommode, \& on fent vne grande emotion ducerueau, parce que larc fe tait ainf tout entier, \& qu'il n'y a rien qui termine l'élancement \& l'impetuofité qu'on fe donne. La troifiéme, que la percuffion du mail ne fe pouuant acheuer fans les bras, elle exerce grandement ces parties, c'eft pourquoy la poitrine en fouffre, par la connexion des nerfs du diaphragme auec ceux des bras; de forte que c'eft par cette railon que les jouëurs de mail crient, \& s'inquietent fouuent, qu'ils fe difpofent aux inflam mations des poulmons \& à la pleurefie, fur tout s'ils entrent dans la ville tous effouflés, \& s'ils veulent temperer leurchaleur par quelque fraicheur furprenante. Quon ne doute pointcependant de la liaifon des nerfs dont nous parlons; car outre que les diffections anatomiques l'ont découuerte, la raifon fait voir que la nature a voulu cette correfpondance pour auertir ceux qui s'eflouflent, de moderer leur trauail \&leur exercice par le repos: Et l'experience d'ailleurs nous monftre que c'eft de là que les cheuaux fatigués deuiennent poufifs, parce que leurs pieds 
250

Des carroßes.

de deuant, qui leur tiennent lieu de bras, \& qui ont vn confentement pareil auec la poitrine, alterent par leur mouuement extraordinaire le diaphragme, \& par confequent le poulmon, qui fe fert cöme de main de cette partie, \&qui en eft pouffé quelquefois d'vne façon fi extraordinaire auec les conduits de la voix, qu'il excite bien fouvent ces élans \& ces éclats de voix quion entend de ceux quigemiffent par la peine \& par le travail de leurs bras.

\section{CHAPITRE IV.}

\section{Des Carroffes.}

T Os corps fe meuuent en deux manieres 1 car ou ils s'exercent eux-mefmes, ou bien ils reçoinent d'ailleurs leur branle \& leur agitation. Ils re meuuẽt eux-mefmes dans toutes les actions volontaires;mais par exemple, c'eft dans les berceaux, les nauires, \& les carrofles; quils fouffrent vne autre impulfion : voyons en mainrenant la nature, \& propolons icy premieremẽt les reflexions que nous auons faites fur les carrofles, deuant que de découurir nos penfées fur le mouuement des berceaux.

Il eft certain que les carroffes font v ne grande impreffion fur nous-mefmes; cela fe verifie par cette experience fameufe, d'vne bâle qu'ón lance perpendiculairement au deffus, pendant que le carroffe roule, qui ne va iamais en ligne droite, qui fait toûjours vn demy arc, \& qui retombe 


\section{Des Carroffes.}

dans la main de celuy quil'a jettée quoy qu'il foit déja auancé : cela montre clairement que la projection ne deriue pas feulement de la main, mais qu'elle fe troure mêlée auec le mouuement du. carroffe; \&que c eft parce mêlange que la bâle ne fçauroit retomber en mefmelieu, qu'elle va toûjours en auant, que la main luy donne vne impulfion, qui eft jointe à vne eftrangere, \& quiluy fait faire ainfi des cercles, des arcs, \& des angles bien grands. De tout cela on tire vne preuue tres éclatãte de l'effet du carrofle fur tout le refte des parties, de la force de fon mounemét \& de la neceffité qu'il y a de faire des obferuations fur cette matiere, pour eclaircir la gymnaAtique, \& pour conferuer la fanté.

La premiere obferuation qui fe prefente, confifte en ce que le carrofle ne paroift pas fi vifte à ceux qu'il entraine, qui femblent fixes \& fans mouuement, \& aufquels neantmoins les objets paroiflent vagabonds \& mobiles; en forteque fi leur imagination n'eftoit corrigée par la raifon, ils croiroient que les rochers fe détachent de leur carriere, que les montagnes roulent, \& qu'elles fuiuent quelquefois les paffans. Or cette experience fait voir limpulfion des parties, par le carroffe qui agite le cerueau, \& les nerfs optiques, \& dont le branle meut les efpeces cachées au fond de l'oil, les brouille, \& les poufleconfufement : \& certainemêt il leur arriue ainfi qu'aux jmages lors qu'on remuë les mirøirs, ou comme aux fontaines \& aux eaux les plus pures, quireprefentent dans leur lit flotant, tantôt lesarbres renuer $(\mathrm{ez}$, ou bien les fueilles tremoutfantes. La 
s. $\int^{2}$

Des Carrofies.

mefme chofe fe fait dans l'ail, parce que fon mouuement, ou celuy des efprits eft joint àl'aSitation du carrofle, ainfl que nous auons expliqué de la main, ou du moins que l'impulfion fecovë les tuniques $\&$ les humeurs. De là vient aufi que comme les parties ébranlées hors de leur centre cherchent enfin leur repos \& leur veriable fituation, que dis-je, par confequent le carroffe eftant arrefté, le mouuement des objets dure encore, qu'on les void mouuoir par vne ligne opposée à la route qu'on a tenuë, parce que les nerfs ne s'arreftent pas promptement à la façon de ces machines, qui s'agitent long temps pour feremettre dans leur place, \& que le cer. aeau, les efprits, \& les yeux en reprenant leur fituation naturelle, d'où le carroffe les auoit pouflez, entrainent auec eux les efpeces verscet endroit.

De tout cela on void la raifon pourquoy orr eft faifi foument du vertige dans le carroffe, \& d'où vient que les apoplectiques, \& tous ceux qui font fujets à l'epilepfie doiuent y monter rarement; pourquoy eft-ce que la veuë en eft alterée, \& que Pline vouloit qu'on abattit les mantelets de fon carroffe de peur d'affoiblir la fienne.

Par ce difcours on peut eftablir maintenant vne feconde obferuation, fçauoir que les carroffes ont vn grand rapport aux nauires, puis que les ports, les fortereffes \& les villes paroiffent fe mouuoir des nauires, ainfi queles montagnes descarrofles; qu'on fait aux nauires, la mefme experience des projections; que les bales des ca- 
Des Carrafes.

nons n'y vont pas fouuent en mefme ligne; que l'eftomach eft affoibly dans les carroffes aufi bien que dans les nauires, \& $q$ que c'eft par cette raifon qu'on couronnoit d'abfynte ceux qui eftoient vainqueurs dans les jeux deschariots, parce que ceft icy vneplante fort amie du ventricule, dont les nerfs font alors indubitablement agités auec ceuxducerueau : Cette comparaifon eft fi jufte qu'il femble qu'elle ait inf piré au peu pleduPaysbas, d'auoir des carroffes à la voile qui ne roulent que par le vent, \& dont la courfe eft fir rapide, que ceux qui s'en feruent dans leurs voyages, voyent les chofes confonduës \& commerenuerfées par l'interfection des efpeces, des lignes \& des angles caufée du mr ruement trop violent du cerueau, de l'œil, \& des nerfs. Seroit-ce point ce rap port quiauroit fait autrefois cöfacrer les carroffes \& les cheuaux à Neptune, \& qui éclaircit vn lieu affez remarquable qu'on trouue dans Hip pocrate au liu. de l'epilept. Si auctiorem ovegetiorem vocem edat ager, equo finsilem effe dicun o ad Neptunum cau fam referunt.

Et voila tout ce que nous pourons dire des maux qui procedent de l'agitation du carrofle, qui a pourtant fon vtilité comme toutes les cho: fes du monde ; en effet les hydropiques, eeux qui ont du fable dans les reins, ou dont les entrailles font bouchées, tirent vn merueilleux profit des carrofles, les femmes encore qui ont des obftrutions \& de l'embarras, \& dont les flancs one retenu leurs impuretés ordinaires: En forte que c'eft à caufe de cela peut-eftre que les Dames Romaines refuferent de congcouoir, lors qu'on 
254

Des Berceaux.

leur en eut interditl'vfage, \&que les Scytes fuiuả Hippocrate, ne conduifoient leurs fëmes que fur des chariots. De tout cecy on connoit pourquoy les anciens $M$ edecins recommandoient fi fort l'exercice du carroffe, pour dégourdir ceux qui eftoient malades depuis long temps, \& qu'ils leur ordonnoient partant de ne monter au carrolie, que quelques heures apres le repas, de peur que les viandes ne fuffent Hottantes, \& que les parties les plus gluantes del'aliment ne priffent la place des fubtiles dans la furface ainfi que la Medecine ftatique fait voir.

\section{CHAPITRE V.}

\section{Des Berceaux.}

DOur agir auec ordre dans ce chapitre, il faut 1 examiner les differences, la matiere \& le mouuement des berceaux, voir les effets qui en deriuent, les coûtumes que les anciens y ont obferueés \& \& les circonftances qui font neceftaires, \& qui accompagnent leur branfle \& leur agitation.

11 y a deux fortes de berceaux, les vins font fufpendus en l'air à la façon des liss branflans, \& on fecoué les autres fur la terre, ainfi que le peuple a coûtume de pratiquer en plufieurs endroits.

Afclepiade a mis les premiers en vrage, il foû* tient quion n'y fouffre point ces agitations importumes qui viennent du choc, \& du relancement; que le corps des enfans douillet \& tout 
delicat ne court pas danger d'y eftre meurtri par la refiftence de la terre, que le mouuements $s^{y}$ fait fans bruit, qu'il eft plus paifible, plus facile, \& plus doux, qu'on éueille ainfi les efprits qui participent de l'air \& de l'element des eftoiles, que c'eft par cette railon que'les hommes aiment à eftre fufpendus \& à fe balancer quelquefois parmy l'air, \& que dans l'ancienne Romeils flas toient leurs enfans de cette maniere.

$$
\text { D. M. }
$$

\section{L. Ėmili victori qui pridie}

Natalem furm viceffimum, \& fecundun

Pruna in penfili pojita, vrgente fato

Sanum ipfe necauit fe L. Emilius

Victor principalis, \& EliaVeneria

Filio pientißimo

$$
\text { Et fibi Gruterus? }
$$

La Grece partant, fuiuant Oribafe, a fort eftimé les berceaux qu'on roule fur la terre auec la main : c'eft pourquoy les Empereurs les fai roient couurir de pour preà la naiffance des Porphyrogenetes, \& les Pö̈tes les ont rendus le theatre du combat, dans lequel le petit Hercule triompha d'vn effroyable ferpent. Aufi c'eft de ceux-la dont nous auons fait deffein d'occuper nos lecteurs dans le refte de ce chapitre, \& dont nous voulons diuertir leur efprit.

La matiere des berceaux dans Pline, \& parmy. les riches du vieux temps, eftoit d'or, d'argent, ou de quelque autre chofe brillante, parce que la lueur eft agreable aux enfans, \& qu'elle fert 6 fort à emouuoir leurs efprits, \& à deueloper leur lumiere, que c'eft par cetteraifon qu'ils ay: 
ment à voir, ou à faire des feux; qu'ils cherchent les verres, les bijoux \& les petites pierres luifantes, \& qu'ils deuiennent quelquefois louches pour trop regarder les flambeaux : ceft pourquoy on pend à leur col du corail, des pieces de cryftal, ou quelques ornemens quiéclatent, afin de les mieux diuertir, \& de moderer leur chagrin. Il eft partant veritable que les anciens cherchoient plus à propos pour les berceaux des bois odoriferans \& aromatiques, parce qu'ils font propres à fortifier le cerueau des enfans, qui fouffre ordinairement dans cet âge.

Les couftumes que les anciens ont obferuées pour les berceaux n'ont procedé que de leur crainte, \& de leur grande fuperfition: car ilsont fort apprehendé pour les enfans dans cet eftat, ils fefont imaginés pour eux des genies \& des aftres fort malfaifans, \& ils ont taché à diuertir le regard des perfonnes enuieufes, ou ennemies dont ils tiroient beaucoup de maux. A cet effet les Egyptiens ont graué au berceau, la figured'vn chien : lesRomains pour arrefter les fafcinations y ont fufpendu du corail taillé à la façon du membre qui nous fait hommes, ils y ont caché les deftinées des petits, c'eft à dire des abjurations, \& des caracteres, que Seneque appelle execrationesparentum, ils ont recommandé les enfans à la Deefle Cunina parce qu'elle prefide aus berceaux, \& là ils les ont enuelopés de vieux haillons tirés des habits que leurs peres auoient portés aux myfteres de Cerés, pour les mieux pre.. feruer des dangers. Mais taplus for teap prehen fion des anciens a roulé fur les influences, \& fur le 

le pounoir que la Lune a fur les petits corps des enfans à caufe de fon humidité, \&de fa tendrefle: voila pourquoy dans Hippocrate, au liu. de l'epilepfieles fuperftitieux a p prehendoient les embuches d'Hecate, Hecates infidias, \& les Hebreux Liliht, qui vient de l'ail, d'où on deriue le nom de Lucine, de forte qu'ils grauoient ces mots à leurs berceaux, procul binc, procul efto Lilibt pour en efloigner l'nfortune, \& les qualitez.

Le mouuement du berceau eft vn mouuement de libratiō qui a du rapportà celuy du nauire, car il balance le corps des enfans comme luy, \& ii fait les humeurs fi flotantes \& fi mobiles, qu'elfouffent vn flux \& reflux à la maniere de la mer. Ondoit remarquer neantmoins que ou ce mouuement eft doux, \& reglé, ou bien impezueux \& tumultuaire, tous les deux font des effets particuliers qu'il eft à proposd'obferuer : \& pour conceuoir ceux du mouuement impetueux,

Il faut fuppofer que le petit monde commence par vn chaos comme le grand, qu'à l'enfance il fe trouuedans la confufion, que l'efprit y roule fur les humeurs à la façon de celuy du grand monde qui promenoit autrefois fur les caux, qu'il trauaille ainfi pour feparer, \& pour polir, pour épurer \& pour refoudre, bref pour acheuer fon ouurage, \& qu'il ny a rien quifoit plus contraire à fes deffeins que ce qui brouille, \& qui remefle, qui trouble, \& qui agite forte. ment. On void de là les effets du mouuement impetueux des berceaux, car les humeurs alors reffemblent à la mer orageufe, elles fubmergent, \& cuuclopent les efprits, elles les meflent \& les 
$2{ }^{2} 8$

Confondent; elles éclipfent leurs lumieres par leurs va peurs, \& elles interrompent leur trauail \& leurs routes, elles caufent les fonges, la terreur, elles déreglent les petits eftomachs, à la façon dela tourmente, enfin elles jettent la na-." ture dans lechaos, font que le feu furmöte l'eau, \& qu'il ne peut acheuer les trois cerc̀les qu' Hip. pocrate luy atrribue, parce qu'il a befoin du repos au lieu du tumulte pour trauailler : Et certes fi lesenfans qu'on berce font comme des malades, \& fi fuiuant les Medecins, ils reprennent comme ceux-là, leur force $\&$ leur vigueur par feptenaires; fi Platon dans le 7.de fa Republique, o rộnne à cét effet de les exercer doucemẽt, $\&$ de ne les porter que par des chemins agreables : qui doutera donc qu'ils ne fouffrent des fecoufles \& des mouuemens exceffifs, \& que les berceaux ne leur foient alors ainfi que les nauires qui nous menaçent du naufrage?

Toutes ces confiderations fans doute on fait apprehender quelques peuples d'efleuer leurs enfans au berceau, ainfi les Lacedemoniens repofoient les leurs fur des Boucliers fuiuant $T$ he ocrite.

Lauit vbi genitrix, of latte impleuit verumque Et rapto impofuit clipeo.

A quoy Claudien a fait allufion en parlant d'Honorius, reptaftiper fcuta puer, les Soldats fe reruent d'vn Tambour, ou de la bouche d'va canon, les Habitans du nouueau monde lailent rouler leurs petits à quatre pieds, \& Marc. Paul remarque que dans la $T$ artarie les maris ne fe mettent à la place des accouchées, que pour te: 
Des Berceaux.

nir les enfans dans le lit, \& pour les fomenter de leur chaleur, comme eftant plus viuifiante que celle de leurs meres.

Nonobftant tout cela les berceaux, fi leur mouuement eft reglé, font tres-profitables, \& tres-vtiles; la raifon de cela eft prife de la conftitution des enfans, car leurs efprits font embarraffez, \& leurs corps font tout plejns des matieres gluantes, replentur mucco, dit Hippocrate, leurs chairs mefine font fi molles, \& fi douilletes, qu'elles diminuent la tran(piration, leurs chemins font d'ailleurs fort eftroits, \& fort affaides, \& ils donnèt peine aux feptrations, \& aux vuidanges; ien vn mot ils s'oppofent à ce confer. temét general qu' Hippocrate demande, afin que la nature exerce librement fa merueilleufe oconomie par tout. Cela eftant ainfi il faut recourir au mouuement, \& à l'agitation du berceau, pour exciter ce qui eft languiflant, pour efueil. ler les efprits quigemiffent, pour ouurir les partres, \& pour en dilater les conduits, \& pour faire penetrer l'aliment, \& res petites particules dans leurs pores \& dans leur fond. Et voila peut eftre la caufe pour quoy les enfans aiment le berceau, parce que par fon impulfion la nourriture fe gliffe micux par tout en forme d'vne petitero. fée, qu'elle adoucit ainfi, \& remefle les matieres picquantes qui leur donnent fowient du chagrin, \& parce que les efprits coulant doucement dans les humeurs, \& dans les entrailles font comme vn petitzephire, qui euente \& quipum rifie, ou bien comme vne efpece de chato :illemẽt quiflatte les enfans \& qui appaife leur do = Rij 


\section{0}

Des Berceasut.

leur. Cieft pourquoy on eft contraint de les bercer alors, puis qu'on void quil h'y a rien qui les appaife que le branfle reglé qu'on leur donne: On peut merme dire que les hommes treuuent par la mefme raifon vin pareil foulagement dans les carroftes, \& dans les exercices qu'ils pratiquent quelquesfois pour branfler. Ilrefte main: tenant à examiner d'oú vient que les berceaux font dormir plus facilement les enfans.

Quelques vns fe font imaginés pour cela que le berceau produifoit vne efpecede vertige qui fe terminoit enfin au fommeil, parce quil enuelopoit les efprits, en agitant le cerueau tout tendre, \& en remuant fes humeurs, qu'il les inondoit ainfi en fecouant la tefte, \& quill les poufloit au centre, à la maniere des poiffons quivont aufond de l'eau par l'agitation de la mer; fi cela neantmoins eftoit veritable, il n'y auroit rien de plus dangereux que le mouuement du berceau, puifque les enfans font fujets à l'epilepfic dont le vertige eft vn veritable commencement. Prenons donc d'autres mefures fur ce fujet, Inais cherchons premieremét le principe du fommeil \& desveilles, \& defsourons quelle eft leus fin.

Les veilles ne deriuent que des efprits qui fe tirent toûjours hors du centre, \& qui, à la façon des corps lumineux, fe portent facilement au dehors, c'eft pourquoy le fommeil eft vn effet du retour qu'ils fe donnent, \& de la reflexion qu'ils fouffrent de la circonference au centre pour vivifier les entrailles, \& pour prendre quelque vis geux. Or il arriue de là que le mouuement dus 
berceau balotant ces mefmes efprits quifont à la furface pendant les veilles les repoufle enfin au dedans, \& fait à la maniere peut eftre des bales qui font lancées \& relancées par les mains des jouëurs, ou qui retournent vers elles par la re. fiftance des corps qu'elles rencontrent dans leur chemin. C'eft pourquoy comme les bales fe jettent dans quantité des trous, \& qu'elles y demeurent cachées, les erprits aulfi eftant pouf. fés de tous cótés, coulent dans les cauités des parties, fecachent, \& s'arreftent dans leurs détours, \& caufent ainfi le fommeil comme nous auons déja dit ; \& certes tout cela fe fait fuiuant l'ordre de la nature qui veut reparer l'interieur des enfans, \& en renouueller les efprits quifont les miniftres de fes ouurages; auff elle fait flotter ces petits durant neuf mois fur les eaux, 2fin que le moindre mouuement des meres les berce \& les fecoü̈ doucement, qu'ils puiflent dormir tout le temps que le chaleur naturelie les forme, \& qu'ils reftabliffent leurs efprits par la sranquillité \& par le repos. Et voila ce qu'Hippocrate a entendu, lors qu'il a dit que tout fe faifoit parvn retour de la lumiere aux tenebres? ou bien des tenebres au jour.

Cependant lors que les efprits ainfi pouffés rentrent dans leurs fources, \& qu'ils penetrent \& fe gliffent jufques au fond; ils font aux humeurs ainfi qu'vn zephire fur l'eau la plus calme, \& ils agiffent à la façon des petites pierres, qui jettées dans vn eftang le couppent en des cercles, le diuifent en des bluettes, ou elles en efleuent \& en font fortir des vapeurs : les efprits 


\section{Des Berceart.}

balotés remrent ainfi les humeurs, ils les éueno tent, fans y excite: la tempefte, ils en feparent: ce qu'elies ont de plus impur, \& ils y excitent des vapeurs qui fotit l'effet des pluyes les plus rafraichiffantes \& les plusdouces, ou qui reffemblent à ces nuages, qui arreftent la mobilité des rayons, ainfíclles peuuent retenir quelque temps les efprits que les berceaux ont mis au centre, arrefter l'emotion que les fecouffes leur ont donnée \& produre ainfí le fommeil qui procede de leur repos.

Neantmoins les chanfons des nourrices contribuent grandement a cela, celt pourquoy elles font dormir les enfans, car elle's ramafient les efprits que l'agitation des berceaux rend d abord trop vagabond's, \& troperrans, lles leur impriment yn cours regulier, \& qui garde quelque mefure, elles les vniffent dans les organes, \& les tiennent à demy fufpendus, il temble mefme qu elies les placent les vns fur les autresà peu prés comme on void les Abeilles lors qu'on bat v ne tuille, ou quelque inftrument refonant. Et voila la raifon pourquoy les chanfons plaintiues amufent \& font mieux dormir les enfans, pourquoy quelques-vne les font pleurer, \& les chagrinent, que dautres leur infpirent la gayeté, \& que lès anciens pendoient à leurcol des joü̈ts qu'ils appelloient crepundia à crepando, afin que leur fon fuppleat au deffaut des chanfons. Ariftote a fort bien remarqué tout cecy dansfes Probiemes, lors qu'il a fait des remarques fur la melodie qui entretenoit les enfans, car on a reconnu le mefme aprés luy, \& Platon. 


\section{Des Chaires:}

\& Crifipe n'en ont jamais douté, puis quìi's ont ordonné aux nourrices, certaines chanfons, pour fléchir, \& pour amufer leurs petits.

\section{CHAPITRE VI.}

\section{Des Chaires.}

Ts chaires font de deux façons; car ou elles L feruent au tranfmarchement des perfonnes malades \& delicates, ou bien elles font propres à foulager la lafitude, \& à nous donner le repos; celles-cy font plus importantes \& plus en vfage, ceft pourquoy nous ferons preceder leur exdmen, \& en premier lieu nous en confidererons les effets.

On a certainement à s'étonner que l'homme fe puiffe foûtenir fur deux pieds, qu'il foit toûjours dans l'equilibre, que fa tefte luy tienne lieu de contrepois, \& que le moindre faux pas le bleffe, ou luy fafte coutir des rifques. Auffil fe laffe ficilement eltant droit, fes jambes deuiennent bien fouuent tremblantes, \& ce ront propremẽt les lits \& les chaires quile roulagent dans cét eftat. De là vieñ qu'A riftote i'emarque qu'il n'y a que les hommes, \& fi vous voulés, les finges, qui puiffent demeurer a fis qui ayent les parties du derriere difpofées à cette figure, que leurs cuifics auancent en dehors, ainfi qu'on lit dans Hippocrate, $l i b$, de fract. \& qu'elles foyent caues au dedans pour faire les angles neceflaires, \& pour ramaffer \& plier les. Riiij 
menbres quil les font demeurer affis. Et veritablement c'eltoit de la prouidence de la natare de nous rendre ainf tous flexibles, parce que les nerfs $\ddot{x}$ les mufcles font dans vne tenfion continuelle, lors que le corps demeure droit, \& que les jambes eftant perpendiculaires à l'efpine dus dos, \& faifant des angles droits auec elle, fe treuuent furchargées du poids de toutes les parties: de forte qu'elles ont befoin d'vne fituation mo. deree \& accommodante qui puifle les defcharger \& les devaller quelquefois. Or les chaires contrio buent ilfort à ce mainnen, quec ét par là qu'elles on paru agreables à tout le monde, qu'on s'encit leruy de meible \& d'ornement, que les malades y ont treuué quelque adoucifiement dans leurs peines, que les laponois ont creu que fans elles on ne fçauroit s'entretenir ciuilement, que les grands hommes les ont recherchées pour com pofer leurs beaux ouurages, qu'elles ont tenu lieu de recompenfe à la vertu, \& de thrône aux Roys, \& que c'elf fur elles que la jultice a fait valoir, \& a prononcé fes oracles : il faut partant n'abufer pas du doux repos qu'elles nous donnent, c'eft pourquoy il elt à propos de bien faire reflexion fur ce que nous y allons maintenant obferuer.

Premierement que la fituation eft à noscorps à proportion des poles quideterminent l'eguille, \& l'aimant. La raifon de cela eft parce que tourescholes tournent autant qu'elles peuuent, ou panchent à la polturequia contribué \& concouru a leur production, c'eft ainfi que le bois fufpendu prend la place qu'il auoit dans l'arbre ou 
Des Chaires.

qu'on luy a donné dans le trauail, que les pierres aiment à eftre placées à la maniere qu’elles gardoient dans leurs carrieres, \& que l'homme noyé, flotant fur l'eau, affecte la pofture qu'ilauoit, lors que dans les flancs de ia mere, la nature le formoit fur les eaux. De la vient que puifque là il tient les jambes rephées, \& les bras \& les membres ramaffés, il cherche par confe. quent, aprés auoir demeuré droit, de reprendre fon ancienne figure, $\&$ de fe mettre fur les chaires à la façon \& fuiuant l'ordre que fes membres obferuent dans les flancs. Dece fondement onfait deriuer ces confequences, içauoir

Que la fituation des chaires nous eft naturelle, que c'eft par cette raifon qu'elle plait à tous, qu'on la recherche dans le trauaii \& dans les veilles pour pounoir agiren repos, qu'à caufe de cela ondort fouuent eftant alfis, \& que l'ame femble alorsabandonner fi fort l'oconomie des parties, qu'il n'eftoit pas permis autrefois d'adorer les Dieux furr vn liege, de peur que le cultene vint à degenerer en langeur.

En fecond lieu, que la polture \& la fituation qu'on fe donne dans vn endroit, nonobftant qu'elle foit naturelle, doit garder quelque proportion, \& quelque mefure, crainte quelle ne foit forcée, \& qu'elle ne mette à la géne toutes les parties du corps. Et voila la railon du choix que nous faifons des fieges, \& pourquoy quelques-vns nous delaffent, \& que les autres nous incommodeut fortement. En.effet les corps vaftes ont les flancs trop preffés dans les petites chaires, ils s'y treuuent trop ramaftés, leur ventre 
\& leur poitrine en fouffrent, ceft pourquoy il faut qu'ils fe leuent ou qu'ils fe dreflent bien fouuent: la bienfeance miefme \& la majefté perdent leur éclat dans cét eftat, \& fi on drefle des thrônes aux Sounerains \& aux Magifrats, c'eft afin qu'ils foyent efleués \& qu'ils prennent leur extenfion. Difons-en de mefmedes grandes \& eminentes chaires qui font inutiles aux petits corps, car elles furpendent leurs membres, au lieu de les ramaffer mediocrement, elles ne core rigent point leurs tracas, \& elles augmentent les fuxions, les viceres \& les douleurs des jambes, parce qu'ainfi elles font comme droites \& chancelantes, \& elles nont pas le moyen de fe ramafier \& de s'appuyer juftement. Et certes la naiure aime la mediocrité dans toutes les fituations corporelles, elle ne fçait fouffrir que le corps Coit trop étendu, ou trop replié; de forte que ceft la raifon pourquoy la trop grande extenfion que les malades gardent fuiuant Hippocrate, eft vn prognoftique de quelque grand mal à venir. Peut-eitre queles Turcs ont confideré tout cela, \& quiils n'ont point voulu des ch ires pour éuirer la contrainte qu'elles nous caufent lors qu'elles ne font pas dans la proportion. On connoit de tout ce difcours dioù vient qu'on fouffre des crampes \& des engourdiffemens fur les chaires, parce que foutent les membres ne fe maintiennent point par les regles geometriques, que la nature a obferuées exactement dans leur fabrique, dansleur extenfion \& dans leurs replis.

En troifíme lieu, que toutes les fituations. donncnt v ne figure \& vre confitution partacu: 
liere aux entrailles \& aux cauités. Pour faire voir cela par la polture que nous tenons eftant athis, on doit remarquer qu'alors le bas ventre fait vn repli auec les cuiffes \& la poitrine, qu'il fe treuue dans la contrainte de cette façon, que les boyaux n'ont pas le mouuement periltatique aflés defgagé, qu'ils font vn peu repoultés en haut, fur tout fi leschaires font dures, \& qu'ils preffent ainfi le ventricule, qui s'élargit dans fom orifice par la compretion de fon fond., De là on tire plufieurs confequences tres-certaines, f $\mathrm{cg}^{-}$ uoir que les vuidanges ordinares font bien fouuent fupprimées \& fufpendues, lors quon demeure trop long temps affis, que c'eft par cette raifon qu'il faut promener ou fe drefler aprés le repas, que les femmes \& les gens d'étude ont des obftructions opiniatres, quon deuient gonfle ainfi aprés auoir mangé, \& qu'alors les promenades foulagent , parce qu'elles font nos entrailles femblables aux facs qu'on ouure, \& qu'on rient élevés. On infere encore du merme principe pourquoy eft-ce qu'on afleure quon mange \& qu'on feremplit dauantage eftant droit que demeurant affis, \& qu'on a fort bien fait dechangercette pofture que les Anciens gardoient d̀ table, qui eftoit afleurement fort etrange \& fort incommode.

Deuant que de finir cette matiere, il faut voir dans peu de mots les effets de la chaire, que Sanctorius a reprefenté a commencement de fes aphorifmes. Caril propofe dans cét endroit vne chaire à bras fufpenduè au plancher par vne corde, \& balancée par vn contrepoids, \& cét $A u=$ 
theur pretend qu'il y faut affeoir vn homme at jeun lors qu'il veut prendre fon repas, afin que le poids de l'aliment abaiffant infenfiblement la chaire puifle determiner la quantitédes viandes, \& feruir de mefure à ceux qui defireront obferuer vr regime exacte \& reglé, \& certes il femble gue ce dellein foit aflés bien imaginé, car s'il eft veritable, fuiuant Hippocrate, que les cauités foyent remplies d efprits, que ces efprits influent abondamment dans le ventricule, qu'ils donment la legereté, eftant ä̈riens, \& que c'eft par cette raifon que la pefanteur aux malades eft vne marque de leur perte; il eft affeuré que l'aliment venant à prêdre la place des efprits, \& liant toutes ces effences mobiles, produira la pefanteur dans lecorps, l'augmentera fuiuant fa quantité \& ra confiltance, \& qu'ainfi il balancera la chaire, \& la faifant defcendre par dégrés, marquera le regimedont nous parlons. Et voila la caufe que les petits enfans, \& les animaux égorgés pefent dauantage s'ils ont mangé, \& li les eftomachs deceux-cy fe treuuent remplis de pafture, \& qu'il faut excepter feulement ceux qui font ì demi-morts de faim, dont les parties font affaiffées, les chairs endurcies, \& qu'vn peu d'aliment rend legers, en ranimant les membres, en rallumant les efprits, \& en rendant les pores \& les chairs de cette façö plus ouuertes, c'elt icy le tour qu'on doit donner au paradoxe de ceux qui croyent que nous fommes plus pefans à jeụn, ou bien il faut foûtenir hardiment le contraire. Pour bien montrer cela il eft neceffare d'obferuer le fondement de la medecine tatique, fcauoir que 
la legereté procede de l'euaporation de ces matieres volatiles quifurmontent deux fois plus les folides \& les groffieres, \& qui fe vuident par vine tranfpiration infenfible, pendant le fommeil \& durant la nuit ; c'eft pourquoy nous nous treuuons libres \& dégagés, aprés vn repos doux \& paifible. Or il arriue par confequent de là, que nous deuons eftre moins pefans le matin \& jeun, \& que l'aliment \& les veilles peuuent donner vn poids à nos membres, que la chaire découtrira eftant fufpenduë. On doit conjecturer de ce difcours que cette chaire marquera facilement les changemens de la fanté, \& les alterations qui precedent les maladies, comme par ex. emple fi fans aucune raifon euidente, ceux qui fe repofent fur elle, l'abaiffent \& la font defcendre fenfiblement. Car il y a alors de l'apparence que la tranfpiration eft interrompué, fuiuant lias phorifme de Sanctorius.

si corporis pondus plus foliro augeri incipiat fone mat jori cibi, aut potus addikione, vel fenfibilium excreshentorum retontione, facta eft adiapneuftia.

A prés auoir demeuré long temps fur les fieges: changeons de maintien \& de figure, \& examinons dans peu de paroles les chaires qu'on employe au tranfmarchement des perfonnes indif. pofées ou delicates.

Les chaires de cetre façon ont fort plû aus Romains \& aux Grecs. On fçait que les Senateurs de l'ancienne Rome faifoient vanité de les faire porter aprés eux dans la Ville, c'et ainf qu'il faut expliquer Iuuenal.

Refpici bec primum qui litizat an tibi forsi 
octo, decem comires, an poft te fella, togati

Ante pedes.

\& ailleurs,

Noctibus hic ponunt lecticas, micturiunt bic

Effigiemque Dea longis fiphonibus implent.

Ce qu'on ne f̧̧auroit entendre quie des chaires lourdes, \& pefantes, que quantité d'Efclaues Allemands auoient coûtume de porter... Les Grecs neantmoins en auoient des moins pefantes \& de moins incommodes, Plutarque les ap-

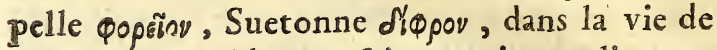
Galba, Artemidore en fait mention au liure 5 . cap. 67. Et vn fçauant remarque qu'elles reffembloient aux chaires des femmes I uifues, dont on conçoit quelque idée grofiere au 1. de l'Exode. Quioy qu'ilen foit, ces chaires ront fort en vfage aujourd'huy; les femmes Chinoifesen ont d'vn bois aromatique garnies des treillis, d'hywoire, ou d'argent, parce qu'elles ont leurs pieds - If petits qu'elles ne fçauent pas marcher parles rues: les Indiens en font de rofeaux, que les efclaues portent fur leurs efpaules; celles des Ragoufois font fi legeres que ce peuple fe fert desfemmes à la façon denos porteurs; enfin par toute la France \& 1 Italie on void quantité des chaires dépeintes \& hiftoriées, quelquefois auec descouleurs qui font fort nuifibles à la poitrine $\&$ au cerueau. Voyons maintenant les effets qu'elles peuvent produire fur ceux qui en font leur vfage.

Les chaires font fort commodes aux bilieux, aux tranfpirables, \& aux flouët, non feulement en empéchant quele mouuement n'augmente leur feu, mais encore en les preferuant 
Des Chaires.

de ces changemensimpreueus du chaud au froid, qui font les rhumes, \& tes pleurefies, \& quantité d'autres grands maux que nous voyons arriuer de ce principe. De là, vient que Jors qu'ils jouënt au mail, ou à la paume, qu'ils s'échauffent dans les affaires \& dans le trauail, qu'ils fe treuuent embaraffés dans la foule \& dans le tumulte, ils courent fortune de tomber dans des maladies, fi, fans le fecours des chaires, ils s'exporent fubitement au vent \& à l'air.

Difons en de merme des perfonnes quire fentent facilement.incommodées du Soleil \& du ferain, qui fe diffipent à la moindre abtion, \& qui eftãt difpofées à fuër par la rareté de leurs chairss \& par l'ouuerture des pores, fouffrent fouvent ces retours \& ces condenfations qui procedent de l'exterieur.

Adjoûtons à tour cela que les chaires font fort vtiles aux lieux oủ le temps \& les fairons font inegales, \& où les peuples gemillent fourent fous la tyrannie de la goute \& des fluxions, parce que le mourement moderé ne lalle, \& n'affoiblit point les jointures, \& que les qualités étraz. geres ne fe gliffent pas librement.

On void de ce difcours pourquoy les chaires ront fort commodes aux malades, qu'on les tranfmarche mieus par leur moyen, qu'elles leur feruent mefme de quelque exercice, pour ueu qu'ils nefoyent point épuirés, qu'ils n'abondent pasen humeurs crues, que la nature ne trauaille point aux feparations, ou que leur ventre ne foit extraordinairement lache, parce que Celfe compare le mouucment des chaires, à celuy des 


\section{$27 \overline{2}$}

\section{Du รeu.}

nauires, lors qu'ils flotent doucenent au ports de forte qu'elles brouillent, qu'elles remuënt, \& qu'elles peuuent détacher ce que les facultés tâchent de conferuer dans les paries.

\section{CHAPITRE VII.}

\section{Du Iew.}

T Es hormmes ne recherchent ordinairement a 1. fe diuertir dans le jeu, que pour relâcher l'efprit, pour delaffer le corps, \& pour donner à rous les deux de la vigueur \& de la force: Ils abus. fent neantmoins bien fouvent du plaifr qu'ils $y$ trouuent, \&: ils s'emportent d'autant mieux dans cette volupté, parce qu'ils la croyent innocente: c'eft ainfi qu'on void de l'excez dans les diuertiffemens lesplus doux; que la morale en qualité de Medecine de l'efprit, a reglé l'emportement des joueurs par les loix \& par les preceptes, \& que la Medecineà fon imitation a prefcrit des regles, \& a fait des obferuations fur les jeux. Deduifons ces obferuations pararticles, afin de découurir les biens \& les maux, auec toutes les circonItancesqui precedent, ou qui fuiuent les jeux.

La premiere eft qu'on doit éuiter les jeux trop ferieux, quigénent \&qui attachent l'ame, \& choi* $\sqrt{1} x$ feulement ceux quil'éueillent $\&$ la degourdiffent, enfin qui luy feruent de medecine pour adoucir fes peines, \& pour relacher fon ennuy: C'eft ainfi qu'il faut conceroir Platon lors qu'il ordonne le jeu au 7. de fes loix, difant que tout 
Ic monde n'eft qu'vn jeu, que Dieu l'a fait en fe joüant, que l'homme a efté produit de cette maniere, qu'il doit dans fes aetions imiter quelquefois fon outrier: Et veritablement Ariftote a efté du fentiment de ce grand homme lors qu'il confeille de jouër pour bien trauailler. Les Anciens d'ailleurs n'ont celebré des jeux apres les funerailles \& les maladies, \& Homere n'a fait jouër fes heros à laguerre de Troye, que pour montrer que le jeu n'eft que pour delafter l'ef. prit, pour le guerir \& le foulager.

La feconde, qu'il n'eft pas bon qu'on s'appliqueaux jeux purement de fortune, parce qu'ils balancent trop l'efprit par l'euenentét incertain. qu'ils luy font quitter par ce moyen le foin \& le regimedes paries, \& parce que l'efpanouiflant lors que le fort eft fauorable, \& le reflerrant fabitement lors qu'il change \& deuient oppofé, il fe fait vn flux \& reflux des efprits \& du fang dans les veines, qui déregle fouuent la fanté. Les dez font de cét ordre là, aufiils eftoientconfacrés \& fufpendus dans le temple de la Fortune, les anciens ont creu qu'il en eftoit d'eux comme de la geomantie, dont les nombres marquent quelque princıperéleué, quiles infpire \& quiles dirige, mais dont les reuolutions continuelles caulent les changemens qu'on y void. Le Roy des Parthes fit connoitre cette verité à Demetrius, en luy enuoyant des Tales d'or, parceque ron efprit eftoit inquiet, \& fon humeur fort in. conftante, \& les Lacedemoniens lont autorifée, en accufant de legereté tous ceux qui sappli. quoient au jeu, mais fur tout, les hommes qui 
274 Du Ieu.

pratiquent les dez, \& les autres jeux qui leur refLemblent.

La trolféme, quiil eft neceffaire d'éviter la contention dans le jeu, c'eft pourquoy Caton ne rougifloit point de jou $\mathrm{r}$ auec des enfans, \& Antioche Roy de Syrie, au rapport de Diodore, relâchoit fes inquietudes par les marionnetres, dont le jeu appellé neurofpaftique, eftoit fort recherché autrefois. On rçait mefme que les Romains les plus ferieux aimoient à fe diuertir au pair ou impair, \& on admire la lettre d'Augulte I $f_{a}$ fille, mifs tibi denarios centum quinquaginta quos fingulis conuiuis dederam, fi vellent inter fepoft caname vel Talis s vel par impar ludere. Or la raifon de cet. te obferuation procede de ce que la contention allume la bile, qu"elle la detache \& la fait bouil. lir, qu'elle échauffe \& émeut les efprits \& caufe ces douleurs de tefte, ces veilles, ces fiéures \& tous ces fimptomes qui deriuent fi fouvent $d u$ jeu.

La quatriéme, que le deplailir ne fuccede point au jeu, car on ne doit point douter des mauuais effets qui en procedent: il en eft de mefme du defefpoir, \& des extrauangances qui accompagnent les joüurs, lefquelles font voir que les hommes ne s'appliquent au jeu que par interêt, \& que par foibleffe, \& non pas pour s'en reruir d'adouciffement \& de medecine à relâcher lecorps \& l'ame.

La cinquiéme, quon ne s'amufe point à des jeux quifigurent des armées \& descombats, parcequ'ils allument, \& qu'ils animent, \& nefont ronuenables qu'aux perfonnes parefleufes \& 


\section{Du IEs.}

phlegmatiques, à qui on confeille quelquefois la colere \& l'emportement, \& non pas aux har dies, aux entreprenantes, aux fanguines \& aux bilieufes. Les dames, \& les efchecs font decette façon, ainfi que Lucain le remarque,

Callidioye modo tabula variatur aperia

Calculus, ó visyeo peragantar milite bella.

I a fixicme, qu'on connoit par le jeu l'inclination \& le temperament des jouëurs, c'eft de ce principe que quelques peuples ont coûtume de faire jouër ceux qui fe marient, pour découurir les fecrets mounemens de leur coeur, La raifon de cela eft parce que les bilieux s'allument facilement, \& qu'sls agiffentd'vne maniere quelquffois infolente, comme les melancholiques paroiffent triftes, chagrins \& intereffés. Orily a des jeux qui découurent principalement ces demarches, comme par exemple les jeux d'attache \&decontention, celles des bilieux \&c.C'eft pourquoy ceux qui veulent conferuer leur fanté, \& garder quelque mefure dans la vie ciuile, doiuét rechercher des jeux qui adouciffent leur foto \& quicorrigent leur humeur turbulente.

La feptiéme, que la force de l'imagination eft la fource des excés que nous remarquons dans le jeu, car ceft elle qui flatte alors, ou quifait conçeuoir des idées furprenantes à l'ame, quả luy infpire des penfées d'interêt, d'ambition \& de defefpoir, quil'amufe par vne application qui eft J'image du micmac qu'on void dans ce monde, \& qui propore des moyens dans le jeu à feruir aux biens, aux intrigues \& à l'amour. De là vient qu'il n'y a proprement que lesfoux, les fermes, Sij 


\section{6}

Du Ieu.

les enfans, les faineans, les melancholiques \& les bilieux quis'appliquent volontiers au jeu, parce que limagination de ces perfonnes eft fort exprefliue, oudu moins parce qu'ellen'eft pas fou. uent corrigé par la folidité de l'éprit \& du ju. gement. On void de ce principe les grands maux que le jeu peut produire, puifque les Medecios nous enfeignent que la fantaifie a vn grand empire fur tout le corps, qu'elle peut fi fort enlever l'ame, gu'elle la tirera du foin de l'cecono: mie qui elle exerce dans nos parties, ceft pour. quoy les Lydiens, fuiuant Herodote, oublioiente la famine pendant le jeu; enfin qu'elle pouffera les efprits auec tant de vigueur du centre à la circonference, qu'ainfi elle empéchera le fommeil \&e troublera fi fort le fang, quelle pourra jetter dans la folie, comme l'experience a fait voir; \& certainement l'effort de cette faculré paroit $f_{B}$ fenfiblement dans le jeu, que ceft de là que les femmes ardentes au jeu y pâment fousent, ou quelles y fouffrent des fuffocations de matrice. parce que leur imagination, comme tout lemon. de eft d'accord, a vn grand pouuoir fur cette par. tie, \& qu'elle y trouble founent ce que la nature yébauche dans fes productions. Mais d'ailleurs ce qui fait mieux encore valorr la vertu de la fantaifie fur le fujet que nous écriuons, c'eft qu'elle fert de guide aux aueugles, \& qu'elle fupplée quelquefois au deffaut de leurs yeux dans le jeu; en effet nous en auons veu qui fe font ainfi démelés des cartes, des boules \& des échecs auec auantage, n'ayant autre confeil \& autre lumiere. que celle quils empruntoient deleurs phätôncs. 
Du Ien.

277

La huitiéme, qu'on deuient étourdy \& perant apres anoir joué, car comme fuiuant Hippocrate à 6. des Epidemies, tout ainfi que le mounement exerce lecorps, les penfées font le mefine à l'ame; il arriue par côfequent de là que puifque dans le jeu, les penfées font pour la plurpart extraordinaires \& violentes, qu'elles, troublent l'ame, qu'elles l'exercent, qu'elles l'agitent trop fortement, ¿z qu'elles nous rendent alors femblables à ceux qui gemiffent fous le poids, \& fous l'embarras des affaires. Delà vient que puifqu'il fe fait vne methaftafe de l'ame au corps, que le corps fe reffent alors de ce trouble, qu'il aime, pour fe delaffer, la compagne, la folitude \& le repos, qu'il fe treuneabbatu de douleur, \& de la nonchilance : En vn mot qu'il fe fent tout malade \& tout allumé. De là on void la raifon pourquoy le jeu eft nuifible apres le repas, parce que l'ame occupée entraine au cerueau, qui eft la fource des penfées, les efprits qui font neceflaires au ventricule, c'eft pourquoy les grands jouëurs font fort fujers aux maladies qqui alterent la nourriture \& les organes de la digeftion. Mais pour mieux faire voir les émotions \& les fecourfes que l'ame reffent des penfees dans le jeu, \&e pour montrer qu'elles fe terminent aux parties; il faut reprendrece que nous n'auons fait qu'éfleurer, \& fe fouuenir que les paffions rendent l'ame toûjours partagée \& flotante, \& qu'elles deriuent des differentes pensées que les euenemens du jeu excitent \& fourniffent inceffamment. Or entre toutes les palfions, lame fe treuue ordinairement attaquée de quatre qui triom. Siij 
phent de resiumieres, de l'erperance, de la joye, de la crainte \& du deferpoir, toutes l'épanourfent. ou la reflerent, \& ce quily a deremarquable, elles le font auec violence, auec furprife, \& fubitement, \& cntrainent neceflairement les organes des efprits auec le fang de cetre maniere. En effet l'efperance que l'ame re donne par quelque auantage qui luy fait conceuoir la pensée d'vn bonfuccés, louure, élargit auec elle le coeur; \& fait que les efprits fe répandant par tous les membres, produifent ces delis ou ces railleries qu'on fouffre foucent des joüurs fortunés: lincertitude quelque temps a pres retient l'ame \& le coeur, balance les efprits \& fufpend leur cours \& leurs routes; la peur en fuitte refferre l'ame, repouffe \& ramaffe tous fes reflorts, jufques a ce que la grande joye les dilace de nouueau, \&les relance hors du centre, pourueu que le deferpoir, \& que la trifteffe nétouffent ce que l'efperance auoit relâché. De tout cela on doit tirer des reflexions tres-profitables. Sçauoir, que le flux \& reflux des efprits fait celuy du rang dans les veines, qu'il caufe de grands changemens, que tous les changemens impreueus font ennemis de la nature, que c'eft de là que le pouls s'altere fi founent aux joueurs, que la tranfpiration s'arrefte, que l'ame fe jette dans desempor. temens qui font excufer les jouëurs, qu'elle deui nt impaticnte \& inquiete, \& quecelt par cette raifon que les jouëurs changent de place, \& quils ne peuuent quelquefois demeurer en repos, en vn not qu'ils s'offensét de la moindre parole, qu'ils s'efrarent du moindre bruit, quils de- 


\section{D红 I}

uiennenr liberaux, \& que les Princes donnent des graces, \& accordent des recompenfes.

La neufiéme obferuation eft tirée des principes aftrologiques. Car tous les fçauans Aftrologues foûtiennent que Venus, Mars \& Saturne font les directeurs \& les maitres des jeux. En effet Venus les a infpirés aux Orientaux aufquels elle domine, il eft certain d'ailleurs que les fema mes, quiluy font foûmires, aiment fif fort ̀̀ fe diuertir au jeu, que fi on concerte auecelles quelques mariages, les jeux en font tous les commencemens; entin les Autheurs, qui décriuent les lineamens de nos mains, remarquent que ceux qui ont des lignes fur la montagne de Venus qui fe terminentà la plainedeMars s'appliquent au jeu auec ardeur, \& empreflement, fans fonger a leurs biens, \& à leur fortume. Mars partant difpofe, $\&$ encline les hommes a jeu auec excés, parce que le jeu eft vne forte decontention \& de querelle. Et veritablement les injures, les profufions, l'infolence au jeu, l'ambition de gaigner, les railleries \& la colere deriuent de cette planette, \& tout ce que le Poëte Ouide a de crit, en parlant dus jeu.

Ira lubit deforme malum, lucrique cupido, Iurgiaque, of nxe, Sollicitusque labor.

crimina dicuntur, refonat clasnoribus ether,

Inuocat iratos \&o floi quifque Deos.

Nulla fides tabulis, que non per vota pezuntegy

Et lachrymis vidz Japè madere genas.

Il faut croire quelque chooe d'approchant de Saturne, car il y a de l'apparence que c'eft de luy que les jouëurs viennent reueurs, qu'on les ob: $S$ iiij 
280

ferue intereft's, Du Peu.

peurs, rufés \& foupçonneux, auares, trom chapeau en dent long femeng temps jour; enfin qu'ils fuyent les quils nes'onme les Martiaux les recherchent, \& lent furprendre \& quaux perfonnes qu'ils veuOn peut concludont ils peuuent triompher. Saturniens, c'eft à de cette obferuation que les gmentent la malignité les melancholiques, auauec ceux qui font d'vn femb nature en jount ment, \& qu'il en eft ainfi des lieux fuiuant les principes Martiaux ou des biqués au premier pro nous auons marcha pitre dece volume. Etcerduchagrin \& de arriuer de ce commerce que defe diuertir au emportement, \& il eft mieus ceur peuuent modec cen dont la gayeté \& la doules mouuementer nos humeurs, \& corriger

Ie ne parle poin fe foûleuent dans nos ames. nuits, \& parties, parties, car tout le monde eft d'accord desindifpolitions quifuruiennent de tout cela, \& des ef. fets qui en procedent.

\section{CHAPITRE VIII.} De la Danfe.

10 Vifque ruiuant Platon les Intelligences qui 1. roulent les aftres danfent au fon de leur concert; \& puis que les Poëtes font danfer les 
Diuinitez dans leciel, \& les Mures fur le Parnaffe : Nous pouuons bien prendre la liberté d'esercer noftre ef prit \& la danfe, \& de voir fuiuant noftre deffein fa nature \& fes qualitez; mais pour le bien faire auec ordre, il faut confiderer en general cet exercice, \& faire les obferuations fur les perfonnes quile pratiquent, \& y 1oindre les cirs sonftances qui deriuent du temps \& des lieux.

En premier lieu la danfe denoue lecorps, \& rend les parties flexibles, auffi elle difpofe fi fort à la yymnaftique, qu'elle en eft le principe \& le fondement. Voila pourquoy les Grecs inftruifoient leurs enfans à la guerre a pres les auoir fair danier, \& ils ordonnoient leurs armées au fon de la flutte, afin que l'harmonie de cet inftusment peût regler en cadance la marche des Cas pitaines \& des foldats.

En fecond lieu la danfe amaigrit mediocres ment lecorps, \& empêche ainfi la groffeur exceffiue du ventre, parce qu'elle a du rapport à la promenade vn peu forte quivuide, qui diffipe, quiattenue, \& quirefout: \& voila ce qui obligeoit les Grecs à eftablir des danfes publiques, ò les vieillards danfoient auec les enfans, \& 12 jeunefle, chantant tour à tour ces vers

- Les vieillards Nous auoxs efté jadis

$V$ aillans bommes of bardis?

les jeunes

Nous le fommes mainienan

A. l'efpreure s̀ tout venans.

les enfans

Et vn iour nous le ferons

Quis tous rous furpafferons? 


\section{2}

De la Danfe.

En troifiéme lieu Socrate nous apprend dans le feltin de Zenophon, que la danfe fait vn effet bien different de tous les autres exercices: Ceuxcy exercent plûtotvn membre qu'vn autre, ils grofiffent, ou ils amaigriffent tantôt les cuiffes \& tantôt les bras parl'inegalité de leurs mefures. au lieu que la danfe par fon harmonie, \& par fes mouuemens reguliers balance le corps également, \& rend l'equilibre à tous les organes: C'elt pourquoy Socrate fe plaifoit à danfer pour donner vn brânle mefuré à fes parties, parce quiil les aucit mal compofées.

En quatrieme lieu, la danfe aide à la tranfpiration, \& prouogue aux femmes les humeurs abondantes quiles rempliffent \& quiles fouillent, parce que les fecoufies quielle donne, font ces parties, que l'Hippocrate a deftinées à eribler dans nos corps, ainfi que le mouuement au crible qui fepare \& épure le grain; \& peutefrec'efticy la raifon pourquoy Orphée ayant eftably les Bacchantes, vouloitqu'elles danfaffent au fon des clochettes \& des tambours, \& les obligeoit de reclamer ainf le foleil fous le nom de Bacchus, qui mene la danfe des aftres, afin quayant mieus depore ces reftes qui incommodent fi foutuent les femmes, ellesappriffent à en gendrer auecvne plus grande pureté. De là vient aufiqu'on portoit en danfant deuãt ellesla figure du Dieu Priape, pour auertur leurs femblables defe difpofer de cette maniere. Et certes le fondement de cecy procede de ce que la danfe ébranlant les cuiffes, les lombes \& les reins, émeur les ligamens qui fufpendent \& qui tiennent 1 . 
matrice attachée; de forte que cette partie reçoit 12 mefme agitation \& qu'elle. fe defcharge ainf de ce qu'elle a d'inutile, \& de furchargeant. De ce difcours on connoît pourquoy Hippocrate ordonna la danfe à vnefemme qui auoit conceu, pourquoy le mouuement que la danfe donne à la matrice, poufte les femmes \& leur donne quel. que fatisfaction à danfer; enfin pourquoy elles doinent danfer l'eftomach vuide, \& fans interrompre leur repos ordinaire, car il n'y 2 rien qui les rende pâles \& qui les embarraffe alors dauantage que la danfe opiniâtre, \& longueapres le repas \& durant la nuit; c'eft elle qui precipealors les alimens à demi-cruds dans les veines $\&$ dans les entrailles, qui porte à la furface des matieres grolferes, quiterniftent l'éclat \& la viuacité du teint, \& qui engage les deftours des membres , que la nature tient necellairement toújours oue uerts.

En cinquiéme lieu, la mufique \& le fon font danfer l'ame en faifant danfer les efprits, celt à direen leur donnant vneagitation, vnecadence \& vn branfle harmonique, la poëfie luy fait cette impreffion immediatement, jufques à la rauir \& la jetter dans l'enthoufiafme, \& 12 danfe eft vn effet des mouruemens que l'ame fe donne, \&e auec lefquels elle émeut \& elle ébranfle le corps en fuitte de ceux qu'elle reçoit des tons de la mufque, de la poéfie \& des chanfons. On peut dire mefme qu'elle eft comme vne reflexion \& vn retour de l'agitation de l'ame vers les parties, vne image de ces mefures, que lestons \& les airs impriment à l'efprit: bref v echo 


\section{4}

de De la Dsmfe.

ce harmonie, qui fe fait dans les fibres \& dans les mufcles, \& qui garde vn ordre pareil \& en re. prefente la regle. De toutcela on tire plufieurs confequences, fçauoir que la mufique, \& les tons mefurés font comme les formes \& les couleurs qui releuent \& animent la danfe, quils guerifset plufieurs maladies en degourdiffant l'ame en enchantant\& en euentãt les efprits, \& que la danfeleur aide en agiffant ainf qu'eux fur les parties sroffieres, ou delicatès qui feruent d'inftrument pour danfer; \& voila la raíon pourquoy dans le venin de la tarente, les infrumens deftachent ales efprits toutes les qualités mal-faifantes, \& que la danfe, par vne vertu ap prochante, poufle des organes ce qu'ils ont reçeu de mauuais \& de venimeus. On conçoit encore dumefme prinaipe pourquoy la melodie nous fait danfer d'vne maniere differente fuiuant fes mefures \& fes tons differens, comme par exemple, les tons aigus nous font fauter, nous infpirent vne danfe fort Eite, au contraire des graues \& de ceux qui vont lentement: car l'ame prenant les mefmes routes, les communique ainfi à nos corps, qui imitent par vne reflexion merueilleufe la fourcede leur mouuement. Ceft pourquoy, comme les tons aigus, ainfi que nous verrons bientot, éueillent les melancholiyues, \& que les graues compofent la fougue \& l'emportement des bilieux, les danfes qui en deriuent font les mefmes effets, de forte qu'elles doiuent eftre proportionnées, ou pour mieus dire qu on les doit regler fuiuant Ia qualité du temperamment; on en peut direle mefme des rexes, dẹs agges, \& treuuer ainf la 
De la Dange.

saufe pourquoy certaines danfes plaifent aux vns \& qu'elles font abandonnées des autres. Adjothtons à tout ce difcours, que la danfe par confequent $a$ de la proportion dans fes varietés aus tons croamatiques, enharmoniques, \& que la danfe pirrique par exemple, l'ithifmique approchent des chants doriens, phrigiens, \& elles émeuuent le corps à proportion que ceux-cy aggatent nos ef prits \& nos ames.

En fixiéme lieu, pour bien conceúoir la danfe. il faut obferuer ce qu'Ariftote auance dans fon art poëtique, car apres auoir là fuppofé que la poëlie eft vne imitation pure, il dir qu'il fe fait plufieurs imitations, comme par l'harmonie, par loraifon, enfin par le nombre \& par la mefure qu'on a coûtume de garder en danfant, \& certes la danfe eft vne poêfie miëtte, \& vne mufique d'ailleurs fi reglée, nonobftant qu'elle n'ait point de fon, qu'elle peut agir de la mefme maniers qu'Ariftote propof $e_{i}$ en effet les anciens ont foûtenu qu'elle cóferuoit la portion que nous auons de l'ame du monde, en entretenant les mouremens harmoniques qu'elle garde dans nos parties, à l'imitation de ceux auec lefquels elle fair rouler les Aftres, le Soleil \& le Ciel; c ceft poure. quoy les Bracmanes regardoient en haur en danrant, \& les Preftres de Delos facrifioient à A pollon en danfant d'vne danfe oblique. De là on connoit pourquoy les anciens danfoienten figure, \& quion fe diuertit de cette façon, \& d oú vient qu'on melle la danfe à la comedie, parce que toutes deux font des imitations. Et veritablement on compole diuerfes figures dams les 
balets , pour marquer les palfions des hommes; \& pour donner plus de jour à la comediequien reprefente les mœurs: les Grecs appelloientces figures $\beta$ mot de bal, \& de balet: On defcouture encore par la mefme raifon que la danfe irreguliere \& violente, comme eft celle du peuple \& des pairans, eft tout à fait nuifible à nos corps, parce qu'elle eft sás harmonie, qu'elle trouble\& qu'elle confond, mais fur cout parce qu'elle n'a point de rapport, ny ax vers, ny à la mufique, à caufe quielle el concertée fans cadance \& fans iugement, aufi il faur d'inftrumens extraordinaires qui la prouoquent, \& qui faffent fauter, \& meutent les efprits materiels du peuple, pour imprimer en fuitte vne agitation extraordinaire \& turbulente à des parties trop dures, trop marfires \& trop mufculeures, quidemeurent fouvent engourdies toute la repmaine, par l'application affiduč au trauail.

Apres auoir obferué la nature, les differences \& les effets principaux de la danfe, il nous refte à examinervne circonftance qui luy eft eftentiele, que les mâtres de danfe recommandent fi fort $\&$ qui ef cōmune prefque à rous les exercices d'importance. C'eft le port quion donne au corps, \& - res parties, lors quion fe deftine à danfer; ce port convient à ceux qui s'appliquent aux armes, ou bien qui veulent s'exercer à monter cheual, à parôtre en public fur vn theatre, ou à faire quelque autre demarche. C'eft pourquoy. pour le bien expliquer,

On doit rupporer ce qu' Axiftote renarque au 
De la Darfé

5. de l'hiftoire des animaux, fçauoir que les oiSeaux font dans le bilibre par le penchant qu'ont leurs parties fur deuy pieds, \& parce qu'elles ront là balancées de la queuë \& de la tefte : que les brutes au contraire font foutenuës de quatre pieds comme fur quatre fortes colomnes, de forre quielles niont pas befoin d'eftre balancées de deux poids comme les oifeaux, \& qu'elles portent à cét effet des chores lourdes \& perantes mais que l'homme eft droit, qu'il a vne fituation. exactement perpendiculairs, \& quil eft ainfir dans l'equilibre, afin qu'il ait correfpondance auec tout l'vniuers, qui a le haut \& le bas comme luy, par vne figure éleuée. De là vient qu'ili tombe facilement, lors qu'il eft courbé, ou qu'il emprunte le bâton, parce que l'equilibre cefTe, quil prendvn poidsqui le fait pencher en arriere, ou en auãt, qu'il deftruit ainfi cette proportion, \& cette fituation geometrique que la naturegarde en le produifant, \& que la tefte quifait vne partie de lequilibre, entraine auec foy tout le refte du corps.

On conclud de tout ce principe, que le port qu'on demande aux exercices ne confifte qu'à l'erection \& à la rectitude de tout le corps, qu'ainf on le partage mieux dansle mouuement, qu'on le balance auec plus de mefure, \& que la daní, qui eft dans liordre \& dans la regle, acheue mienx res pasmefurés, ceux d'ailleurs quil la pratiquent ont plus de grace, parce quils obferuent cette fymmetrie, qui eft la caufe de la beauté, de la fanté, de la perfection \& de l'arrangement de nos membres; ciett pourquoy tous les exercices qui 
288

Do l'Exercice des Armes.

plient \& courbent le corps, qui alterent, \& qui corrompent fa figure, abregent la vie, \& font ennemis de fes fondemens.

\section{CHAPITRE IX. \\ Do "l'Exercice des carmes.}

-Application aux armes exerce les hommes 1 en agitant l'ameauecles efprits, en pouffant les parties, ou bien en changeant leurs figures, enfin en metamor phofant le temperament \& la confirution du fang.

Elle agite l'ame auce les efprits, parce quielle infpire, ou qu'elle dirpole aux combats les plus cruels \& les plus funeftes, \& qu'elle donne à la partie irafcible de la violence \& de l'emotion.

Elle poufle les membres, ou bienelle en change les figures fuiuant les inflexions des nerfs, 8 des mufcles, qui font neceffaires pour deffendte, ou pour attaquer; c'eft pourquoy l'eftude qu'on a faite aux armes, rend le corps generalement frompusque Galien l'a nammée la plus forte \& la plus penible de toutes celles qui nous exersent.

Bref elle altere fi fenfiblement le temperamment $\&$ la conftitution du fang, que les anciens fe font feruis du fang d'vn gladiateur, pour guerir Fauftine amoureure; que Scribonius Largus ordonne aux epileptiques la chair d'vn animal égorgé par vn coûteau rougi du fang d'vn homMe, qui pratique les armes; quareteus employoit 


\section{De l'Exercice des Armes.}

ployoit vn pareil remede contre les maladies du froid, \& que certains fuperftitieux le propofoiet aux malefices \& aux enchantemens les plus formidables. Toutes ces verités nous fourniffent maintenant vne infinité de confequences.

La premiere, que les armes preparent à la colere \& à l'emulation, qu'elles excitent vne tempefte dans les efprits, dans l'ame $\&$ dans fes parties, qu'elles y foûleuent des fortes pations, \& que c'eft par cette raifon, \& de ceprincipe que ceux qui s'eftudient à pouuoir combattre, combatent quelquefois tout de bon, \& qu'ils contraignent le maitre de fale de leur faire fouuent le hola \& d'appaifer leur emportement \& leur fougue.

La feconde, qu'il arriue alors que la bile s'allume \& s'irrite, que le fang prend fes qualités, parce qu'ilbouillonne dans le cour, \& vers les entrailles, \& qu'il s'échauffe par la colere, l'emulation \& la fierté ; c'eit de là au fi qu'il peuç guerir les maladies froides, fuiuant Areteus, \& qu'il fait juger qu'il n'y a rien de plus ennemy des bilieux, des coleres \& des turbulens, que l'exercice dont nous efcriuons maintenant la nas. ture.

La trøifiéme, que les fecouffes, l'agitation, ou le moutiement des parties, di fipe, amaigrit les chairs, \& efpreint ce qu'elles ont de fuccul lant, que le changement des figures en élargit; ou en comprime les cauités, \& les ventres, \& qu'il en tire, ou qu'ily precipite les humeurs? enfin que la grande impulfion des bras, qui font employés principalemeat dans l'eftude des are 
290

De la Chaffe.

mes, donne des fi rudes fecouffes à la poitrine \&. aux poulmons, qu'vn moderne a obferué par les frequentes diffections, queceux qui font profeffion des armes, ramaffent ordinairement vn fang: efcumeux vers les parties de la refpiration, qu'on 1e defcounre apres leur mort, \& qu'il eft vn prognoftic des guerres ciuiles, fi on le treuuc ainfi à la plus grande partie du peuple.

\section{CHAPITRE X.}

\section{De la chajfe.}

42 A chaffe eftant l'exercice des Roys, des $\mathrm{He}$ Los \& de la Nobleffe, ce feroit à oublier noAre fujet, \& à n'acheuer point noftre ouurage fi nous n'y donnions quelque place, \& fi nous n'en faifions vne des parties de la Gymnattique, que nous auons entrepris de traitter.

Difons donc en peu de mots qu'elle eft fous l'empire de Mars, \& de Saturne, \& que la Lune y mefle partant fes vertus. Et premierement Mars infpire fi fort la chaffe qu'on l'a nommée vne guerreinnocente, \& l'efchole des grands $\mathrm{Ca}$ pitaines, \& des bons Soldats. En effet elle feruoit autrefois à les rendre robuftes, elle les difpofoit aux combats, \& c'eftoit par fon moyen, queles $L$ acedemoniens dreffoient aux armes leurs cnfans, \& les Perfes leurs Satrapes \& leurs Monarques. Saturne neantmoins prefide quelquefois aux chaffeurs. Auffi ceux qui font ennemis des femmes, comme Hyppolithe, s'appliquent 
foument à la chaffe, tous les melancholiques d'ailleurs qui ont les ongles crochuës \& noires, fuiuant les principes de la chiromance, \& qui aiment la folitude, \& d'eftre errans parmy les montagnes \& les forêts. Auffi il y a de l'apparence, difent les Aftrologucs, que Saturne leur fait auoir bien fouuent la rencontre de ces phantômes horribles, que les Hebreux attribient à leur Azazel, \& que les cheutes, les bieflures, \& les autres infortunes, qui leur arriuent fi frequemment, deriuent fans doute des influences decette planette. Les Anciens partant confacroient la chaffeà la lune, \& c'eftoit fous le nom de Diane, qu'ils en imploroient le fecours en chaffant.

\section{--- Tibi Sapè Diane}

Manalios arcus, venatricefque pharetras

suspendit puerile decus---- dit le Poëte parlant des Nymphes.

On doit conclurre de ce fondement que les bilieux, les maig res, les triftes, les difiipables \& les Saturniens doiuent s abftenir entierement de la chaffe, qu'il en eft ainfi des violens \& des cruels, dont la cruauté, fuiuant Porphyre, s'augmente dauantage par cét exercice, qui n'a pour but que de prendre, \& de tuër. Mais pour donner des regles fur ce fujet qui foyent moins vagues, \& plus precifes,

On doit fuppofer en premier lieu, que la chaffe eft vn ramas de tous les exercices les plus forts $\&$ les plus penibles, car elle a befonn de la courfe, des fauts, du cheual, \& de quantité d'autres mounemens, ainfi que le lecteur peut voir.

En fecond lieu, qu'elle fait reffentir fubiteTij 
292

De la chafje.

ment aux chafleurs toutes les inégalités de l'air \& du temps, qu'elle en échauffe les parties, \& qu'elle les émeut grandement. De tout cela on conclud, que la chaffe endurcit les chairs, quoy que la medecine nous enfeigne, que pour retarder la vieillefle, on les doiue entretenir tendres; que diffipant l'humide, \& faifant euaporer les efprits, qui nous tiennent lieu de fel, \& debaume, elle deffeiche \& fait les tabides; enfin qu'il n'y a que les robultes \& les forts, les gras, les pefans \& les phlegmatiques, ceux encore qui ne font pas tranfpirables \& qui ne fouffrent point les imprefirions de l'air, à qui il foit profitable de chaffer. Mais pour mieux encore découurir la verité de ces confequences,

On doit fuppofer en troifiéme lieu, que la chaffe fe fait par tromperie, \& par addrefle, par force, par enchantement \& par poilon.

Le poiron n'emeut point le corps de celuy qui ledonne, feulement il rend la proye mal faine, \& an ne doit point douter qu'il ne luy imprime des qualités malignes, puis qu'il corromp les efprits $\&$ le cour; il en eft de mefme lors qu'on triom. phe des beftes par les rufes, \& par les fineffes, car on nefait pas vn grand exercice, fi on fe fert de la glu, des rets \& de la pipée, pour furprendre les oifeaux, ou lors qu'cn dreffe des pieges aux lieures \& aux lapins. Auff les animaux moins vigoureux ont des petites tromperies, que la nature leur 2 infpirées, pour chercher leur pafture, ainfi que Pline obferue de quantité des quadrupedes \& des poiffons, fans qu'ils foyent obligés de s'élancer ou de courir. L'enchantement n'eft 
point de noftre connoiffance; il faut donc conliderer la force comme le principe des chaffes les plus penibles, les plus dangereufes, \& les plus belles, \& comme la caufe du iamas de tous les exercices qui concourent à les acheuer \& \& à émouuoir principalement nos parties. Et certaimement c'eft de là qu'elles s'efpuifent quelquefois $f$ fort, \& que leurscauités fe rendent fi vuides, qu'elles produifent cette faim canine quiaccompagne les chaffeurs fi fouuent, \& qui eft vn effet de l'exolution quiles diminuë, \&les amaigrit.

Il faut fuppofer en quatrieme lieu, qu' on chaffe ordinairement fur la terre, fur l'eau ou dans l'air. De cette fuppofition, on doit confiderer premierement,

Que la chaffe fur l'eau eft fort differente, car elle eft nuifible aux eftangs \& aux eaux marécageufes \& croupifantes, parce que la vapeur qui en exhale, eft fouuent la fource des grands maux, celle d'ailleurs qui fe fait fur la mer feiche, \& eft ennemie du ventricule, elle fournit des animaux venimeux, \& qui engourdiffent les bras ; c'eft pourquoy les Agyptiens mefprifoient les pefcheurs, \& les anciens offroien: leurs poiffons à Vulcan, afin que cette Diuinité fût ainfi adoucie, \& qu'elle foulageât les morts. De làvient qu'on doit choifir les eaux qui font pures, coulantes \& belles, qui réjouiffent la veuë par leur clarté, qui amoliffent, qui humectent \& qui temperent, bref qui rafraichiffent les melancholiques \& les bilieux; \& certes les Romains les eftimoient fi fort, qu'ils mefloient au cryftal des eaux de lcurs

T iij 
294

De la Chaffer

viuiers \& de leurs riuieres, des rets tiffus de filets d'or \& de pourpre, \& que leurs Medecins ordonnoiẽt cette forte de pefche auxpersõnes amaigsties ou conualefcentes, \& à celles qui auoient perdu. l'appetit, parce que l'eau pure exhale en coulant certains efprits acides, par leficuels elle creufe infenfiblement les rochers, elle fecharge des mineraux, \& fe joint au fel de la terre; en vn mot elle éueille cette aigreur naturelle qui chatouille nos eftomachs: \& voila la raifon pourquoy les caux de certaines fontaines excitent vn appetit, \& vne faim infatiable.

Ondoit confuderer en fecond lieu, que la chaffe quil'c fait fur la cerre, elt auni differente que celle qu'on pratique fur l'eau; car ou on chafle dans des forefts, fur des pleines, dans des valées, \& fur les montagnes, ou au bord des eaux. Ces chaffes font plus douces, ou plus penibles, \&elles exercent ou elles alterent les chaffeursen diuerfe façon. En effet il y a des cauernes qui ont changé les chaffeurs en pierre, des valons peftilens qui ies ont fuffocqués, \& des montagnes dont les vents, les mineraux \& le froid de la neige leur ont caufé des maux furprenans, \& dont la hauteur les a rendus effouflés durant toute leur vie; enfin des forefts dont l'ombre en quelques endroits leur a efté nuifible, \& qui ont caché des eaux trop froides, ou imbuès de quelque venin; cependant toutes ces fortes de chafle fe font à pied, ou à cheual, ou fans s'émouuoir \& agir, \& châcune d'elles exerce le corps d'vne façon particuliere; ainfi la chafle à pied agite, lafle \& efchauffe grandement, elle difpofe les $j$ ointures 
引̀ auoir la goute, fuiuant Hippocrate elle y precipite quantité d'humeurs qui produifent la laffitude, \& elle agite auec plus de force, fi on $y$ joint la courfe, $\&$ fi les lieux font difficiles \& rabouteux.

La chaffe qui fe fait à cheual ćbranle le cerreau, les reins, l'efpine du dos, \& principalemēt le bas ventre \& les entrailles qui y font contenuës, ainfi que nous montrerons bien-tôt; enfincelle qui fe fait en repos, comme lors qu'on eft à l'affuht, n'eft remarquable que par le temps, \& la qualité des faifons: c'eft pourquoy il faut fuppofer en dernier lieu, que ou on chaffe $1 x$ nuit ou le jour, l'hywert ou l'efté, \& qu'on court ou on attend des beftes qui font timides ou formidables. Tout le monde f̧̧ait les grands maux qui font arriués aux chaffeurs du Soleil, du froid, ou bien des rayons de la Lune: on lit mefmeque les anciens choifflioiét la matinée\&inuoquoient l'Aurore pour chaffer, qu'ils fe retiroient à midy. que les Nymphes cherchoient alors les ruiffeaux \& les ombres, que les bons chaffeurs reconnoiffoièt que la chaleur diffipoit l'odeur desanimaux, \& qu'elle irritoit la bile des beftes fougueufes, \& violentes. De tout cela, on void pourquoy on deftine certains habillemens aux chaffeurs, afin qu'ils les muniffent \& qu'ils les preferuent, \& que leurscouleurs feruent tout enfemble à amufer, à furprendre ou à attirer : ainfi le verd eft agreable au cerf, le gris n'effare point la chaffe; mais le rouge rend cruel le chaffeur, \& les animaux qu'il pourfuit.

Enfin les animaux qu'on pourfuit font geneT iiij 
296

reux ou pufillanime la chaffe.

crainte, exionimes, les premiers infpirent la font reflechir en fuitte, partagent l'efprit, \& parties : c'eft de là peut toutes ces émotions aux void fubitement, peut-eftre que le loup qu'on a veu devenir vn alterc la voix, \& que la Nauche fanglier aux abbois, melancholique, parce qu'vn ment heurtédela ans le blefter, auoit feuleLa chaffe qui he ure contre fa cuife.

\& exerce les yeur fait dans l'air efmeut les bras, des pileptiques, \& de tefte, elle eft ennemie ueau aflés fort, elle fufpen quin'ont pas le cern'y a rien qui rende plus mefme l'efprit, il pourquoy les impatien $\&$ melancholique; c'eft fent pas à chafter a tiens \& les bilieux ne reüllirquelquefois, pouinf, ils fe precipitent mefme confpection, \& l'attauoir la prudence, la cirles broufrailles \& attache, \&ils fe bleffent dans pliquent point $\$$ aux rochers, parce qu'ils n'apjugement.

\section{CHAPITRE XI.}

De la Comedic.

C Imagination a vnfi grand empire fur nous, L \& l'Hippocrate a fi jultement ordonné d'obferuer ce quientre par les yeux \& par les oreilles, que nous auons jugé neceffarre d'examiner fi les comedies, qui exercent la fantaifie, \& qui s'infinuent de ces deux façons, eftoient affés fortes, pour faire quelque impreffion fur nos amss, qui 


\section{De la Comedie.}

peût agiter en fuitte nos corps. Et certainement il faut qu'elles foyent bien puiffantes, puifqu'au commencement du monde les peuples ontaimé les reprefentations, que les ruftiques s'en font diuertisen y meflant la fatyre, \& les rithmes, que les Grecs s'expofoient au Soleil pour les admirer, qu'ils donnoient, pour des loges, jufques à des dragmes, \& des oboles; puis qu'ils recompenfoient par des places, ceux qui auoient de la ver$\mathrm{tu}$, que les Romains apres eux abandonnoient leurs maifons, \& leurs meubles aux Comediens.

-.-At fi dulcedine fama

Succenfus recitet, Maculonus commodat ades, qu'ils parfumoient le thearre des fleurs,

Et cum fcena croco ciliciperfufa recens eft. Enfin quils preftoient leurs jardins, leurs fo: refts \& leurs terres, fujuant le Poëte,

Frontonis platani, conuul saque marmora clamant. Nos ames donc font fortemẽt éprifes des comedies, il y a de l'apparence par confequent que les corps, qui ont vne fi grande liaifon auec elles, fe reflentent de leur emotion : examinons maintenant de quelle maniere cela fe peut faire; joüons noftre role, en parlant des comedies fur le theatre du monde, quoyque ce foit en tremblant, \& auec regret; faifons voir enfin que, comme les vies des hommes ne font que des comedies continuelles, que dis-je, ce n'eft pas merueille, fi le monde eft émeu des comedies du theatre, puis $q$ qu'elles font $v n$ racourcy de fes actions.

Il fat donc remarquer en premier lieu, que thomme, fuiuant Ariftote dans fes politiques 


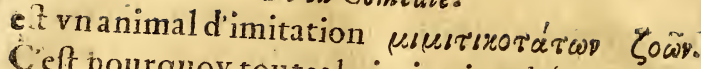
C'eft pourquoy toutes lesimitationsl'émeuuent, clles frappent fa raifon, \& fa fantaifie, \& elles paffent apres, \& font de l'imprefiron au corps. $C^{\prime}$ ef de là que les vers \& les peintures lafciues font dangereufes, \& que les reprefentations du theatre nous réjouiffent, ou nous font pleurer, qu'elles nous inf pirent l'amour, ou nous animent a la colere, qu'on dit que l'exemple peut beaucoup fur nos cours, que le peuple dans $S$. Auguftin, aime fi fort les fpectacles, \&que Lamblique a foûtenu que les comedies purgeoient quelquefois nos efprits, \& nos mœurs. Pour faire voir maintenant auec ordre cõme quoy en reprefentant elles agiflent fur nos ames \& fur nos corps, i) faut contiderer les chofes qui contribuent, \& qui aident à leurs impreffions, comme les perfonmes qui les obferuent, celles qui les reprefentent, leurs façons, \& les circonftances qu'elles gardent dans cét eftat, ou qui font ellentieles au theatre.

Les perfonnes qui ariftent aux comedies en font facilement émeuës par le deffaut du juge. ment, comme les enfans, \& les femmes, ou par $v$ ne imagination viue, côme les melancholiques \& les bilieux, ou par vne grande difpofition à imiter, ainfi qu'on remarque aux Peintres, aux Poctes, aux Danfeurs \& aux Muficiens qui font touchésde ce qu'ils tâchent de produire eux-mermes, enfin à certains peuples des Indes, \& de l'Europe, commeaux Conchinchinois,aux Grecs, aux Italiens, aux François \& aux Prouençaux, quiaiment à cét effet les chanfons, \& qui auoien? 
vne fi grande eftime de leurs Troubadours, qui leur tenoient lieu des Comediens, qu'ils leur accordoient des priuileges \& des honneurs.

Les perfonnes qui reprefentent, font valoir les comedies par la fympathie, par la reffemblance, par la n̦ature \& par les actions. Ainfi. les femmes parleur douceur infinuante, \& par la qualité de leur fexe, excitent fortement fur le theatre les fpectateurs; les hommes agiffent ainfi fur les femmes; c'eft pourquoy Tertullien a fort exageré là deffus, \&: l'inclination d'ailleurs qưe nous auons pour les Acteurs, fur tout fi on $y$ joint la reffemblance, foufleue d'eftranges fentimens, \& des fortes paffions dans nos ames.

Leurs façons font auffi fort preffantes, comme les geftes, la voix, la bonne grace, qui font aux comedies, comme à la peinture les plus viues, \& les plus brillantes couleurs; auffi c'eft là ce qui occupe les Comediens, \& qui abrege fouuent le cours de leur vie, car ils font toûjours dans la contrainte par les mefures qu'ils obferuent, \&. par les démarches qu'ils tiennent, afin de toucher, \& d'ćmounoir leurs Auditeurs, jufques là mefme qu'ils fouffroient autrefois d'eftre à demi priués des parties de la generation, pour parler d'vn ton qui füt \& plus doux \& plus agreable. Neantmoins la matiere des comedies eft encore fort propre à augmenter leur pouuoir, \&. leur impreffion. Et certainement le fujet tragique fait des grands effets aux melancholiques, aux femmes, aux affligés, \& aux enfans; \& le coinique aux eftourdis, aux bilieux \& à la jeuneffe: c'eft pourquoy le tragique, par exemple, ne doit 
300

De la Comedie.

efreque pour les libertins, les infenfibles \& les enioüés, dont le feu rend les efprits trop turbulens, \& trop mobiles; parce qu'alors ils fe fixent \& fe concentrent par le trifte, par le funefte, \& par le ferreux. Aufi pour deftacher l'ame abbatué, on fait alors fucceder ordinairement le diaertilfant, \& le ridicule, que les anciens concevoient fous le nom de faturam fo mimum, \& que Tertullien a blàtné, ne talia spectandi confuetrdo, dit ce grand homme, etiam faciendi daret audaciam. Et voila la raifon pourquoy les comedies, dont Iintrigue eft agreable \& diuertiffante, feruent de medecine aux Roys, aux politiques, aux gens d'eftude, \&aux perfonnes occupées, pourquoy d'ailleurs on a retranché du theatre tous ces fpectacles d'horreur qu'on pratiquoit anciennemét; d'où vient qu'on reprefentoit autrefois les comedies a pres le foupper, pour adoucir les inquietudesde la journée, \& que dans Plutarque c'eftoit mefme apres le repas, pour donner vn plus grand plaifir.

Faifons des reflexions fur les difcours, les actions, \& fur les parolles quon obferue aux reprefentations du theatre, qui foient, femblables à celles que nous venons d'écrire fur leur fujet en effet.

Les actions releuent fort les comedies, \& les infinuënt grandement dans l'efprit. Ces actions confiftent aux fpectacles, aux machines, aux figures, \& aux mouuemens qu'on void, quiont fait appeller ce genre comique motorium, parce qu'il émeut puiflamment, ainfi qu'on remarque dans l'Amphitruo de Plaute, \& dans I'Adelphus de 


\section{De la Comedie.}

Terence. Et certes les actions excitent fi fort dans cet eltat, que durant le fommeil elles fe prefentent quelquefois à la fantaifie, \& elles faifflent fi fenfiblement les fpectateurs, que les Comediens anciennement leur donnoient des bornes par vne corde blanchie de croye, fuịant le Poëtę pour arrefter leurs emportemens.

\section{-...-- Cogit nos linea iungi.}

Les parolles font le mefme effet par leur fens, ou par la cadance \& l'arrangement qu'on leur donne : Le fens abbat, éleue, ou réiouit les auditeurs, il doit eftre mefnagé à la maniere que nous auons touchée fur le fujet des comedies, \& il nous fait connoiftre l'humeur \& le temperament de ceux qui écoutent par le choix qu'ils font de quelque endroit de la comedie, \& par la paffron quils en ont retenu: Mais la cadence des mots agit encore auec plus de force, elleconfifte à la poéfie. Confiderons donc auec eftude, fa na: ture \& res qualitez.

La poëfie eft vne peinture parlante, comme dit le vulgaire : C'eft pourquoy comme la peinture nous émeut, \& comme on luy permet toutes chofes; il en eft ainfi de ka poëfie: A ufil Linus, Orphée, \& tant d'autres grands perfonnages ont infinué aux peuples Barbares leur doctrine par le noyen des rithmes, \& de la poëfie : de là vient que tout de mefme que la peinture reprefente des païages, ou des combats, \& qu'elle nous figure des tombeaux, ou de funerailles: la poëfie nous produit la paftoralle comme vn paifage charmant, les intrigues d'amour comme tes nudités, leo tragedies comme des peintures 
funeftes quiinfpirent la triftefle \&lacompafions comme les autres donnent le plaifir, l'enjouëment, \& la tendreffe.

La poëfie d'ailleurs eft la veritable danfe de l'ame; car c'eft par fon moyen qu'ellefe donne des diuerfes mefures \& des diuers tours : Auff les Comediens mêlent les balets aux comedies par la proportion de la danfe de l'ame auec celle qu'on fait de nos corps. Or la danfedu corps s'eft renduë fi agreable, qu'elle eft l'vnique diuertiffement du monde gallant; il y a donc de l'apparence que la danfe de l'efprita vn ponuoir plus energique, puis qu'elle eft plus éleuée, \&qu'ainf elle rend les comedies plus fortes à toucher les ipectateurs.

Enfin fi la harmonie, la mufique, \& les infrumens font d'admirables effets fur nous-mefmes, il ne faut pas douter que les vers n'agiffent auec plus d effort, euxqui font la belle harmonie que l'enthoufrafme conçoit dans l'ame; en forte que cout ainfi que la mufique emeut le corps par les efprits, les vers font le mefme par la mefurequ'ils domnent à l'ame, ils ont comme elle le diapente \& le diapafon, leur diuerfité produit les palfions de la mefme maniere, elle approche de la difference destons; \& fi on les mefle fur le theatre aux violons \& aux autres inftrumens de mulique, c'eft à caufe de la proportion qu'ils ont à la melodie, $\&$ aux fons.

On conçoit de re principe, pourquoy il nous faut du gefte en recitant les vers, comme il faut battre la mefure en chantant la mufique, pourquoy la roix eft fi neceffaire aux Comediens, 
De la Comedie.

d'où vient qu'on chantoit autrefois en recitant les rithmes \& les poemes, enfin par quelle raifon la profe n'agit pas fi fenfiblement, \& que les comedies reçoiuent leur ornement, \& toute leur force des vers.

A pres tout cela on ne doit point douter desémotions qui deriuent des comedies, puis qu'elles agiffent parl'harmonie, par les paroles, par les perfonnes \& par leurs actions; qu'elles frappent la fantaifie, que cette faculté fournit des penfées à nos efprits, que ces penfees font des mouuemens, que ces mouuemens en font d'autres dans nos parties, \& produifent ainf les paffions, l'ennuy, l'emportement, \& mille autres chofes qui font la fource de beaucoup d'effets furprenans, \& qui parvne methaftafe que nous auons déja marquée, $f e^{\prime}$ terminent enfin $2 u$ corps.

\section{CHAPITRE XII.}

Des chanfons, des Inftrumens of de la CMrnfigue.

Ts Chanfons font comme vn compofé d'vin 1 corps \& d'vne ame, premierement l'air en eft le corps, les mefures en font les articles $\&$ les jointures; l'accord \& la cadanceen font l'ame; les diuers cercles, les paroles \& les rithmes donnent la figure \& le coloris; \& nous reprefentent les chants ainfi que des animaux aëriens \& mobiles. Orces animaux ont leur energie \& leur vertu; 
304 Des Chanfons, des Ixftrumetrs ofe.

leur fubtilité les fait penetrer \& les difpofe à fe joindre à nos ames; par leur mobilité ils remuënt nosefprits, nos humeurs \&: nos nerfs; \& ils laiffent à nos cerueaux, ou pour mieux dire, ils y impriment leurs veftiges, $c^{\prime} e f t$ à dire ces efpeces $q u i$ nous font rouler les chanfons dans les veilles, \&c dans le fommeil. Examinons maintenant les effets de ces imprelfions, \& pour le bien faire confiderons les perfonnes qui chantent, celles qui écoutent la mefure \& la melodie des airs.

Les airs émeutent fortement nos ames; celles-cy agitent en fuitte nos efprits, nos parties \& nos humeurs, \& verifient le principe d Hippocrate, au liure des affections, que la plufpart des alterations, qui furuiennent à l'homme, ont pour fource la bile, le phlegme, les alimens, louye \& les yeux; \& certes if l'ame donne vn branfle mefuréà tout le corps \& à fes organes, \& fi elle agit ainfi que l'air, qui eft renfermé dans les orgues; par la regle de proportion elle receura des chanfons, \& de leur harmonie, des mouuemens $\&$ des mefures, $\&$ elle les reflechira aux membres qu'elle a foin de mounoir \& d'entretenir. Les raifons fuiuantes nous montrent cette verité. Quelques-vnes preuuent l'impreffion des chanfons fur l'efprit, \& les autres font voir que les parties s'en reffentent, \& qu'elles font comme vn echo de ce quife paffe \& quife remuë en haut.

Les raifons qui montrent limpreffion des chanfons dans l'ame, font premierement que nous fommes fouruent contrains de rouler dans nos teftes certains airs qui nous ont pleu; \& que nous 
Des Chanfons, des Inftrumens boc. nous auons peine de les effacer durant longtemps de la memoire, ce qui fait voir qu'ils ont laiffé quelque teinture, qu'ils ont ébranlé quelque reffort, \& qu'ils ont émeu \& mis comme en danfe noftre ame, puis qu'elle a peine à quiter l'ordre \& la mefure de ces chanfons; \& veritablement cela fe fait fur tout lors que la reffemblance \& la proportion s'y rencontrent; ainfi ceux qui ont vne forte inclination à l'harmonie, font faifis d'vne tendreffe plus fenfible lors qu'ils entendént les chanfons, les melancholiques foûpirent aux triftes \& aux pitoyables, \& les bilieux deuiennent gays aux enjouées.

En fecond lieu, les chanfons excitent les paffions, c'eft pourquoy, comme les paffions font des mouuemens de l'ame, que Platon compare aux tons qui font aigus ou graues; il y a de l'apparence qu'ils fe forment en fuitte de ceux que les chanfons luy ont donnés, \& quainfiles larciues caufent l'amour, les douces font la tendreffe, \&c.

Pour ce qui eft maintenant $d u$ corps, il eft certain que les chanfons font fi fortes $\& f_{i}$ puiffantes, qu' elles remuent l'ame jufqu'à luy faire entrainer aux mefmes cadances les membres; ainfi elles nous font faire des grimaces en les chá. tant, ou elles nous prouoquent à da nfer. De 1 yıent que nous ne fçaurions remuër nos jambes, fi la difproportion en péche la force de leur me. lodie, \& fi nous naimons point leurs airs: c'eft pourquoy le peuple ne fe remuë point à ceux qui font doux \& charmans, parce qu'il a les efprits, les humeurs, les parties, \& l'ame groffiere, de V. 
306 Deschanfons, des Iuftrumens \&oc?

forte qu'il faut des tons aigus $\&$ des fons bruyans pour l'émouuoir, enfin des chanfons ridicules, irregulieres, à caufe que, comme remarque S. Augultin, l'efprit des perfonnes vulgaires eft ordinairement dans la diffonnance, comme on void par leur emportement; \& par leurs par. fions.

On connoît de tout ce difcours pourquoy il faut des melodies differentes dans les lieuxfaints, $\&$ dans les prophanes; \& pourquoy quelques malades ont recouuré la fanté par les airs: car leur mouuement a purgé leurs efprits, il a reglé leurs mauuaifes mefures, \& il a donné quelque agitation aux humeurs qui eftoient croupiffantes \& pareffeufes.

Ceux qui écoutent les chanfons, doiuent ob: feruer celles qui corrigent l'excés de leurs mouuemens interieurs, prendre garde qu'elles n'excitent des paffions dans leur coeur, ny du trouble dans leurs parties, qu'elles donnent à leurs efprits vn cours \& vne mefure harmonique; bref qu'elles ayent de l'accord, \& de la proportion auec eux, à la maniere de deux Luths quon a mis dans vn mefme ton, \& dont l'vn refonne, lor's qu'on a pincé les cordes de l'autre. On tire de ce fondement deux confequénces veritables.

La premiere, qu'on peut faire librement amitié auec ceux qui fe plaifent, ou qui font efmeus des mefmes chanfons, car apparemment ils ont quelque chofe de femblable \& de fympathique, quifert de bafe, \& de fondement à l'vnion.

La feconde qu'on doit fe regler à ouir la me: 
Des Chanfons, des Inftrumens, 6r6. $\quad 30^{7}$ lodie, fuiuant le mouuemer $t$ du pouls, car comme l'ordre des parties eft tout harmonique, la nature par confequent en bat la mefure par les arteres, \& par le coeur; de maniere que, fuiuant la lenteur, \& la viteffe de cecte mefure, on peut s'appliquer à la danfe, aux inftrumens \& à entendre les chanfons pour augmenter la bonne difpofition, ou pour en corriger la mauuaife:

Ceux quichantent font confiderables par leur exercice, \& par leur nature.

Leur nature, fuiuant les Aftrologues, en rujette à Venus, ou au Soleil; c'eit pourquoy lés animaux folaires chantent volontiers, \& mar. quent ainfi la venuë du Soleil, fes routes, fís influences \& fa carriere; \& pour ce qui eft de $\mathbb{V e}$ nus, on obferue icy fon pounoir fur ce que les femmes \& les jeunes hommes qui luy font foûmis aiment principalement à chanter, que les filles par leur voix \& leurs chanfons douces tâchent de pouuoir attendrir le coeur, qu'à cét effet lesfabies ont parlé des Syrenes, \& les Plato: niciens des Mufes, \& que le Poëte a dit,

Res eft blanda canor, difcant cantarepuella, Profacie multis voxfua lana fuit. Ouid.de art.

Neantmoins il n'y a dien de plus opporé àceux qui chantent que Venus, car apres leur auoin donné la voix, elle la leur corromp, \& elle en deftruit les organes; en effet elle les dilate, les rend âpres \& raboteux, elle les fletrit $\&$ les feiche; de forte qu'il a fallu lier autrefois les $\mathrm{Co}$ mediens jufques aux partiesqui font confacrées à sette Deeffe, pour cöferuer la bonté de leur voix.

$\mathrm{V}$ ij 
Soluitur bis magno Comedi fibula, funt qua Chrifogonon cantare vetent -...

On peut voir de ce difcours pourquoy les en: fans \& les filles, lors qu'elles chantent auec les hommes, font ordinairement l'octaue, ou le diapafon, parce qu'elles ont linftrument de la voix petit, auec politefle, \& fans âpreté; au lieu que celuy des hommes eft âpre, dilaté \& concaue, par la débauche, le déreglement \& la chaleur.

L'exercice de ceux qui chantent, eft remar: quable en deux manieres, car ou le chant de ces perfonnes eft violent, haut \& aigu, ou bien il eft bas, doux \& mediocre, tous les deux exercent plus ou moins la poitrine $\&$ les parties qui y font contenuës, ils en feparent la pituite, \& ils en détachent ce qu'il y a d'inutile \& d'impur. Neanmoins le chant violent exerce $\&$ échauffe vn peu trop cette partie delicate, \& il remuë \& porte en haut les boyaux auec elle, \& les matieres qu'ils ont coûtume de receuoir ; c'eft pourquoy il eft nuifible de chanter apres le repas. Et fi autrefois ceux qui s'appliquoient à chanter, fe baignoient, \& fe leuoient de bon matin ; c'eftoit pour ramollir tout le bas ventre, pour empécher le deftachement des boyaux, \& pour éuiter les fumées que les chanfons foufleuent à ceux quichantent a pres auoir mangé. Pour faire voir cette verité par la connexion des parties, \& par l'enchainement des nerfs,

Il faut remarquer que le nerf recurrant, qui fert à flechir \& à mouuoir le larinx, a diuers rameaux, les vns aboutiffent aux poulmons, au 
Des Clsanfons, des Inftrumenseirc.

Fond de l'eftomach, \& dans le bas ventre; \& ils remue nt les entrailles dans les chanfons, à la maniere que nous auons imaginée : \& les autres fe répandent au cour en forme de petits filamens; c'eft pourquoy ils changent le pouls de ceux qui chantent, \& ils leur excitent la tendreffe, la. compaffion \& la joye, parce que ou ils preffent, ou ils élargiffent le coeur: Et voila la raifon pourquoy les chanfons foulagent, \& donnent de la joye aux triftes, qu'on treuue de l'allegement lors qu'on raconte fes malheurs, que les airs effeminent ceux qui font profeffion de chanter, \& que cette ap plicatiō eft ennemie de ceux qui font attaqués de la fiéure, parce qu'elle eft la veritable maladie du cour, qui eft alors agité par les nerfs comme par des petits cordages qui le preffent, l'ouurent, quile fecouënt \& qui l'entrainent: Enfin on void de là pourquoy ceux qui chantent, s'épuiffent en jettant quantité d'efprits, qu'ils peuuent communiquer ainfi des maladies \& des paffions à ceux qui écoutent, d'où vient que les Authears ont dit qu'il faifoit dangereux d'ouïr chanter les meridionaux, à caufe qu'ils fafcinent par leurs yeux \& par leur melo-die, en pouffant quantité d'efprits au dehors.

Frigidus in campis cantendo mumitur anguis. Et que le frequent changement des airs montroit la mobilité des efprits, la foibleffe du cœur, \& la reuolution des Royaumes : c'eft pourquoy Timothée fut banni, pour auoir choifi vn inftrument nouueau, \& nous voyons que les reuolutions des fiecles, les changemens des aages, $\&$ la varieté des temperamens nous font parồ$\mathrm{V}$ iij 


\section{Des Cbanfons, des Inftrumens ors.}

tre les anciennes chanfons, \& ceux qui les chan: tent, ridicules, \& les modernes au contraire diuertiffantes \& agreables.

Les inftrumens, font le mefme que les chanfons. Sil eft partant veritable, fuiuant Iamblique, que les animaux foient des inftrumens refonans, \& queleur ame foit vne harmonie ; ily a donc de l'a pparence queles inftrumens, par lavertu de la reflemblance y font des plus forts \& des plus fenfibles effets. Lt certes leurs mouuemens artificiels corrigent auec vigueur la mefure \& le mouuement naturel des efprits, ils leur donnent vne regle \& vne cadance, \& ils contribuent beaucoup a cépofer la jeuneffe, ou à émouuoir fa langueur; cieft de là que quelques inftrumens ont excité à la fureur, que d'autres l'ont temperée, \& que Regiomontanus faifoit éueilier fon fils au fon du Luth, afin que fes actions fuffent tout le jour dans l'harmonie, dans la confonnance, \& dans l'accord.

On connoit de là qu'on fait fort bien de diuertir les grands par les inftrumens, \& par la mufique; car comme ils- font femblables à ces arbres dont les branches montent fort haut, ils reffentent aufi comme eux les fecouffes \& les tempêtes, c'eft pourquoy il faut arrefter le trouble de leurs efprits, de leurs humeurs, \& de leur ame par lordre, la douceur, \& la fymphonie des inftrumens; dont partant on doit confiderer les qualités, la nature, \& le temps qu'on a coîtume de prendre pour les ouir.

En effet la trom pete en eft vne preuue certaine, car par vn fon efclatant \& aigu, elle agit fur les 
Des Chanfons, des Inftrumens toc.

éprits ainfi que le vent qui pouffe l'air violëment par bouffées : C'eft pourquoy elle anime aux combats les hommes tout enfemble \& lesanimaux; \& elle eft vn inftrument de Mars, qui eft 'vne Diuinité turbulente. C'eft clle auffi qui feruoit à Afclepiade à guerir les fourds par fon bruit, \& mefme Merfene a ofé foutenir apres quelques Saints Peres, que ce fut par le fon bruyant de cet inftrument, queles $\mathrm{Capitaines} \mathrm{He}-$ breux firent tomber les murailles de Hierico. De là on conclud que les perfonnes releuées ne doiuent employer la trompete que dans les combats, qu'elle rend leurs ef prits trop flottans, \& leurs humeurs trop ondoyantes, qu'elle les difpofe à l'emportement \& au mépris, qu'elle leur ofte cetteaffabilité qu'il faut qu'ilsgardèt auec le peuple; \& que durant le repas exerçant trop les nerf's des oreilles elle trouble toute leurs entrailles, \& porte leurs efprits au cerueau. Plutarque a conceu cela lors qu'il a reietté des banquets les inftrumens \& la mufique, difant que la melodie enyuroit auff bien que le vin, qu'elle prouoquoit les conuiez à fe tirer de table pour danfer; \& quec'eft ainfi qu'vn joueur d'inftrument fit fortirAlexandre du bãquet. Difons donc qu'il feroit plus à proposque la trompete éueillât les grands pour les porter aux actions hautes \& genereufes, \& pour détacher quantité de vapeurs.melancholiques qui embarraflèt leurs efprits; pendant que les inftruments plus doux tout le refte de la journée calmeroient cette humeur fiere \& guerriere, qu'elle a coûtume de foûleuer.

Pour acheuer cet article ie ne dis rien desexerciV iiij 


\section{Deschanfors, des Inftrumens orc.}

ces quideriuent des inftrument $s$, car il eft certain que parmy le grand nombre qu'on en remarque, les vnșexercent les bras, les mains|\& les doigts, \& donnent à leurs tendons, à leurs efprits, \& â leurs fibres vn mouuement proporticné à la danfe: c'eft pourquoy les agitations trop fortes, comme les efrorts affoiblinet ces particsis leur oftent la difpofition habituelle quelles ont: les autres exercent les poulmons, comme les infruments $q u$ on appelle pneumatiques, ils échàufët la poitrine, \&afloibliffent les organes de la refpiration, ils lachent mefme les entrailles, \& rendent le vifage $f$ refroigné, que les grimaces firent bannir vn excellent jouëur de flutte, parce quil paroirfoit hydeuxen ieiant, \& qu'il perdoit fa bonne mine.

La mufique fait la mefme impreffion que les inftrumens; c'eft elle qui compofe les efprits, \& qui les reftablit dans leur ordre, c'eft pourquoy Ariftote a confeillé dans fes politiques d'en inAtruire les enfans qui font turbulens. Pour bien obferuer maintenant fon pouuoir, remarquons les regles fuiuantes.

La mufique difpofe les efprits, ainfi qu'vn IMPR IMEVR qui arange les caracteres, ainfi elle imprime des veftiges \& des efpeces au cerueau, ceft pourquoyceuxquil'ont nol, font plus efpris de l'harmonie, au contraire des païfans, $\&$ des vieilles gens qui ont cét organe fort dur.

Tous ces veltiges font agir l'ame diuerfement, en fourniffant pluficurs images à la fantaifie, parce qu'ils ont leur ordre, \& leurs figures dont le moule eft la fubftance du cerueau. 
Des Chanfons, des Inftrumens érc.

La mufique guerit les maux, parceque, comme la plufpart de nos maladies procedent des efprits mutinés, qui font fans mefure \& fans ordre, ils reprennent neantmoins leurs routes \& leurs figures ordinaires par la mufique, à la maniere desparties difloquées qui font remifes dans leurs lieux.

Comme la danfe nous diuertit, \& fert d'exercice à nos membres, la mufique fait le mefmeen. faifant danfer nos efprits \& en les remuant, \& leur donnant des figures agreablement concertées. De là vient qu'ils s'infinueñt de cette ma. niere dans les nerfs, qu'ils les gonflēt, \&qu'ils remuënt ainfi les mufcles, qu'ils föt aux fibres, qui font comme autant des cordes tenduës, ainfi que In main aux cordes duLuth, \&qu'ils prouoquent de cette maniere les grimaces des Muficiens, \& la danfe de ceux qui aiment la mufique; il arriue mefme que le nerf des oreilles receuant ces impreffions \& ces figures, remuë les entrailles \& le bas ventre, \& luy donne diuers fentimens, \& montre pourquoy, fuiuant $S$ caliger, vn certain ne pouuoit retenir l'vrine, lors qu'il entendoit la vielle; \& d'où vient qu'on repete fouuent les chanfons par les rameaux de ces nesfs qui aboutiffent à la langue, \& aux organes de la voix.

On découure de ces reflexions le fondement de deux propofitions que Pic de la Mirande a au ancées : la premiere eft que commela me. decine guerit lane par le corps, que la mufique guerit le corps par lame : \& la feconde que comme la medecine ne meut les efprits qu'à caufe qu'ilsregiffent le corps, la mufique les remuę 
3.4 Du Chatorillement or duRis.

parce qu'ils feruent à l'ame ; En effet tantôt elle les dilate, les comprime \& les eflargit, elle les arrange en rond, ou en pyramide, \& elle leur fait ainfi que le foufle qui produit les verres, en pouffant l'air en des differentes façons, \& donne dinerfes agitations à nos ames, parce qu'elles font comme attachées aux efprits.

\section{CHAPITRE XIII.}

\section{Du Chatouillement $\mathcal{O} d u$ Ris.}

NOus ne pretendons pas dans ce chap. d'exaI miner la caufe du ris, de peur de ne paroîrre trop ridicules, puifque la fource de cette paffion a demeure trop lony temps inconnue pour mous imaginer de la découurir. Contentons nous done den voir feulement les fymptomes, \& de confiderer fi ce qui fait l'vniqueplaifir de lavie ne cache point fous fes a pasquelques effets qui nous foient nuifibles. A ce deffein,

Il faut remarquer que ou le ris eft violent, ou il eft doux \& moderé; le ris violent ofte la voix, ou l'entrecoupe, il efpreint les larmes, il lâche le ventre, \& fecouë les flancs, il caufe la douleur aux entrailles, il fait pâmer ou mourir quelques vns fort fouuent, il change l'ordre du pouls, décharge le cour, \& il fait tant d'autres alterations furprenantes dans nos parties, qu'il a infpiréces mots à Seneque perrifum furere, \& au vulgaire ces paroles, mourirderire. Voyonsmaintenât lafourec \& le principe de toutes ces grandes émotions. 


\section{$\mathrm{D} u$ Chatouillement of du Ris.}

Le premier eft la fubtilité des efprits, qui eItans agités fortement dans le ris, comme dans toutes les autres paffions violentes, ils s'éuaporent, \& fe diffipent, \& il leur arriue comme à ces petites lumieres qui s'éteignent à la moindre fecouffe, \& au moindre vent. Et voila la raifon des pâmoifons, des langueurs des perfonnesvieilles, conualefcentes \& affoiblies, fi elles rient auec excés; \& pourquoy Zeuxis mourut en riant, apresauoir acheuéle portrait d'vne femme vieille.

Le fecond confifte en ce que comme le ris immoderé agite les entrailles \& la poitrine, il remuë fouuent des humeurs qui font affoupies, \& excite à peu prés quelquechofe de femblable à ces vapeurs malignes qui exhalent des eaux croupiffantes qu'on a troublées parhazard. Et voila İa caufe pourquoy le ris extraordınaire fait pâ-. mer, ou mourir quelques-vns, \& qu'il produit; ou qu'il guerit les maladies en brouillant ce qui eft feparé, ou en pouffant, \& faifant couler au dehors ce quireftoit dans les parties. Et certes cela n'eft pas difficile à conceuoir, fi on prend garde quele diaphragme qui eft le principal initrument duris, remue alors \& ef preint les entrailles, \& qu'il peut par confequent tirer hors de la rate, des boyaux \& des autres membres, ce qu'ils tiennent de ramaffé: C'eft pourquoy le ris, dont nous parlons, eft nuifible apres le repas, car il auance la diftribution, \& peut engager les parties, en y jettant des matieres encore crues.

Le troifiéme deriue du trouble, que le cour reffent dans le ris exceffif, non feulement parce. 
que toutes les paffions fe foûleuent dans ce vifce: re; non feulement parcéque le diaphragme luy communique fes émotions; non feulement parce qu'eftant fufpendu dans l'homme, ainfi que remarque Ariftote, il fouffre grandement du. ris, \& des autres mounemens extraordinaires de lame; mais encore parce que le ris exerçant la voix, il fait remuër le nerf recurrant, dont les sameaux impriment au cour vne agitation plus fenfible quecelle que nous auons obferuée, lors que nous auóns parlé des chanfons. Car ils le preflent, ils le pouffent, ils le dilatent\&lerelancent ainfi que des petits cordages; c'eft pourquoy on dit que le ris décharge le cœur. Et voila ia raifon pourquoy ceux qui ont le cœur gros, fort efpais \& fort dur. ou le diaphragme fort folide, ne rient jamais, ou du moins ils rient d'vne façon fort moderée, parce que ces organes ont peine de fe rendre flexibles, \& de faire ces mouuemens qui rendent le ris éclatant.

Le quatriéme procede de la connexion du dia. phragme, \& de ce qu'il eft le principal organe du ris, comme nous auons déja dit. De là vient,

En premier lieu qu'eftant fecoué fortement il efloufle, il entrecoupe le difcours \& la voix, il fufpend la refpigation \& la bleffe; bref il agite I'air \& les efprits, ainfi qu'vn gros éuantail qui fait tremouffer la lumiere. De là vient que les afthmatiques, \& ceux qui ont des maladies de poitrine fouffrent grandement du ris violent. qui fe déchargent partant quelquefois par fon INoyen des matieres quiles oppriment, \& que la voix deuient forcée, \& qu'elle s'arrefte \& s'en- 


\section{Du Chatoülllement oo du Ris.}

zrecoupe par l'interfection, \& par les bouffées de l'air.

En fecond lieu le nerf du diaphragme ayant vne liaifon eftroite auec les nerfs intercoltaux, afin qu'il reçoiue vne quantité d'efprits, qui puiffe entretenir vne agitation continuelle, les nerfs d'ailleurs qui fortent des vertebres, \& qui fe répandent aux reins \& aux lombes, s'y joignant par leurs rameaux, \& s'étendant jufques au vifage, il s'enfuit parainfi que le ris violent ébranle \& émeut toutes les parties que ces nerfs rendent fympathiques par les fecouffes du diaphragme, que le vifage fe change, \& que les reins $\&$ les lombes fouffrent alors; enfin que nous portons les mains au colté en riant, \& que nous nous plaignons mefme des flancs par le mounement extraordinaire des mufcles, qui leur fure uient de celuy des nerfs. Et certes cét enchainement, \& cette fructure particuliere fait que 1'homme eft vin animal rifible, que les autres a nimaux ne font pas émeus d'vne telle paffion, \& qu'ils n'en fouffrent point les fymptomes que nous auons reconnu proceder de fa violence; d'autant mieux que leur ame eft plus materiele. \& que celle de l'höme eftant fpirituele femble fe vouloir démeler par les paffions des attachemens quila detiennent.

Le ris moderé exerce, \& remuë paifiblement toutes les parties que le ris violent bouleuerfe, c'eft luy auffi qui épanouit proprement la rate, $\&$ le cour, qui décharge les entrailles \& la poitrine, \& qui fert aux melancholiques, en on. urant ce que leur hupgeur lie \& tient concentiś: 


\section{I8. Chatouillement ơ du Ris.}

auffi ç'a efté l'intention de la nature de faire rire quelquefois l'homme accablé de mifere \& d'ennuy, \& d'éueiller ainfi fon ame afloupie, \& comme gemiffante fous la matiere : c'eft ainfi qu'il faut entëdre Hippocrate au liure de la ftrueture du corps humain, qui dit que le feu fe dilate en riant, qu'il s'étend par le fang oleagineux, comme la lumiere parmy l'huile \& la cire; que c'eft à caufe de cela que les fanguins rient volontiers, que les petits enfans qui font remplis d'vne humeur gluante, ont peine à rire, \& que par la loy des contraires, les malades \& les melancholiques ont plus d'inclination à pleurer, parce qu'ils ont vne humeur plus terreftre.

A pres auoir parlé du ris fuiuant ce que la gymnaftique demande, nous pounons y ioindrelibrement le chaftouillement, qui eft vn de fes veritables principes. Pour le bien expliquer,

11 faut remarquer en premier lieu, quel'homme a vn attouchement fort exquis; que la nature à cet effet l'a pourueu de quantité de nerfs, qui jettent des filamens vers la peau, \& par les membranes; qu'elle l'a couuert d'ailleurs d'vne pea fort delicate \& fort fubtile, \& qu'elle a ioint en quelquesendroits les nerfs \& leurs filamens pour releuer l'attouchement, \& luy donner vne perception plus diftincte, ainfi qu'on obferue au coAté, à la plante des pieds, \&c:

Il faut remarquer en fecond lieu, que lors 'qu'on preffe les endroits ou les nerfs \& leurs filamens s'entrelaffent, qu'on reffent que l'attouchement deurent trop fenfible, \& qu'il luy en eft 
Du Chatouillement of du Ris.

Sllors comme à l'égard des yeux \& des oreilles les couleurs trop fortes, ou les fons trop doux \& charmans.

Il faut remarquer enfin, que cela fe fait encore mieux fi on frote doucement ces parties, parce qu'on imprime vn mouuement aux petits filamens des nerfs, qui fe communique aux efprits qui coulent alors comme vne eau qui eft doucement agitée, \& qui frifant les nerfs quiontvn fentiment aigu, leur font ce qui nous arriue lors qu'on nous frote le bord des levres auec que le bout d'vne plume; \& c'eft ce qui produit le chatouillement dont nous écriuons maintenant le principe, \& qui nous le fait paroiftre incommode à caufe de la fenfibilicé trop grande des nerfs.

On infere dece difcours pourquoy le chatouil: lement fait rirc, parce queles nerfs remués communiquent leur mouuement \& celuy de leurs efprits aux nerfs qui lient le diaghragme, de forte que cette partie s'emeut, \& fait le ris, ainfi que nous auons déja dit.

On connoît encore pourquoy les bilieux, les maigres, ceux qui ont bon efprit, a pprehendent d'eftre chatouillés, parce qu'ils font fort delicats, que leur peau eft fort tranfpirable, que les nerfs y font prefque comme à découuert, que les efprits y font fort mobiles, \& que le mouuement de ceux quichatouillent, les fait comme danfer facilement dans leurs canaux; Et voila la raifon pourquoy Viués rioit mettant le premier morceau à la bouche, parce qu'il reffentoit alors par le branfle des mufcles, \& des neffs du 
320 Du Chatouillement \& duRis:

vifage, \& par la tenuité des efprits, vne efpece de chatouillement.

Enfin on découure pourquoy les carefles font rire, parce qu'elles chatouillent, que les bras correfpondent au diaphragme, \& ont vne connexion auec les nerfs intercoftaux, \& quec'eft auec eux que nous careffons proprement. De là on conclud,

Que les effets du chatowillement font de faire extraordinairement rire,\&de caufer les accidens du ris violent; d'interrompre d'ailleurs le cours des efprits, d'exciter comme vne efpece deconuulfion par le moyen des nerfs comme repouff́és, qui prennent leur fource de la tefte, \& d'alterer ainfi le cerueau : c'eft pourquoy quelquesvns font morts pour auoir efté trop chatouillés, d'autres ont fouffert des grandes douleurs, \& des fymptomes, qu'il eft facile de connoître.

\section{CHAPITRE XIV。}

\section{Des Promernades.}

D Our bien confiderer les promenades qu'Hip 1 pocrate a fi fouuent recommandées dans fes écrits, il en faut voir les differences, \& découurir tous les effets qui deriuent de châcune en particulier.

Les promenades fe diuifent en celles des lieux, des temps, des perfonnes, des maladies \& des aages, \& en d'autres qui font reglées par le mouuement, par la façon de vie, \& par quantité de eircon. 
de circonftances que nous examinerons en leur lieu.

Maintenant pour commencer par les promenades qui conuiennent aux maladies: On doit Iuppofer que beaucoup de nos indifpofitions opiniâtres viennent ordinairement de l'embarras \&des obftructions, ou des humeurs qui brouillent, \& qui arreftent les efprits, qui empéchent leur mobilité \& leur courfe, qui occupent \& qui rempliffent les parties, qui fe jettent dans leurs détours; bref qui éua porent par tout \& rendent comme l'ameengourdie. Cela eftant ainf, il eft certain que les promenades éuentent les efprits, $\&$ les deftachent des humeurs; que par leur mouuement, elles criblent, \& elles feparent les mas tieres: qu'elles dégagent les membres en les fecoüant, \& que de cette façon elles font propres à la rate, a u foye, au mefentere, au ventre qui elt conftipé, \& à l'humeur melancholique :qu'ellesfoulagent les hy pocondres, qu'elles dégagent l'ame de fa pefanteur, qu'elles diffipent les vapeurs de la tefte, \& qu'elles en tirent les efprits éclipfés, comme lors qu'on void fortir le Soleil des nuës les plus épaifles \& les plus fombres. Et voila la raifon pourquoy on eft bien aife de promener apres le trauail, \& d'oú vient qu'Hippo. crate ordonne les promenades apres des fonges turbulens ou funeftes, afin de tirer les efprits, \& de les deftacher des va peurs obfcures quiles attachent, \& qui en empéchent l'éclat.

Les promenades qu'on fait rapporter aux pe:fonnes, fe reglent fuiuant leurs difpofrtions, \& leurs qualités. En effet lés bommes qui for: r. 
buftes, qui ont les chairs mufculeures, le fang cras, des humeursqui font parefleufes, \&qui coulent dans les veines fort lentement, comme les pituiteufes \& les froides, doiuent agir \& promener foument; au contraire des bilieux, des maigres, des delicats, \& des difípables, ruiuant ce que dit Hippocrate que les bilieux ont befoin de l'air, du repos, \& de l'eau. De là on void pourquoy les femmes \& les filles fe gueriflent en promenant, non feulement parce que les cuiftes ébranlées déchargent ainfi la matrice par les ligamens, qu'elle y répand; mais encore qu'elles attenuent \& qu'elles vuident les matieres, \& qu'elles reftabliffent ainfi les efprits, dont la lumierecolore, \&donne de l'éclat au teint, comme l'obrcurité, \& la refraction le rend pâle.

Ces promenades qu'on determine par l'occupation, \& le genre de vie, exigent des differentes reflexions, aufi bien comme les premieres.

En premier lieu les gens de lettre fe doiuent diuertir à promener fcuuent, parce qu'elles font melancholiques \& fedentaires, que leur rate, \& leurs hypocondres fe rempliffent le plus fouuent, qu'il eft neceffaire quele mouuement moderé nettoye les efprits de ces perfonnes des vapeurs qui les obfcurciffent, \& qu'il leur procure le fommeil, que les veilles interrompent $f$ frequemment, fuiuant la doctrine d' Hippocrate, deambulatio articul is labor, vifceribus fomnus. Aufil la plufpart des grands Philofophes ont enfeigné en promenant, ils ont eu foin qu'on fit des portiques \& des allées à l'entrée de leurs Colleges, \& nous deuons à leurs promenades, auffi bien qu'à 
leurs bancuets la plufpart des oun 323 nous ont donnés.

En fecond lieu ceux qui boiuent à la glace, ou des eaux de puis, quife nourriffent de viandes grofferes, \& qui apres cela demeurent long tempsen repos, ont befoin de promener quelquefois, de pouffer au bas ventre les matieres cruès, \& les eaux qui font difficiles, \& d'exciter 1a chaleur naturelle, afin qu'elle les puifle furmonter auec plus de vigueur. C'eft pourquoy les Paifans digerent mieux, parce que leur action ordinaire fupplée au deffaut des promenades.

Les promenades qu'on confidere par le mouuement, nous infpirent quantité des reflexions importantes.

La premiere que les promenades qu'on fait en rond, nous font plus conuenables, que celles quife font en lignes droites, non feulement parce qu'elles font proportionnées à cette circulation du fang, \&à ces trois cercles de feu qu'Hippocrate a remarqués dans nos parties, mais encore parce que noftre efprit eft celefte, qu'il ne fe doit moumoir qu'en roulant, \& qu'eftant pro. portionné à l'element des Eftoilles, il en doit imiter la route \& faire dans nos mëbres ce que les Intelligences font dans le Ciel : C'eft d'ailleurs fo donner alors vn mouuement femblable à celuy de l'air \& du monde; \& il eft à propos que nos parties, dont la figure eft pour la plufpart circulaire, foient émués circulairement, \& fi vous voulés à la maniere de la terre, dont elles deriuent, \& quileur a feruy de prińcipe. Adjoû. tons que le mouuement progrefif de lhomme, 
eft ordinairement circulaire, car les pieds \& les cuiffes font leurs centres alternatifs, \& châcur de ces membres defcrit vn cercle fucceffuement en marchant; il en eft tout de nefme des bras, des efpaules \& de la tefte, fi bien que, l'homme ne pouuant marcher que par cercles, il doit promener circulairement. Il eft partant befoin que ces fortes de promenades fe faffent doucement, $\&$ auec lenteur, \& que leurs tours foient infenfibles, de peur que la viteffe auec la briefueté ne caufat le vertige, \& ne fift tourner le cerueau.

La feconde reflexion qu'il faut faire fur le mouuement des promenades eft, qu'il foit paifble \& moderé, quil ne ferue feulement qu'à ces parties que la nature a deftinées pour cribler dans lecorps, qu'il continuë la confpiration generale des membres, \& que fon excés ne difipe, \& n'épuife point les efprits. C'eft pourquoy on ordonnoit autrefois aux A thletes de promener fort rarement, de peur que l'agitation n'abbatit leur Eorce, \& ne relâchât leur vigueur.

Les promenades qu'on obferue fuiuant les lieux, nous fourniffent diuerfes penfées.

La premiere, que les perfonnes maigres, \&qui ont befoin de la fraîcheur ne promenent point où il y a du fable \& de la pouffieré, puifque les anciens choififloient les lieux fablonneux,afin de feicher les jointures, \& d'abforber des articulations, ce qui s'y ramaffoit de gluant, \& defuperflu.

La feconde, qu'il faut rechercher les promesades, ou il y a quantité d'oifeaux, non feulement parce qu'Antillus croit que le battement 


\section{Des Promenades.}

'e leurs aîles éuente l'air, \& le purifie; mais fur tout parce que l'ame reffent vn doux chatouillemẽt de leur voix. Lit certainement la melodic des oifeaux eft preferableà celle des concerts, \& de la mufique; \& on lit dans Lucrecequ'elle en eft: 1e principe \& le fondement. La raifon decela eft parce que la mufique excite les palfions, \& qu'elJefurpend nos efprits par fes tons, \& par fes meIures, au lieu que nous aimons le chant des oireaux comme vne naturelle, \& vne primitiue harmonie qui ne donne point de contrainte, \&e qui a du rapport au murmure des fontaines\&des r uifleaux.A uffi les oifeaux cherchēt les eauxpour gazouiller, \& la cheute de celles-cy nous fait Lormir ainfí que la voix \& le ramage de ceux-là. Toutes ces chofes méme dans lesPoëtes reçoiuẽt également les plaintes, les foûpirs, \& les chanfons de tous les amans. Et il eft hors de doute que la nature nous a donné vne inclination particuliere pour clles, puifque les anciens fe feruoient du gazouillement des oifeaux pour predire le futur, qu'A pollonius Tianeus comprennoit le deffein, \& les intentions de cesanimaux. par leur melodie. Enfin puifque les oifeaux mefme fe plaifent à nous ouir chanter par vne proportion, \& vn rapport prefque femblable, \& qu'il n'y a rien quiles en rebute que les perfonnes mal-faites \& mal-ajuftées; C'eft pourquoy Lepidus fit mettre dans l'Ifle de la conference, la figured'vn animal affreux, pour en chaffer les oifeaux quil'interrompoient par leur chant.

La troifiéme, que les promenades foient aux endroits ou il y a des fontaines \& des ruifreaux;

$\mathrm{X}$ iij 
non feulement pour rendre l'air plus humide, \& propre à moderer le feu des efprits qui s'allument dans lesaffaires, non feulement parce que le murmure des eaux contribuè à donner le fommeil, mais d'ailleurs parce que nous fommes tous compofés de vents, de fontaines \& de ruiffeaux, que la plufpart de nos mouuemens en dépendent, \& que la nature fe plait à voir au dehors vne image de l'oconomie qu'elle regle toûjours dans nous-mefmes. En effet le fang coule dans nos veines comme dans des petits ruilleaux, les arteres fontautant de fontaines \& de riuieres, \& l'agitation des ef prits eft à leur égard comme celle di zephyre, lors qu'il nous flatte agreablement fur les eatix, ou qu'il fait des petites bluettes $\&$ des cercles dans leur furface. Neantmoins il y a quelques confiderations à garder touchant les promenades qui fe font au bord des eaux; car,

Premierement elles ne conuiennent qu'aux perfonnes feiches, \& à celles où le feu furmonte Ieau, fuiuant Hippocrate; les eaux d'ailleurs en doiuent eftre pures \& nettes, \& éloignées des qualités des eaux de la mer, car leur fel échauffe $\$$ defleiche, leurs fermentations continuelles exhalent ordinairement desvapeurs, d'ailleurs Pla.* ton les a méprifées, il a dit qu'elles ne fçauoient rien produirequi fut dignede Iupiter, que les animaux y font indomptables, \& que les peuples maritimes fo nt barbares, rudes $\&$ colorés d'vn teint bafané.

La quatriéme, qu'on choiffle les promenades ou il y a des prés, des fleurs $\&$ des arbres, fuiuant Ouide. 
Tu modo Pompeia lentus patiare fúb vmbsa. Soit pour moderer la grande chaleur par l'humidité nitreufe, que les arbres répandent, foit pour réjouir la veuë par le verd agreable de leurs rameaux, foit pour fixer \& efpaiffr les efprits aux perfonnes éleuces par la doctrine, pas la pieté, ou par la contention des affaires, moyennant la fraîcheur quideriue des feuilles, \& des gafons; \&veritablement il femble que la nature n'ait fait les arbres \& les fleurs que pour le plaifir \& le profit des hommes, \& que ce n'eft qu'à ces fins qu'elle en a couronné les campagnes, \& les ruifteaux. Montrons cela des arbres, \& apres nous parlerons des fleurs. Et premierement,

Nous nous fentons efpris d'vne volupté deli-: cieufe, lors que nous voyons des allées, \& des forêts; les Poëtes d'ailleurs ont montré que nous prennions la nature des vegetaux par les metamorphofes des Bergers, \& des hommes, en arbres : l'Hippocrate, \& quelques Philofophes ontenfeigné que nous deriuions de leurs troncs \& vn ancien a dit

\section{--- Quercus laurique ferebent}

cruda puerperia, ac populos vmbrofa creauic Fraxinus, of fata viridis puer excidit orno.

Et certes ilfaut qu'il y ait quelque fympathie \& que nous ayons quelque rapport aux arbres puis qu'on a deffini l'homme vnarbre renuerfé, que fes cheueux \& fes ongles ne font que des plantes, \& qu'on a obferué vn prunier qui auoit cru fur la poitrine d'vn homme viuant. Et voila la raifon pourquoy les anciens aimoient fi fort aे promener fous les arbres, \& principalemen: Xiiij 
fous les treilles, que Martial nomme trichilas; de forte qu'ils enuoyoient querir des rofiers en Egypte pour les rendre plus ombragées; ils croyoiẽt méme que c'eltoit par leur moyen qu'ils reffentoient mieux la fraicheur, qu'ils fe preferuøient ainfi de l'epilepfie \& du malde tefte, \& qu'ilsauoient peut-eftre reconnu que leurs projections vitrioliques n'eftoient pas feulement bonnes à purifier les yeux, mais encore à fixer fi fort les chairs \& le fang, quec'eft fans doute de ce principe qu'on conferue long temps lesanimaux égorgez dans les fueilles de vigne.

Les fleurs ne font pas moins vtiles à ceux qui promenent, que les arbres \& leur fueillage; pour faire voir cela il faut remarquer que nos efprits fe conferuent en trois manieres, par l'air, par les harmonies \& par les odeurs: l'air pur \& net les rend tranfparans, legers \& mobiles, c'eft pourquoy on ordonne de promener le matin fur deslieux eminens: l'harmonic donne l'ordre 8 la cadance à leur mouuement, \& les odeurs les reparent, les éueillent, \& les purifient, bref eftant des efprits comme eux, elles fuppleent à leur deffaut; c'eft cequé Pline a entendu en parlant des peuples fans bouche, \& que lesanciens ont confideré en aimant fi fortles parfuns. Or les odeurs qui exhalent des fleurs, font tous ces effets d'vne raçon plus conuenable.

Premierement leur nitre rafraichit nos efprits, leur vertu balfamique les adoucit \& modere ce qu'ils ont d'acre, leur parfun d'ailleurs eft fans artifice, \& deriuant d'vne parfaite digeftion, qui s'eft faitedans le deftours des plantes, \& dans 
leurs tuyaux, il eft fi fort amy du cour, du cerueau \& des nerfs qui font la fource des efprits, que c'eft à ces fins que les anciens faifoient des couronnes de fleurs, qu'ils les portoient fur la tefte dans la débauche; \& que les Medecins en font fouuent couurir les appartemens des malades, leurs meubles, \& leurs lits. Et voila fans doute ce qui a fait dire à Trifmegyfte, que les fleurs eftoient à la terre comme les aftres font au Ciel, qu'il n'y en auoit aucune parmy elles qu'vneEftoille ne luy dit de croiftre : en vn mot? qu'elles reflemblent par leur éclat, \& leurs projections à ces conftellations qui font couler des influences agreables par tout.

La cinquiéme, qu'on obferue exactement l'eftat, \& la conftitution des lieux par oú on promene, s'ils font fombres, ou bien efclairés du So. leil, s'ils font profonds, hauts, ou penchans: les profonds, fuiuant Hippocrate au fecond de la Diete, eftant vne fois échauffés, nous allument $\&$ nous deffeichent, fur tout s'ils font enuironnés de gros rochers; Jes lieux penchans exercent les jambes, parce qu'elles foútiennent ainfi tout: le poids des membres, \& font couler toutes les matieres en bas; les eminens effouflent, \& font muifibles aux poulmons, 1 ls font mefme remon ter les humeurs par l'émotion de la poitrine, \& parce que les mufcles quis'efleuent par la refpiration trop forcée, entrainent auec eux les para ties qui leur font fujettes. Et voila comme quoy Afclepiade ordonnoit à châque malade vne promenade particuliere, \& comme on a coûtume de guerir, ou de preferuer les nerfonnes quife treu- 
330

Des Promenades.

uent accablées parvnequantité d'humeurs. Enhin les lieux efclairés du Soleil font les effets que le Lecteur peut remarquer au fecond chapitre de ce volume, où nous auons dit que le Soleil eft la fource de la lumiere, qu'il eft comporé des petits corps qui ont vn mouuement fort prompt, qu'il fait mouxoir par leur moyen tout ce qu'il ef chaufe, \& qu'il touche, qu'il remue les planettes obliquement, parce que fon mouuement eft eliptique, qu'il fait ainfi fur nos efprits qui font comme autant de planettes, dont nos membres font éclairés, \& qui aiment partant à gliffer dans zos parties en lignes droites; nous auons d'ailleurs obferué au mefme endroit, qu'aux lieux ingaux, \& raboteux les rayons du Soleil font là comme des tourbillons de lumiere, parce que comme ils plient mieux que l'air \& que l'eau, ils ont par confequent vn mouuement extremement vite lors qu'ils contournent, qu'ils fe reflechifent, \& qu'ils fe rencötrent dans des deftours à la maniere des elemens dont nous parlons. Or ils impriment ainfi des agitations violentes à nos efprits, à nos humeurs, \& fur tout au fang, \& font ainf la douleur de tefte, \& d'autres indifpolitions qui deriuent du mouuement tumultuaire qui fe fait dans nos veines. On void de là pourquoy les grandes montagnes produifent quelquefois vne chaleur bruflante, quil en arriue ainft du fablon, des rochers, \& des cailloux; brefde ces lieux que le peuple nomme desabris, qui font partant quelquefois fort nuifibles.

La fixiéme, qu'on falle les promenades, s'il fe peut, en campagne, \& hors des Villes, parce 
Des Promenades.

331 que l'air dergagé peut beaucoup fur la lumiere. qu'vn charbon ardent renfermé cefle de luire, \& debriller, qu'vn bois luifant perd fon éclat, fi. on luy oftel'air par la pompe, \& que c'eft ainf qu'on void paroiftre quelquefois des feux lors qu'on ouure les lieux foûterrains. Or nous aaons vne lumiere qui nous fait viure, tous nos efprits font lumineux, leur clarté colore, \& fait reflexion fur nos joü̈s; de forte qu'ils exigent vn air fort libre, afin qu'ils conferuent leur fplendeur. Et voila la raifon pourquoy nous mous treuuons legers, lors que nous fortons de la Ville; que la campagne nous r joüit, qu'elle nous difpore à des exercices, que les Orientaux promenent au faifte de leurs maifons, que les. anciens faifoient à cét effet, comme nous, des cours dans leurs Villes appellées $\Delta$ poyw's, qu'on remarque dans Fippocrate, au 5 . des Epidemies, vn homme habitant aux cours, \& que Platon dans le Phedre prefere les promenades des chemins à celles qui fe font aux cours.

Les faifons, la durée \& le temps diftinguene encore les promenades. Ainfi on doit promener: plas long temps en Hyuer qu'en Efté, \& obferuer vne durée mediocrement longue,fans attendreny la pefanteur, ny la laffrtude, qui font des effets de la difipation, du tranfport des matieres, ou du defordre de la tranfpiration. On doit: mefme auoir çgard, dans les lieux chauds \& maritimes, que les jambes ne s'exercent trop longuement, parce que là elles fouffrent fouuent, \& que les vlceres \& les playes y font dangereufes, ainfi qu'on a remarqué dans la Candie fameufe 
532

Des Promenades.

par lavaleur, \& par la mort de tant des Soldats? La raifon de cela deriue du rapport que les jambes ont auec le foye qui fe defcharge fur elles de quantité d'humeurs ardentes, file climat eft chaud, le temperament bilieux, \& fi lesblefSures, ou les mouuemens alterent \& affoibliffent ces membres. Et certes on peut dire qu'il en eft dans nos corps comme dans le $\mathrm{Ciel}$, là les parties interieures font comme les planettes, \& les exterieures font comme les maifons qui reçoiuent leurs influences, \& qui en réleuent, \& en determinent les qualités. Ainf le foye par exemple qui ef comme vn autre Iupiter dans nous-merines, a les jambes qui font foûmifes au Sagitaire, qui eft la maron du Iupiter qui eft dans le Ciel; de forte qu'il fait couler fes humeurs fur elles, quielles font ordinairement acres \& falées dans les endroits dont nous parlons, \& que les jambes les reçoiuent fi librement, lors qu'elles font malades ou fatiguées, que c'eft parcette raifon qu'il les faut baigner fouuent en Efté, \& qu'apres les promenades on y reflent vne demangeai. Son importune.

Le temps exige encore des obferuations im portantes. La premiere que l'efchole de Salerne ordone de promener fur les eminences le matin, \& le foir au bord des ruiffeaux. La raifon de cela eft parce que le matin on doit refpirer vn air qui foit propre à reftablir, \& à purifier les efprits, à les tirer des vapeurs que le fommeil a ramaffées, \& à faire fucceder la clarté par fa trandparance à le place des tenebres qui s'eftoient repanduës pendant la nuit. Or cela fe fait mieux dans 


\section{Des Promenades.}

qcs lieux eminens, où il remble quel'air deftaché des brouillards de la terre, participe de l'element du Ciel.

Pour ce qui eft du foir, les promenades fe font mieux contre les riuieres, \& les fontaines, foic parce que l'humidité \& la fraicheur a ppaifent les efprits qui fe mutinent dans la journée, foit que le murmure de l'eau infpire le fommeil, \& donne vn cours regulier aux humeurs, roit que fa tran parence réjouit la veüé, \& que fes vapeurs ramoliffent les membres deffeichés par l'action, \& par le trauail.

Lafeconde, que generalement parlant, les promenades du matin font preferables à celles du foir, foit parce que l'air du foir eft ennemy de nos efprits, qui retournent alors au centre, qui s'épanouiffent le matin, \& qui fuiuent le cours du Soleil, foit que le froid de la nuit a vne qualité qui les fixe, roit en vn mot que liz journée doit eftre terminée par le repos. Il eft partant veritable que ces deux partics du jour, ont leurs vtilités partagées.

En effet les promenades du matin attenuent; defgourdiffent \& fubtilifent les efprits, elles def chargent les parties, \& font fort bonnes pour les perfonnes conftipées, \& graffes, parce qu'elles amaigriffent vn peu, aufi elles prouoquent l'appetit, \& réjouiffent les melancholiques. Il faut partant auoir égardalors aux broüillards, dont les efprits mineraux font fort nuifibles au cerueau, \& à la poitrine.

Les promenades du foir font cnnemies du cerueau, \& des epileptiques, elles font partant pro- 
535

Du Manege.

pres aux perfonnes qui jouiffent du grand repos aufquelles ilfaut confeiller de promener deuant 1e repas, de peur que l'alimene ne fe precipite à demy digeré dans les entrailles, ou bien ilfaut que leur promenade foit fort lente, \& fort moderée.

\section{CHAPITRE XV.}

Du Manege.

T manege eft vn exercice $f \mathbf{i}$ noble, \& fi ne 1. cellaire aux perfonnes de condition, comme Platon remarque in bippia, que nous auons jugé à propos de l'examiner en peu de paroles, \& d'y. joindre en fuitte les effets qui deriuent du mouuement \& de l'agitation du cheual. Il faut donc obferuer en premier lieu, que

Le manege infpire la crainte aux jeunes hommes, à caùfe qu'ils montent ordinairement des cheuaux fougueux, il tient leurs efprits fufpendus, \& les partage par les contre-temps qui leur furuiennent. C'eft pourquoy il fant que les perSonnes qui s'appliquent à cét exercice, ayent vn cour qui foit ferme, qui foit hardy, \& qui reiffe à beaucoup des paffions qui l'attaquent.

11 faut obferuer en fecond lieu, que le manege eft nuifible à ceux qui rempliffent leurs eftomachs, quis'addonnent à la débauche, qui ne fe reglent point, \& qui font foutient excés; car outre qu'ils ne peutent pas maintenir ainfi leur corps auec la jufteffe que cét exercice demands, 
d'ailleursil fe faitalors vn tranf port des matieres mal-digerées, par les raifons que nous deduirons cy-apres.

On doit obferuer en troifiéme lieu, que les hommes qui font fort grands doiuent éuiter le manege, parce que leurs reins, leurs lombes, \& leurs efpaules fouffrent du mouuement qui en deriue, \& que leur corps fe plie, \& s'abbat; c'eft pourquoyil n'y a proprement que les petits, \& ceux d'vne mediocre ftature quireçoruent moins de peine, qui courent moins de danger, qui foient plus fermes à cheual, \& fous lequel, comme on dit, le cheual prenne plus de plaifir à manier.

Qu'on remarque en quatriéme lieu, que le Caualier doit auoir la tefteaffeurée, \& le cerueau. bien compofé, \& hors des maladies qui l'affoibliffent, car il s'émeut par le mouuement dtr cheual à peu prés comme par celuly du carroffe; d'ailleurs il faut apprendre à tourner à l'entour d'vn pilier, ce qui eft fort nuifible aux efprits, aux humeurs, \& à leurs organes; ceft pourquoy quelques-vns, quoyque mal à propos, ont blâméceux qui ont efté les inuenteurs de cette methode.

Qu'on prenne garde en cinquiéme lieu aux cheuaux \& à leur nature, comme aux coleres, aux pareffeux, aux ardens, \& aux rufés, car on peut receuoir de là des bleffures $\&$ des fecouffes, qui outre les effets generaux, en caufent des particuliers. En effet le pasagite autrement que le trot, le galop fait des im preffions differentes : il en faut raifonner de mefme, lors qu'on vaterreà terre, par courbetes, parbalotades, groupades, 


\section{6}

caprioles, du pas, du fault \&c. lefquels mouucmens procedent de l'action\&du temperament des cheuaux, qui fe reglent fuiuant leur caprice. Auf: les anciens flairoient jufques à leurs excre mens pour les connoiftre, \& les difcerner.

Qu'on confidere en fixiéme lieu, que le port qu'on garde au manege, exerce les jambes, les lombes, l'efpine du dos \& les cuiffes; c'eft pourquoy il faut prendre garde fi ces parties font affligées de quelques maux, afin que leur force ne prenne vn accroiffement plus fenfible. En feptiéme lieu,

Qu'on choifffe pour le manege le matin comme vn temps plus commode, foit parce qu'alors l'eftomach eft vuide, foit parce que les parties ront plus difpofées, plus fortes, \& plus propres au mouuement; enfin parce que le fommeil les a renduës plus legeres, comme eftant le principe de la bonne tranfpiration. Adjoûtés, qu'ainf ont agit plusloing du repas, de forte que lefto. mach qui s'exerce fort au manege, fe r'affeure, s'affermit\& fe dif́pofe à mieux embraffer \&à curre les alimens. Mais pour donner vn plus grand éclarciffement à tout ce fujet, il faut voir en general les accidens qui procedent de l'agitation du cheual qui fert au tranfmarchement, \& au commerce.

Premierement ceux qui vont à cheual ordinairement, fuiuant Ariftote, prennent vne difpofition à la volupté, foit par l'exercice desaines, des reins \& des lombes, foit par la chaleur qui furuient à certaines parties que la nature a definées à la generation \& à contenir l'humeur qui 


\section{Du Manege?}

Iuy eft necellaire: c'eft pourquoy la veffe 337 alors des indifpofitions qu'il eft fouuent malaifé de guerir par fon voifinage \& fa connexion. $D_{i-}$ fons en de mefme des cuifles, de manierequion. deffendit lecheual à l'Empereur Adrien, parce qu'il fouffroit des vlceres vers ces endrcits, \& qu'on remarque par experience que la goutie afflige ainfi plus fortement toutes ces parties pour peu de difpofition qu'elles yayent.

En fecond lieu les cheuaux qui vont au trot remuent toutes les entrailles, \& ils exercent fur tout la poitrine, en y faifant deriuer les humeurs du cerueau; feulement tout le bien qu'ils font c'eft de pouffer le fable, \& de deliurer les reins de leur embarras.

Enfin les cheuaux qui courent, alterent $1 a$ veuë, échauffent le corps, amaigriflent, \& feishent les membres, bieifent la velifie, les boyaux \& les reins, \& font de fi grands maux à la tefte, que quelques-vns en font morts par vin vertige quiles a faifis dans cet eftat, ou pour eftre tombés du cheual dans la courfe. A uffi il n'y a eu que les Centaures fuiuant le Poëte, quife foient rendus fameux pour pouffer vigoureufement les cheuaux; ou bien les Tartares, fuiuant Hippocrate, c'eft pourquoy ils eftoient contrains de s'ourrir les veines des temples, comme ce grand homme remarque dans le liure des eaux, parce qu'ils auoient coûtume de courir ainfi toute $1 a$ journée, \& qu'ils n'auorent pas l'adrefle de fồtenir leurs jambes fur des eftrieux.

FIN. 


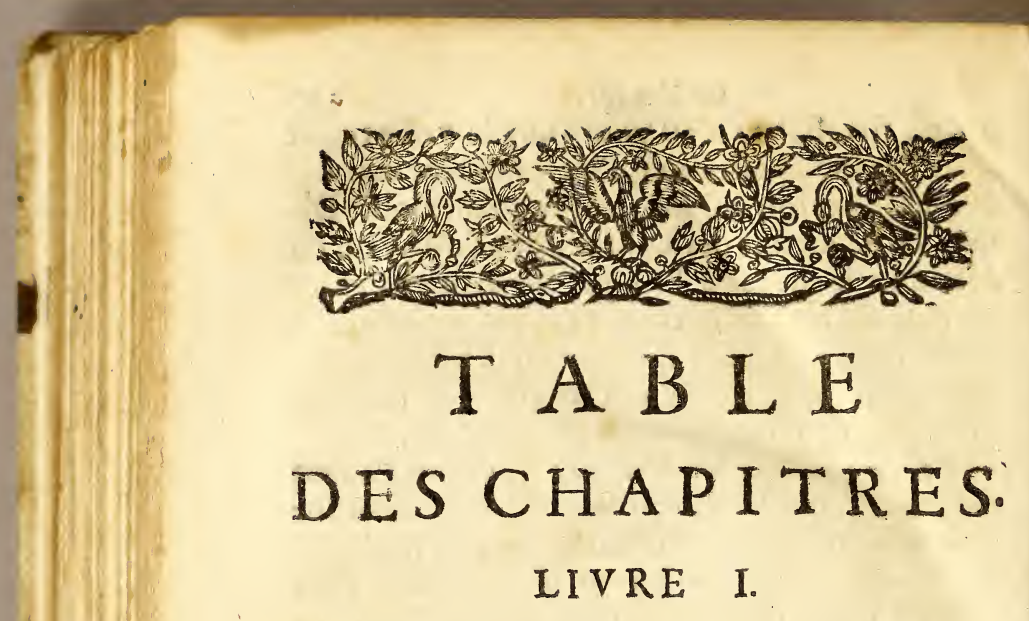

Des chofes qui nous enuironnent, on qui font au dehors de nous.

Chap. I. Es Aftres qui nous influent. pag. I? Chap.II. Du Soleil. pag.6. Chap.III. Des Ombres \&r des Parafols. pag. 20. Chap.IV. Du Serain ơ de l'Atmofphere. pag. 28. Chap. V. Des Rafraichiffemens, des grandes Chaleurs, du Tempscounert, \& duV ent coulis. pag. 40. Chap. VI. Des Euentails. Chap. VII. De la Foule, du Soufle, of de fes qualités.

Chap. VIII. Du Brait.

Chap. IX. Des Halits.

Chap. X. Des Mafques.

Chap. XI. DesBaftons.

Chap. XII. Des Calotes.

Chap. XIII.Des Perruques. pâg. 6 I. pag. 67. pag. 78 . pag. 99. pag. 108. pag. $11 \%$ pag. 126. Chap. XIV.Des Hommes, de leurs differences, \& de la vertu de leurs aransmißions. pag. 133 : 


\section{TABLE:}

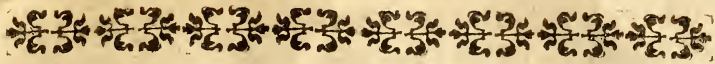

\section{I VRE II.}

Des chofes que nous receuons, \& qui paffent dans nos parties.

Chap. I.

Chap.II.

D loeuf.

Des Poiffons?

Chap.III. Des Fruits.

Chap. IV. Des Fruits verds:

Chap. V. Du Melon.

Chap. VI. Des Fraifes, 6 des Afperges. pag. 1790 Chap. VII. Des Champignons, ơ des Trufes.

Chap. VIII. Des oublies. pag. 182 . pag. 192. Chap.IX. De la Limonade, du Sorbet, of de l'Aigre de Cedre.

Chap.X. De la Glace.

Chap.XI. Du Tabac en fumée.

pag. 196. pag. 202. pag. 216.

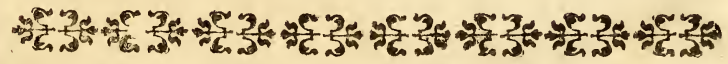

\section{I V R E III.}

Des Ieux, \& des Exercices, ou de la Gymnaftique moderne.

Chap. T. De Exercices en general. pag. 228. Chap.II. D Reflexions particulieres ơ generales fur les Excrcicis des Enfans.
Chap. III. De la Paume 2 o du Mail.
pag. 24.5. 


\section{TABLE:}

Chap.IV. Dès Carroffes, Chap. V. Des Berceaux. Chap.VI. Des Chaires. Chap. VII. Du Ler. Chap. VIII. De la Danse. Chap.IX. Del'Exercice des Armes. Chap.X. De la Chaffe. Chap.XI. De la Comedie.

pag. 250 ? pag. 2540 pag. 263. pag. $27^{2}$. pag. 280. pag. 288. pag. 290. Chap. XII. Des Chanfons, des Inftrumens, 296 de la Muflque.

Chag. 303. Chap. XIV. Des Promessades. Chap. XV. Da Manege.

pag. 320 .

pag. $334 \%$

- Fin de la Table des Chapitres. 


\section{Fautes à corriger.}

DAge 16. ligne 22. des oyfeaux, lifee de ccs oyleaux.

Page 24. ligne 15. leur infpirent, lifer leut donnent.

Page 40. ligne 18. qualitez, lifez cauitez. Page : oo. ligne 8. \& va mafque, lifez of vn malque. 


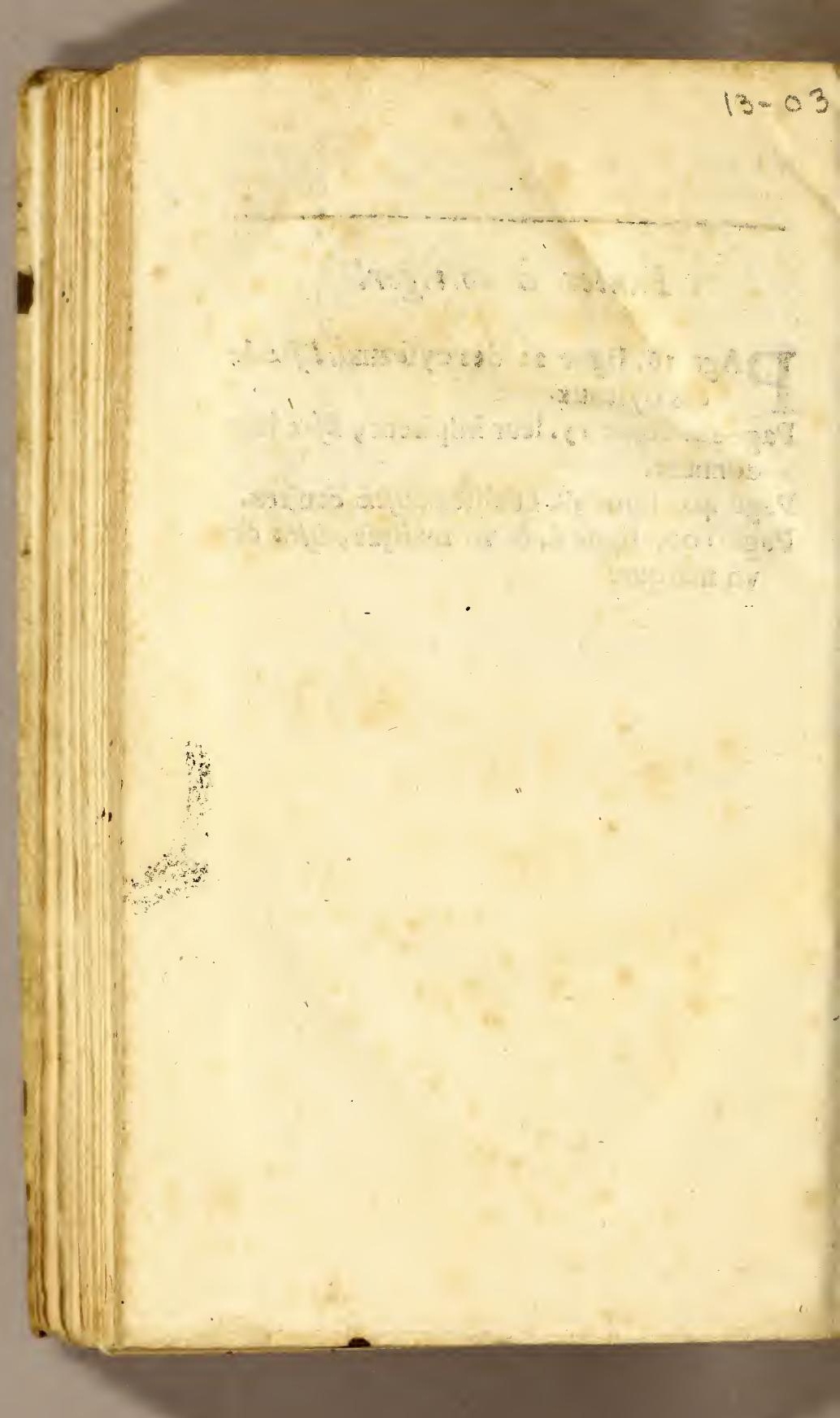




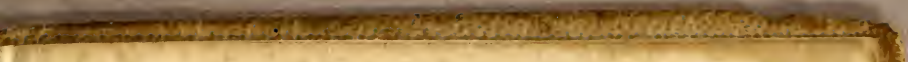




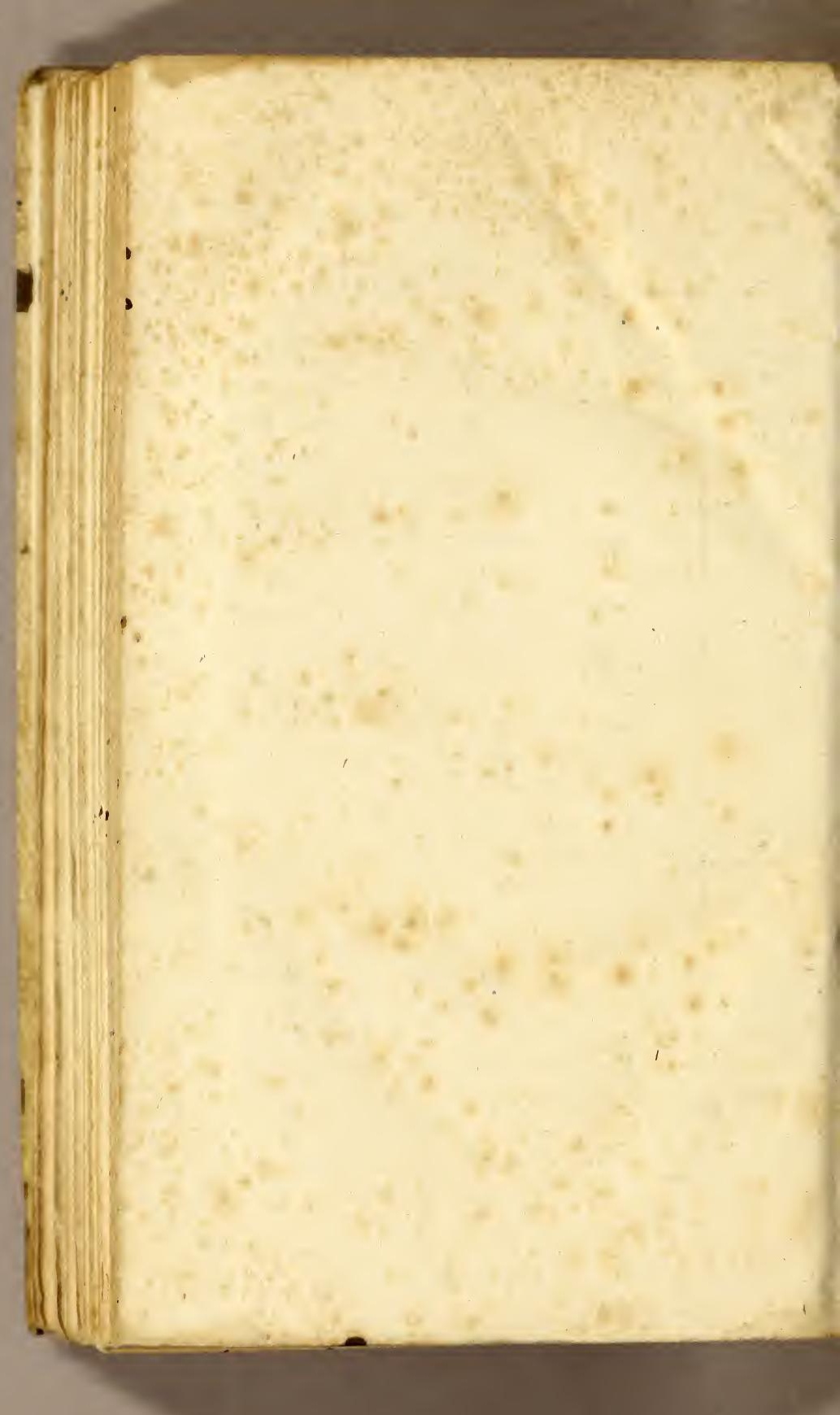




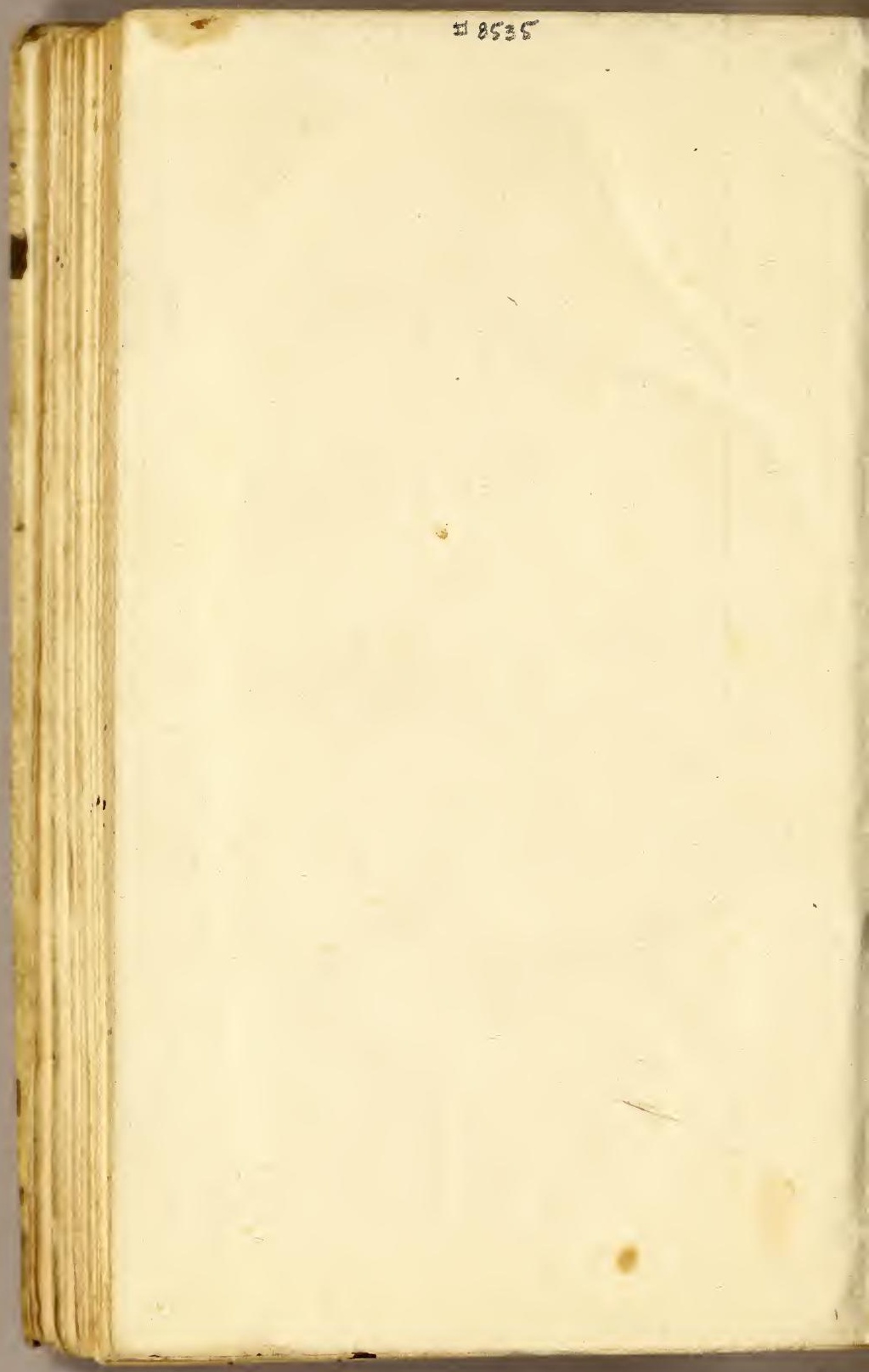





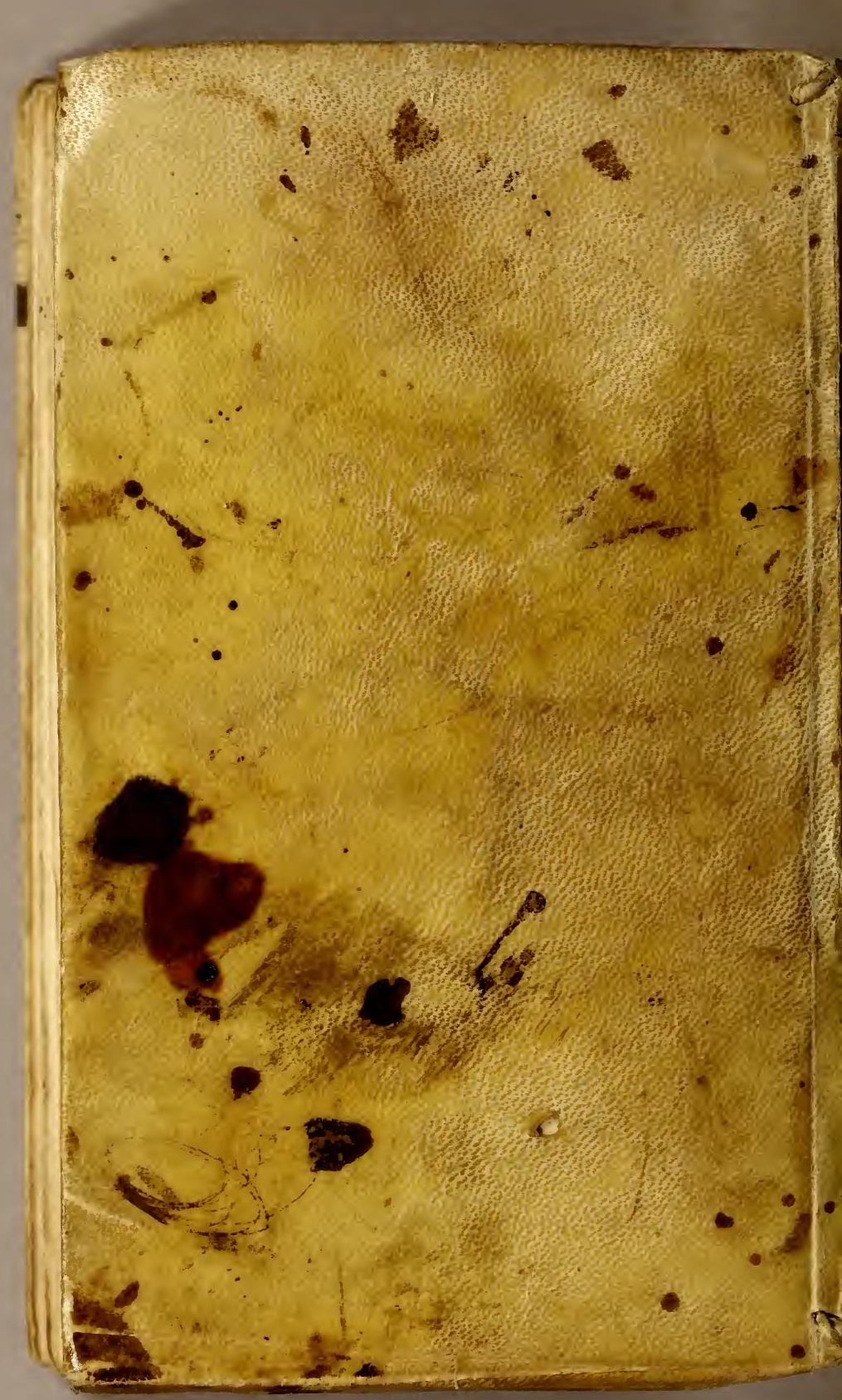

